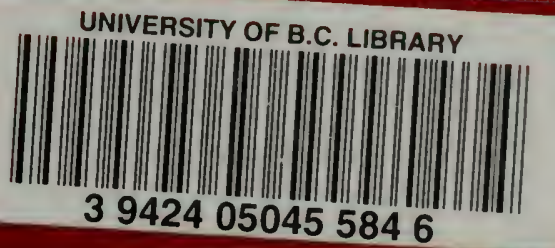

STORAGE ITEN

PKCCESSING-CNE

Lp $1-D 16 G$

U.B.C. LIBRARY 


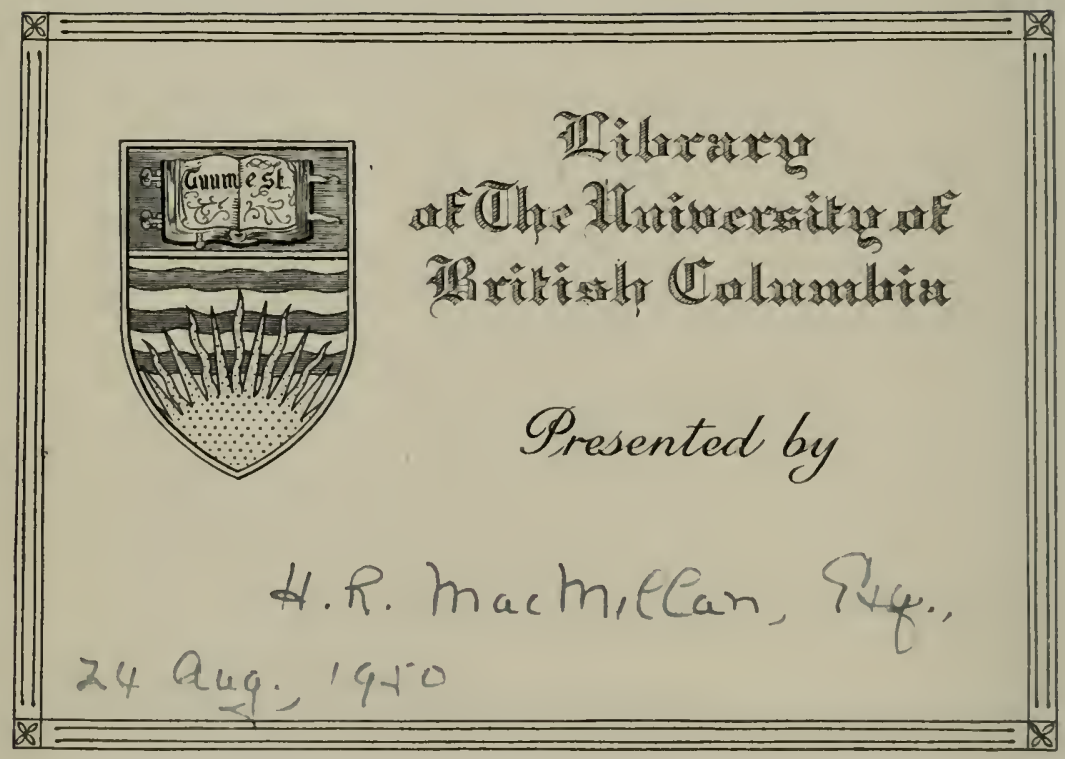

The HP.R. Hers Ilillum

Gollection in Forestry

The Otruivensitly of SPritish Golumbire 


$$
a_{g_{2}} 17-1027
$$






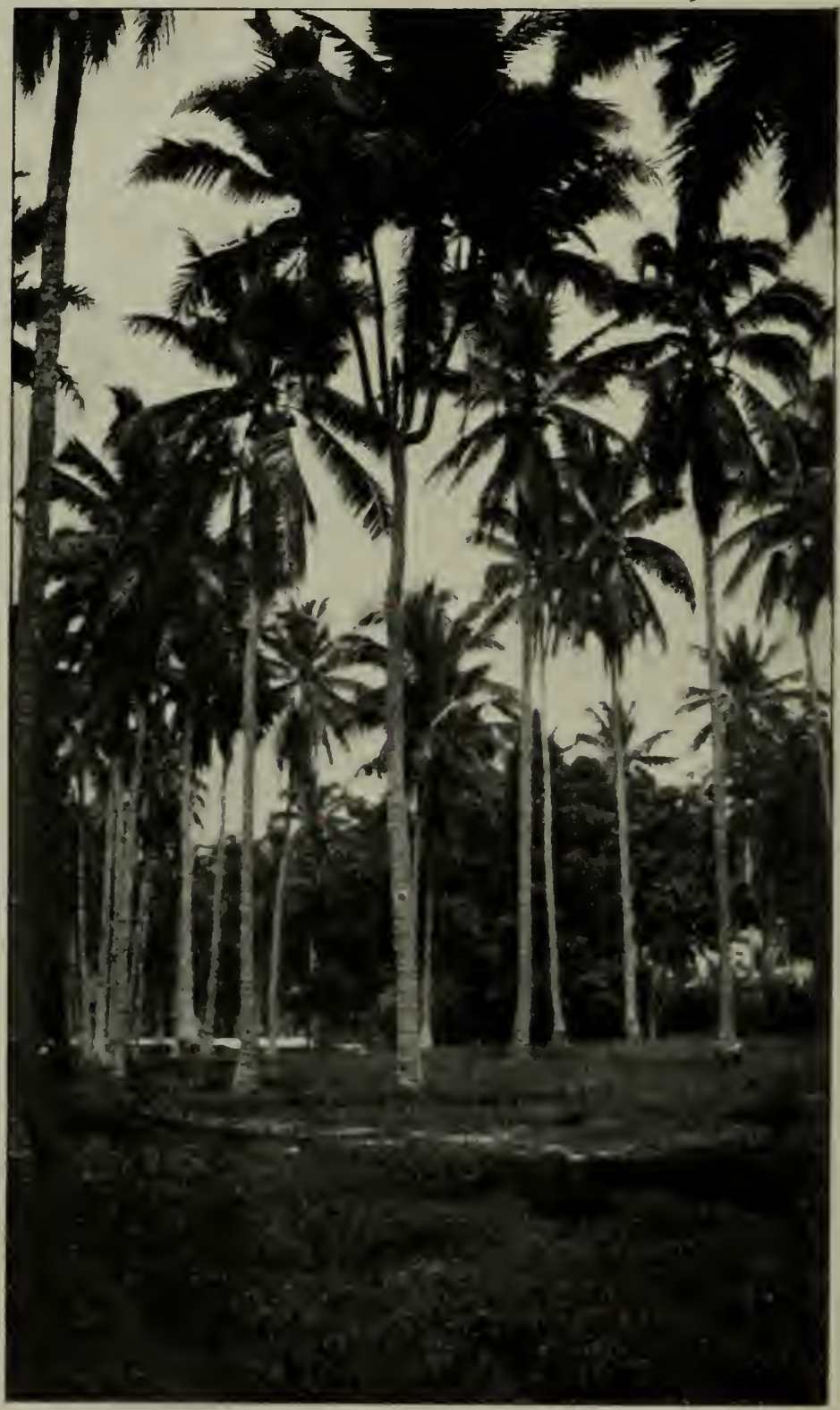

Fic. 1.-Coco-nut Tree branching out near the top into five distinct stems, each of which carries fruit. 


\title{
A PRACTICAL GUIDE
}

\section{TO COCO-NUT PLANTING}

\author{
BY \\ R. W. MUNRO \\ AND \\ L. C. BROWN
}

Late Government Inspector of Coco-nut Plantations, F.M.S,

WITH 108 ILLUSTRATIONS

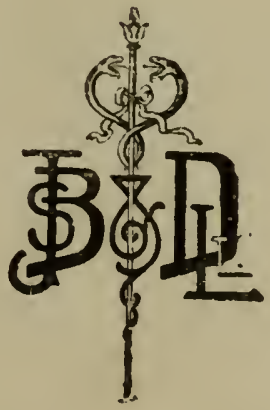

SECOND EDITION

With Appendix by Editor of "Tropical Life"

\section{Lolloon}

JOHN BALE, SONS \& DANIELSSON, LTD.

83.9I, Great Titchfield Street, Oxford Street, W. I. 
Ist Edition: . . . . October, I916 and Edition, with Appendix, July, 1920 
BY KIND PERMISSION

THIS BOOK IS DEDICATED TO

\section{SIR WILLIAM TAYLOR, K.C.M.G.,}

WHO HAS ALWAYS TAKEN A KEEN INTEREST IN

THE COCO-NUT INDUSTRY

AND DID MUCH TO FOSTER AND ENCOURAGE

EXTENSION OF THE

CULTIVATION IN THE FEDERATED MALAY STATES

DURING HIS TENURE OF OFFICE

AS RESIDENT-GENERAL FROM I9O4 TO IgIO.

R. W. MUNRO.

L. C. BROWN. 



\section{PREFACE.}

This book on Coco-nut Cultivation is the outcome of a request made by the Government of the Federated Malay States for an enlargement of Mr. Brown's Bulletin No. II, written on the same subject in $19 \mathrm{IO}$, and is by no means intended to be an "Enquire Within" about everything connected with the coco-nut.

In acceding to this request it was decided, in order that the work might be as useful as possible, to bring it out in its present form abundantly and suitably illustrated.

Hitherto, to our way of thinking, few of the publications that have been brought out on the subject of coco-nut cultivation and the industry in general, appear to contain the amount of material necessary for the "intending planter" in this country, and our object and joint endeavour in the present issue has been to make it more in the form of a "Planter's 


\section{vi GUIDE TO COCO-NUT PLANTING}

Note Book" than an "Investor's," and as such we trust the work may serve as a really useful guide for all those who are interested, or may later on care to interest themselves in the industry.

Perhaps one of the most striking features in the commercial world is the growing demand for the products that are obtained from the fruit of the coco-nut palm.

Owing to the increasing consumption of vegetable oils and foodstuffs derived from the kernel of the nut, for which there is at the present time so much inquiry, it would appear that in the near future, at least, the cultivation can hardly be overdone. It is not surprising, therefore, that its cultivation is attracting great attention in all countries where the land is suitable and good climatic conditions prevail for the growth of the palm; as in these circumstances, with careful and economical supervision, it should undoubtedly afford a sound, lasting and remunerative investment.

It must be borne in mind that the present work, as far as it deals with cultivation, \&c. has special reference to the conditions prevailing in the Malay Archipelago, Sumatra and 
Borneo, and is only intended to be a guide for coco-nut planters in these countries. Further, it should be distinctly understood that the estimate for bringing a plantation to a producing stage is only framed on the basis that thoroughly suitable and accessible land, capable of perfect drainage, is selected, and that the work of opening up the estate is to be placed in the hands of really experienced and competent men. We admit that these are not so easy to be found in large numbers, but we maintain that the services of men who have had experience of planting in this part of the East are of more value than those of people with experience (however wide) of conditions totally dissimilar to those met with here.

We say this because adverse criticisms in the past on results achieved and attempts by financial advisers to scare the investing public from - what is an acknowledged sound industry are, more often or not, the outcome of unwise selection in one or other of the above important questions.

In view of the fact that most of the general information and hints as to the methods to be 


\section{viii GUIDE TO COCO-NUT PLANTING}

adopted which are given in this book are not derived from any theoretical source, but are the results of practical knowledge and experience, it is to be hoped that there are some to whom it will be found a guide and assistance. To those who are apt to ignore the question of heavy upkeep expenditure when it arises, the estimates will be of little interest, and we ourselves are not concerned with speculating, on the number of years it will take before their plantations become self-supporting.

Apart from the knowledge of the stability of the coco-nut industry itself, the recent discovery of practical methods of converting crude copra oil into a palatable and satisfactory vegetable butter has given a great impetus to this particular business, and has had a marked effect upon the price of the raw material; so much so that it has led in a great many instances to intending investors taking an over-sanguine view of the ultimate profits to be derived from the industry.

It is undoubtedly the generally acknowledged security of the investment that constitutes its strongest recommendation, and this being so it is very undesirable to see a sound 
enterprise suffer by being inflated beyond its merits.

Adverse criticism of obviously undesirable propositions should be welcomed by all those interested in seeing the coco-nut industry established on a sound and permanent basis, but we think that these criticisms should be confined to propositions such as mentioned above, as it serves no good purpose to indulge in wholesale condemnation in a manner sometimes noticeable by persons who are doubtless more or less prejudiced.

It is necessary, too, that a critic to be convincing should be furnished with accurate information, but this, unfortunately, does not always appear to be the case.

We know of instances where the annual reports of London companies have been critically examined for the benefit of the investing public, and where the examiners have attributed the annual unsatisfactory output to anything but the right cause.

We gratefully acknowledge assistance received from: Messrs. Ash, Brown, Bayley, Denny, The East Asiatic Company, Evans, Gillespie, Kennedy, Lewton - Brain, Tait, 
x GUIDE TO COCO-NUT PLANTING

Yourg, van Helken, and Richards, who have kindly allowed us to reproduce photographs which we trust may add materially to the interest of the publication.

$$
\begin{aligned}
& \text { R. W. MUNRO. } \\
& \text { L. C. BROWN. }
\end{aligned}
$$

Federated Malay States,

September, I9I6. 


\section{SYNOPSIS OF CONTENTS.}

PAGE

CHAPTER I.-SELECTION OF LAND AND CONDITIONS

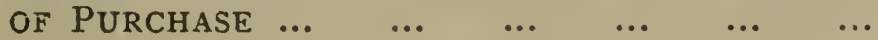

Inland plantations-future prospects discussedthe soil in the F.M.S.- where inland plantations have paid-coast or seashore plantations-where to choose land - in the State of Perak-in the State of Selangor-the question of drainage-planta. tions in Johore-in Kelantan and Trengganu-in Sumatra-land conditions in the F.M.S. - firstclass land - second-class areas - conditions in Pahang are easier-the Pahang terms-transport facilities-quit rents in Pahang-terms in the Dindings-terms in Penang and Province Welles. ley-land tenure in Sumatra-soils-suitability of the climate very important-rubber $v$. coco. nuts-beware of over-fertilization-clay and sandy soils compared-droughts and mulchirg.

Chapter 11.-The Preparation of LaNd For Planting $\quad \ldots \quad$...

The question of drainage - felling by contract - burn. ing off-when to fell-results of a good burn and how to assure then:-clearing the land after burning-exterminate lalang and how to do so.

CHAPTER III.-SElection OF SELD AND NURSERIES

Great care necessary when selecting seed nuts-what to avoid and what to choose - after selecting dry out the seed nuts - where good nuts are obtainable - which to choose-nurseries-the question of shade-how to "lay" or plant the seed nutsgermination in mid-air-the advantages of the idea. 


\section{xii GUIDE TO COCO-NUT PLANTING}

Chapter IV.-Planting $\quad \ldots \quad$.

The distances between the palms-how to prepare the area to be planted-digging the holes-"laying" $v$. planting in holes - try new methodsmoulding-up - deep planting unwise - planting where wild pigs abound - the best age at which to remove the seedlings-difficulties of late planting -planting "at stake" - the king coco-nuttwo estates planted $=800$ acres-results still to be ascertained-possible yields-this variety may require high cultivation-is its copra heavier and richer in oil?-advantages on paper of the king coco-nut. Chapter V.-Maintenance and Cultivation ...
Drought the great danger-failures when yields are
expected - watch individual trees - the palm's most critical time-the question of weedingwhere forking is needed - leguminous greenmanuring-keep the soil friable-the crowning importance of ploughing and cultivating the land - even more important than manuring - covercrops-a clay subsoil an advantage-how to encourage success-the treatment of the landploughing - mulching - economical method of cultivation - weeding after planting - the disadvantages of removing the humus-when weeding does harm-O.W. Barreit on mulching.

Chapter VI.-Cattle-KeEPing

.. $\quad \ldots \quad \ldots$

The breeding of cattle may be harmful-the value of cattle and sheep manures-keep the cattle on the move-the storage of the manure-keep goats away-number of cattle and sheep to the acre of palms.

Chapter V11.-DRains and Drainage $\ldots$...

Keep the drains clear - stagnant water is badcross drains. 
The great difference between the two-do not keep on catch-crops too long-coffee as a catch-crop -the ext:a cost of running catch-crops as well as the main one-native $v$. European methods and profits-sweet potatoes-green manures for in. creasing the humus - a list of catch-cropsbananas-the value of cover-crops must become known-setting, mulching, green manures-the results of drought-Copeland (of the Philippines) on checks by drought - suitable plants for greenmanures-analysis of Boga medelloa or Candida tephorie-equivalents between green-manures and artificials-the "Mascate" (mucuna) or velvet bean -its recommendations and cultivation-its seeds as a cattle-food-sword bean or pois sabre (Canavalia ensiformis) - its advantages and analysisM. Bonâme explains its value as a fertilizer-how to plant it-soaking the seeds hastens germination - Tephrosia candida hard to beat-all these plants need nitrates-how to improve peat soils-Passiflora and sweet potatoes.

Chapter IX.-Gathering and Storing the Crops

Methods of collection-unripe nuts lower the quality of the copra-best method for collecting from tall palms-rough handling must be avoided-fallen $v$. collected nuts-thieves-climbing difficult or im. possible in wet weather - heap the nuts after collection-transport on the canals-keep the husks for burying as manure-theirvalue as suchcopra improved by leaving nuts unhusked for a time - changes in nuts whilst ripening - the hardening of the meat-from blossom to mature nut=eleven months-plant-food removed per tree in two years -analyses of plant-foods.

Chapter X.-MANuring

... $\quad \ldots \quad \ldots \quad \ldots$

Cost and compensations-vegetable $v$. artificial manures-cow dung and fish manures-supplies of cattle manure insufficient-amount to give per tree-cattle on estates an advantage if not a necessity-trench manuring $v$. spreading-rich 


\section{xiv GUIDE TO COCO-NUT PLANTING}

\section{Chapter X.-continued.}

fertilizers must be applied sparingly-applying lime-its action on hard soils-and on ordinary soils-quantity of lime per acre-forking it inIo to $12 \mathrm{lb}$. per tree-if spread over one to two tons per acre-the coco-nut's ability to take up salt -but its presence is not contributory to the health, \&c., of the palm-laboratory analysis as a guide when manuring-analysis shows the value of the husks - burying husks advantageous but costly - husks retain moisture - drastic measures sometimes necessary to make palms productive - scorching - ring-barking - baring the roots, \&c.-a severe burning made a barren tree yield fully in four years - unhealthy or immature seed give bad yielders-apply violent remedies only as last resource-cattle dung the best manure-working-up clay soils-basic slag most useful-mixing and applying manures-Kelway Bamber on coco-nuts-a coco-nut palm forms a ton of organic matter - and consumes much plant-food - annual consumption of mineral inatter-importance of lime, potash and phos. phoric acid.

\section{Chapter XI.-CURING COPRA FOR MARKeT}

Husking-artificial dryers-native curing-moulds and the percentage of moisture-kilns and barbecues-rain discolours copra-cement barbecues bad-yields for five years-fuels-coco-nut butter and the treatment of oils--nuts to the picul and ton of copra-picked $v$. fallen nuts-effect of soil on the nuts.

Chapter XII.-PestS AND Diseases... ... ...

Beetles - the Oryctes beetle - the red beetle-black beetles - many varieties of Oryctes - do cover crops discourage beetles?-does trimming the trees encourage red beetles?-preventive measureshand collection-use a piece of wire-close the holes-rats very serious-the harm they doH. C. Pratt on rat shields-the design he recommends- - wild pigs-how to discourage their visits 
-hunting with dogs, good-inter-crops attract both rats and pigs - squirrels - porcupineslocusts very serious-white ants bad, especially between second and fourth year-how to exterminate them - several suggestions - old timber attracts ants - the ordinary red ant a friend of the planter-it feeds upon scale insects-a plague of ants-how to get rid of them-diseases-Pestalozzia palmarum - when most virulent-Bordeaux mixture a cure-Brachartena caloxantha a lepidopterous pest-remedial measures-a parasitic ichneumon a great help - Helmithospodium another pest---caterpillar-how to check themspraying--bud-rot disease-what it has done in Cuba - bud-rot disease in Penang-another trouble in Jamaica - Prof. Earle in JamaicaPestalozzia described - remedies discussed further information needed-Mr. Richards' (the Mycologist) letter on Pestalozzia-Bordeaux mixture and spraying-how to make the mixtureand how to apply it -an improved formula.

\section{Chapter XIII.-Estimates}

True estımates $v$. extravagant and unnecessary figures-inexperienced experts (?) - the cost of opening up and maintenance to the sixth yearcost of buildings, kilns, \&c.-age when estate should be self-supporting.

Chapter XIV.-The Principal Commercial ProDUCTS OF THE COCO-NUT TREE $\ldots$... $\quad \ldots \quad \ldots \quad$ I6O

The products of the palm-toddy and sugar-how they are made-fibre, coir and rope-copra-oil -the last-named should fear no competitors.

Chapter XV.-The Coco-nut INDUSTRY IN THE

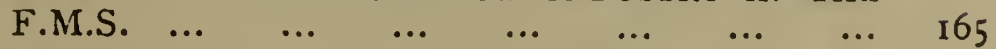

Area planted-the progress of the industry-area under cultivation since 1903 -copra prices since 1903-copra exports since 1904-average price of 


\section{xvi GUIDE TO COCO-NUT PLANTING}

CHAPTER XV.-continued.

nuts-area planted in Perak-in Selangor-in

Negri Sembilan and Pahang--European cultivation-inter-crops and main-crops-native holdings and kampongs - some have fine palms-the Coconut Ordinance-it prevented a distinct set-backthe kampongs of Temelok, Pahang, are ideal-the care bestowed on them-the "Malay Reservations Enactment " to check alienation-the "Coco-nut Cultivation Enactment" in Kedah-reporting to the Penghuhi-land inspection under the Enactment-collecting nuts with the "Broh" or monkey -its drawbacks. 


\section{ILLUSTRATIONS.}

FIG. I.-Coco-nut Tree branching out near the top into five distinct stems, each of which carries fruit $\quad \ldots \quad \ldots \quad \ldots \quad \ldots \quad \ldots$...Frontispiece facing page

FIG. 2-A Coco-nut Plantation on slightly undulating land

Fig. 3-New Clearing as it appears after a burn $\quad \ldots .44$

FIG. 4-Original Felling allowed to get into secondary growth to secure a good burn when re-lopped...

FIG. 5-Planted area, previously in good order, after three months of neglect... $\quad \ldots \quad \ldots \quad \ldots \quad$ Io

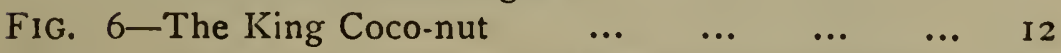

FIG. 7-The King Coco-nut three years from planting... I4

FIG. 8-A newly-planted Clearing on Sandy Soil (Tringganu)

FIG. 9-Nursery under Natural Shade (I) $\quad \ldots \quad$... 26

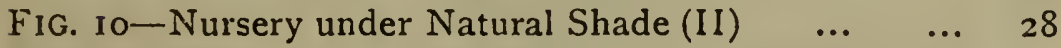

FIG. II-Nursery under Artificial Shade, showing rails

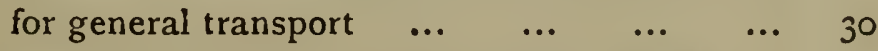

FIG. 12-Plants put out at five months from Nursery $\quad \ldots \quad 34$

FIG. 13-Clearing of three years old, illustrating the disastrous effects of Deep Planting... $\quad \ldots \quad \ldots \quad \ldots \quad 36$

F1G. I4-Effect of continuous Clean-Weeding and Coffee $\begin{array}{llllll}\text { as a Catch Crop ... } & \ldots & \ldots & \ldots & \ldots & 38\end{array}$

FIG. 15-Disc-harrows at Rest $\quad \ldots \quad$... $\quad \ldots \quad$... 40

FIG. I6-Disc-harrows at Work $\ldots$... follows 40

$\begin{array}{llllll}\text { FIG. 17-Digging and Mounding } & \ldots & \ldots & \ldots & \ldots & 42\end{array}$

FIG. 18-Ploughing on light sandy soil (Tringganu) $\quad \ldots \quad 48$

FIG. 19-Fine Plantation work, showing the growth on Arcadia Estate, Bagan Datoh ... $\quad \ldots \quad$... 50 
Facing page

FIG. 20-A well-kept Plantation cultivated in accordance with the Author's methods

Fig. 21-A Grass Field kept in order by mechanical mowing

FIG. 22-A Young Coco-nut Plantation with a Sea 54 Frontage ...

FIG. 23-Keeping down the Grass ... $\quad \ldots \quad$ follows

F1G. 24-A Sluice Gate

FIG. 25-Outlet Canal, showing volume of water when the Sluice Gate is Shut ... ... follows

FIG. 26-Outlet Canal in a low-lying district follows

FIG. 27-A Main Drain, supposed to be efficient, but in such a condition as to be of no value on low. lying Land $\quad \ldots \quad \ldots$.... follows

FIG. 28-Deepening and Regrading Outlet Drains follows

FIG. 29-Robusta Coffee as a Catch Crop... ... ...

FIG. 30-Three-and-a-half year old Tree in Coffee $\quad . .662$

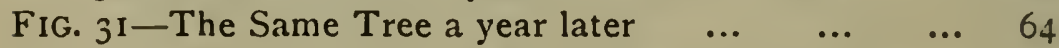

FIG. 32-Young Coco-nuts with a Cover Crop of Sweet $\begin{array}{llllllll}\text { Potatoes } & \ldots & \ldots & \ldots & \ldots & \ldots & \ldots & 66\end{array}$

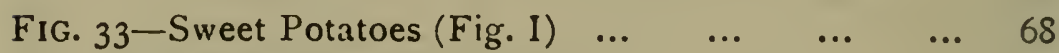

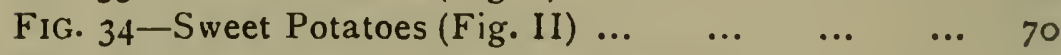

FIG. 35-Cover Plant-Crotalaria striata... $\quad \ldots \quad \ldots \quad 72$

FIG. 36-Cover Plant-Mimosa pudica ... follows 72

FIG. 37-Cover Plant-Tephrosia purpurea (Fig. 1) $\quad$.. 74

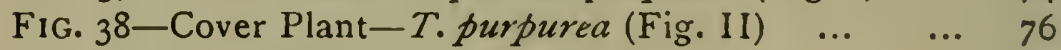

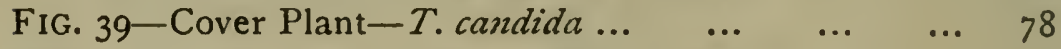

FIG. 40-Cover Plant-Canavalici ensiformis $\quad . .6 \quad \ldots \quad 80$

FIG. 4I-Centrosema plumieri with young Coffee follows 8o

FIG. 42-Tephrosia candida with young Coffee follows so

FIG. 43-Cover Plant-Mucuna ... ... follows so

FIG. 44-Cover Plant-Clitoria cajanifolia follows 80

FIG. 45-Two. Palms in good bearing, both propagated from the one seed

FIG. 46-Ideal Foliage on a young Tree, with a heavy crop supported naturally by its own fronds without necessity of staking ... follow's

FIG. 47-Staking. One method of preventing crop from young tree falling to the ground prematurely... 
FIG. 48-Picking Coco-nuts

follows 84 Facing page

FIG. 49-Transport of Coco-nuts by Main Estate Drain... 86

FIG. 50-Transporting Coco-nuts by Road follows 86

FIG. 5I-Large Collection of Nuts from one Estate being dealt with for Manufacture ... ... ... 88

FIG. 52-The Life of a Nut, i.e., the Blossom, Fruits at $2,3,5,9$, and II months old ... follows 88

Fig. 53-Illustration showing the distance from the tree at which the circle is made for mulching and manuring ...

FIG. 54-Covering the Green Mulch with Coco-nut leaves 90 92

FIG. 55-Ideal Method of Mounding Trees with Soil from "Supper" Drains

FIG. 56-Mulching with Coco-nut Husks...

FIG. 57-Mulching with Coco-nut Husks-a Complete Cover

FIG. 58-Ring-barking

FIG. 59-Collecting, husking and splitting

FIG. 60-Drying Kiln-showing one method of curing copra

follows

FIG. 6I-Drying Kiln-showing furnace and adjustable roof... $\quad \ldots \quad \ldots \quad \ldots \quad \ldots$ follows

104

104

104

FIG. 62-Sun-drying-showing another form of adjustable roof

follows 104

FIG. 63-Artificial Drying with hot air follores 104

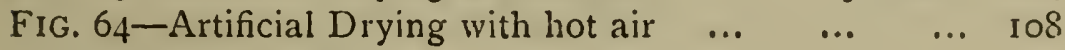

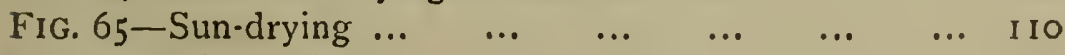

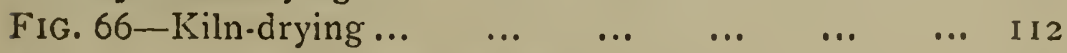

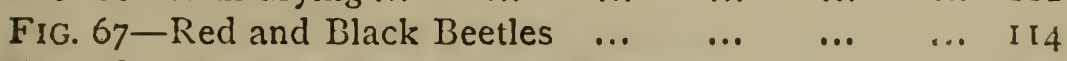

FIG. 68-The Black Beetle-and a cocoon _.. $\quad$... I 16

FIG. 69-A Palm killed by a Rhinoceros Beetle... ... I I 8

FIG. 70-A King Coco-nut attacked by Beetles ... … $\quad$ I22

FIG. 7 I-Style of Fence recommended as being inpervious to Wild Pigs

FIG. 72-Illustration showing the Inefficiency of Wire Fencing $\ldots \quad$... $\quad \ldots \quad$... $\quad \ldots \quad$... 126

FIG. 73-Typical Native (Malay) Kampong $\quad \ldots \quad$... 123 FIG. 74-Monkey (Broh) Collecting Nuts... ... ... I $30^{\circ}$ 
FIG. 75-Coco-nut Tree in bearing notwithstanding a large hole right through the trunk near the base

$1 j 0$ Facing fage

FIG. 76-A Caterpillar Pest and the results ... ... 140

FIG. 77-The Life History of a Caterpillar $\quad \ldots \quad$... 142

FIG. 78-Bud-rot Disease-Pestalozzia palmarum $\quad \ldots .144$

FIG. 79-Bud-rot Disease at an early stage $\quad \ldots \quad \ldots l$ I 46

FIG. 80-Bud-rot Disease-nearing the end $\quad . . \quad \ldots \quad$ I 48

FIG. 81-Bud-rot Disease-the final stage $\quad \ldots \quad$... 150

FIG. 82-Native Woman making Fibre from the Husk... I 54

FIG. 83-The only possible Method of Planting where the land is subject to Continual Flooding ...

FIG. 84-Photograph taken two years later (than illustration facing p. $1 ; 6$ ), showing that the Palms do grow and thrive to a certain extent under these adverse conditions

156

FIG. 85-Native collecting Toddy ... ... ... ... I58

FIG. 86-Some by-products of the Coco-nut Tree $\quad \ldots .162$

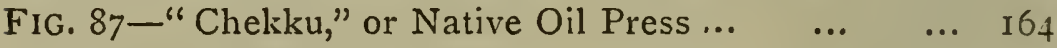

FIG. 88-Another Native Press $\quad \ldots \quad$... $\quad \ldots \quad$... 166

FIG. 89-Native Method of expressing Oil from Copra... I72

A Series of Fourteen Photographs illustrating the Life and Work in Progress on various Estates ... 176

FIG. 90-Dwarf Coco-nuts growing on clay, Negri Sembilan, Federated Malay States ... ... 184

FIG. 9I-Dwarf Coco-nuts on four-year-old trees on Sungei Napah Estate (taken Christmas, 1917), Negri Sembilan, Federated Malay $\begin{array}{lllllll}\text { States } & \ldots & \ldots & \ldots & \ldots & \ldots & \ldots\end{array}$

FiG. 92-Dwarf Coco-nuts growing on peat in Salt Area, $\begin{array}{lllllll}\text { Negri Sembilan } & \ldots & \ldots & \ldots & \ldots & \ldots & 185\end{array}$ 


\title{
A PRACTICAL \\ GUIDE TO COCO-NUT PLANTING
}

\author{
CHAPTER I. \\ SELECTION OF LAND \\ AND CONDITIONS OF PURCHASE.
}

Indian Plantations.-Where possible we would very much like to see the region of coco-nut culture extended in the inland districts, and as the difficulties of obtaining suitable land near the seashore are likely to become greater it makes it all the more desirable. There is no doubt that inland soils if properly treated should afford any investor a handsome return, although he may undoubtedly have to wait some time longer for the first crop. The land should, of course, be well chosen with special regard to accessibility and easy and inexpensive transport. It has proved a fallacy to suppose that the salt water from the sea of itself has any influence worth talking 
about on the trees in its vicinity. The actual porosity of the soil is greater near the sea than inland.

The growth of the trees, the colour of the leaves and area of leaf surface are governed to a very large extent by the water supply. Surface drainage requires more attention than subsoil drainage from our observations, although the latter is of special importance also.

Unfortunately in the Federated Malay States, with the exception of the State of Pahang, where special terms are offered by the Government, as afterwards referred to, it will, we think, be difficult to find any large blocks of land suitable for the cultivation. The reason of this is that there is hardly any very large contiguous area to be found now where the lay of the land is fairly flat or nicely undulating, as those that do exist have been largely taken up for rubber cultivation.

On the higher and hilly ground throughout the States the soil is mostly laterite, which unless very much decomposed on the surface when cleaned up, especially during the dry season or in times of drought, becomes very hard and impenetrable. In consequence it is 


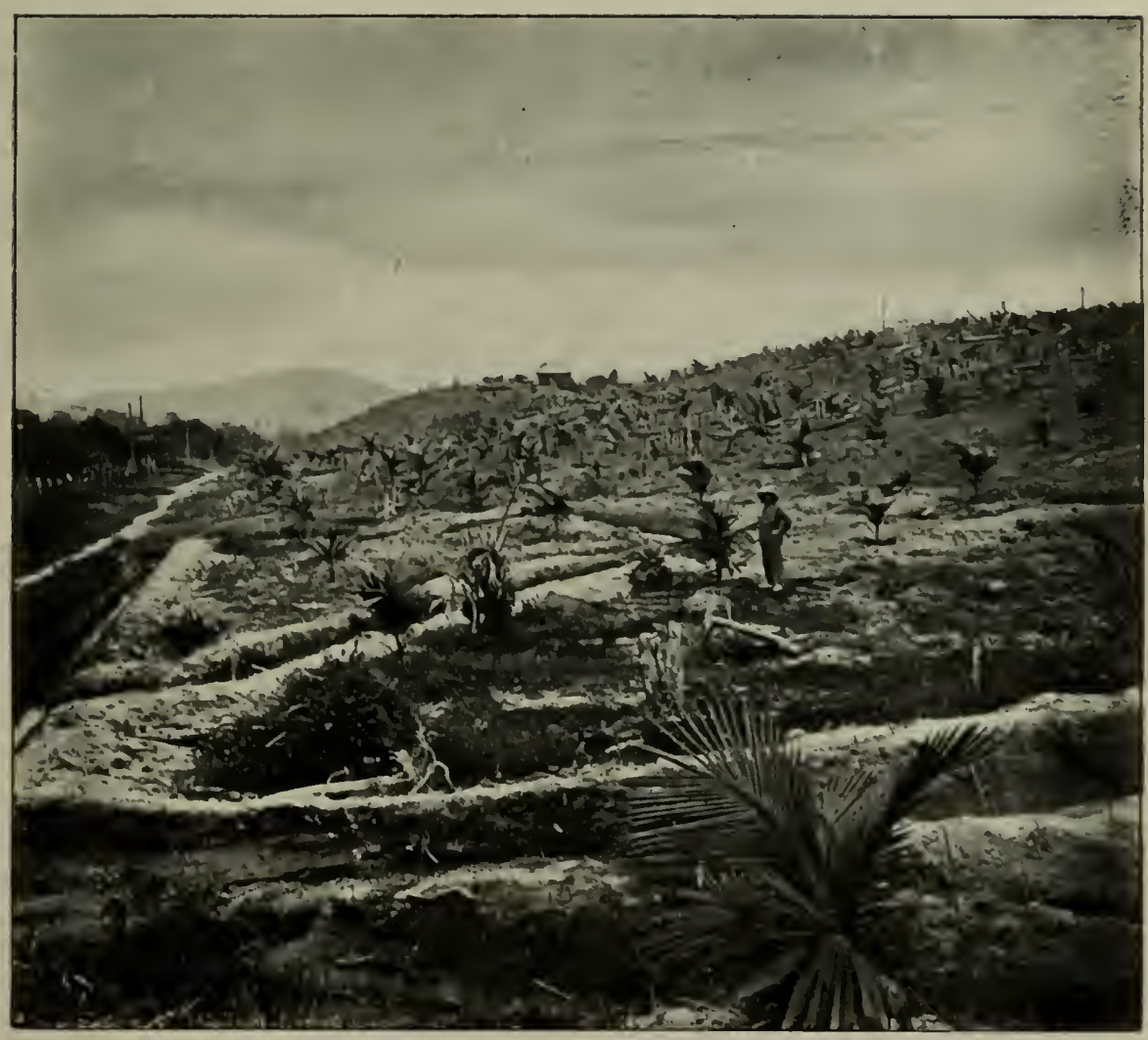

FIG. 2.-A Coco-nut Plantation on slightly undulating land (Tringganu).

The trees continue to be almost as good, growth for age, as anything found on flat land. 

a most costly and difficult business to get the young seedlings at the time they are planted out to make a good start, and so in the earlier stages, during which period the expenses are of necessity very heavy, the growth of the plants is much retarded, and but poor and extremely slow progress the result. It is not until the roots are well established and have reached the more friable soil generally found deeper down that the trees are likely to come on at all well, and owing to the previous set back already mentioned it is often not till the tenth year, sometimes even later, before the trees reach maturity and come into bearing.

Small plantations inland, of which there are a great number situated on flat or slightly undulating land, when in proximity to towns or villages have proved quite remunerative for the proprietor of moderate means. The yield in quality, i.e., outturn from nuts to copra, will we believe be found just as good from inland trees as from those from the seashore, for though the underground water treatment has in our opinion a great deal to do with heavy yields, it has, we think, little to do with the size of the nut kernels. 
Coast or Seashore Plantations. - We believe that the chemically richer soil inland should really conduce to the greater productivity of nuts, but it appears to us to be of special benefit to the tree to be exposed to wind and to intense illumination, and having regard to this fact it is not surprising that the natural habitat of the coco-nut should be near the seashore.

It must be remembered too, that the transport of the fruits it bears being large it is more economical as a rule to deal with this by water than any other means; on the other hand the fact of being able to create conditions more favourable than is usually known to occur in Nature is more true perhaps as regards the "coco-nut" than it is in any other form of cultivation and we make bold to affirm that there is no tree that responds so gratefully to the treatment given to it.

In the selection of land suitable for the cultivation of coco-nuts in the Federated Malay States, we consider that preference should be given to the coast districts where there are still several sites available. In the State of Perak the land lies between the Krian 


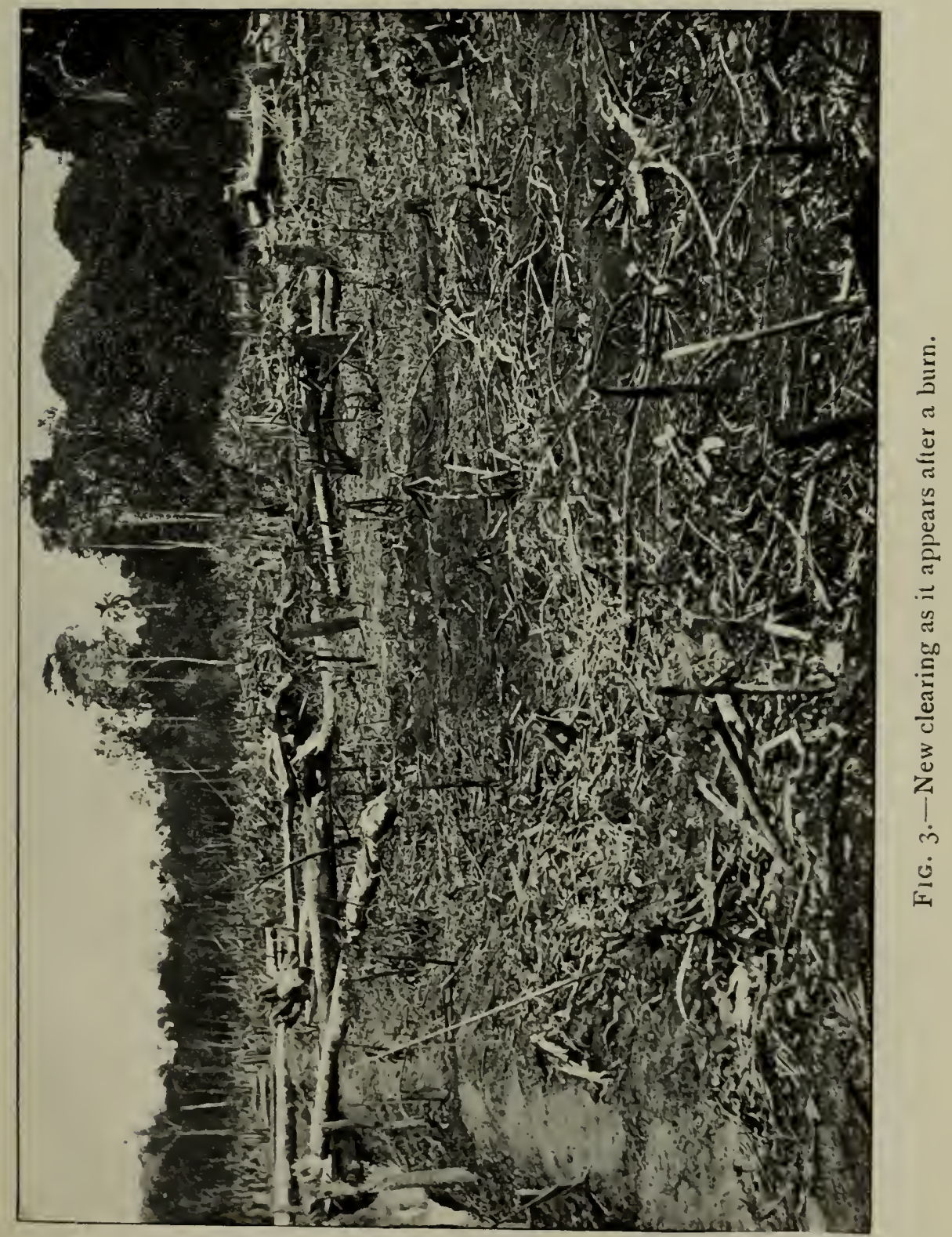

Face p. 4 . 

and the Bernam rivers, and again in the State of Selangor from the Bernam river east as far as Sepang.

It must not be imagined when we talk of land in the coast districts or on the coast that it refers only to an actual narrow strip. Suitable and really first-class land is continually found behind the mangrove where this exists, and inland of this strip to a depth sometimes of four or five miles. Again, proximity to the sea does not necessarily mean cheap transport, and this fact when selecting land has to be carefully considered.

The most important matter when taking up any large area in these districts is to ascertain beforehand that the land allows of thorough good drainage. It is only waste of money to select what is considered first-class soil unless an efficient fall for the water from every part of the estate is available, therefore the first thing to do is to select "outlets" rather than land. Nothing is more discouraging than to find one's first clearing an expensive failure owing to this want of foresight.

As may be gathered from the foregoing, the land in these parts is generally flat and low- 


\section{GUIDE TO COCO-NUT PLANTING}

lying. The soil is mostly alluvial and under good conditions exceedingly well suited for coco-nut cultivation. It is by no means uncommon to come across healthy young trees here showing flower in their third or fourth year, and also when seen in full bearing the yields are exceptionally heavy and with proper cultivation good average crops may safely be depended upon each succeeding year.

Johore.-There are many native plantations in this settlement, and perhaps the finest blocks to be seen are in the southern part where the land appears to have been especially well chosen. On the east coast large areas of available jungle have recently been prospected and reported on. It is probable that from here northwards as far as the Siamese border, according to statistics available, it will be shown that there exists an area of land under coco-nuts about equal to that of the whole of Selangor.

Kelantan and Trengganu.-There is every sign that the area planted in these states recently is likely to do well. Opening up on a comparatively large scale has been going on for some years past and there are at present 


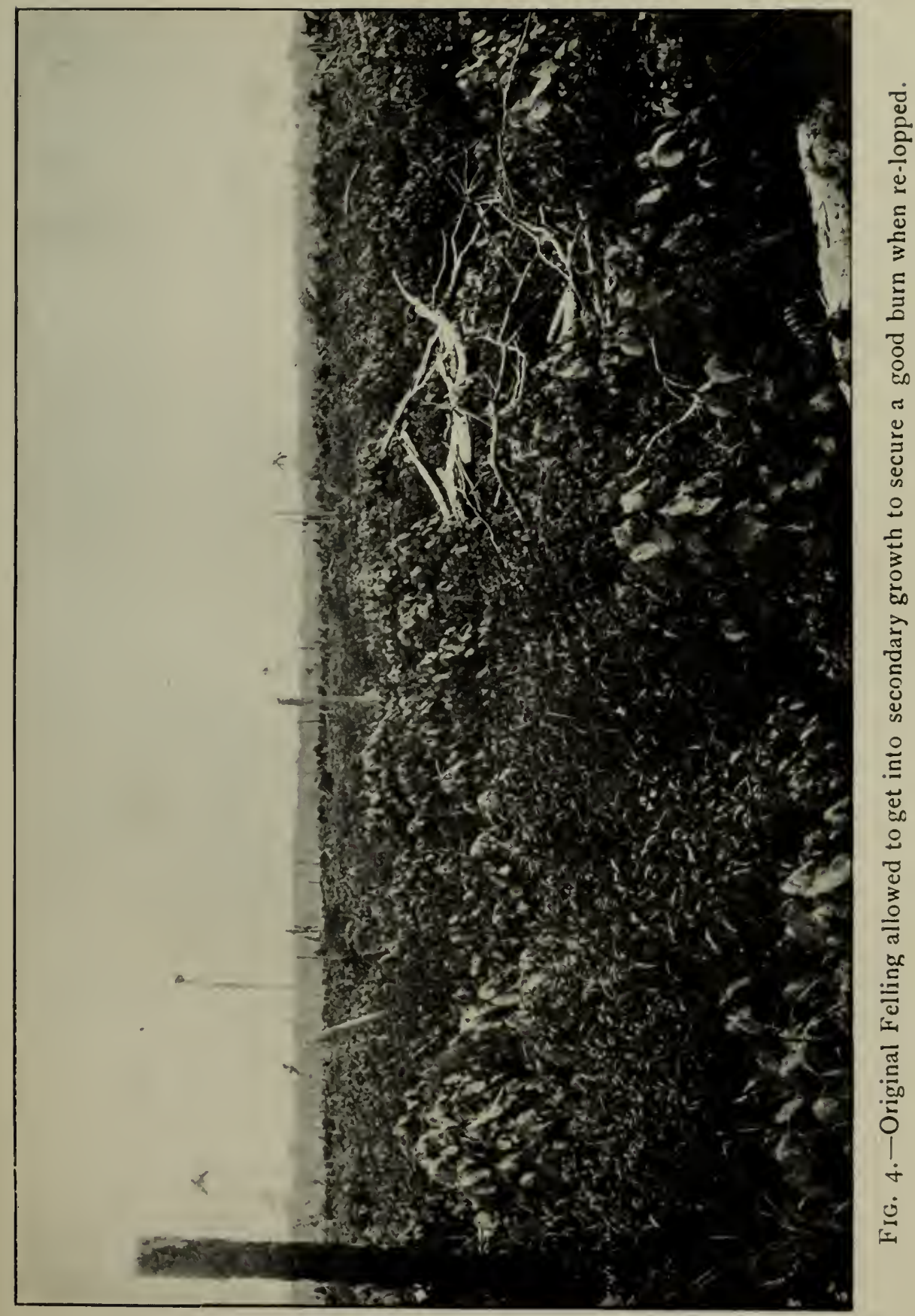

Face p. 6. 

upwards of 20,000 acres under European management.

Sumatra.-The available land on the east coast suitable for coco-nuts is unfortunately limited, and moreover the fact that the rich volcanic soil inland, which would perhaps grow the finest coco-nuts in the East, is also the best in the world for a special class of tobacco, i.e., the covering leaves for cigars, naturally precludes any possibility of any great extension of the coco-nut industry taking the place of the more remunerative product, at any rate during such years of prosperity as the Dutch Colony is at present experiencing.

Land Conditions.-In the Federated Malay States the ordinary terms on which the land may be acquired are as follows:-

\section{For First-Class Land.}

From the beginning of the Ist year to

Per annum the end of the 6th year... $\ldots$... $\$$ oo per acre.

From the beginning of the 7 th year to the end of the roth year

From the beginning of the IIth year to the end of the $15^{\text {th }}$ year

From the beginning of the 16th year to the end of the 20 th year

From the beginning of the 21st year and thereafter I'50 , , 
For Second-class Land.

From the beginning of the rst year to the end of the 6 th year... $\quad . . \quad \ldots \quad \$ 1 \cdot 00$ per acre.

From the beginning of the 7 th year to the end of the roth year f.. ... $1.50 \quad$ "

From the beginning of the I Ith year to the end of the fifteenth year ... ... 2.00 ", From the beginning of the 16 th year and thereafter ... $3.00 \quad$,

Nothing in the notification affects other than paragraphs $a$ and $b$, "The Country Lands (Cultivation of) Enactment, I9I4," nor does it render any person liable to pay rent at a higher rate than would otherwise be payable by him.

The notification has effect from and including the first day of January, I9I4.

While these are the usual conditions laid down, a few large concessions have in the past been granted on more favourable terms, and at present easier conditions are given in the State of Pahang to those desirous of taking up land for the cultivation of coco-nuts in accordance with a notification circulated in the Government Gazette towards the end of I9I3 to the following effect :-

"In order to encourage the cultivation of coco-nuts in the coast districts of Kuantan 
and Pekan, the Government of Pahang is prepared until further notice to receive applications for land for that purpose and to grant to approved applicants blocks of 2,000 acres on specially favourable terms. The title of the land will be a grant in perpetuity, subject to an annual quit rent, and to other conditions as follows :-

"(a) Quit rent will be charged at the following rate per acre: for the first year Io cents ( 2.80 pence); for the second year 20 cents; for the third year 80 cents; and so on increasing by ro cents each year until the maximum of $\$ 1$ per acre is reached (2s. $4 d$.).

"Kuala Pahang is an open roadstead, but the steamers enter Kuantan Harbour all the year round at high tide. The Straits Steamship Company maintains a weekly service between these ports and Singapore and other vessels also call. Pekan and Kuantan are connected to the F.M.S. telegraph system. A railway steamboat service is maintained between Pekan and Kuala Krau on the F.M.S. railway line. The distance is I 29 miles. Tributaries of the Pahang provide access for native boats. A Government cart road is 
being constructed from Kuantan to Jarantut Station also on the F.M.S. railways. The total distance is about $\mathrm{rO}_{3}$ miles, of which thirty-three miles from Kuantan are now open to motor and other wheeled traffic, and the remainder should shortly be completed. There is a large area of land available and the Malays plant coco-nuts both on the coast and inland. The climate of the coast has a good reputation for salubrity, but it is, of course, impossible to dispense with the medical and sanitary arrangements usually enforced on estates elsewhere in the Federated Malay States. The ordinary rates of quit rent in Pahang are 50 cents per acre for six years, and thereafter $\$ 2$ per acre.

" (b) One half of each block of 2,000 acres must be cultivated within five years from date of occupation of the land or the date of the grant, whichever is earlier, and nine-tenths of the land must be cultivated within ten years.

"Export duty will be charged on the products at the current rates (at present $1 \frac{1}{2}$ per cent ad valorem).

"No premium will be charged, but the applicant must pay the cost of survey, boundary 


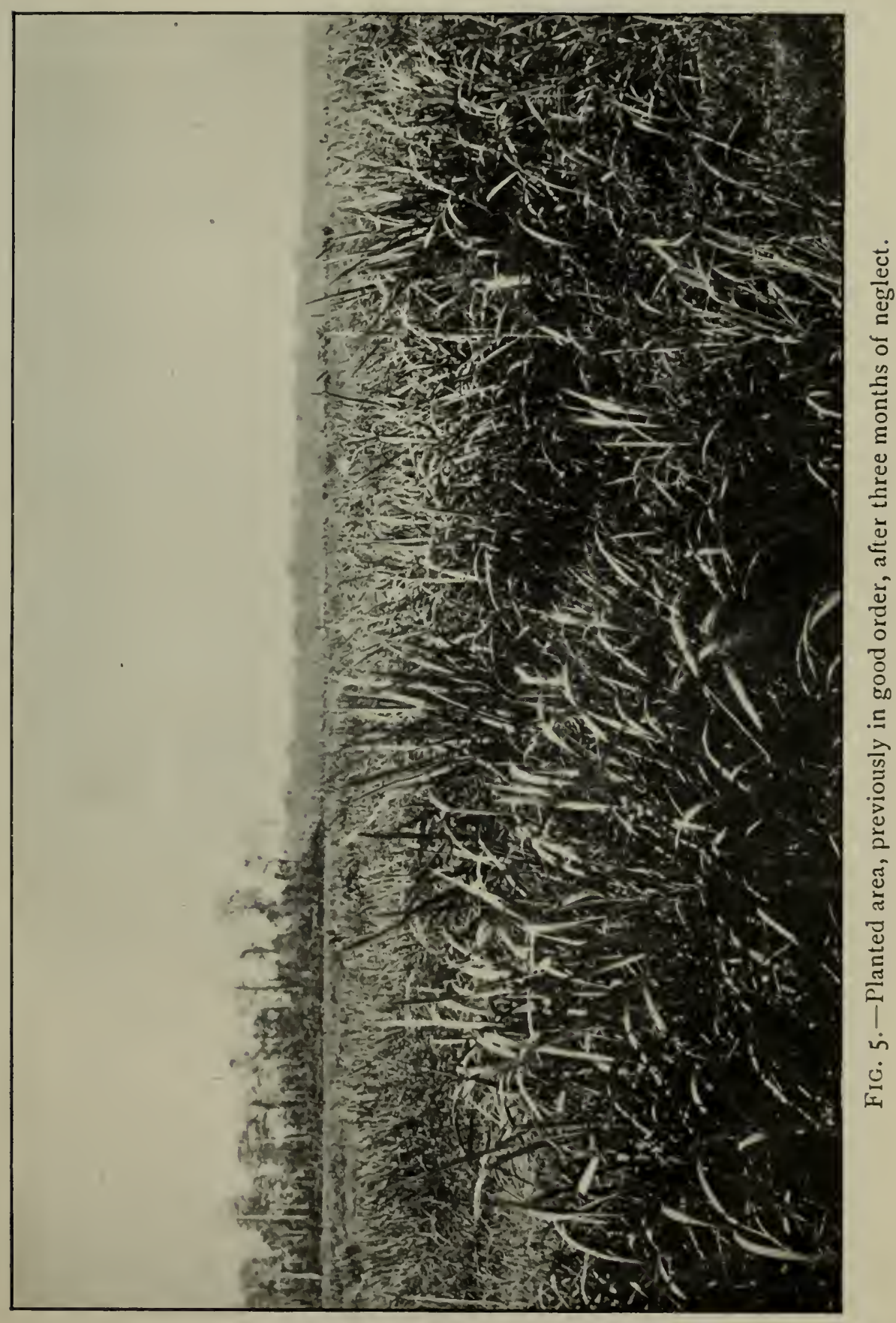

Face p. 10. 

marks and preparation of the title, which on a block of 2,000 acres would amount approximately to a sum of $\$ 1,500$ to $\$ 1,700$. An applicant may apply for more than one block but the conditions mentioned would apply to each block granted."

The districts of Pekan lie on the east coast of the Peninsula facing the China Sea. Kuala Pahang, the port of the Pahang district, is I 7 I miles by sea from Singapore, while the harbour of Kuantan is twenty miles further north.

\section{Terms in the Dindings.}

The terms for each particular application are fixed with reference to the condition of that particular application. But the terms which, in absence of special circumstances, would probably be approved for coco-nut land in the Dindings to-day are as follows:-

Premium \$5 per acre.

Rent ... \$3 per acre per annum with 2/3rds Rebate for six years, on condition the land was planted up in such a way as to secure that the whole should be planted within the period of Rebate.

The payment of enhanced rent at the rate of 5 per cent. per annum in lieu of $\$ 3$ per acre of the premium would probably be approved if desired. 
Survey fees are on a fixed scale as follows: for lots exceeding 500 acres and not exceeding I, 000 acres, $\$ 480$ for the first 500 acres, and 70 cents an acre for every additional acre or part of an acre.

For lots exceeding 1,000 acres, $\$ 8,0$ for the first 1,000 acres, and 50 cents an acre for every additional acre or part of an acre. .

Other fees incidental to the acquisition of the land would be :-

Preliminary Survey $\quad \ldots \quad$ say, $\$ 2$.

Grant Fee $\ldots \quad \ldots \quad \ldots \quad \$ 5$.

Boundary Stones $\ldots . \quad \ldots \quad$ \$I per stone.

There is plenty of excellent coco-nut land still available.

Land Terms in Penang and Province Wellesley.

The ordinary condition on which land may be obtained from the Government are as follows :-

Premium $\$ 20$ to. $\$ 25$ per acre.

Survey Fees-

100 to 500 acres... \$1 20 for 100 acres and 90 cents

per acre afterwards.

500 to $\mathrm{I}, 000$ acres $\$ 480$ for 500 acres and 70 cents. per acre afterwards.

$\mathrm{I}, 000$ and upwards $\$ 83$ o for $\mathrm{I}, 000 \mathrm{acres}$ and 50 cents.

Rent. per acre afterwards. 


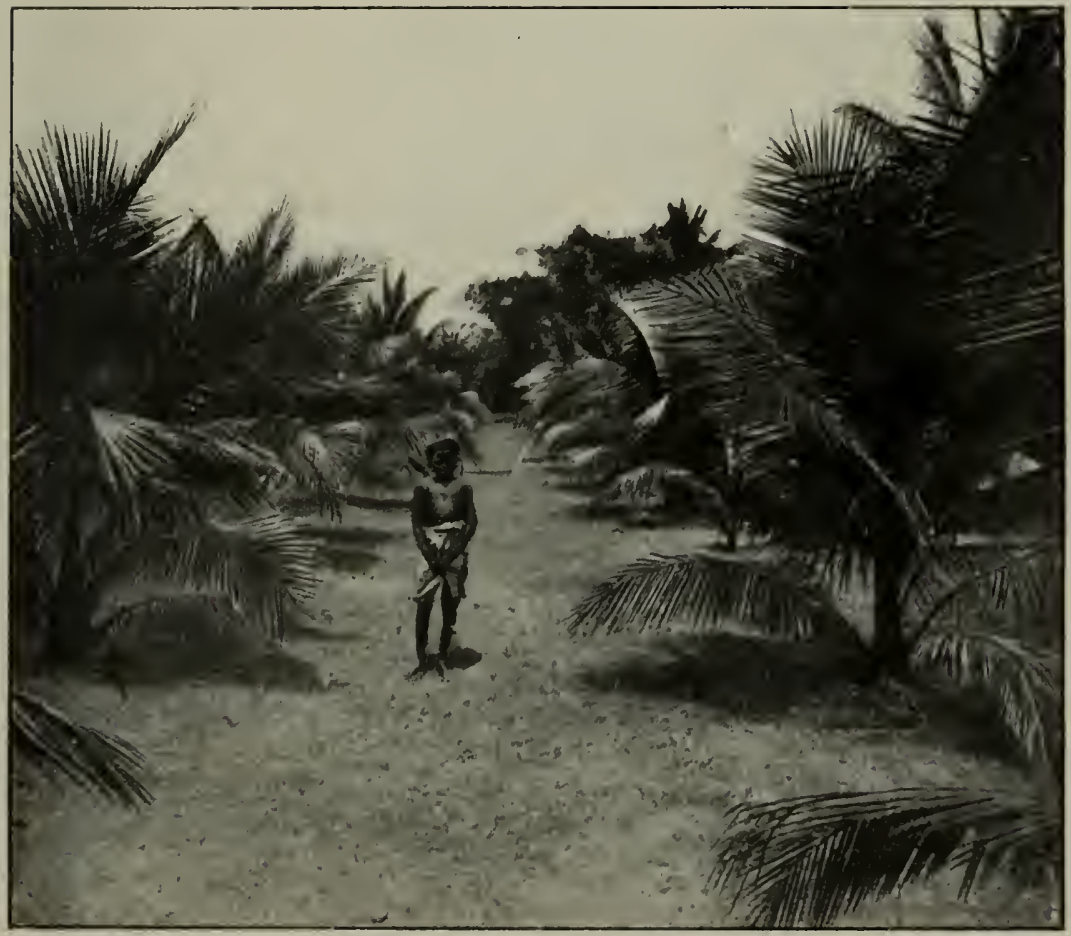

FIg. 6.-The King Coco-nut.

$1 \frac{1}{2}$ years from planting. Planted ${ }_{5} \mathrm{ft} . \times{ }_{5} \mathrm{ft}$. 

As regards these terms, which may appear rather high, we would point out that there is practically no land at all available in Penang and very little left in Province Wellesley.

\section{Sumatra.}

Lana Tenure.-The form of title is a deed of concession or contract made in due form, signed and sealed by the Sultan, and ratified by the Resident. The terms are favourable compared with those on which most of the grants are now issued in the Federated Malay States. For coco-nut cultivation special terms have recently been offered, and are, we understand, as follows :-

A maximum of 42 cents per acre on a seventy-five years' lease.

This commences after the fifth year ; during the first five years the annual rental charged is only $8 \frac{1}{2}$ cents, rising annually by $8 \frac{1}{2}$ cents to the maximum of 42 cents.

\section{SoILs.}

When asked what constitutes first-class soil for coco-nuts, a good deal of deliberation is required before giving a definite reply, but 
the following particulars as to the variety of soils best suited for quick growth, and the best method of dealing with them on the spot, may perhaps, be a guide to those seeking for this kind of information.

We are not so much concerned with the cultivation as we hear of it from other tropical countries, though in the natural course of things comparisons are bound to awaken a certain amount of interest. Dealing with the conditions as to soil and climate here, it appears that, generally speaking, we have little to complain of, but it would seem necessary for the benefit of those who intend interesting themselves in coco-nut cultivation to place the soils found inland in a somewhat different category from those on the coast; and in this connection there would be a great many things to be taken into consideration before choosing what the position of the estate should be.

From general observation it is quite reasonable to assume that we have the climate, and it is not too much to affirm that the acknowledged success in the growth of our rubber plantaticns may be attributed more to this than 


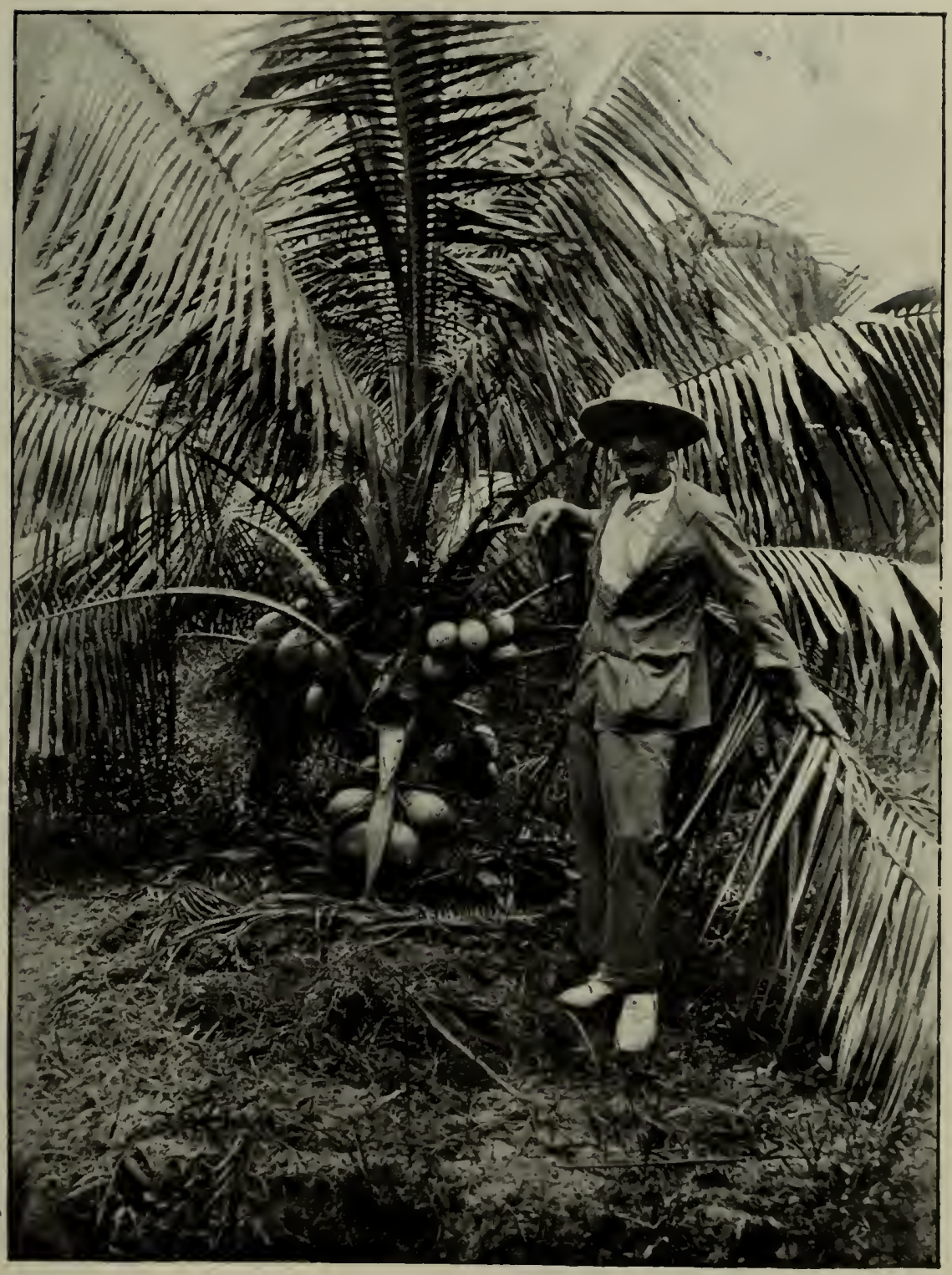

FIG. 7.-The King Coco-nut.

Three years from planting. 

to any question of superiority of soil so far as comparison with other countries goes.

Undoubtedly the question of soils is one that must be very carefully taken into account ; it should be borne in mind that coco-nut land, apart from the soil, must be capable of perfect drainage; so that it is better to choose some of the stiff clays, which, when worked up, produce excellent and lasting crops, provided they are not allowed to become sodden through periodical flooding, rather than the best looking, free soil often containing more organic matter, but so situated as to be incapable of affording the amount of drainage that the coco-nut seems to demand, not only in the initial stages of its development, but in the bearing periods as well.

The following astounding statement appeared in a home paper the other day: "Coconut cultivation is only advisable where the land is unsuitable for rubber."

We trust that there are few who, having read this remarkable statement, would be inclined to take it seriously, or even to give to it a moment's consideration. There is no doubt that the idea was at one time very 
prevalent that any land was good enough for coco-nuts; just put them in, do nothing, and await the result. Fortunately, so far from this idea gaining ground, there is a marked tendency now towards gathering what information is available regarding the conditions necessary for the well-being of the coco-nut palm, and touching upon this subject, it would not be irrelevant to express the hope that (although it generally says so in the prospectus of any company) all the land chosen for rubber cultivation is the most suitable land obtainable.

Personally we have seen rubber planted and existing on soils which in their natural state it would be quite useless to expect coconuts to thrive on. They might exist on it as they seem to, but no yields worth talking about need be expected from the trees.

The quickest growth that we have seen, that is to say, the quickest yield from the time of planting, was on land subjected to tidal influence when stiffish clay was found beneath a very considerable depth of humus. The chemical analysis of this soil showed it to be particularly rich in phosphates and nitrogen- 
in fact well supplied with all the constituents essential for plant nutrition.

One question which will take a long time to settle is whether abnormally forcing soil will turn out the best in the long run, i.e., will give more steady and lasting yields than some lands where the growth is by many degrees slower. We do not think that this point is worth discussing under the present heading, as it may be assumed that most of our readers would be attracted by the soil that was likely to be earliest productive, and required the least amount of expenditure to bring about the desired results.

Heavy jungle is usually an indication of soil where the requisite depth of humus exists and in the majority of instances should be chosen where it is noticed in low-lying districts.

The land stretching along the banks of rivers is almost always good up to the tidal point, although in some parts of Sumatra and Borneo this does not hold good on account of the very slight variation in the rise and fall of the tide, thus precluding the possibility of what we understand by perfect drainage facilities. 
Clay soil devoid of humus, although there are exceptions to this in some cases, cannot as a rule be described as first-class land, any more than sandy soils which are to be seen in large tracts sometimes along the East Coast of the Peninsula; these latter, although comprising areas of very excellent material, are not found in sufficient quantities to be attractive by comparison. When sandy soils are chosen, however rich they may appear, the question of special treatment from the commencement is a point that cannot be too strongly advocated: for these soils require aeration just the same as any other class of soil, only not, of course, quite to the same extent. The same precautions have to be taken against droughts, and systematic mulching becomes almost a necessity from the start. As these soils again are most lacking in nitrogen and phosphates, green manuring cannot be too strongly advocated. Cover plants are not easy as a rule to establish, but once this difficulty is overcome they can be made quite a success. 


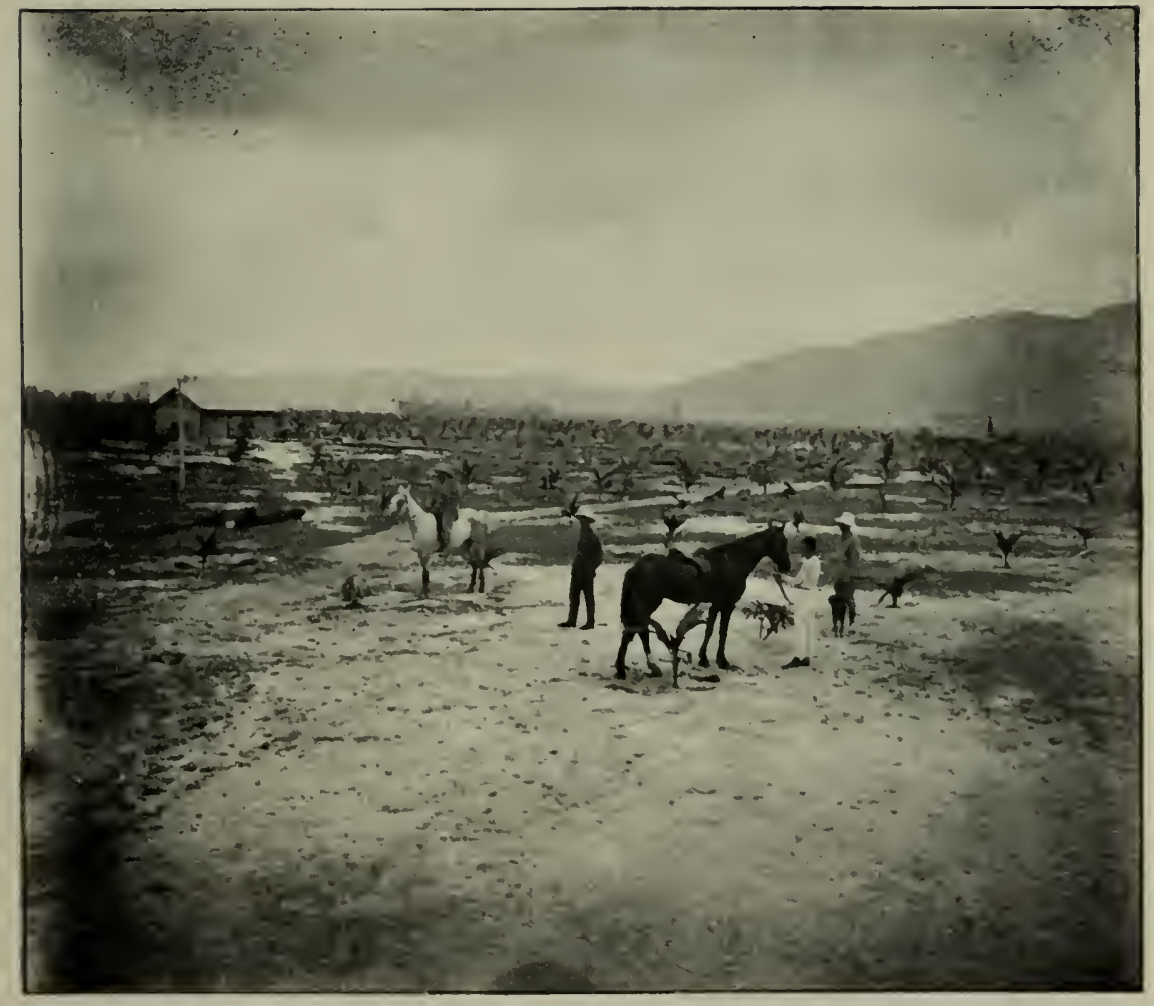

FIG. 8. A newly-planted clearing on sandy soil (Tringganu).

Face p. 18. 

CHAPTER II.

\section{THE PREPARATION OF LAND FOR PLANTING.}

If the land is comparatively low lying and some of the soil of a peaty nature, as is very often found to be the case in the coast districts, where the rich alluvial loam exists, rentices must first be cut through the area to be opened up and drains immediately afterwards put down in order that the ground may be as dry as possible before the felling is commenced. In referring again to this allimportant question of drainage it is almost universal to find that planters who have no experience of low lying soils in the coast districts fail to realize at the outset the vital importance of obtaining tap drains of sufficient size and depth, and that the money has been too lavishly spent on field drains without proper attention being given to the outlets.

Where the ground is higher and there is no, possible chance of it becoming flooded when 


\section{GUIDE TO COCO-NUT PLANTING}

the rainy season sets in, this precaution may not perhaps be required; at the same time, to drain the land thoroughly prior to felling is always to be strongly recommended.

The next step is to contract on the best terms possible for felling the jungle or secondary growth as may happen to be the case. As regards this work it will, no doubt, be found that the rates vary slightly in the different localities, also that some forest is more expensive than another to fell as so much depends on the nature of the jungle that has to be dealt with.

The felled jungle or secondary growth after it has been allowed sufficient time to get thoroughly dry is then burnt off. Both the felling and burning out of season should always be avoided, and should not even be thought of, as there can be no object in doing it. Notwithstanding the fact that one occasionally hears of what is called a "lucky burn," this system has been responsible for more failures in opening and subsequent extravagant upkeep than is generally supposed.

In nearly all the districts of the Federated Malay States, the Straits Settlements, Sumatra 
and Borneo the months for felling are December and January, with a view to a March burn, and May and June for an August burn.

The advantages gained by a good burn can hardly be over-estimated, and on this account, even although the weather is rather a capricious and uncertain element, great precautions should be taken to carry out the programme that has been recommended, as the chances are more likely to be favourable than otherwise.

The result of a good burn, with an experienced manager in charge, ought to mean an immense saving later on in upkeep and maintenance, and therefore is of great importance as regards the future prosperity of the undertaking.

It must be realized that a good burn, even under favourable conditions, depends very much upon the manner in which the jungle is felled. It should not be necessary to describe this, but we have seen such fatal consequences rom lack of knowledge in this respect that a description of the orthodox method seems to be essential.

After the undergrowth is cut and allowed to dry, the small trees are felled and the 
branches lopped; then the big timber. Trees should be felled so that no stump remaining appears more than $3 \mathrm{ft}$. 6 in. in height, but the most important part of the whole proceeding is to see that the branches are lopped and cut into pieces as soon as possible after the trees have fallen. This is where the felling contractor requires such close supervision, and where he will take advantage if not carefully looked after. It is no use to wait until the leaves have withered and fallen on the ground, as by this time it is too late to get the material for the fire "packed" as closely as it requires. Before the clearing is taken over from the contractor, it should, when looked at from the boundaries, present a perfectly level appearance, no timber, branches or undergrowth being more than $4 \mathrm{ft}$. above the ground. After the burn as much of unburnt timber as possible should be stacked and set fire to whenever the weather permits. Not nearly sufficient attention, as a rule, is paid to the stacking, which should be done around the big stumps and closely packed; first the small dead wood, and lastly the logs. Small heaps should not be made promiscuously all over the clearing, 
but at more or less regular distances; the larger the pile the better, provided it is properly built up.

As regards the amount of clearing necessary after the burn this must depend upon circumstances, but as a rule money is only wasted in going in for a perfect "clean up." One of the first things to do when the rain comes after the burn is to look over the whole clearing for any sign of lalang. On its first appearance every blade should be taken out, and every root eradicated; if this work is not done from the very commencement, or in the slightest way neglected, this dangerous weed will spread itself quickly to an extent almost incredible in a comparatively short time. Merely cleaned by scraping the surface is positively worse than useless, and an enormous waste of money, for all the time the roots are extending underground and spreading themselves far and wide all over the estate. This method, in fact, is only courting disaster. Should large stretches of lalang occur in the block being opened (and this is unfortunately very often the case) it will almost invariably be found that insufficient labour is available when required to eradicate it in one digging. 
There is only one satisfactory method to be then employed, viz., to dig a foot deep with changkols, turning over the earth and exposing the lalang roots, but not separating them by hand; then to come back on the same area in ten days' time at the outside, in another ten days do the same thing, and again the third time with forks, not changkols, and the lalang should be finished. In no case should lalang be taken into the ordinary weeding ground; it should be seen to that the weeders do not touch a blade of lalang, and that this work is left entirely to be dealt with by a special gang.

All these remarks will no doubt appear very commonplace to Straits and Sumatra planters with any experience, but having seen such terrible results arising out of want of knowledge, mostly on the part of managers whose early training as planters was not in this country, and who naturally do not fully realize the amount of destruction that lalang can bring about, we may be excused and forgiven for sounding as loud as possible this note of warning. We have known cases where hundreds of acres of young, flourishing coco-nut 
trees have had to be abandoned, not on account of the actual existence of lalang, but simply on account of those in charge of the property having been ignorant of how to deal with it, and also ignorant of the policy of those responsible for the financing of the estate. 


\section{CHAPTER III. \\ SELECTION OF SEED AND NURSERIES.}

Selection of Seed.-In order to ensure as far as possible what should at a later stage become not only good, healthy and vigorous young plants, but trees of a uniform yielding capacity, the greatest care must be taken in the selection of the seed.

In the first place they should be gathered from trees which are bearing well at the time of collection and by previous statistics show that they have for a considerable period given consistently good average yearly crops. Under these conditions the trees may be anything between 15 and 40 years of age and the nuts of fair size and of a roundish shape for preference. Very large nuts and those of a particular oblong shape are better to be avoided, as in the former case there will only be as a rule fewer nuts on the spathe, and with regard 


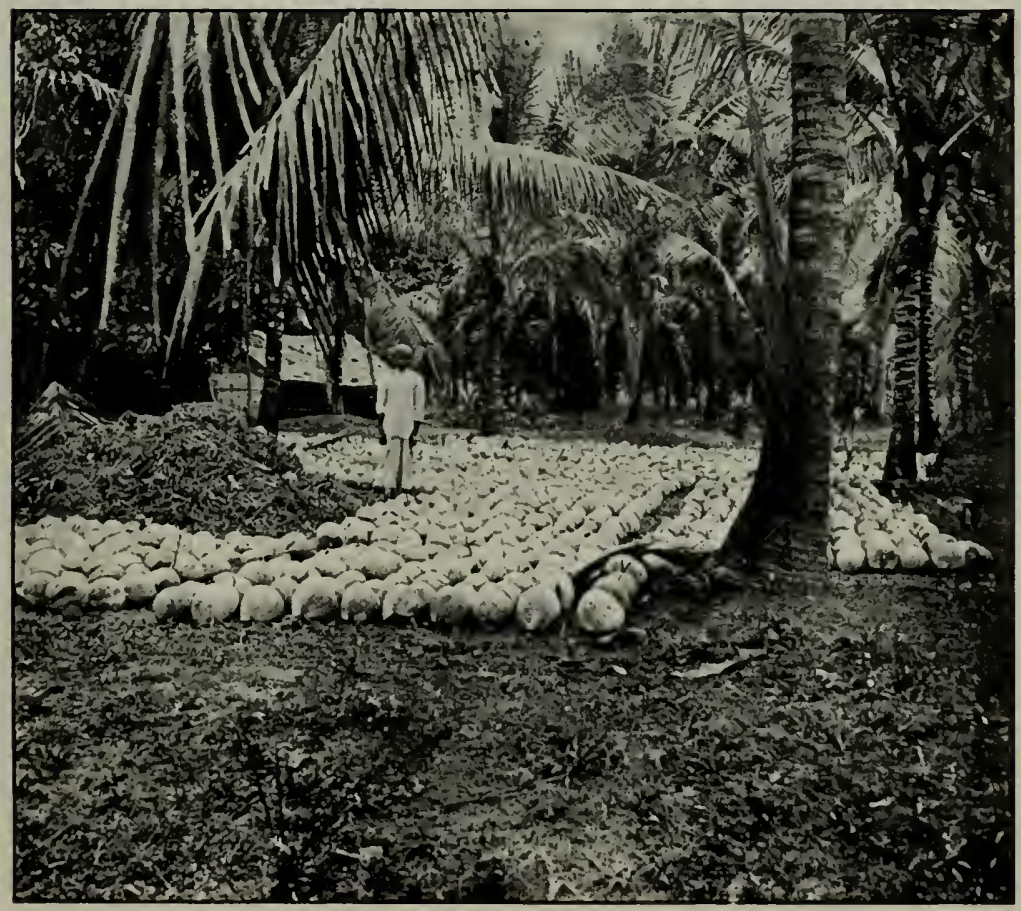

$F_{1(i,}$ 9.-Nursery under natural shade (I). 

to the latter they do not usually contain so much meat in the kernel.

Proper precautions must be taken to see that the nuts are fully matured before being plucked from the tree, and a strict examination made to ascertain whether they are damaged in the slightest degree, and if this is found to be the case they should be discarded.

Unless the seed comes from a long distance (in which event probably a sufficient period has elapsed since the picking of the nuts) it will be found advantageous to keep them for a short time to allow them to harden, in order that the outer covering or husk may be thoroughly dry before being put down in the nursery.

Seed nuts of good quality may, among other places, be obtained from Kuala Langat, Kuala Selangor, Bernam, Lower Perak, Penang and Province Wellesley. In placing orders for seed nuts, a guarantee of germination should be asked for, so that the purchaser may calculate on having at the very least 75 per cent. of good, healthy plants.

The results of observation show that as a rule nuts taken from trees growing on thoroughly well-drained land contain a thicker 
layer of meat and a higher percentage of oil than those taken from trees on swampy soil or land that is subject to constant flooding, and we think that selection in this respect is even of more importance than the question of age.

We are quite satisfied also that the age of the parent tree has little to do with the offspring's yielding capacity. Of course, theoretically, one should plant only nuts that have been proved to give heavy kernels and a good out-turn into copra, for, after all, it is the weight of copra that we require rather than the number of nuts to the acre, but in practice too many obstacles arise to make it possible for any such careful selection to be made, excepting, perhaps, with seeds for a very limited area of planting. Although we have little to go upon actually, we think that the estates. near the coast should be planted with seed from as far inland as possible and vice versa.

Nurseries.-It is a very common practice "just to lay out the seed nuts under the shade of the coco-nut trees without any kind of attention in addition to that of laying them out on the ground close to one another; the 


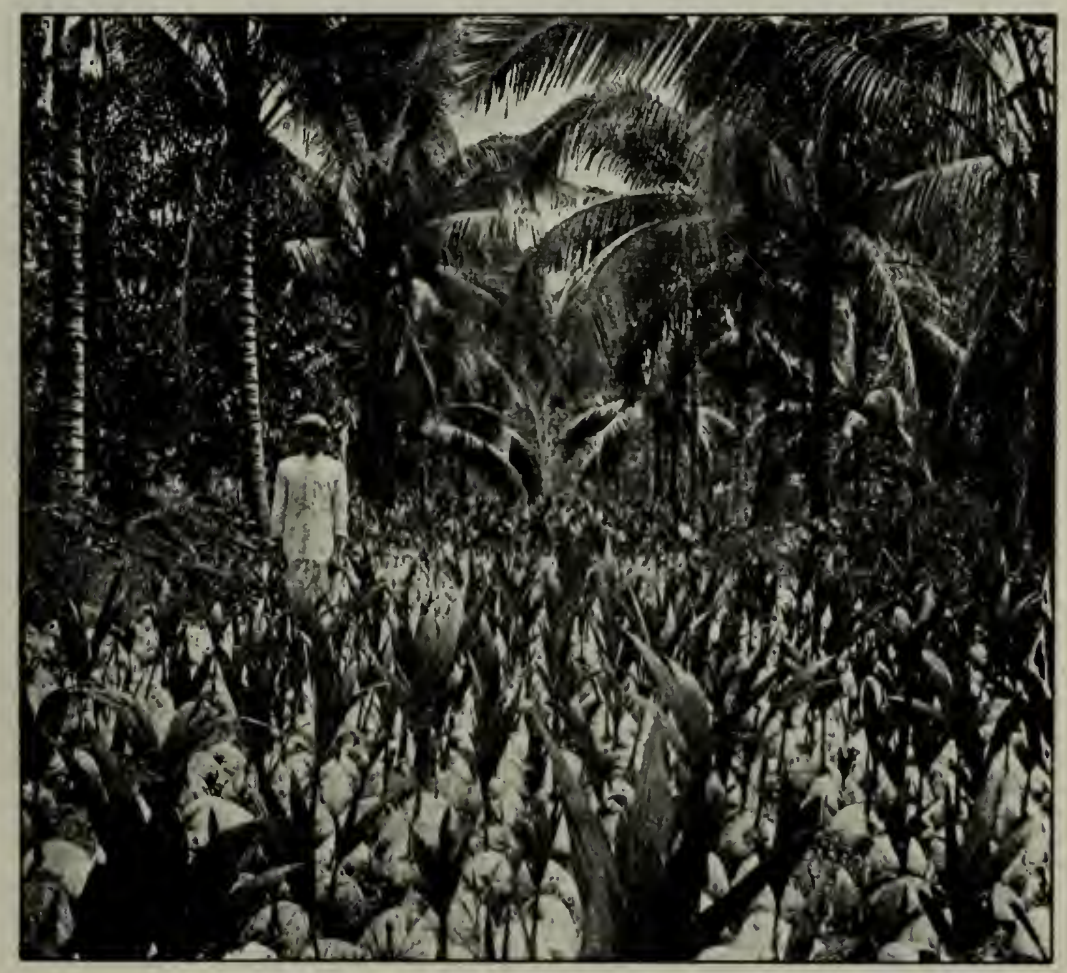

FIG. IO.-Nursery under natural shade (II). 

better course, however, in our opinion, in order to allow the seed the best chance of sprouting and making a start under more favourable conditions, is to have beds carefully prepared with good soil for the purpose and slightly raised so as to permit of efficient drainage. A thin layer of sand on the surface of these beds will also be found beneficial as it prevents the ground from getting too damp, which causes the roots to rot. The seeds after the beds are ready should be placed on the ground in rows about $2 \mathrm{ft}$. apart, slightly buried, and in an oblique position with the acute end of the nuts downwards. If found to be too much exposed they should be shaded for a time and this gradually removed, so that the nut may harden with the exposure of the sun before it is removed for planting out. It is not altogether an uncommon custom to cut a small section of the husk off from the top of the nut prior to the seed being placed on the ground, as this is believed to afford easier egress for the shoots to sprout.

Another method, especially among the Malays in certain places, is to allow the seed nuts to germinate by tying them in pairs by 


\section{GUIDE TO COCO-NUT PLANTING}

means of a portion of the outside husk and hanging them on long bamboos or poles supported on posts at a height of about $6 \mathrm{ft}$. from the ground and under shade, so that the nuts are not liable to too much exposure. No doubt this method has been adopted with a view to safety from the ravages of the wild pigs, but at the same time it has a special advantage inasmuch as the leaves and roots protrude in the usual way, so that when ready at the customary period for planting out neither the leaves nor roots need in any way be destroyed or interfered with; this very materially assists the growth of the plant in the younger stages of its life. 


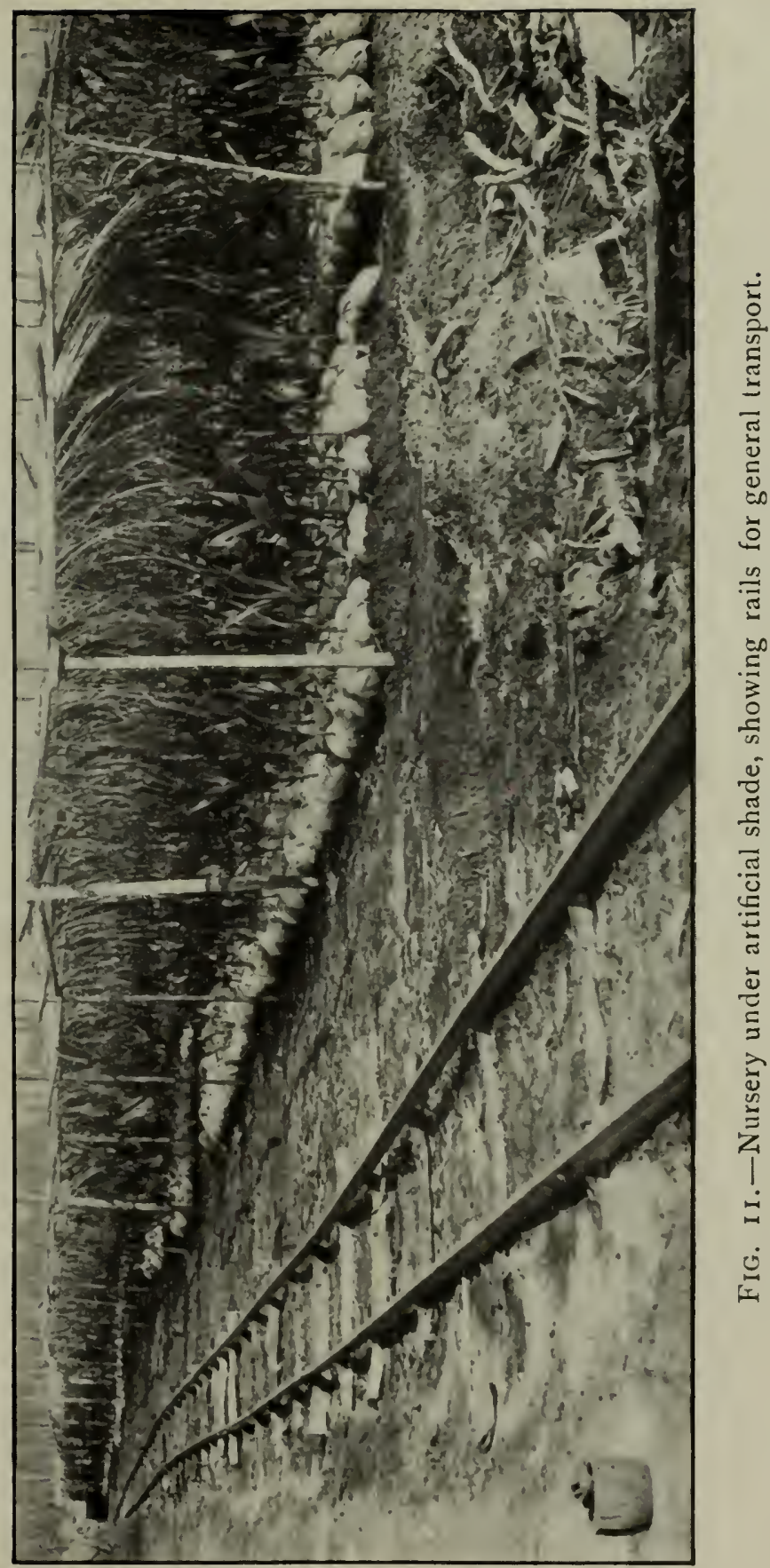

Face p. 30 . 

CHAPTER IV.

PLANTING.

In our opinion the best distance all round for planting the young plants is $30 \mathrm{ft}$. by $30 \mathrm{ft}$., nominally forty-eight trees to the acre, and if put down diagonally a few more trees are taken in; we, however, give the preference to square planting.

Before commencing on this work the ground must be thoroughly cleaned up and properly prepared for the purpose. When the land is high enough to allow of this being done, pits should be dug at the distances mentioned above to receive the young plants. These pits may be square or made in circular form, the larger the hole the better, but not less than $2 \mathrm{ft}$. in diameter and $\mathrm{I} 8 \mathrm{in}$. in depth, after which the holes can be filled with good surface soil and the seedling planted so that the top of the nut where it first starts to germinate is just about on a level with the surface. In many localities, especially on very low lying 
land, the question of holing or making these pits may not be considered necessary because of the amount of humus and decayed vegetable matter found on the surface, often for a very considerable depth; in fact the actual cutting of holes, even if not an impossibility, would be a waste of time and money. We have seen many thousands of acres planted on this class of soil, and the system usually adopted has been to simply lay the plant on the surface, and mould up with good surface soil so as to form a mound about $4 \mathrm{ft}$. in diameter. What will happen, it may be asked, when the natural subsidence of the land takes place and leaves the nut and sometimes the roots partially exposed? The remedy is fairly simple, although entailing a certain amount of expenditure, and this is one of the penalties to be paid for taking up land of this description. As a matter of fact there is no harm done by departing in certain cases from the orthodox methods, and we have seen very fine clearings indeed, and yielding excellent crops too, which are known to have been planted in this way.

As the land subsides, moulding has to be systematically done, and it will almost always 
be found necessary in addition to support a large number of the trees by staking each one exposed with at least two stout supports tied securely to the stem of the tree to prevent damage by swaying in the wind.

For moulding at this period, do not take the loose top soil, but the heaviest soil within reach, so as to give as much stability to the tree as possible, and encourage it to take a hold sufficiently firm to prevent any falling over at a later stage.

Deep planting in this country is not only unwise, but absolutely fatal in every class of soil and under every condition. We are able to produce a photograph of what happens when trees are put in deep on a sandy soil. No matter how well the land is drained this system brings about complete waterlogging and conditions that would actually be the death of any plant less vigorous than the coco-nut.

Native methods, although treated with all due respect to ancient custom, should be indulged in with extreme caution.

Another method of planting which has been brought to our notice as a preventive against 


\section{GUIDE TO COCO-NUT PLANTING}

wild pig is to leave the pits open and support the seedling with a stout stick firmly fixed in the husk and the other end of it securely fixed in the centre of the hole at the bottom. Later, when the danger is past, the cavity is gradually filled up with good soil. We have never tried this experiment ourselves, but it is possible where there is trouble from wild pig that it would be of some advantage to adopt this method to allow of a fence being put up meanwhile.

From our experience we think there can be little doubt that the best age to remove the seedlings from the nursery to plant out in the clearings varies from three to five months, when the roots can, with care, be easily dislodged from the ground with very little or no damage, an important and vital consideration for insuring the chances of the nut making a good start immediately after it is put out. There is also the advantage of the nut at these ages having plenty of nutriment still in it to subsist upon until the young plant has thoroughly established itself in its new locality.

When retained in the nursery and not removed until at a much later stage, it will 


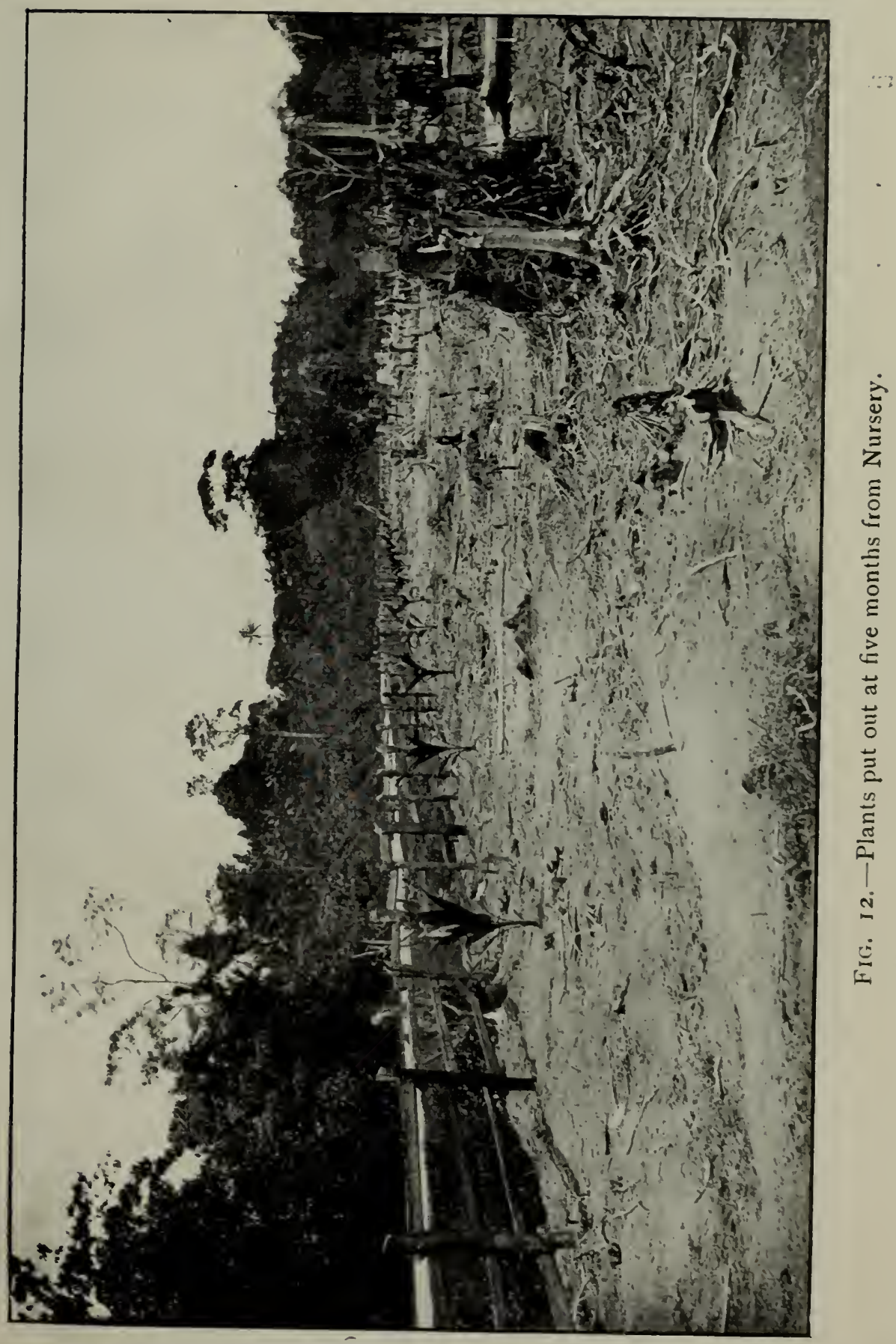

Face p. 34 
be found almost universally the case that the difficulty of transplanting is both more costly and less satisfactory as the roots are often damaged and broken off while this work is being carried out, and in consequence the young plants, more often than not, get a decided set-back, and it takes several months for them to recover from the effects. It is also, of course, a good deal more expensive, not only on account of transport, but in the treating of the big plants when finally placed in the holes, or on mounds, or in whichever way it is found necessary to plant them.

Planting from "seed at stake" has, in instances that we know of, been a decided success, and there is really no reason why this should not prove the best method on clearings that have been thoroughly well cleared of timber and kept clean-weeded from the start.

\section{The King Coco-nut.}

Whether it is advisable or not to plant a certain area with the dwarf nut commonly known as the King Coco-nut (in Malay, Nyor Gading) has not so far been ascertained, but two estates were opened in 1912 in the 
coast district, Port Dickson, and planted with this smaller variety on what might be called a commercial basis, as there are about 800 acres now under this cultivation. The result of this experiment when the trees come to maturity (and this should be comparatively soon now) will be watched with much interest as some reliable figures may then be obtainable to estimate the profit and value of the product.

It is not uncommon to see one or two of these trees planted in Malay holdings, also in gardens and around house-grounds in many localities, and we have trees of our own, nearly twelve years old, from which we have been getting large crops for many years, but these were planted on the drain edges, and had a better chance of doing well than those put out in a clearing.

From large, well-cultured trees in full bearing all over the Peninsula we consider an average of sixty nuts a tree per annum the actual limit (nothing approaching this result, however, need be reckoned on without high cultivation), and a much larger yield of a smaller nut would necessarily have to be obtained from the dwarf tree. As regards this, however, we have 


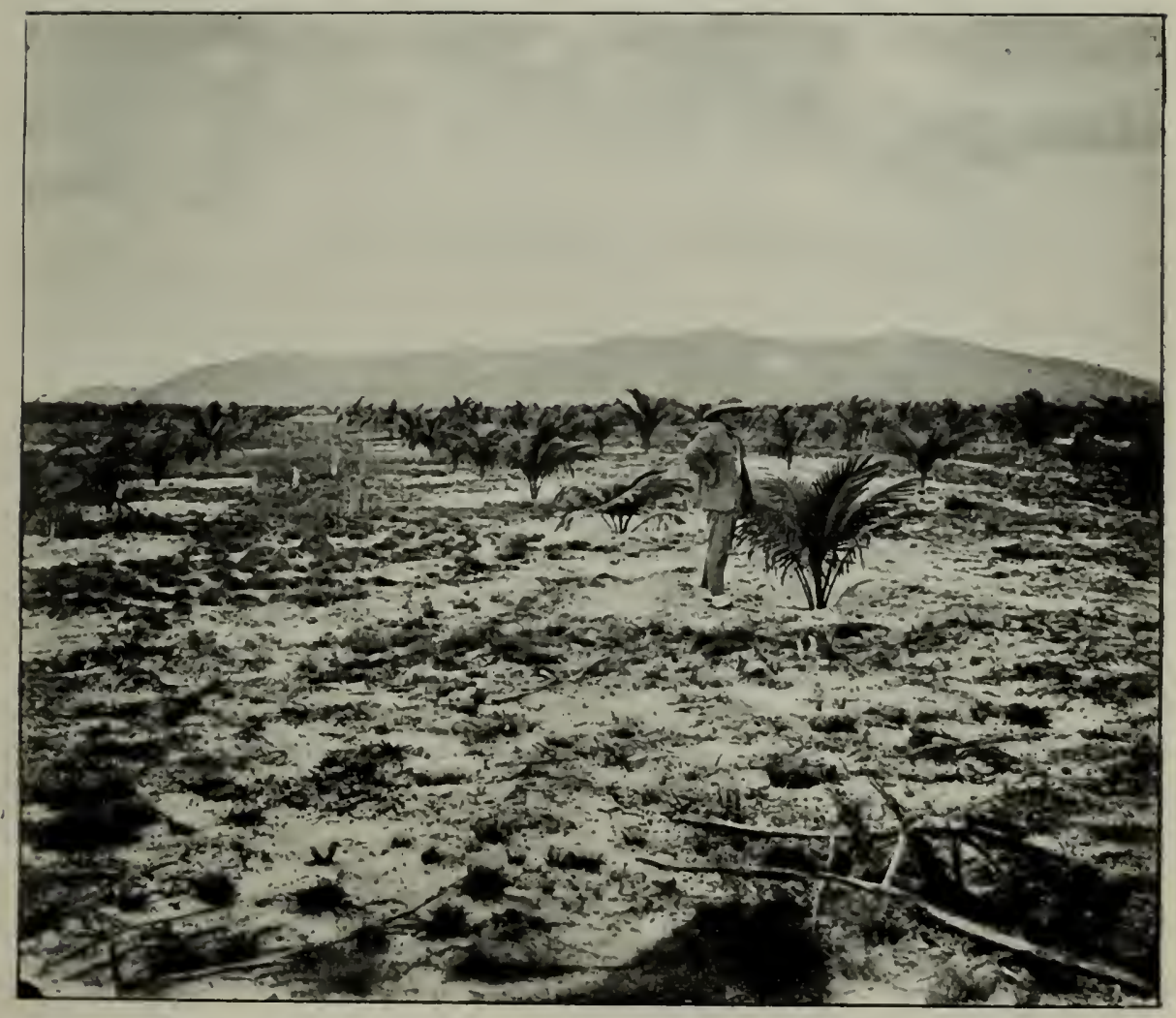

FIG. 13.-Clearing of three years old, illustrating the disastrous effects of deep planting. 

never heard of any estimates based on actual results, but from our observation so far, we incline to the opinion that the "King" variety will require rather high cultivation in order to obtain satisfactory returns, and may then possibly yield as much as an average of seventyfive nuts per tree per annum.*

Proportionately there is no doubt that the copra from the dwarf coco-nut is heavier than that obtained from the ordinary nut and is generally considered to be richer in oil.

The advantages on paper are :-

(I) The tree should come into bearing about one and a half years sooner than the ordinary one.

(2) The nuts are more easily harvested, without damage to the immature fruits and blossoms.

(3) The tree is more easily handled for beetles and other pests.

(4) The trees may be planted $20 \mathrm{ft}$. by $20 \mathrm{ft}$., giving over 100 to the acre.

In the photograph shown the trees are planted i $5 \mathrm{ft}$. by $15 \mathrm{ft}$.

* Actual yields and returns, according to a recert report, are given in the Appendix, together with photographs of the palms. 


\section{CHAPTER V. \\ MAINTENANCE AND \\ CULTIVATION.}

WE have now arrived at a stage when the most important question for the future welfare of an estate has to be considered, viz., the "cultivation of the coco-nut."

It becomes every day more apparent how rapidly the tree responds to any special treatment, which need not necessarily, however, be of a costly nature, and on this we have to rely for uniform and lasting returns.

From our experience and observations made in most districts, there is not in our mind the slightest doubt that with coco-nuts, at any rate, a drought is the danger that we have most to guard against.

We are quite satisfied as to the method necessary to adopt to avoid this and are gradually formulating a line of action to meet the case. It is one thing, however, to devise schemes, but quite another to get them carried out. 


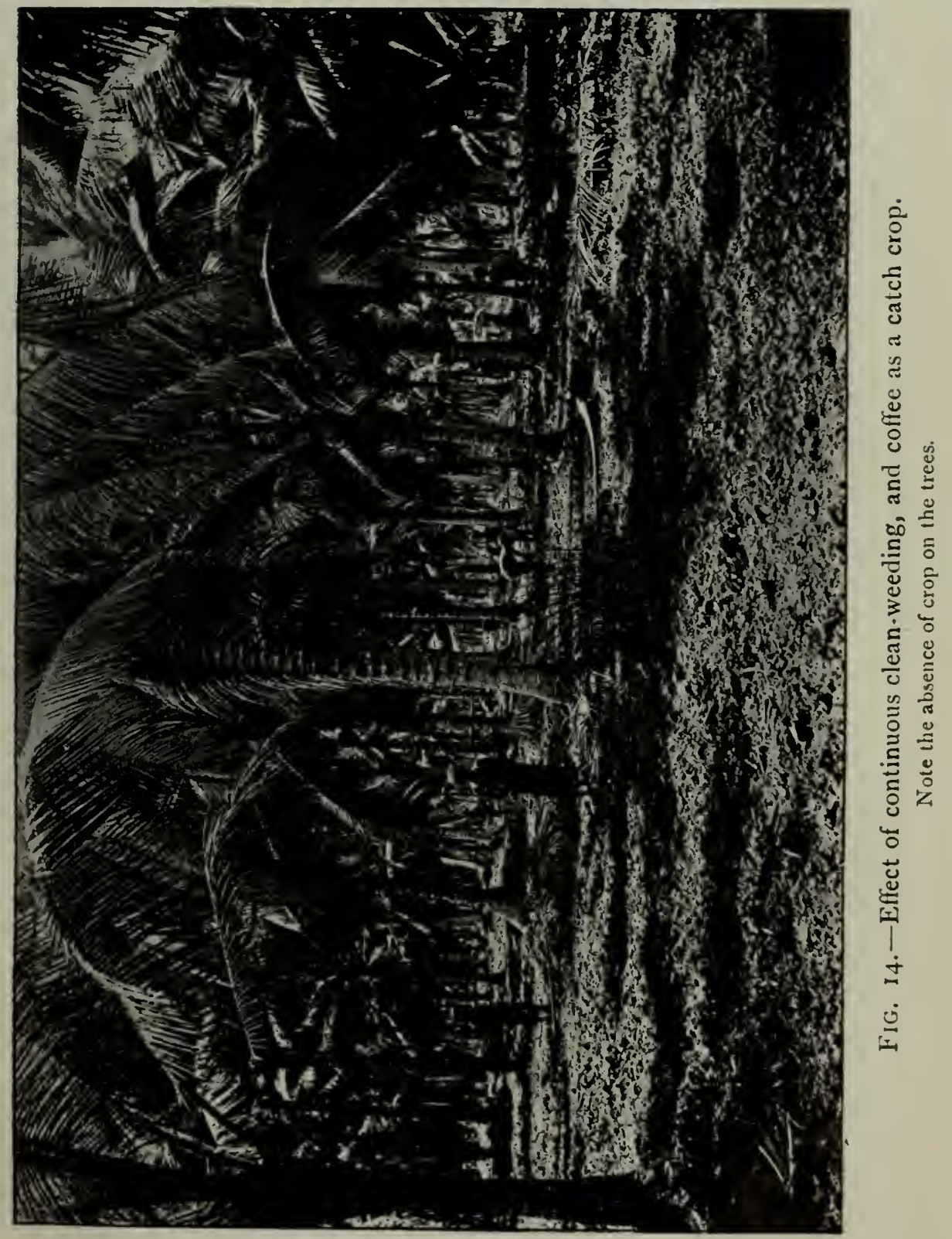



On a rubber clearing it is known that with ordinary care and supervision nearly every tree will yield latex, and the time from planting to tapping can be very closely determined by those of quite ordinary experience and intelligence.

What happens on a coco-nut estate is becoming more widely known every day: how that a large percentage of trees on the best regulated properties fail, for some reason or other, to produce at the required time, and that some will never give what is expected of them if left to themselves.

As it is not, therefore, so much a question of special treatment of the whole blocks that we are brought face to face with, but of individual trees over a somewhat extensive area, it becomes obvious that very special and intelligent supervision is required. Any departure from the ordinary routine takes up the time both of manager and assistant, and what was once called "cultivation experiments" have now developed into works of real necessity requiring much undivided attention.

Those who have had any long experience in coco-nut planting will, we feel sure, have 
found that the most critical time of the palm, to produce really vigorous, healthy, and wellgrown plants, is in the earlier stages of its life, i.e., practically from its infancy until it is thoroughly established, say up to the third or fourth year: therefore, it is only by giving very careful attention during this period that early matured and good bearing trees are likely to result.

For this reason we may safely lay it down as an axiom that in the ordinary course no necessity should arise for departing from the orthodox method of clean weeding until the trees have reached the age above mentioned; that is to say, that under ordinary circumstances the land should be clean weeded for a certain time, and that no grass or noxious weeds of any kind be allowed to interfere with or retard the proper growth of the young plants which may come about if this work is in any way neglected.

To protect the feeding roots and keep the soil on the surface that surrounds them, up to a given distance from the base of the stem, in a friable condition and able to take every possible advantage of the moisture prevailing, 


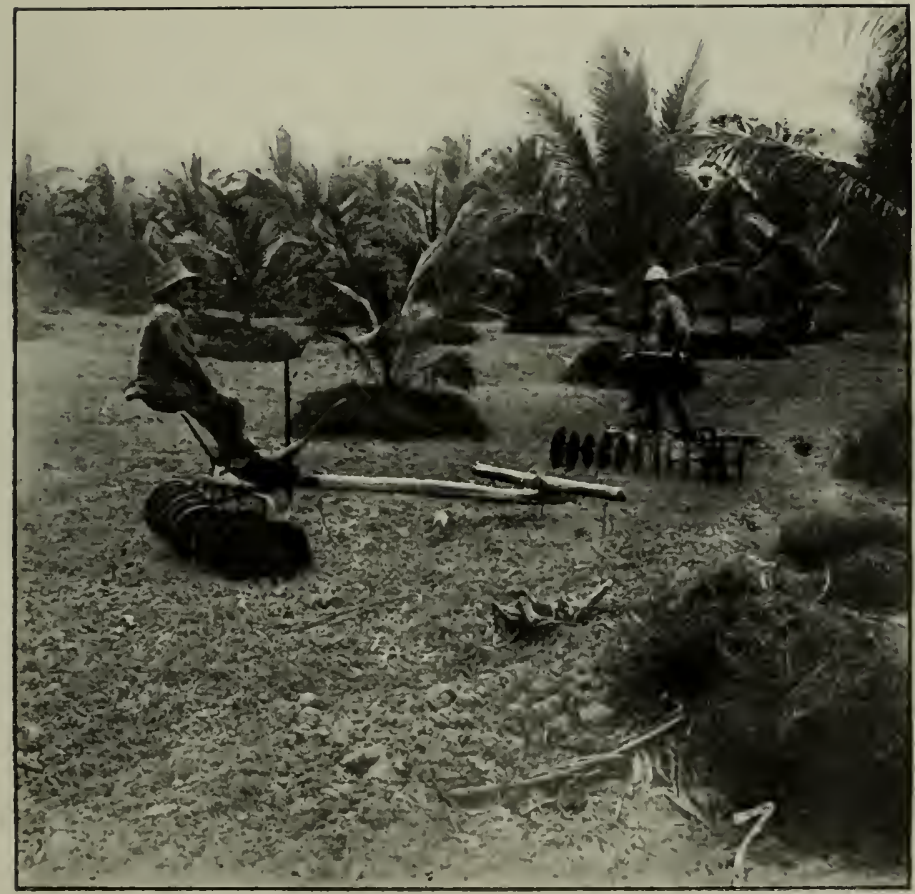

FIG. 15.-Disc-harrows at rest.

Face p. 40. 



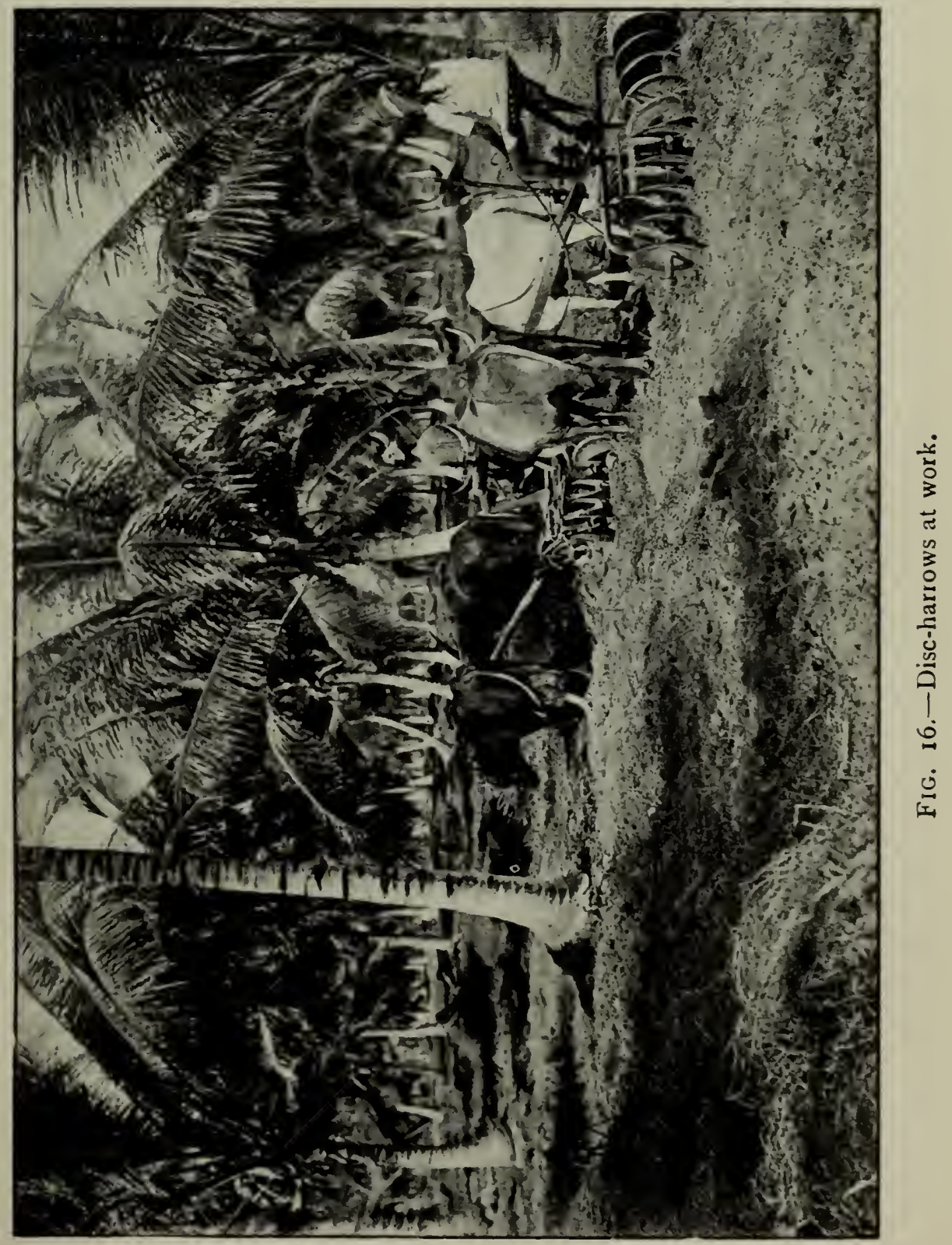

Follow 15. 

it necessarily requires that the ground be loosened by digging or forking, at least once in every three months, when some mulching may also be done as afterwards referred to, and which is so beneficial towards the well-being of the plant.

For the above treatment a radius of, say, $2 \mathrm{ft}$. to $3 \mathrm{ft}$. from the stem may be found sufficient when dealing with one-year-old plants; a year older the radius should be increased to, say, $4 \mathrm{ft}$., and so on, until ultimately the circle to be dealt with in this way, when the trees have reached maturity and in full bearing, varies from $7 \mathrm{ft}$. to $8 \mathrm{ft}$. and sometimes ro $\mathrm{ft}$.

After the trees have attained a certain age, and the land practically cleared of all roots and timber, a great deal may be done to sustain and improve the bearing qualities of the trees by the use of leguminous and nitrogenous plants to be applied as "vegetable manures," and special reference to this comes under "cover plants."

As it is a matter of some importance that the soil generally throughout a plantation should be as friable as possible, to enable the trees to 
continue in a good state of culture, both ploughs and disc harrows can be utilized for the purpose of continually breaking up the top surface wherever the land is inclined to harden. The beneficial effect this tilling has on the wellbeing generally is difficult to imagine unless one comes across an estate which is maintained by this method of cultivation.

It appears to be a very general impression that making a success or otherwise of a coconut plantation depends entirely upon the soil chosen, but it is difficult to understand why more stress should be laid on this when planting coco-nuts is under consideration than any other form of cultivation. Undoubtedly, the question of soils is one that must be taken into regard very carefully, inasmuch as it is a generally accepted fact that wherever land is chosen for opening an estate the block must be capable of perfect drainage; at the same time it has been found that sometimes the best looking free soil, which doubtless contains more organic matter and which brings the trees into bearing at an abnormally early age, is not necessarily capable of yielding lasting returns that can be recorded from soils of 


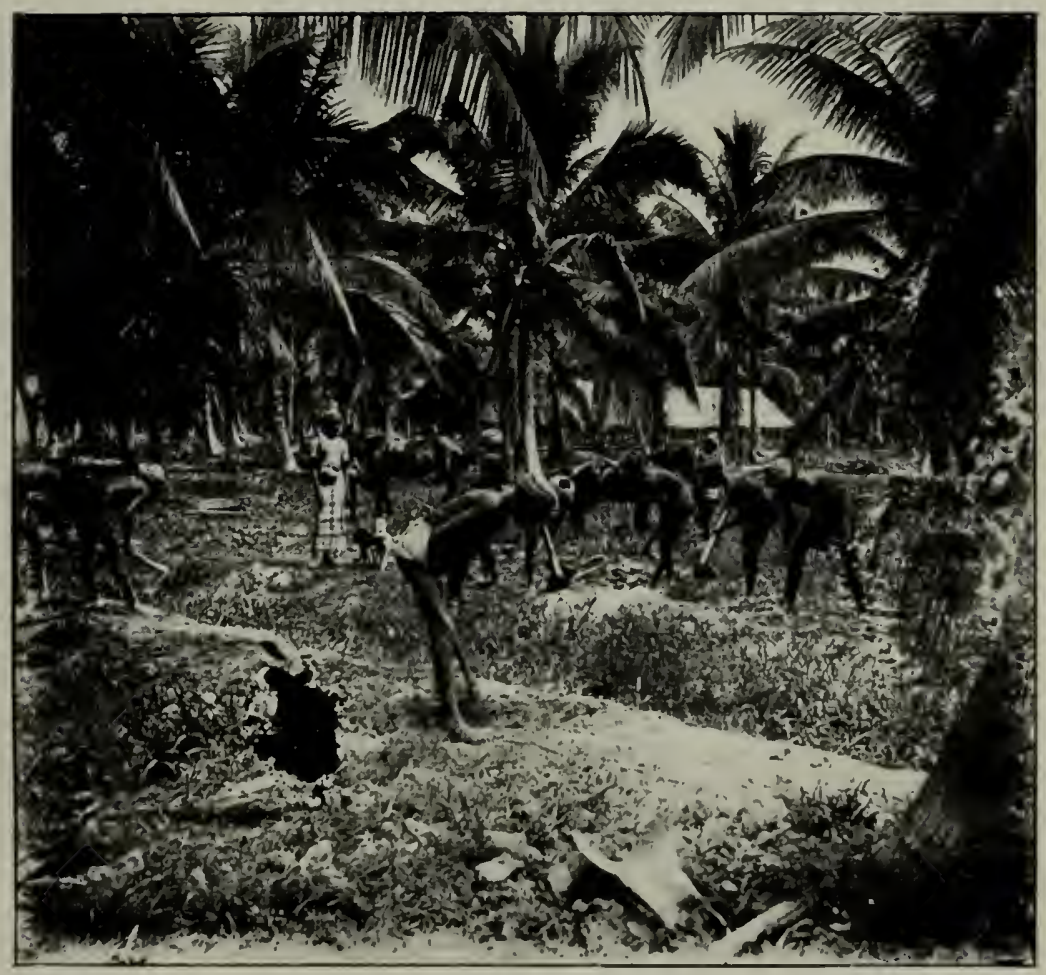

FIG. I 7. - Digging and Mounding. 

a stiffer type. Taking all these things into consideration, however, the point which appears to stand out above all others is the question of the treatment of the soil at all stages of the trees' existence, and it is obvious how little attention is given to the benefits derived from keeping the soil in a friable state by ploughing or harrowing. The roots of the trees are made by this means to find their way to regions of permanent moisture, the loose soil on the surface acting as a mulch and preventing evaporation. The deeper the roots go the better able the tree is to withstand droughts and to bear better crops. One cannot get away from the scientific fact that the ventilation of the soil renders the plant food in the soil more soluble. It is not of rare occurrence to notice instances where labour and money are being misplaced in carrying out the doctrine of clean weeding, after the trees have matured, at the obvious expense of cultivation.

We know of some estates on which large sums of money have been spent on the purchase and application of artificial manures because a serious falling off in the crop was 
noticeable. The soil on the blocks to which this manure was being applied, and on which trees of twelve years old were growing, had not been turned over or harrowed since the jungle was cleared, so it is not surprising that the trees were calling for some kind of treatment; but the policy of artificial manuring in a case of this sort cannot be too strongly condemned, and should in any case be resorted to only when the trees have failed to respond to every other kind of treatment, or the soil has been impoverished by paddy or any other equally exhausting crop.

It should be specially borne in mind that the successful establishing of cover plants is by no means an easy matter, and requires a great deal of thought, and personal supervision. With a view to economy in weeding it is often considered judicious to try and establish a cover, but in no case should this be resorted to in the early stages of the estate's development without a great deal of deliberation.

As soon as hand weeding through one misfortune or another has to be abandoned, it may be time to discuss the advisability of saving 
money by other methods, and also saving the soil from temporary destruction, which must inevitably be the result if continued scraping by hoes is carried on, and no system of tillage adopted.

There are few soils in the Malay Archipelago which, when chosen for coco-nut cultivation (and therefore presumably capable of yielding satisfactory crops), do not contain the amount of humus necessary for the well-being of the tree for several years after planting, without the necessity for the additional stimulus in the way of nitrogenous plants, even though an analysis of the subsoil should show a deficiency in this respect.

In dealing with the treatment of the soil by cover plants, one of the main advantages to be borne in mind is undoubtedly that of having the material at hand to alleviate, to a very large extent, the effects of a drought : these droughts are of no uncommon occurrence. We believe it is not generally known, but the fact is very clear to those who have had the opportunity of observing the growth of coco-nuts under conditions which prevail in most parts of the Federated Malay States, Straits, Borneo, and 
Sumatra, viz., that the trees are not only capable of yielding more lasting crops on a clay subsoil than on a sandy one, but that, as a rule, they come into bearing quicker.

Exceptions which prove the rule may be instanced in the very fine volcanic soils of Java and Sumatra; of which, however, there is a comparatively small area on the coast line.

Of the 200,000 acres of coco-nuts in the Federated Malay States it is fairly safe to assert that most of this area is planted on clay soil, therefore it may possibly be of more general interest to describe the methods which have, so far, been found most effective in treating these soils, with a view to affording the trees what they require at a stage beyond that of very early development.

From the commencement it should be realized that nothing in the shape of a hollow or depression should be allowed to remain within a certain radius from the stem of the tree (the spot to be determined according to the age of the tree).

A great deal must naturally depend upon the porosity of the soil under treatment, but 
as a general rule the system of deep planting in this country, as before mentioned, should not be encouraged.

The treatment of land on which any depth of peaty substance or decayed vegetable matter occurs presents many difficulties, even though very deep drainage is obtainable (it is assumed that land of this description would not be selected under other conditions owing to the amount of subsidence which takes place after the land is opened),

On this class of soil the necessity for moulding or banking the young plants very soon becomes apparent, and this attention will be found essential within the first twelve months from planting. For the next two years, at least, this system will have to be continued, and until the land has settled down to its normal level. Even on sandy soils the method of deep planting is much to be deprecated; one obvious reason for this being the increased difficulty of affording the necessary stimulus when required; and it must not be lost sight of that most of the sandy soils in this country are not of a quality sufficiently rich to be independent of special cultivation. 
It should not, therefore, be concluded that sandy soils, on account of their porosity, require less cultivation than others, but, at the same time, it should be realized that they respond, as a rule, very much more quickly to tillage and aeration. Mulching on a sandy soil will show results quicker than on clay soils, and it would be well to adopt this very important method of cultivation at an early stage of development when once the system of hand weeding has to be abandoned (and there are comparatively few soils on recognized coconut land on which it is found possible to carry out for any length of time this very desirable project). The question of other forms of economical maintenance is one that in most cases serves as food for a considerable amount of reflection and is not always given the deliberation that it deserves and requires. The method most prevalent at this juncture is, of course, to use any kind of hoe or scraper that is found the most suitable in removing grass and weeds as they make their appearance.

When once the seed has got in the ground it is necessary, in order to effectually eliminate 


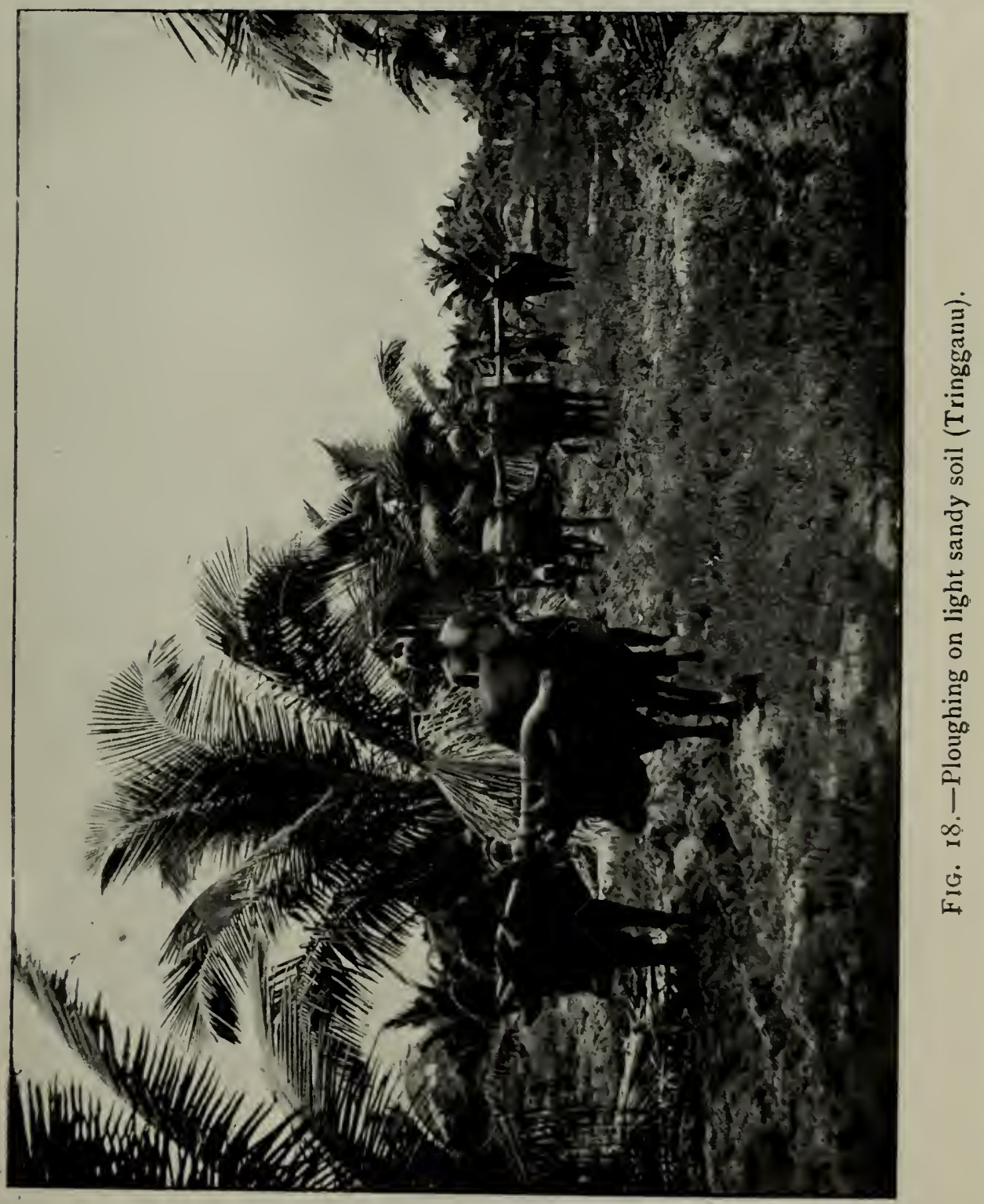

Face p. 48. 

all grass and weeds, that fortnightly weeding be carried out at any cost, no matter to what extent the soil becomes impoverished in the process. This is the point at which the coconut planter should pause before entering upon any specific line of action.

(I) Is the above cost of fortnightly weeding or scraping justified?

(2) To what extent is the soil becoming impoverished by such treatment?

(3) What method should be employed now to save the estate from the effects of a long drought other than by digging, forking, or harrowing, which, combined with the weeding, raises the cost of upkeep to a point far beyond, as a rule, anything mentioned in the original estimates?

(4) What should be done to return to the soil the humus thrown away by surface scrapings?

(5) The trees being planted at a distance that renders any assistance towards the shading of the ground from the spread of leaf more or less nugatory, for how many years are we to continue a system of expenditure that 
would not be justified in any other kind of tropical cultivation?

There can be only two ways of bringing about the desired result.

One is by constantly turning over the soil by mechanical means; and this, it might be remembered, is a very difficult proposition to deal with on a large area, there being only six to eight months in the year when it is practicable, owing to excessive wet or dry, to use the plough or harrow.

Theoretically the solution is simple, but practically it is distinctly the reverse.

We have seen plantations which had the advantage of magnificent soil, and which showed great promise at the start, put into a miserable state by successfully showing "clean circles" or "clean avenues" from which all the rich humus had been systematically removed into the centre of the square or down the rows. The land having been chosen mainly on account of its wealth in humus is thus wilfully impoverished, and can only be brought back to a state when crops can be expected from it by lengthy and expensive methods for which there is possibly no capital available. 


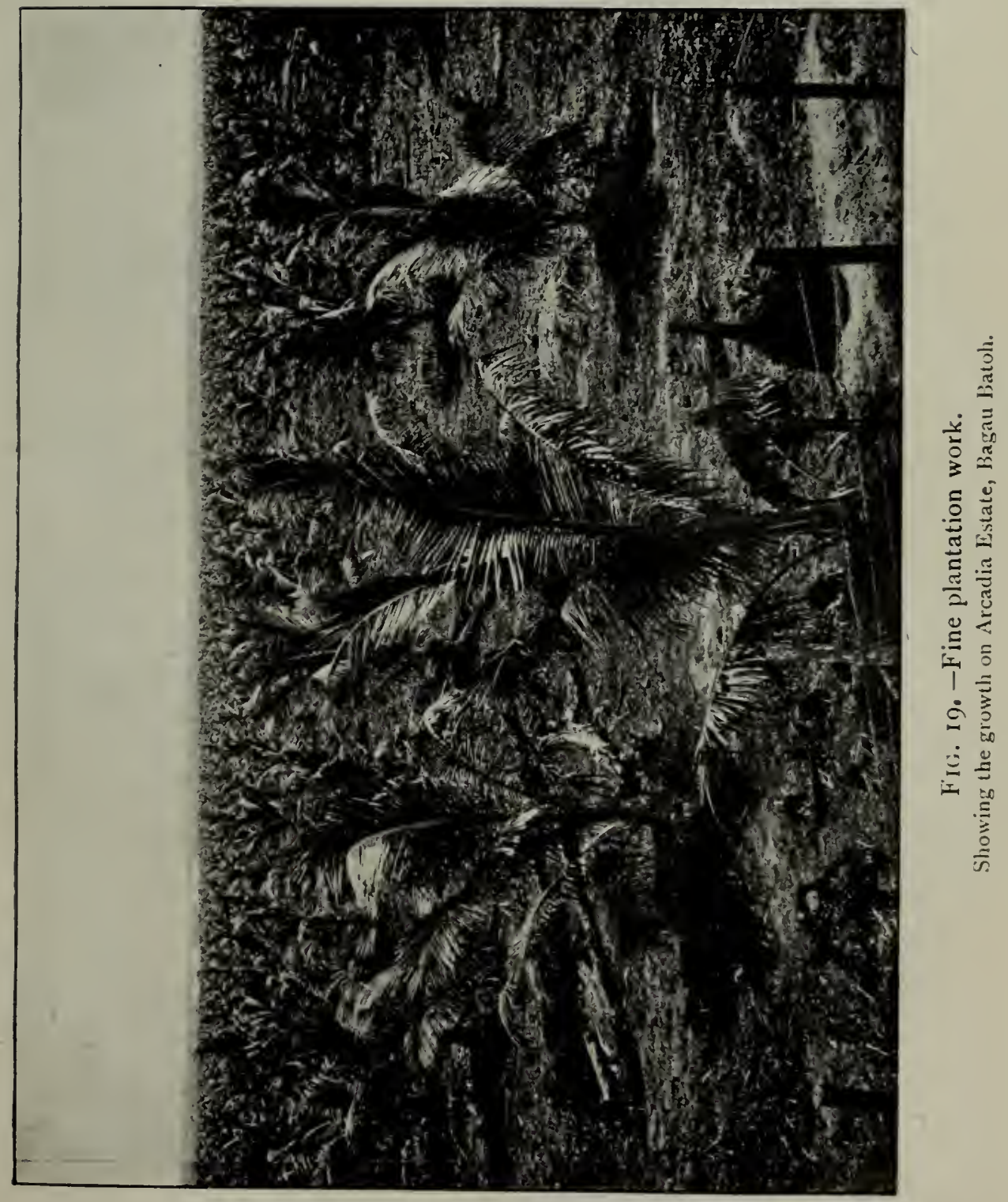



On economic principles, proper soil cultivation (after a certain period has been reached) and clean weeding cannot go hand in hand on a coco-nut plantation where the conditions are so totally at variance with those of most of the other kinds of tropical enterprises. This question should be realized from the first and estimates framed accordingly.

There are doubtless a few favoured spots where coco-nuts grow and flourish under conditions very far removed from those met with in the ordinary course, but we must consider these apart from any general principle.

Those who have had the opportunity of reading the very interesting and instructive articles by Mr. O. W. Barrett, of Manila, must be struck by the principles propounded, when he enlarges on the question of mulching and manuring for coco-nuts, in his practical treatise on cultivation which applies equally to this country, to Manila, and any other parts of the coco-nut zone.

The following, from Mr. Barrett, is well worthy of reproduction: "It is a sad fact that only a small percentage of the producers of. vegetable products know, or even care to know 
52 GUIDE TO COCO-NUT PLANTING

the prime functions and qualities of plant roots ; that is, the very large majority of planters and even horticulturists do not use mulches. It is sad because it means an unnecessary and unconscionable loss of probably about i 5 per cent. of the normal production of the world's cultivated crops." 


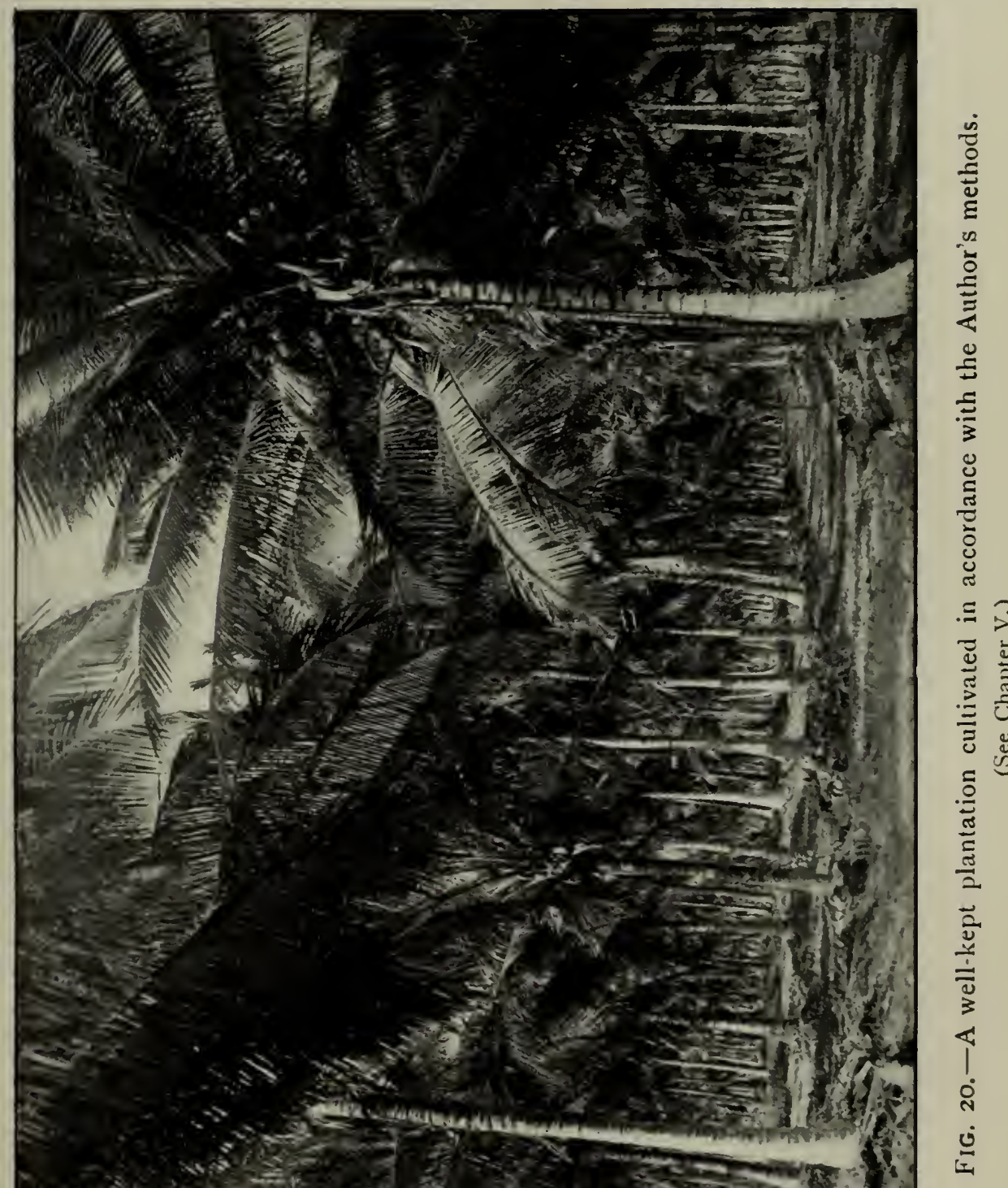

Face p. 52 . 



\section{CHAPTER VI. CATTLE-KEEPING.}

ONE sometimes sees it stated that when the coco-nut trees are of such and such an age it is safe to allow cattle to graze in the plantations. By safe we assume that what is meant is that the fronds of the palm are more or less out of reach of the cattle, because it is known that if badly eaten down the set-back is enormous ; in fact, it is better to supply with new plants than to watch them struggling to recover; but no matter what the age of the tree may be, the grazing of cattle on a coconut estate should only be thought of when it can be carried out on a system. It is very common to notice the incalculable harm done to the soil (not the trees) on small roadside "kampongs," by the continuous treading round the trees by even a small herd of cattle.

It may be-stated without any fear of contradiction that cattle and sheep manures are among the finest manures for coco-nuts. If it 
were possible to get sufficient of these for application on a large area the value would be immeasurable. There is no valid reason, anyhow, why this object should not be aimed at ; and we consider that on every coco-nut estate cattle and sheep breeding should be commenced after the fifth or sixth years. We are not advocating a large capital outlay before the estate has commenced to yield a return, but only the purchase of a few head to start with to become the nucleus of a gradually increasing herd.

The method of allowing a herd to graze on any spot for more than two days at a time is to be condemned. They should be moved about from block to block in rotation, and it should be so arranged that they do not come back on the same ground within six weeks or two months; by this means no harm can be done to the soil.

The cattle sheds should be placed at different quarters of the estate, so as to economize later on in the transport of the manure.

For the satisfactory retention of the properties contained in the dung and urine, pits should be dug alongside the shed and covered over 


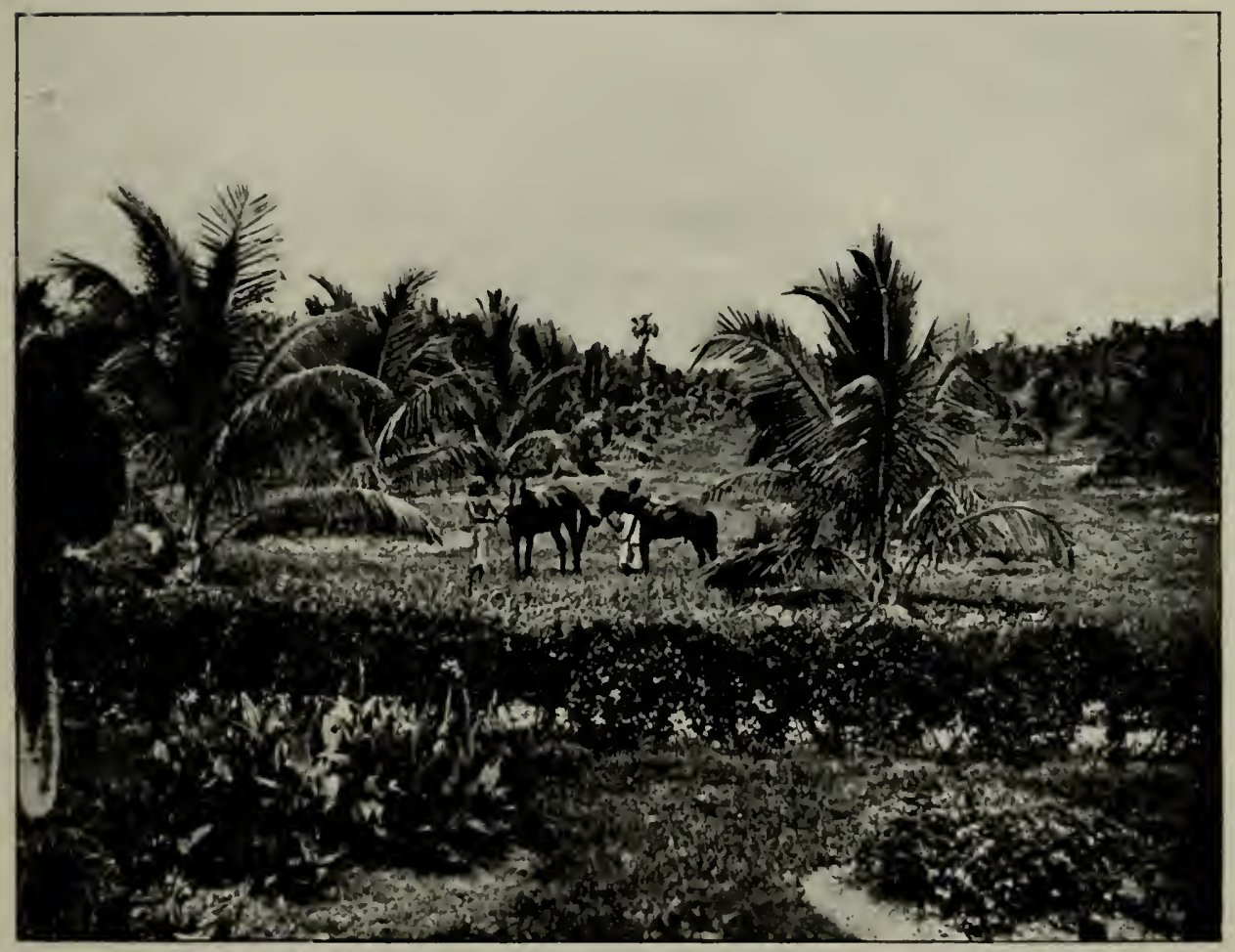

FIG. 21.-A grass field, kept in order by mechanical mowing. 

with a roof. In the case of sheep pens these must always, if the animals are to be kept healthy, be built off the ground, and the floors made of slats through which the urine and droppings can easily be removed.

Country-bred sheep pay remarkably well, and if properly looked after keep very fit ; also, unlike goats, they do not care for leaves of the young coco-nuts, and can thus be allowed to wander about on almost any part of the estate without doing harm.

No goats should be allowed within miles of a plantation. This advice should, one would imagine, be hardly necessary, but in the face of the following incident a passing warning may be considered justifiable. A friend of ours was opening a coco-nut estate with more than average keenness and energy ; one morning, to his dismay, he discovered that something had gone wrong with many of his young plants, and was puzzled as to what pest could have made the leaves look so ragged in so short a time. Unable to find any traces of beetles or grasshopper outside advice was called in, and our friend very gracefully advised to insist upon his overseer either getting rid of his goats or keeping them shut up. 
We are able to give the following from experience, viz. : I 50 head of cattle and sheep can supply the manure necessary for fifty acres of coco-nuts annually, so that if manuring be done once every two years the total number of head required is not excessive.

The number of draught bullocks required when the estate comes into bearing is often considerable, and this fact must be borne in mind when discussing the pros and cons of cattle-keeping. 


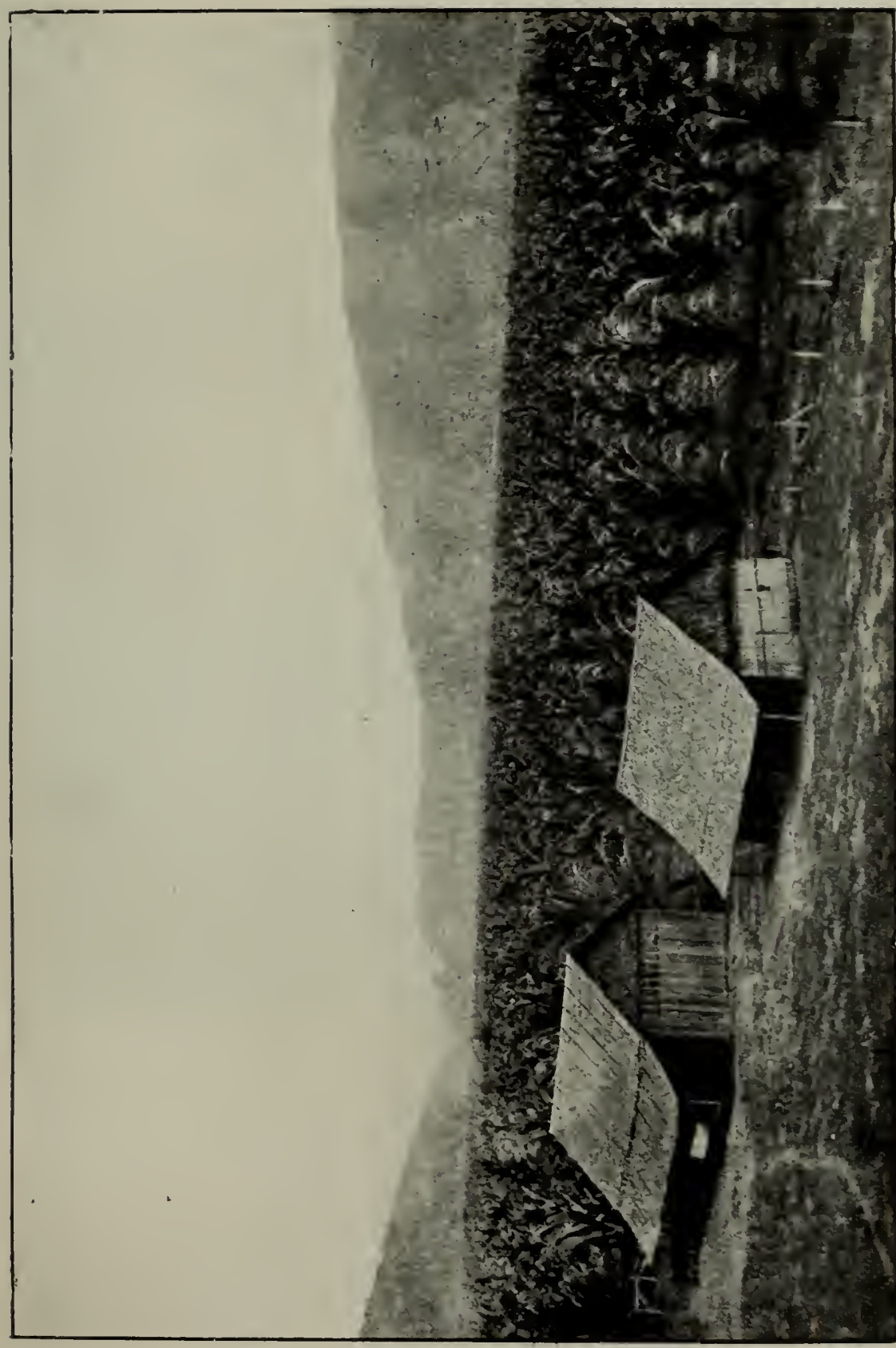

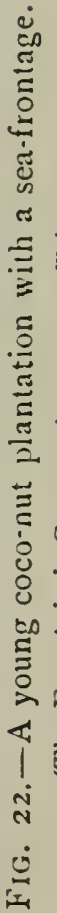

Face p. 56. 



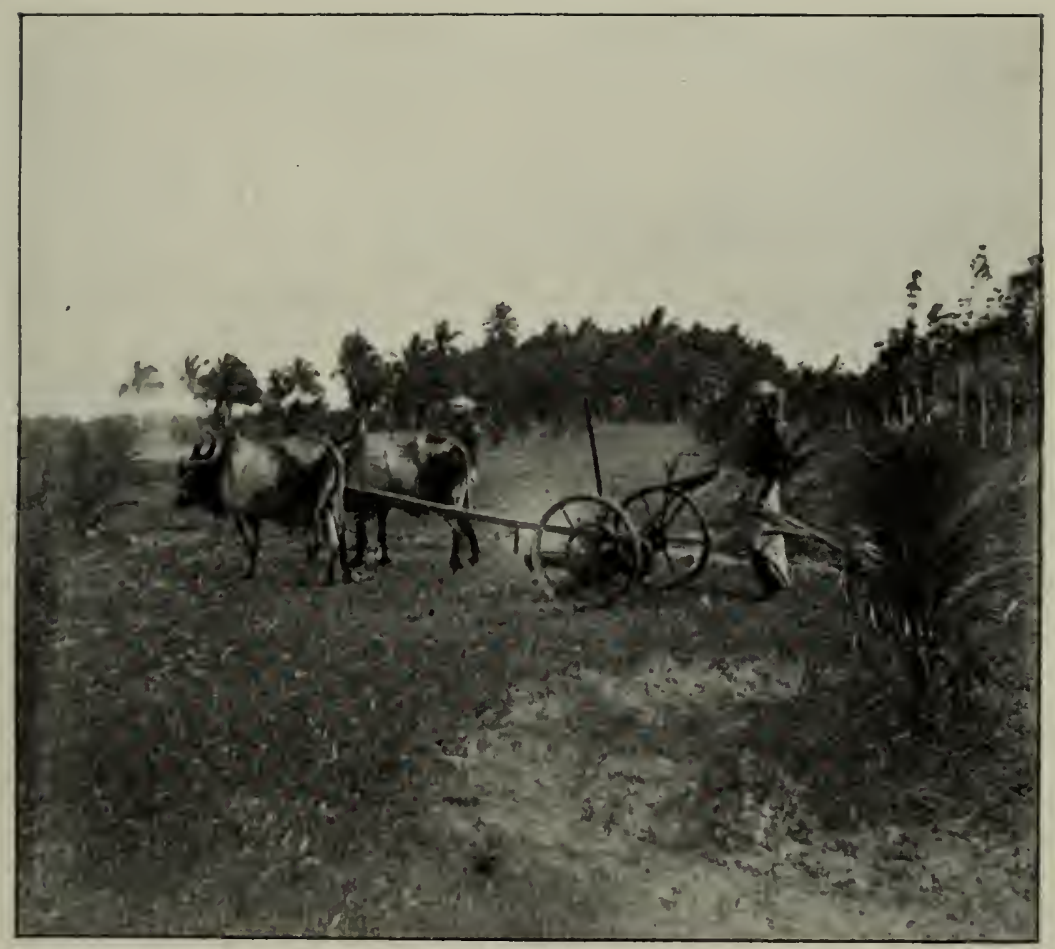

FIG. 23.-Keeping down the grass.

On small areas, and subsequent to de-stumping, the above type of machine has been found to be one of the best labour-saving appliances. 

CHAPTER VII.

\section{DRAINS AND DRAINAGE.}

As previously referred to, a most thorough scheme of drainage should be introduced, commencing from the time the land is being opened up and completed when the clearings have been sufficiently cleaned up to give it full scope.

Very great care must be taken thereafter to see that the drains are not allowed to get blocked up by wood or other matter, in order to assure as good a flow as possible, and the water continually moving towards the outlets. When the land is slightly undulating in even slopes this is not difficult; but, again, in lowlying, flat alluvial soil it will be found that a great deal more attention is required in maintenance. It is on this account, especially where the soil is at all of a peaty nature, that the advantage comes in of having the main drains cut through the block previous to the 
felling of the jungle or secondary growth, so as to get as much water (which, owing to its past stagnant condition, probably contains many deleterious acids) off the land as possible, and allow of the soil becoming sweetened proportionately. The coco-nut probably is less affected by sour land than most tropical plants; at the same time any stagnant water lying in its vicinity will always have a deleterious effect on the growth of the tree, especially in the younger stages of its life.

Subsidiary, Cross-section Drains, \&c.

As long as the outlets and main drains are absolutely free and can show a good clearance even in the wettest months of the year, the question of subsidiary and cross-section drains can be dealt with more or less at leisure, but must always be considered as a matter of very great importance.

A thorough and efficient drainage scheme can only be undertaken successfully by those who have had experience in this all-important question : in fact, it is a study by itself.

It is not at all an uncommon thing to hear of places where quite a lot of money has been 


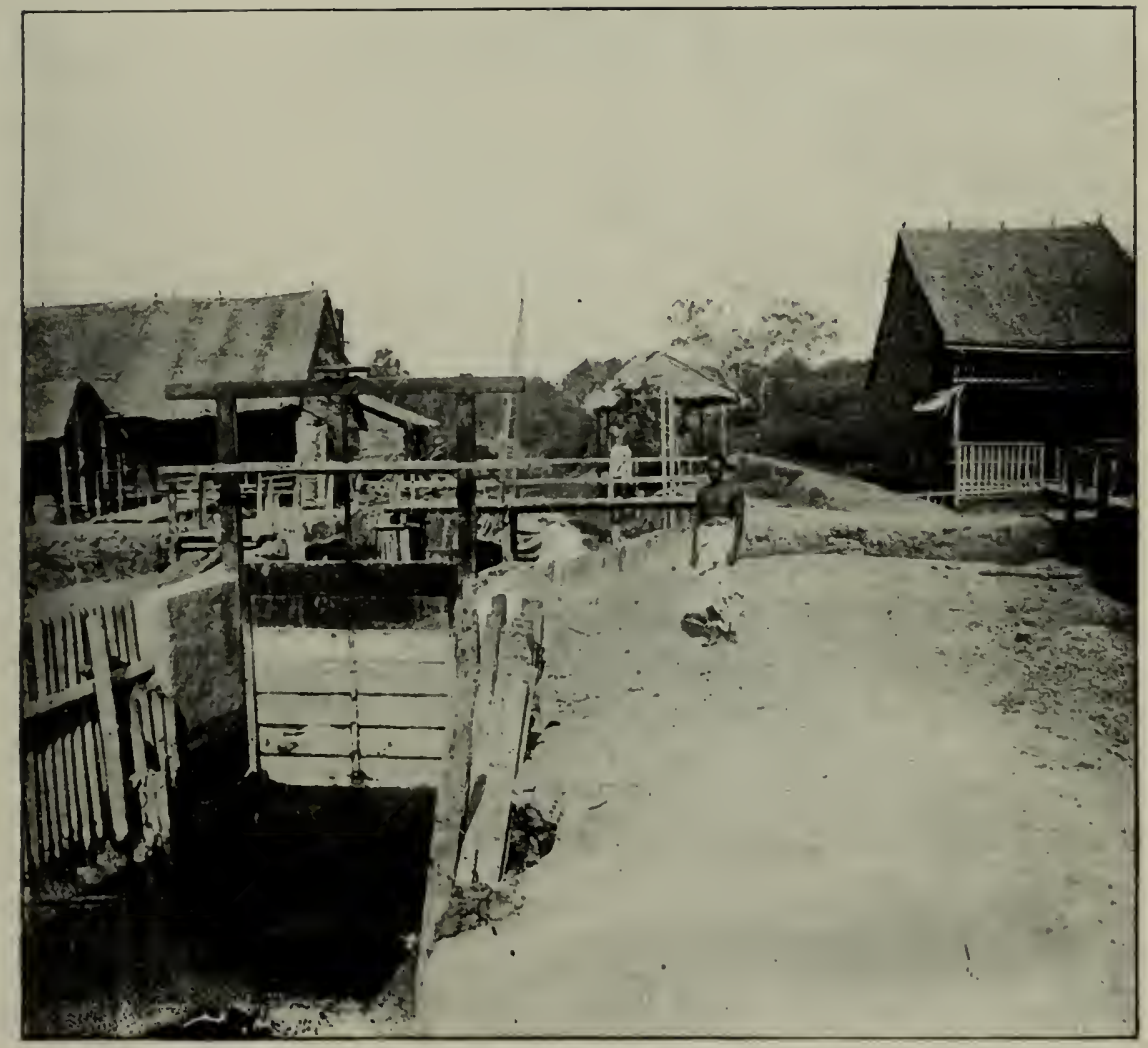

FIG. 24.-A Sluice Gate.

Face p. 58 . 



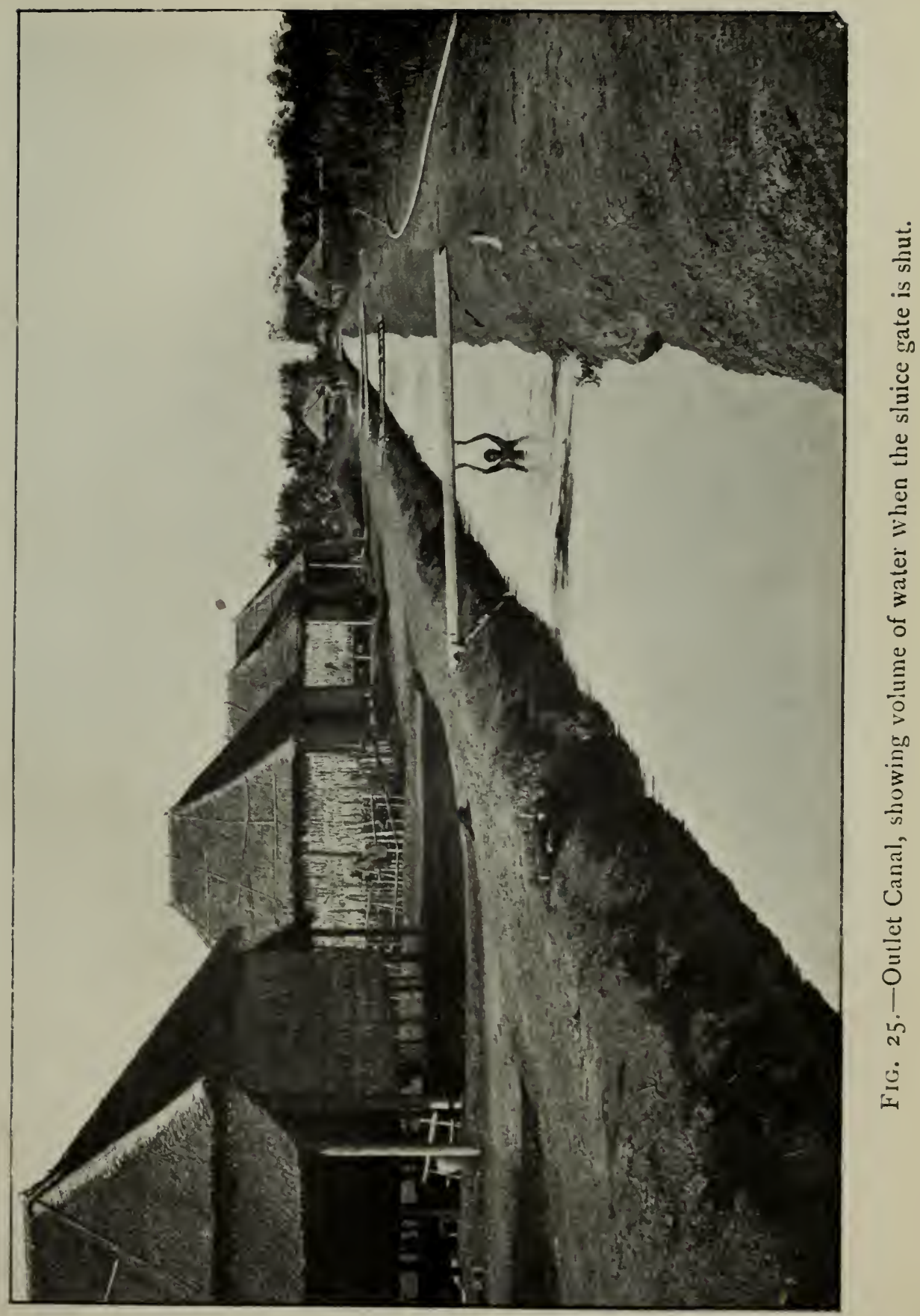

Follow 24. 



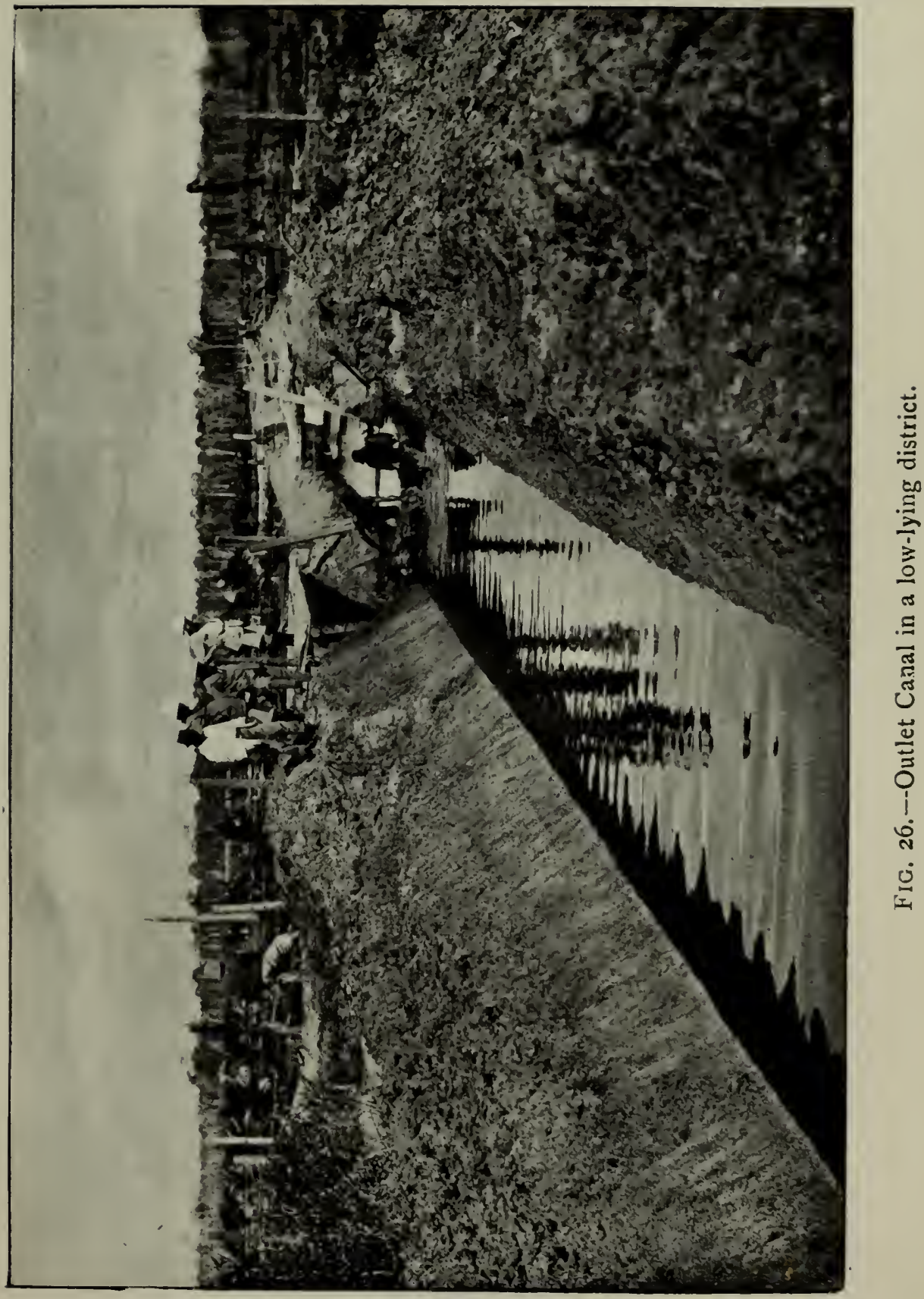

Follow 25. 



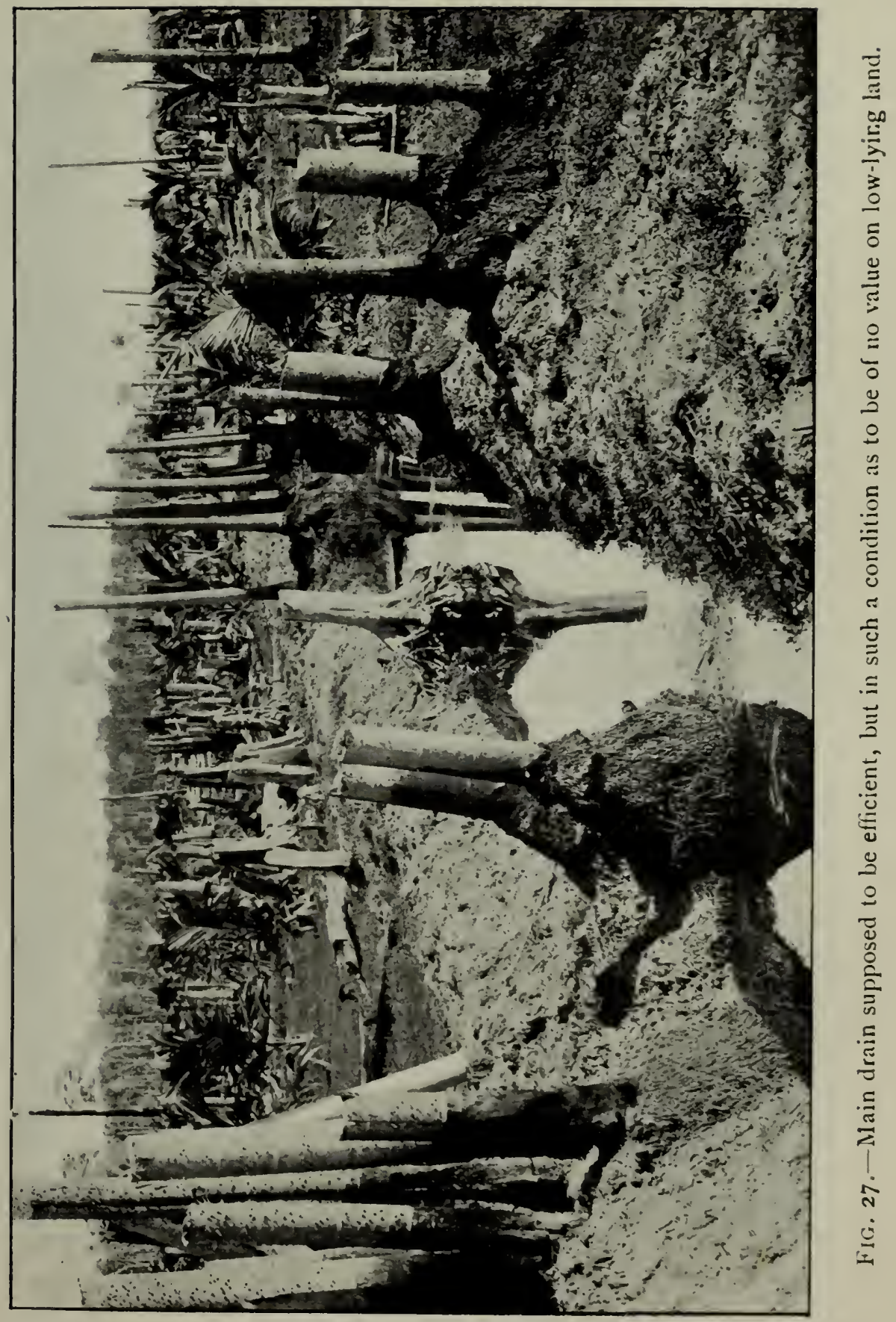

Follow 25 . 



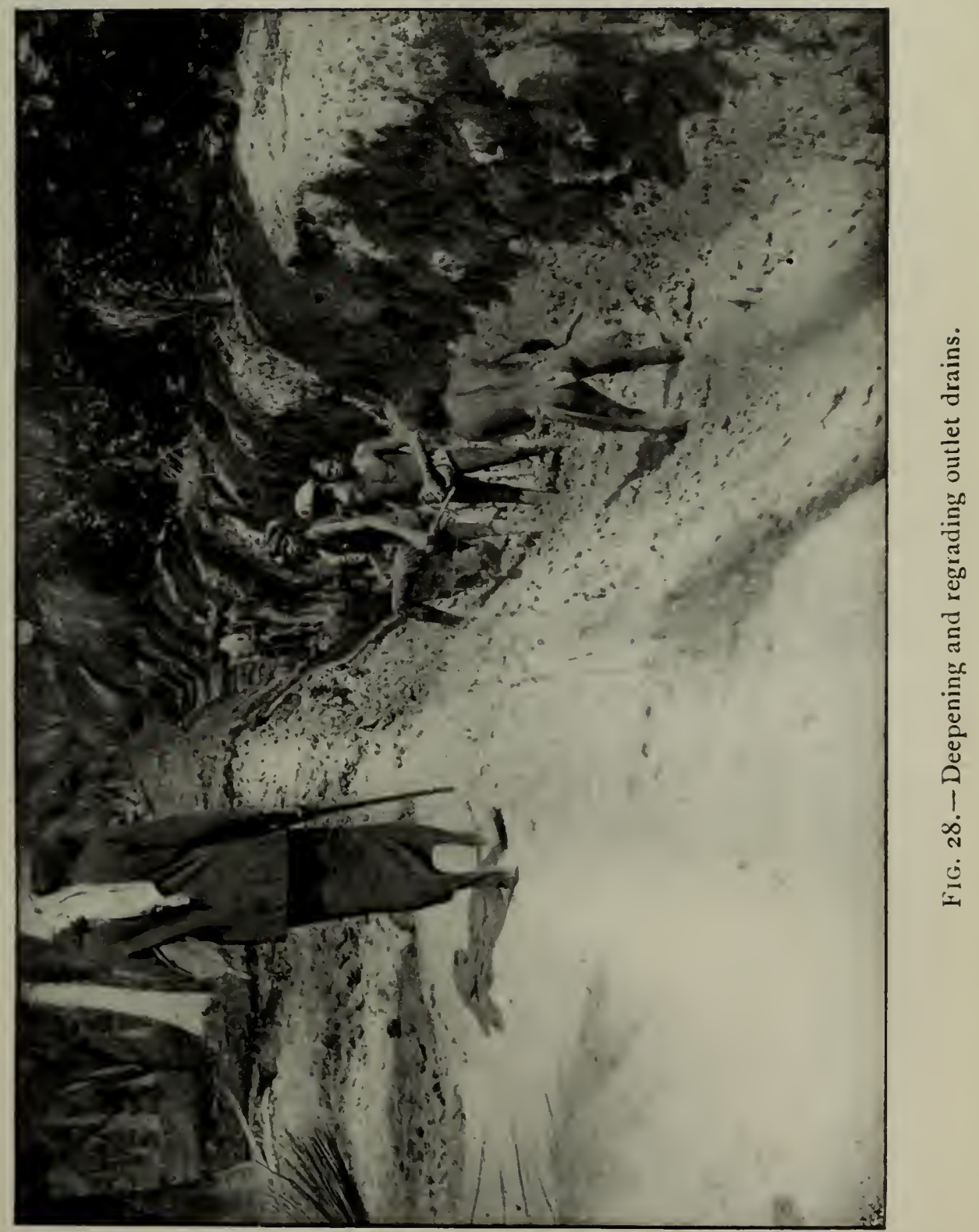

follow 27. 

expended on cutting outlet drains into which the water from the cross drains will never flow, on account of the former having been dug without any attention being paid to the natural fall to the creek, river or sea, whichever it happens to be. 


\section{CHAPTER VIII. \\ CATCH AND COVER CROPS.}

When a plantation is devoted to one crop only, such as coco-nuts, and the planter's exchequer is continually having calls made upon it for at least four years, his thoughts, more or less naturally, turn to the question of how a decrease in the upkeep expenditure may be brought about, and possibly some revenue from the land obtained during the time that his trees are working their way towards maturity, and it has been the aim and object of a very large proportion of owners ever since the commencement of the plantation rubber industry to find something that would prove to be even a small assistance in bringing about the desired results. First of all it should be definitely stated that there exists a very wide difference between "catch crops" and "cover crops," though it is not uncommon to hear the first term used in ordinary conversation when the latter is under discussion. At the same 


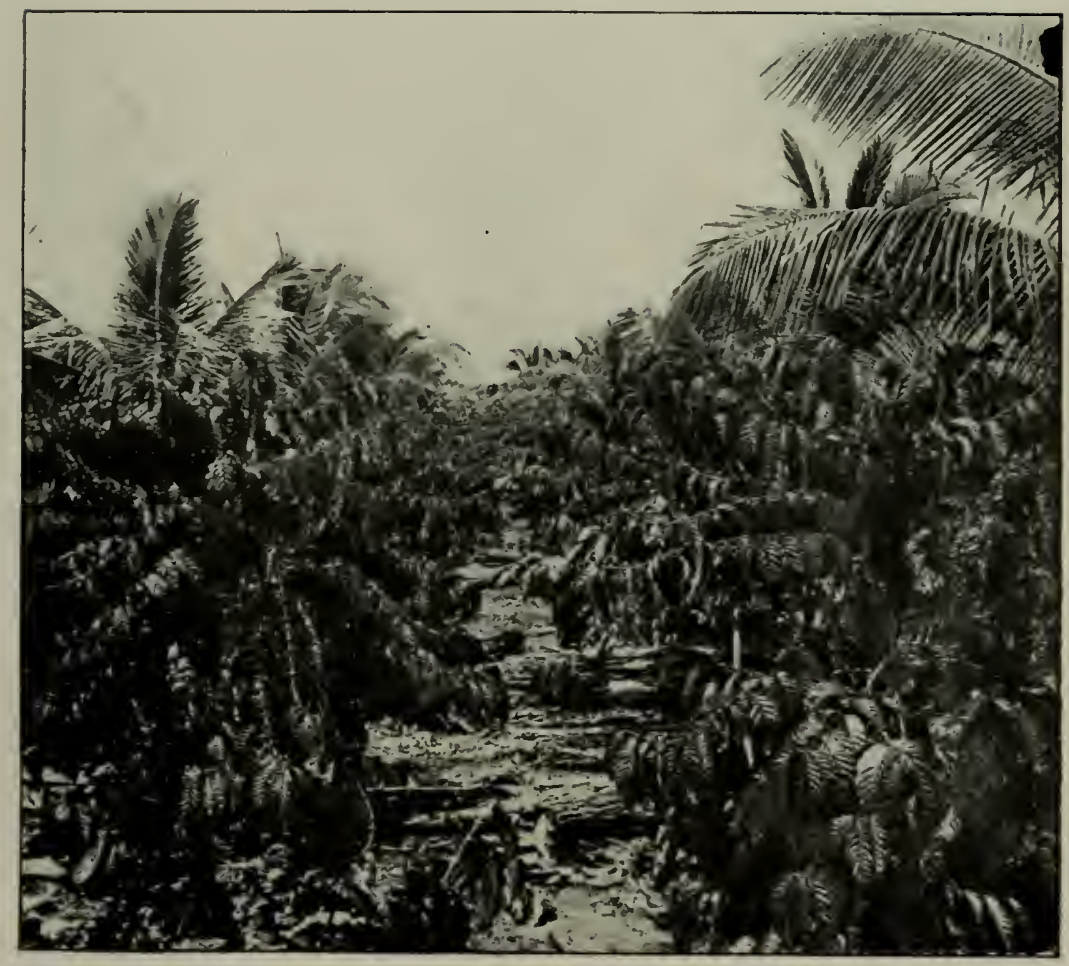

FIG. 29.--Robusta Coffee as a catch crop. 

time it is difficult to enter into a general discussion on the former without touching on the extreme value in certain cases of the latter. Now, dealing with the very wide subjects, "catch crops" and "inter crops," the much discussed question of planting distance is one which is bound to receive the first and foremost consideration. We do not propose to touch upon this equally wide subject in the present treatise, except merely to state without any fear of contradiction that the economic value of catch crops is not worth considering on estates where the principle of close planting of the main crop is still adhered to.

Now the chief danger that presents itself is in the knowledge that certain inter crops, such as coffee, tea, tapioca and a few others, have been found to yield fairly substantial returns for quite a number of years. We call this a danger, because of the natural tendency to continue the minor cultivation when the well-being of the main crop is being sacrificed for the sake of the return of the former, of which many striking instances are often seen, and it can well be realized how easy it is to ignore the fact that the above is taking place. 
But as we wish to weigh the merits and the demerits of the general principle it must, of course, be assumed that the planter will eliminate the catch or inter crop at any expense as soon as he satisfies himself that the main crop is suffering, no matter how much his immediate loss may be by so doing, Granted that he does so, he will then ask himself, "Has it been worth the money expended?. What net profit have I derived since the inception of the experiment?"

Whatever the crop happens to be, it is only the ignorant (granted that the required funds and labour are available) who fail to give to it cultivation in some form or another, and it obviously means a very costly business to give intensive cultivation to two crops interplanted.

It may be considered as a general rule that catch crops such as coffee receive little or no attention in the way of cultivation, but are left to themselves entirely, and that it is quite usual also to notice instances where coffee as a catch crop with rubber has been condemned on account of the soil being supposed unsuitable, when it might have given quite a fair 


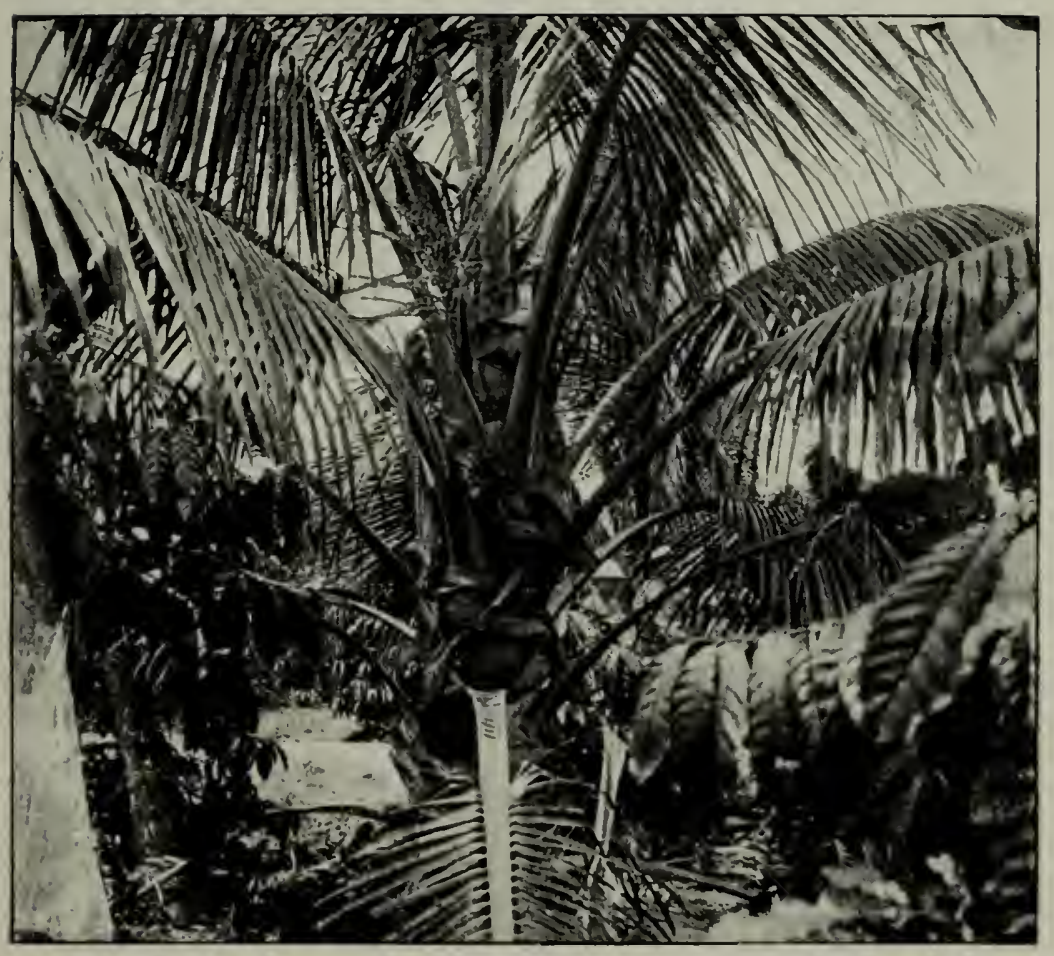

FIG. 30.-Three-and-a-half year old tree in coffee. 

return had it received some sort of treatment, and not been left to fight its way unaided.

Apart from the exhausting properties of most crops (excepting the leguminosæ) the fact remains that when we decide to establish a catch or inter crop we are apt to lose sight of the question of capital cost entailed in so doing, and also the cost of production. Additional capital must be put aside for buildings, recruiting, medical superintendence and other general charges. We find that unless crops can be secured for at least four or five years there is little justification for the above expenditure.

A very important point must be considered also, and that is the question that what pays the native to do on a small scale would not, as a rule, be profitable for the European planter to embark upon. It is well known that such crops as tapioca, pine-apples, sisal, lemon or citronella grass and sugar are most exhausting to the soil, and could never be thought of as paying crops for the coco-nut planter.

The Chinese sweet potato is now commonly seen on European estates, but only as a cover, as it impoverishes the soil to a very great extent. 
This being the case, such an exhaustive crop must not be placed by the European planter in the category of satisfactory catch crops. In a lesser degree tea and coffee are found (when cut out to assist in the development of the main crop) to have left the soil in anything but a desirable condition, and it is at this stage that it may be found necessary to have recourse to artificial manuring. Without wishing to lay down any law in dealing with the cultivation in the abstract, the two points most worthy of consideration are these, viz.: (I) The nature of the soil under cultivation, and (2) the natural requirements of the tree itself. Assuming that our soil is not obviously deficient in the recognized fertilizing ingredients there will also be a certain amount of material available to be taken advantage of to avoid unnecessary expenditure on artificial manure.

The usually accepted constituents of plant food, viz., nitrates, phosphates, potash and lime, can be made available on a very large proportion of the soils in this country, but as a matter of fact they very seldom are.

From personal observation it seems to us 


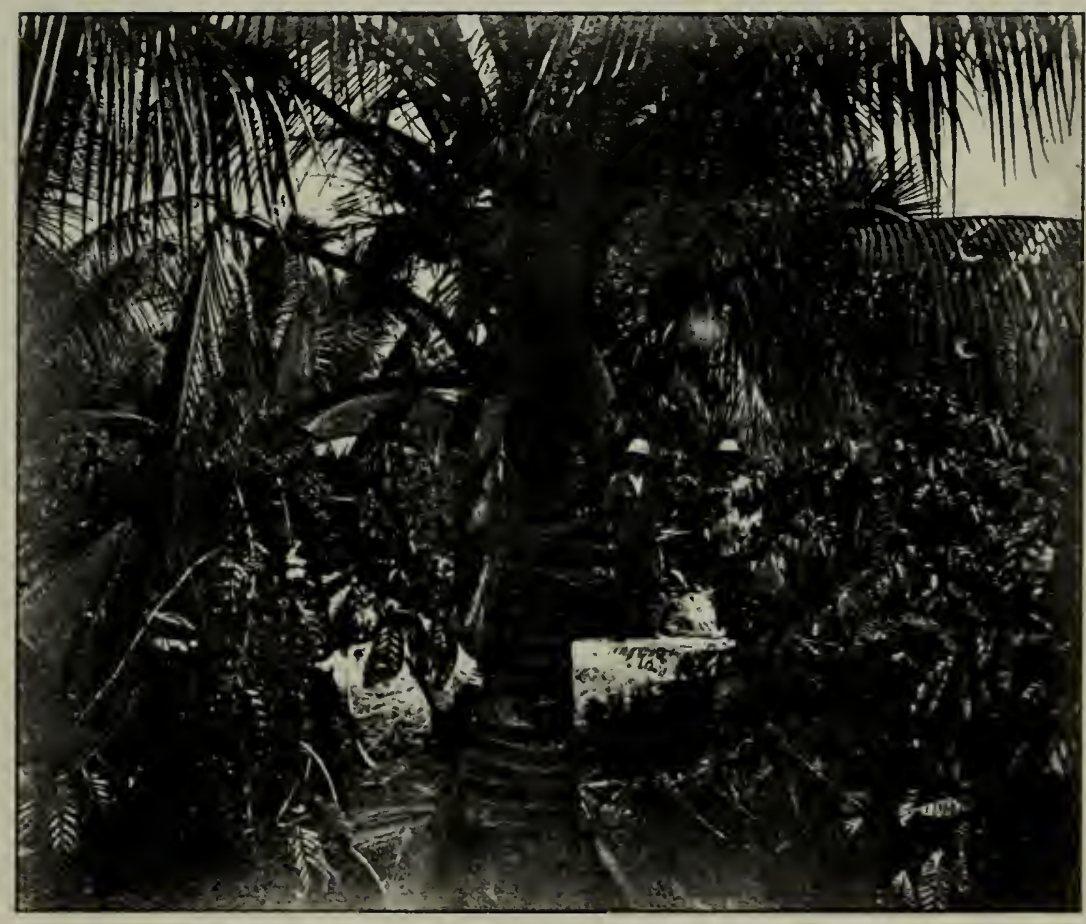

FIG. 31.-The same tree (as facing p. 62) a year later. 

a most essential point to endeavour to give as much humus as possible to soils which are regarded as deficient in this respect, and we doubt whether green manures have been sufficiently tried with a view to supplying a remedy.

Constituent parts of any soil can, no doubt, be determined by analysis, but exactly how to make these available as food for the plant is quite another question.

The benefit from keeping the soil in a friable state by mechanical means or otherwise cannot be overrated. We fear we are departing somewhat from the lines of our original dissertation in touching on the subject of manuring, either natural or artificial, although it will be conceded, we think, that catch crops and manuring are bound to go hand in hand as it were, and that one is, up to a very important point, dependent on the other.

Regarding the varieties of crops other than those already mentioned that can be, and have been, grown in this and the adjoining tropical countries, the following are perhaps the best known: bananas, cocoa, gambier, castor oil, 
ginger, ipecacuanha, indigo, ground nuts, soya beans.

The last three of these are, of course, well known as nitrogenous plants, and are for this reason, therefore, like all their other relations, greatly to be encouraged. We do not say that any of these have proved, or are likely to be, at all remunerative in the way of yielding hard cash to the planter to enable him to bring his main crop into bearing at any lower figure; in fact, we would not encourage him to plant any of them with this idea at all.

The first one on the list, bananas, has been found in some cases to be a success commercially, but not so any of the others. The cultivation of bananas amongst young coco-nuts has shown very excellent results both in reducing the weeding bill and also in returning to the soil when the stools are cut out a very valuable amount of moisture and mulch. This has not, as a rule, been found a very exhaustive crop, but is found to be a drawback to thorough superintendence, as the cover formed is so dense after a few months that it becomes impossible to have control over the coolies working in the area. 


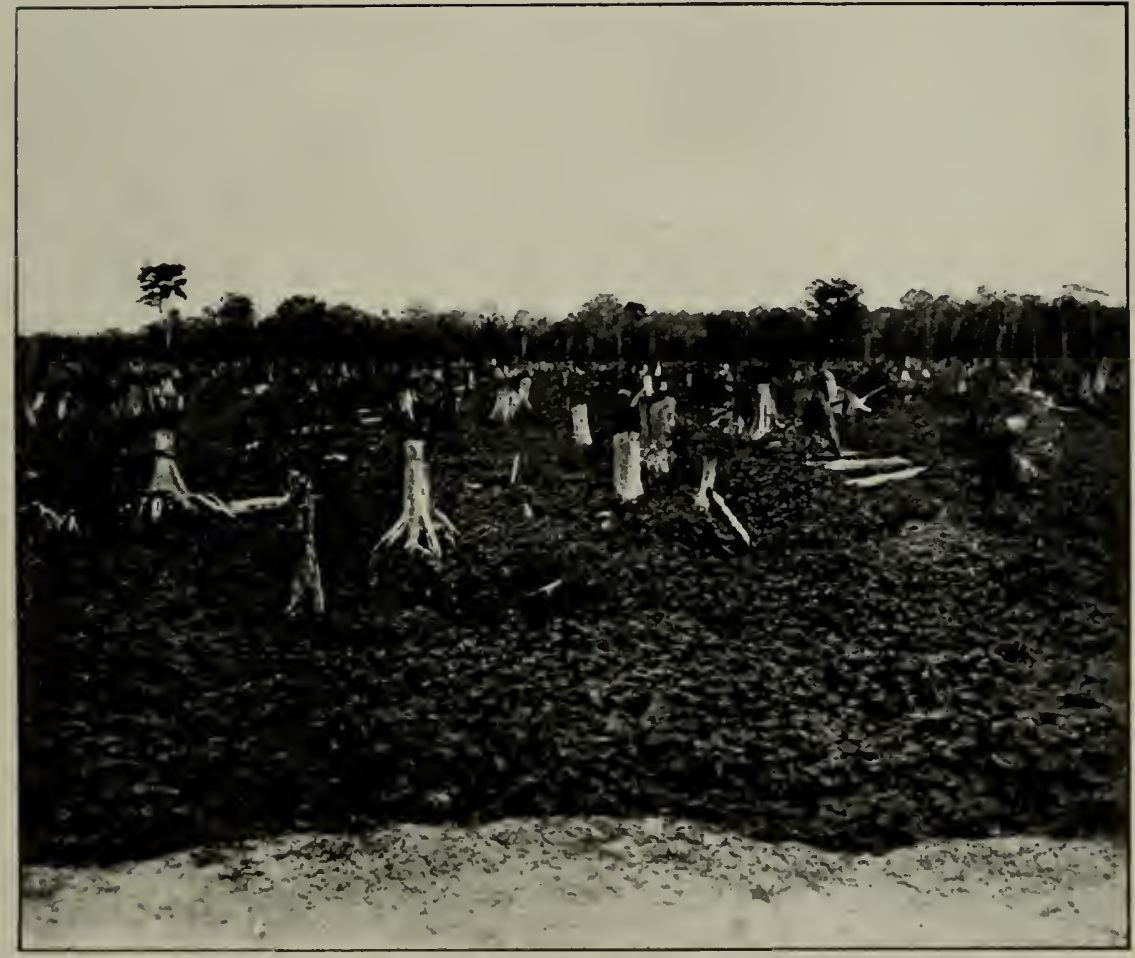

Fig. 32. - Young Coco-nuts with a cover-crop of Sweet Potatoes. 

It will be noticed that we have not disguised the fact that in our opinion we have yet to find a catch crop in the true sense of the word that it will be satisfactory to recommend with a view to minimizing the cost of production of coco-nuts, but, as we remarked at the outset, the question of cover plants, as soon as the extreme value of them becomes more widely known, is bound to receive special attention. The notion has become very prevalent of late that it is necessary to resort to artificial manures in order to develop the growth of the tree and increase the yield therefrom, and this method is often adopted before it has become an accepted fact that the plants or trees have failed to respond to any other kind of and perhaps less costly treatment.

It is an acknowledged and significant fact that the green manures sown on poor or usedup soils are slow to establish themselves, but once established they should, we think, be the means of improving the physical conditions of the soil more effectually and economically than by the application of artificial stimulus which may be found necessary to apply at more frequent intervals and at a higher cost. 
The important principle of cultivation as already referred to would seem to be the protection and culture of the feeding roots of the trees, as a prevention of a check to their growth and welfare in the time of drought, so that the land on which a system of tilling and mulching is practised should, under ordinary conditions, be capable of holding its own against anything artificial until, at any rate, the first crop has been taken off it, while it may prove sufficient for a considerable number of years. Unfavourable conditions consequent on a series of droughts will assuredly mean little short of ruin to the coco-nut planter.

Let us see what Dr. E. B. Copeland says in his very interesting treatise on the "Water Relations of the Coco-nut Palm."

"The direct checking of the growth of the young leaves and flowering branches will be a deficiency in the yield of nuts, beginning not less than nine months after the drought first makes itself felt (nine months being about the minimum time from pollination to maturity) and ending at least eighteen months after the drought is broken. The injury to the tree's vitality during a prolonged drought is so severe 


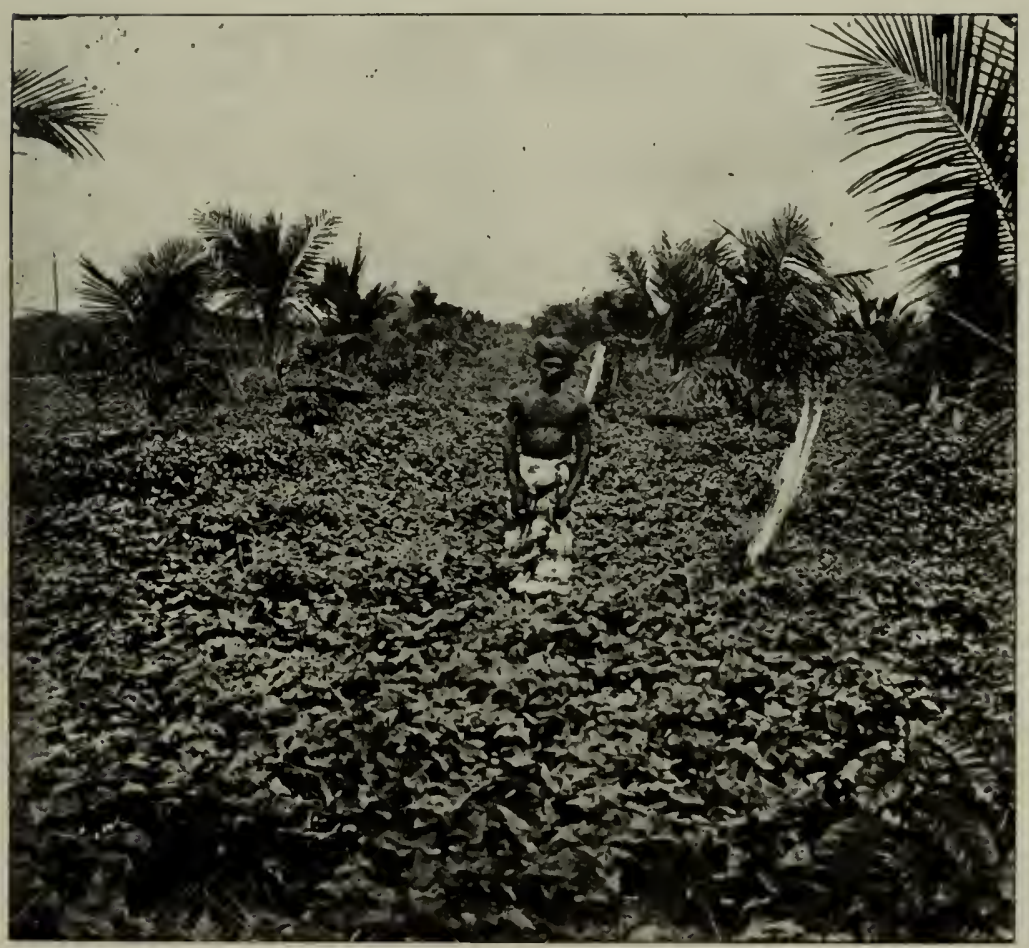

FIG. 33.-Sweet Potatoes (I). 

that the return of favourable weather conditions is but slowly followed by the resumption of the normal activity.

"A tree which through unfavourable conditions has only twenty-five leaves remaining has not the strength, even under the best conditions, at once to return to the formation of new leaves at the rate which is necessary for the maintenance of thirty. Recovery after a drought is a building-up process, and it must be a slow one. It can hardly be complete in two years and the return to the normal crop of ripe nuts which can be reduced during interrupted good seasons can only be well under way in this time."

For the benefit of those who realize the above facts, and who are anxious to obtain the material necessary to bring about the best results, we would mention the names of the following plants as being suitable for planting as green manures (seeds of which can be more or less easily obtained) which from our personal knowledge we can state to have given excellent results :-

Tephrosia candida, Tephrosia purpurea, Mimosa pudica, Mucuna speciosa, Centrosema 
plumieri, Desmodium tortusum, Crotolaria striata, Canavalia ensiformis, Clitoria cajanifolia.

There are, of course, a great many other varieties, but we think that a selection from the above list will meet the ordinary case. One of which we have the chemical analysis (and for this we are indebted to Mr. Kelway Bamber of Ceylon) is the Tephrosia candida, or Boga medelloa, and we are glad to be able to publish it as showing the extreme value of the prunings either wet or dry.

All these plants have a special value inasmuch as they not only collect the amount of nitrogen sufficient to stimulate the tree, but in doing so they make it the more capable of taking up the other necessary ingredients, such as potash and phosphates, which are found so abundantly in the decayed leaves and stems; even without a chemical analysis of the soil we cannot dispute the fact that considerable supplies of both potash and phosphoric acid are withdrawn in the building up of the leaf and stem. 


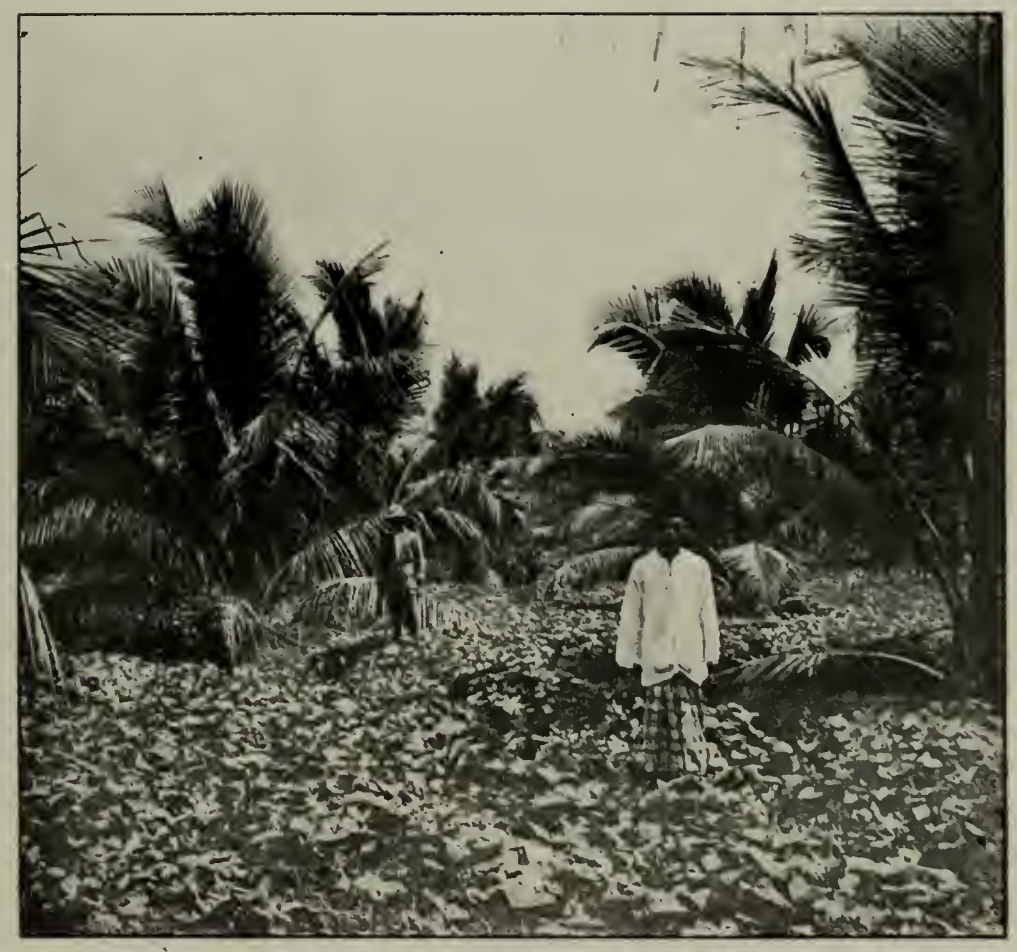

Fig. 34.-Sweet Potatoes (II). 



\section{Analysis of Tephrosia candida or Boga medelloa.}

The samples of leaves and stems were partly withered when received, so that the moisture in the growing plant could not be estimated. The figures given in the "Green Plant" are those calculated on the moisture found at the time of analysis, and this was probably about 20 per cent. lower than it would be in the growing plant; the percentages given are higher in this proportion than would be found in the plant when growing or immediately after cutting. The leaves and stems were analysed separately and gave the following figures :-

Chemical Analysis, supplied by Mr. Kelway Bamber, of Ceylon.

\begin{tabular}{|c|c|c|c|c|c|c|}
\hline & \multicolumn{2}{|c|}{$\underbrace{\text { LEAVES }}$} & \multicolumn{2}{|c|}{ Stems } \\
\hline & & & $\begin{array}{c}\text { In green } \\
\text { plant }\end{array}$ & $\begin{array}{l}\text { In plant } \\
\text { dried } \\
\text { at } 100^{\circ} \mathrm{C} \text {. }\end{array}$ & $\begin{array}{c}\text { In green } \\
\text { plant }\end{array}$ & $\begin{array}{c}\text { In plant } \\
\text { dried } \\
\text { at } 100^{\circ} \mathrm{C}\end{array}$ \\
\hline \multirow{2}{*}{\multicolumn{2}{|c|}{$\begin{array}{l}\text { Moisture } \quad . . \\
\text { Organic matter }\end{array}$}} & ... & $54^{\circ} 53$ & - & $14^{\circ} 06$ & -- \\
\hline & & $\ldots$ & $42 \cdot 86$ & $94^{\circ} 27$ & $82 \cdot 37$ & $95 \cdot 85$ \\
\hline \multirow[t]{2}{*}{ Ash } & $\ldots$ & ... & $x \cdot 6 I$ & $5 \cdot 73$ & $3 \cdot 57$ & $4 \cdot 15$ \\
\hline & & & $99^{\circ} 00$ & $100 \cdot 00$ & $100^{\circ} 00$ & 100:00 \\
\hline \multicolumn{3}{|c|}{ Containing nitrogen } & $2 \cdot 03$ & 4.47 & $I \cdot 7 I$ & I'99 \\
\hline
\end{tabular}




\section{GUIDE TO COCO-NUT PLANTING}

\section{Analysis of Ash.}

Oxide of iron, $\mathrm{Fe}_{2} \mathrm{O}_{3}$

Leaves

Stems

Oxide of manganese, MNO...

Lime, $\mathrm{CaO}$

0.24

0.70

Magnesia, $\mathrm{MgO}$

$0 \cdot 14$

Trace

Potash, $\mathrm{K}_{2} \mathrm{O} \ldots$

$17 \cdot 69$

14.47

Soda, $\mathrm{Na}_{2} \mathrm{O} \quad \ldots$

$4 \cdot 61$

$4 \cdot 67$

Sodium chloride, $\mathrm{NaCl}$

$2 \mathrm{I} \cdot \mathrm{I} 7$

$9 \cdot 78$

$32 \cdot 89$

Phosphoric acid, $\mathrm{P}_{2} \mathrm{O}$

4.47

… 8.10

4.22

Carbonic acid, $\mathrm{CO}$

9.54

Sulphuric acid, $\mathrm{SO}_{3} \ldots$

... 10.06

Silica, $\mathrm{SiO}_{2} \quad \ldots$

\begin{tabular}{lr}
$\ldots$ & 4.15 \\
$\cdots$ & I9.66 \\
\hline & I00.07
\end{tabular}

I I 00

I 3.97

4.35

$4 \cdot 47$

$100 \cdot 28$

Calculating the percentages found in the ash with the corresponding figures for the green plant and the dry plant the following are the complete analyses

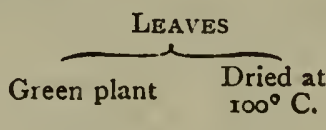

$\begin{array}{lll}\text { Moisture } & \ldots & \ldots\end{array}$

Organic matter $\ldots$.

Oxide of iron - ...

Oxide of manganese

Lime

$\begin{array}{lll}\text { Magnesia } & . . . & \ldots\end{array}$

$\begin{array}{lll}\text { Potash } \quad \ldots \quad \ldots & \end{array}$

Soda

Sodium chloride ...

Phosphoric acid ...

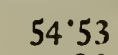

$42 \cdot 86$

Trace

Trace

0.46

0.12

0.56

0.26

0.12

0.21

Carbonic acid

Sulphuric acid

$\begin{array}{lll}\text { Silica } \quad \ldots & \ldots\end{array}$

Containing nitrogen

0.51

$100 \cdot 00$

$2 \cdot 03$

$\begin{array}{r}- \\ 94.27 \\ \text { Trace } \\ \text { Trace } \\ 1.01 \\ 0.26 \\ 1.23 \\ 0.56 \\ 0.26 \\ 0.46 \\ 0.58 \\ 0.24 \\ 1.13 \\ \hline 100.00 \\ \hline 4.47\end{array}$

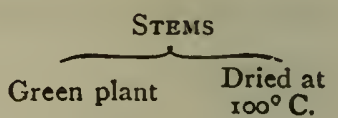

$14^{.06}$

$82 \cdot 37$

0.02

Trace

0.51

0.17

I. 17

0.15

0.34

0.39

0.50

2. 16

0.16

100.00

$\frac{10000}{I .7 I}$
95.85

0.03

Trace

0.60

0.19

I 36

0.17

0.39

0.46

0.58

0.18

0.19
100.00

I.99

I'7 I 


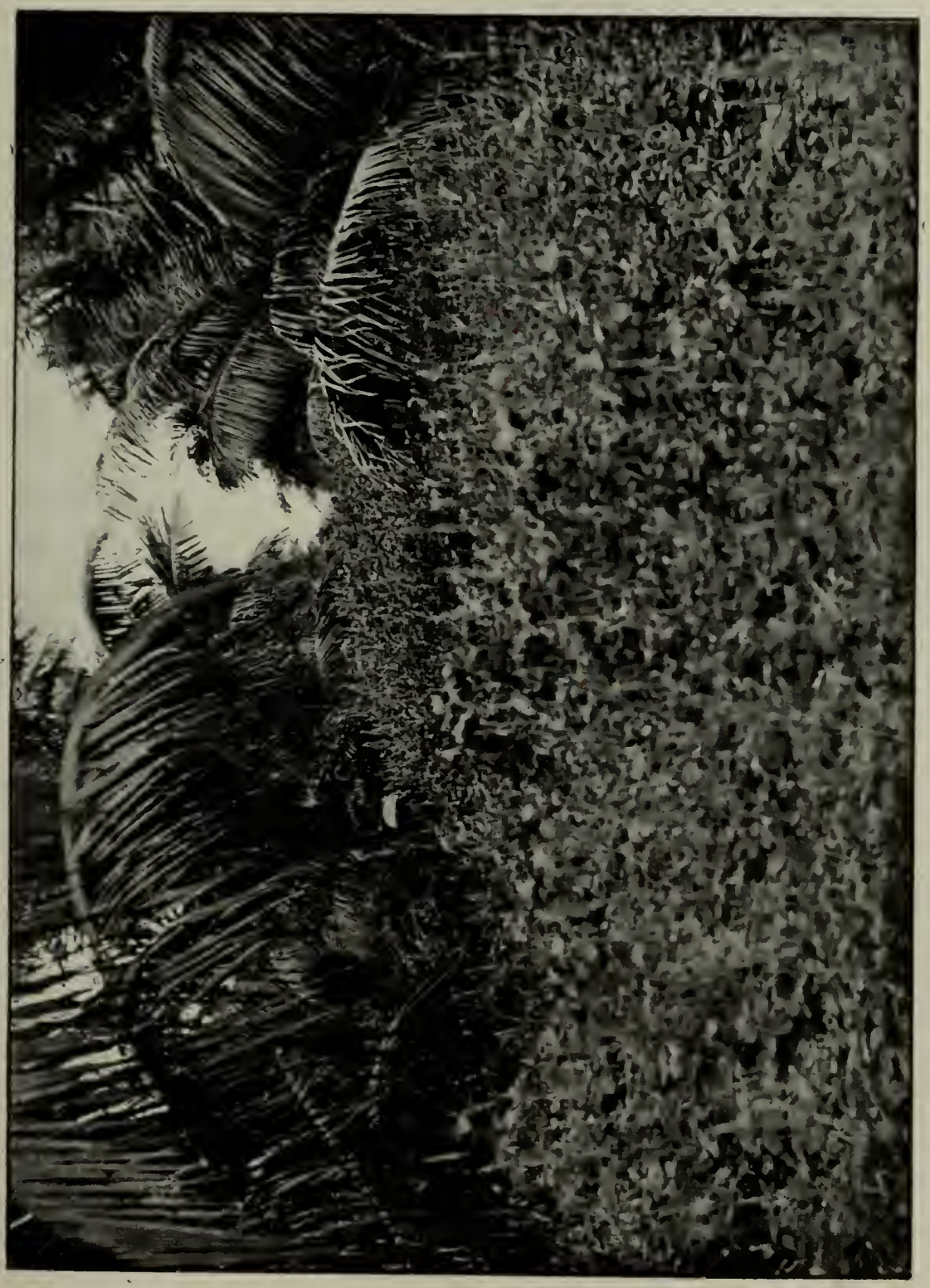

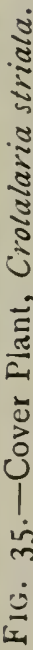





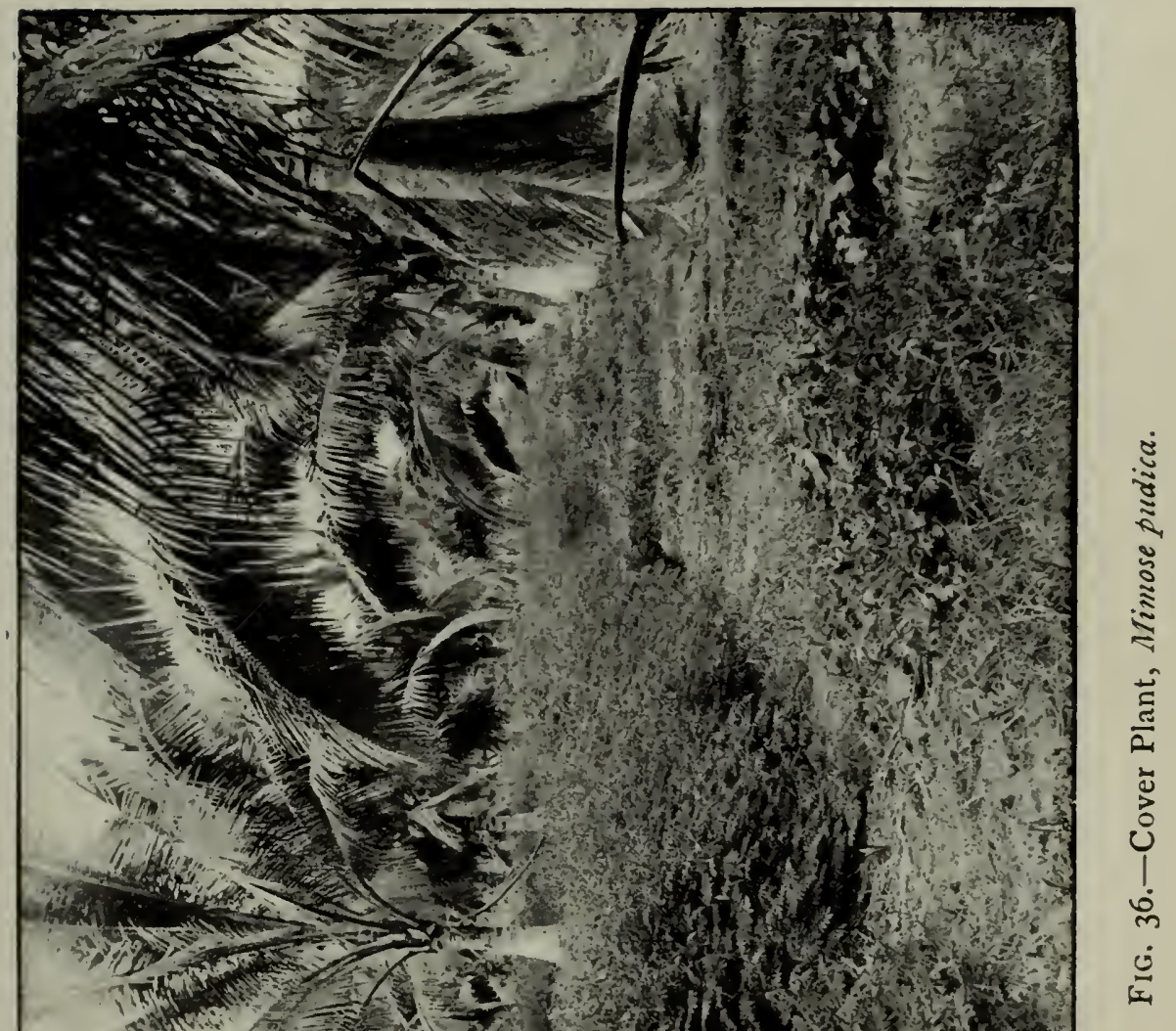



This shows that every $\mathrm{I}, 000 \mathrm{lb}$. of fresh green manure from this plant supplies the equivalent in nitrogen, phosphoric acid, and potash to about:-

$$
\begin{aligned}
& 400 \text { lb. castor cake } \\
& \text { 10 ", bone meal } \\
& \text { 10 ", sulphate of potash }
\end{aligned}
$$

and every $\mathrm{J}, 000 \mathrm{lb}$. of the prunings free from moisture are equivalent to about :-

$$
\begin{aligned}
& 900 \mathrm{lb} \text {. castor cake } \\
& 20 \text { " bone meal } \\
& 25 \text { " sulphate of potash }
\end{aligned}
$$

These figures compare very favourably with those published in the Royal Botanic Gardens Circular, from analysis of various green manures. The leaves are higher in nitrogen than any except dadaps, which are given at 4.78 per cent. on the dry material, and if this plant gives as large a weight of green material per acre it will prove a very valuable green manure.

"Colombo Commercial Co., Ltd., "Analysts.

"April I, I9IO.

"The plants sown early in October, I909, cut at $2 \mathrm{ft}$. and weighed gave $22 \frac{1}{2} \mathrm{lb}$., which planted 6 by 6 equals I $3,590 \mathrm{lb}$. per acre in 
less than six months. One plant sown in 1907, which had been cut in 1908 and 1909 (July) was cut at $2 \mathrm{ft}$. $6 \mathrm{in}$. and weighed $73 \mathrm{lb}$., or, deducting wood, $50 \mathrm{lb}$. Planted $8 \mathrm{ft}$. by $8 \mathrm{ft}$. this equals $34,000 \mathrm{lb}$. per acre, and this would represent about 300 to $340 \mathrm{lb}$. of nitrogen largely obtained from the air.

"(Signed) M. K. Bamber."

The "Mascate" Bean (Mucuna), or Velvet Bean,

which probably originated in Arabia, is known by some people by the name of "Mucuna."

In spite of all our researches we have never found any indication where this bean came from. Nobody knows by whom or at what period it was introduced. Its existence in Mauritius seems to go back as far as the eighteenth century.

As Mr. Desbassyne states, it is quite excellent for rotation of crops; like all the leguminous plants, this must be preferably planted during the rainy. season, and there are here three varieties of this bean, the white, the mottled, and black: this last variety also has 


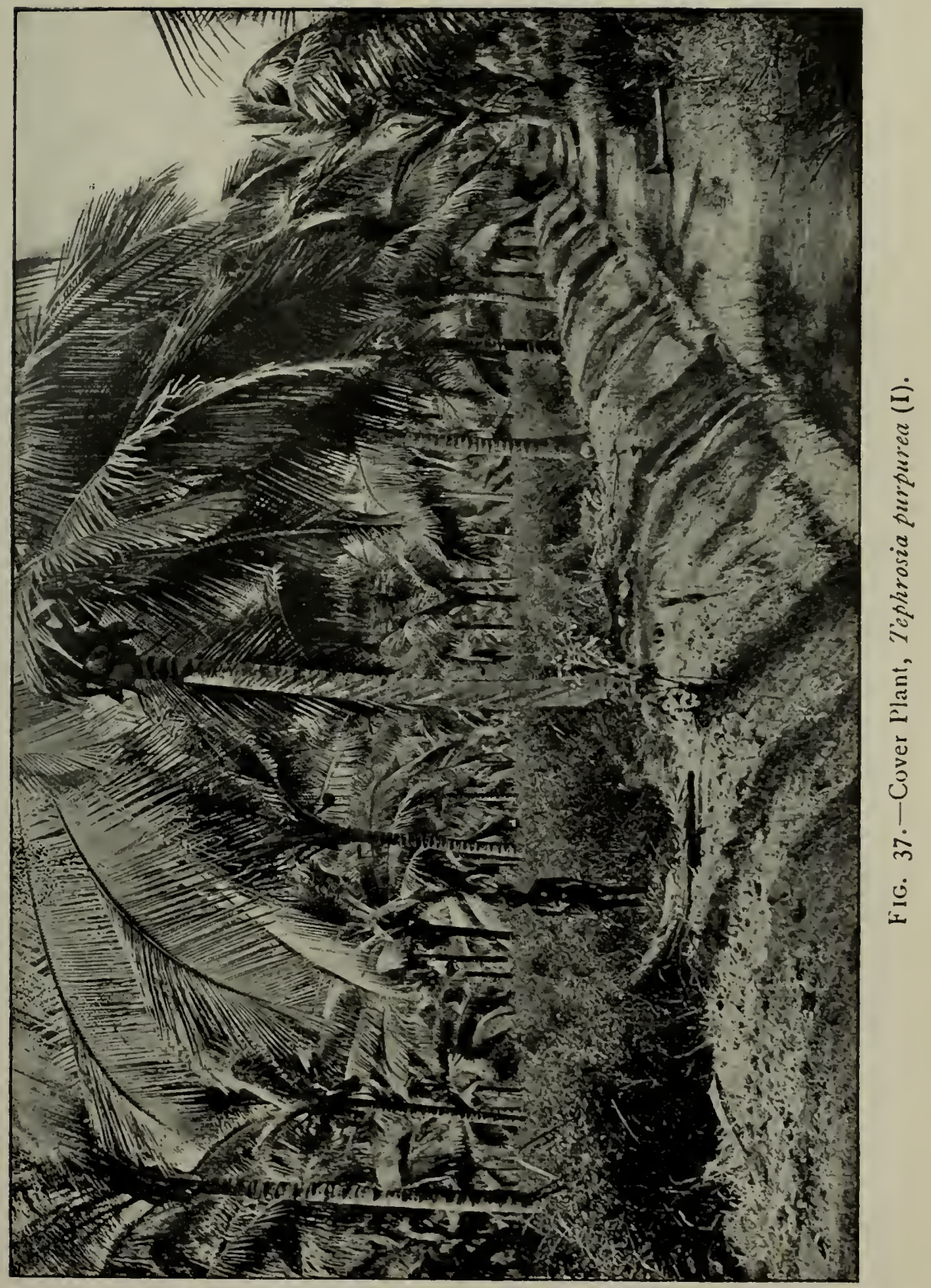



the name of the black bean. From the point of view of agriculture this plant gives excellent results. It is very robust, and forms a true, thick covering on the surface of the ground, hindering the inroad of bad weeds.

Its cultivation is very easy. It is sufficient to put the pockets a yard apart, and to sow in them two or three seeds. It spreads very rapidly, the foliage is large, affording a covering to the ground for two years at least, and produces seed in great quantity. Its big foliage allows this plant to collect more nitrogen, and places it in the first rank amongst beans for covering as much by its abundant productivity as by the fertilizing elements which it contains.

We shall see later on, in the table giving the percentage of nitrogenous matter to the dry matter of the green forage, that the black bean contains 25 per cent. more nitrogenous matter compared with the best leguminous plant known.

Seeds collected serve as a food for cattle, and the stems and leaves are trenched in rows through the plantation. They could also be used as forage, and would be very good on 
account of the high percentage of protein. The pod, which contains 6 I per cent. of seed, is composed as follows :-

The pod itself The seed Entire fruit

\begin{tabular}{|c|c|c|c|c|}
\hline Water ... & ... & $5 \cdot 23$ & $6 \cdot 10$ & I I’33 \\
\hline Mineral matter & ... & $I \cdot 50$ & $I \cdot 87$ & $3 \cdot 37$ \\
\hline Cellulose ... & $\ldots$ & $12 \cdot 7 \mathrm{I}$ & $3 \cdot 78$ & $16 \cdot 49$ \\
\hline Fatty matter & $\ldots$ & 0.28 & I. 78 & $2 \cdot 06$ \\
\hline Non-nitrogeno & & 8. & 58 & \\
\hline Nitrogen ... & $\begin{array}{l}\cdots \\
\cdots\end{array}$ & $\begin{array}{l}1018 \\
I \cdot I 8\end{array}$ & 14.79 & $\begin{array}{l}50 \% 0 \\
15.97\end{array}$ \\
\hline & & $39^{\circ} 00$ & $6 I \cdot 00$ & 10 \\
\hline
\end{tabular}

Canavalia ensiformis (OR SWORD BEAN).

Pois sabre is a plant which came to us from India and derived its name from the Tamil word "Canavali." It is supposed that immigrants coming from India were responsible for the introduction of it into Mauritius. It is a bush of which the green pod makes an excellent edible vegetable.

In one of the last reports $M$. Bonâme has brought to light all the advantages that can be taken or made of this plant. The facility with which it can be grown and its productiveness give to it considerable importance, both as a fertilizer and an economic plant. M. Bonâme 


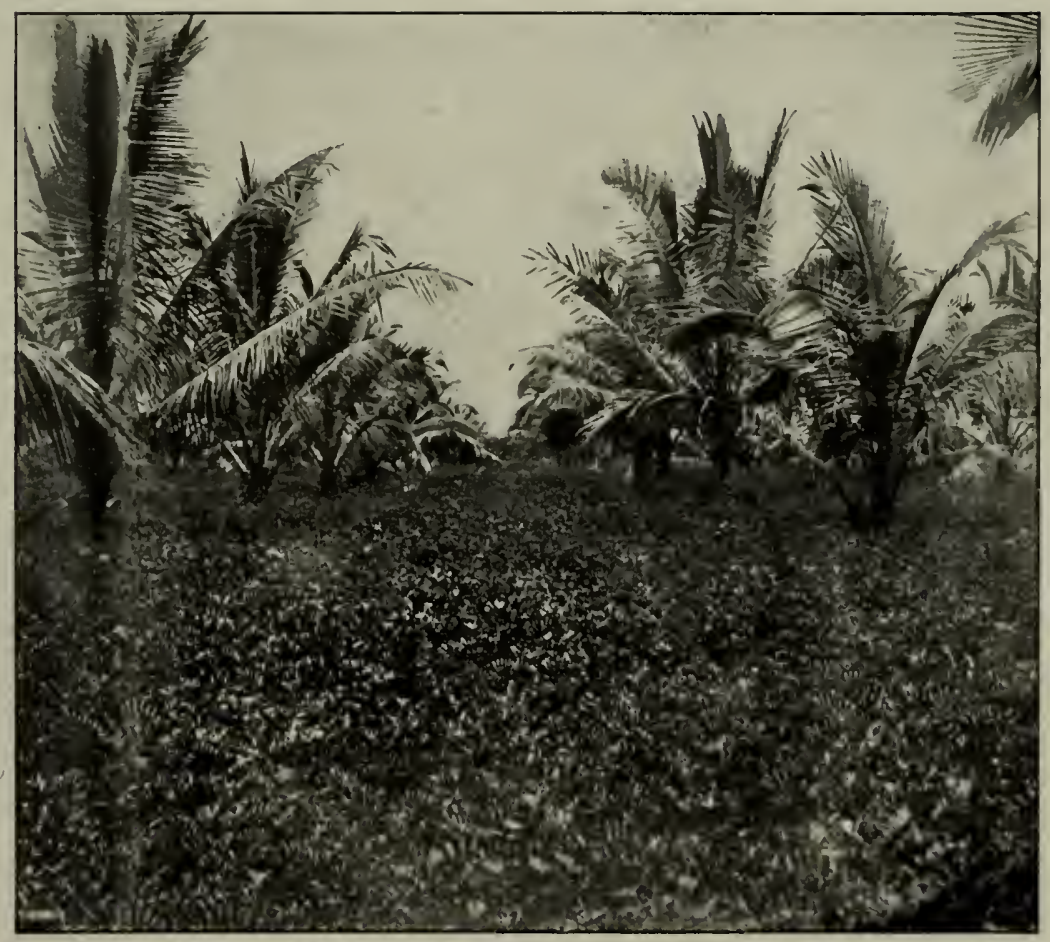

FIG. 38.-Cover Plant, Tephrosia purpurea (II). 

tells us that from a nutritive point of view the seeds of the sword bean ought to be classed amongst the fine leguminous plants, and it is not to be wondered at that they are used as a very valuable food for cattle.

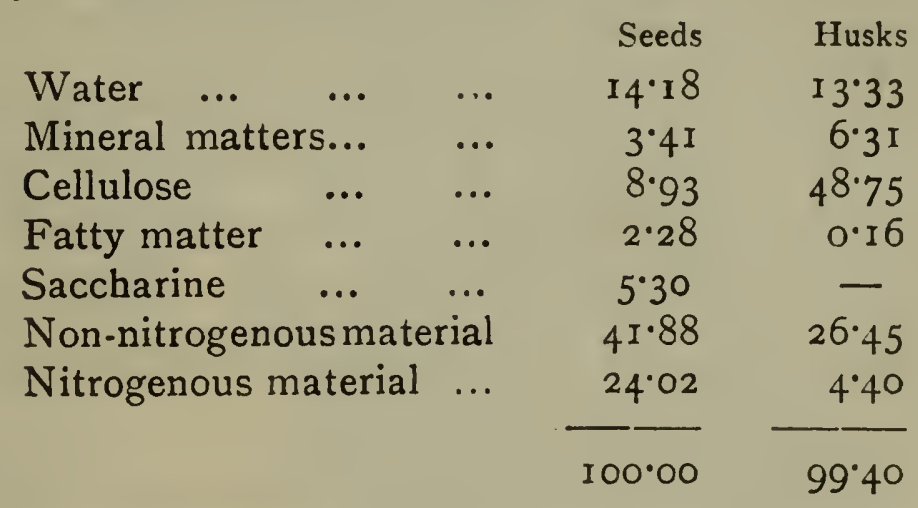

This is the approximate composition of the dry pods as given by M. Bonâme.

As a fertilizing plant the sword bean is a very important one: it offers every advantage where plantations are in regular lines, for it is a shrub whose branches do not extend to any great distance, and its abundant growth furnishes a high percentage of nitrogen per acre. One experiment showed the green material to amount to as much as i 5 tons to the acre. From the point of fertilizing the soil, M. Bonâme recommends that it should be dug in when in full flower, that is to say, at 


\section{8}

GUIDE TO COCO-NUT PLANTING

the time when the plant has stored up the maximum amount of nitrogen.

The Canavalia ensiformis and the "Mucuna" will, perhaps, when known, become the most popular here on account of the rapidity with which they are able to be established. They are both well known in other tropical countries, especially in Mauritius, where the Agricultural Department has made a study of the Leguminosæ for years past. Both can be seen growing in one of the writer's experimental plantations.

Previous to sowing the seed the land should be prepared and weeded as clean as possible. The beans, which much resemble the ordinary English broad bean, should be sown about $3 \mathrm{ft}$. apart and not more than I in. below the surface. The Canavalia can be planted close to the coco-nut trees, as it has not the same tendency to climb as the Mucuna, which spreads with remarkable rapidity in the rainy season, and must therefore be kept at a reasonable distance from the trees. The seeds, if soaked in water for a night previous to planting, germinate in forty-eight hours, and planted at the distance recommended above both develop 


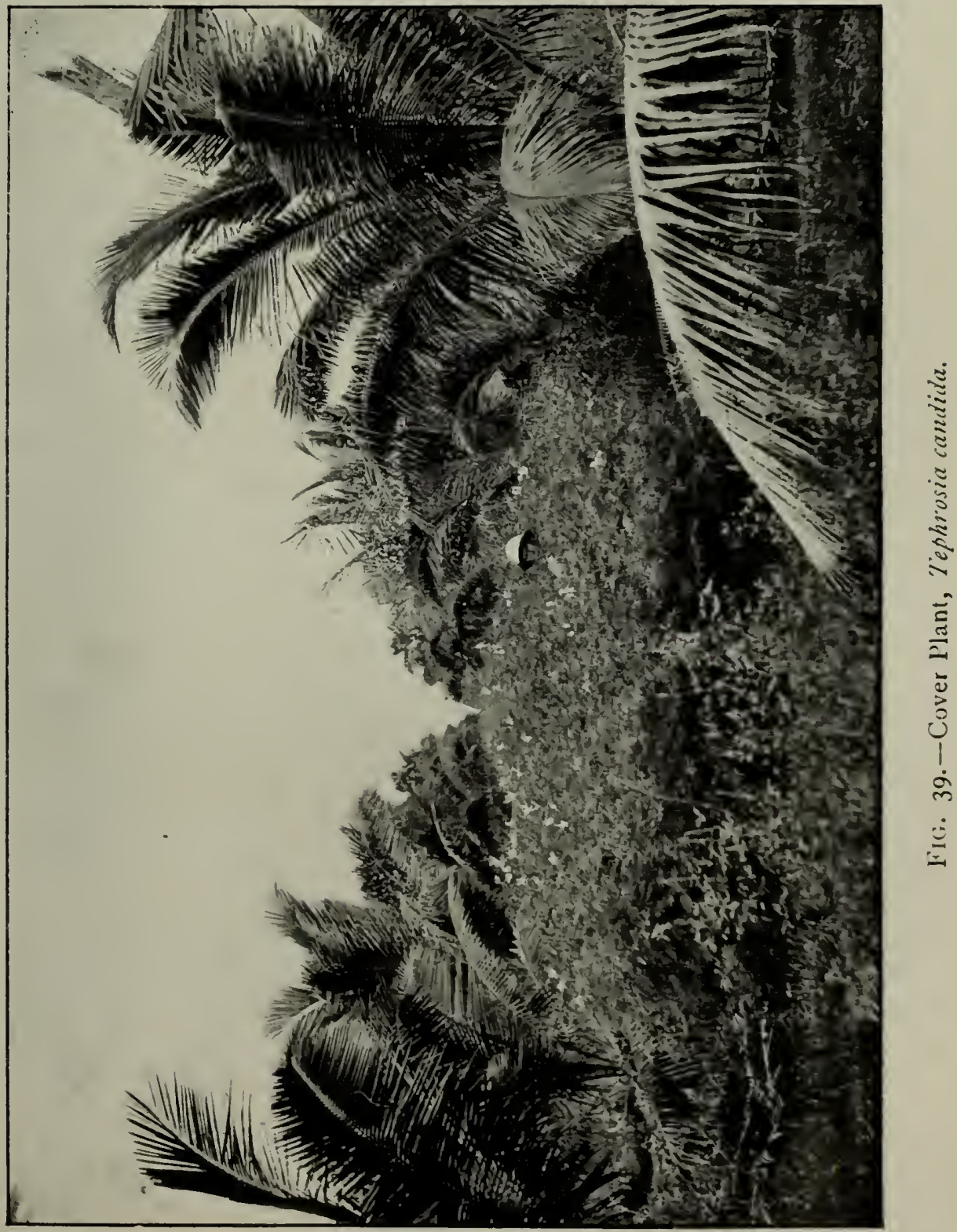



into a complete cover in about a month or six weeks, so that it should only be necessary to give two or three weedings to the land after putting in the cover plant.

It must not, however, be imagined that the planter has now reached the haven where he would be, and that his life will no longer be burdened with thoughts of how money can best be saved on general upkeep; on the contrary, he will find that some of these beans run to seed in about eight months from planting and then the whole plant dies back. It is then necessary to keep on replanting if the above described beans are favoured; in fact, this will have to be considered in all cases when dealing with the Papilionaceæ.

We recommend that all of the three families of leguminous plants be tried, as it is far from easy to recommend any one variety as being suitable to all conditions and classes of soil.

From experiments we have made and seen there is no doubt that Tephrosia candida is very hard to beat, the only drawback compared to the bean family being that it takes longer to establish; more than twice as long, so that it is not so economical at the commencement. 
It should be realized from the start that all these plants take little or no trouble to establish on soils that do not require them, but want a good deal of encouragement on those that are deficient in nitrates; illustrating another instance that there can be no royal road to successful cultivation. It would only. be harmful to cover up peat soils with anything nitrogenous or otherwise, as it is obvious that in dealing with this class of soil the first principle is to neutralize the humid acid and give every possible opportunity of ventilation.

With the idea of economy, temptations often arise to grow cover plants other than the Leguminosæ because they are sometimes of specially rapid growth.

Such plants as passiflora and the ordinary sweet potatoes should only be tried under exceptional conditions mentioned elsewhere.

The passiflora, although very heating and deleterious to the soil, is by far the quickest to establish, and has proved in many instances to be of incalculable value, but although it is recognized that a cover of this sort may, as a rule, reduce considerably the monthly weeding bill, there can be no doubt that preference 


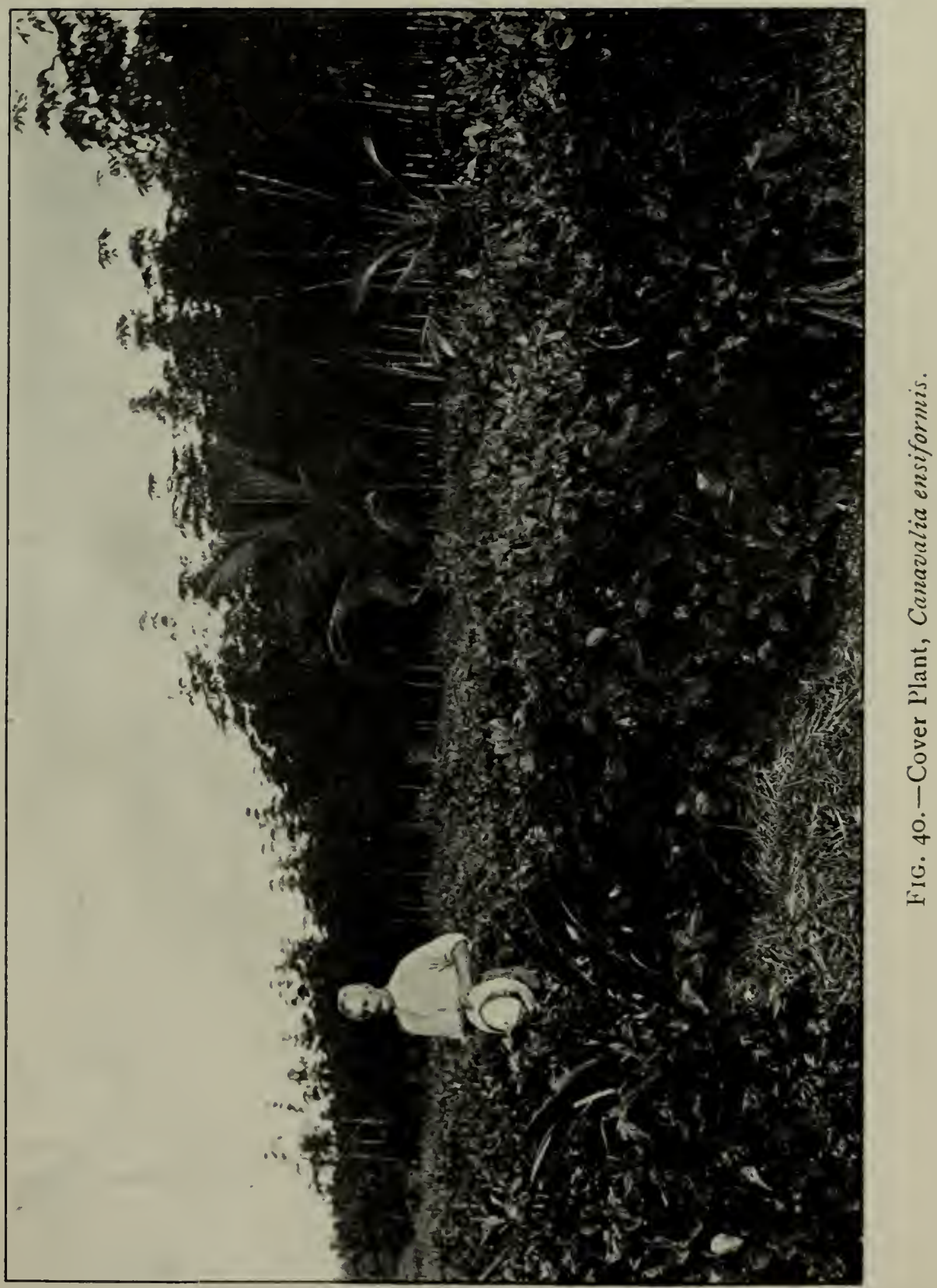

Face p. 80. 



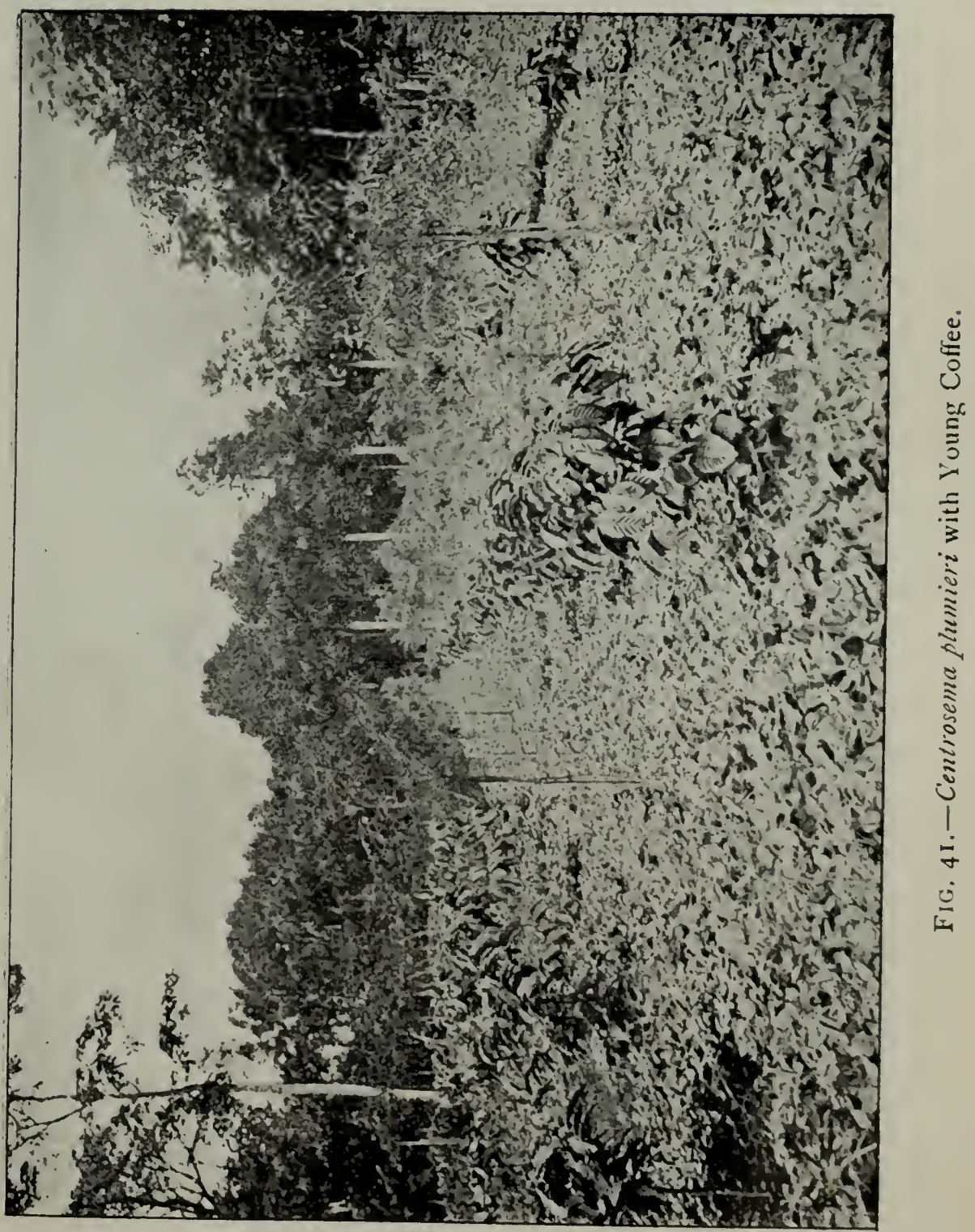





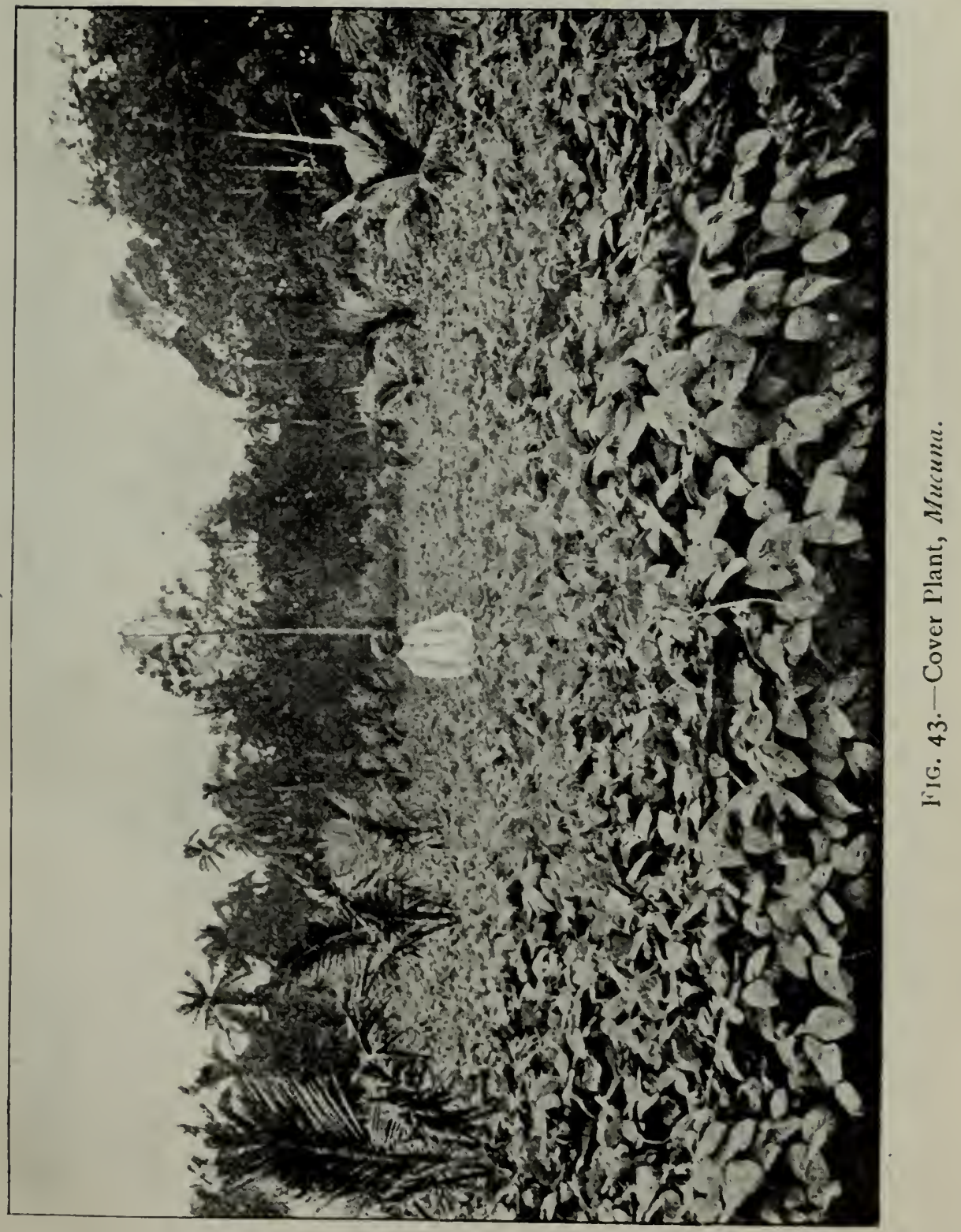





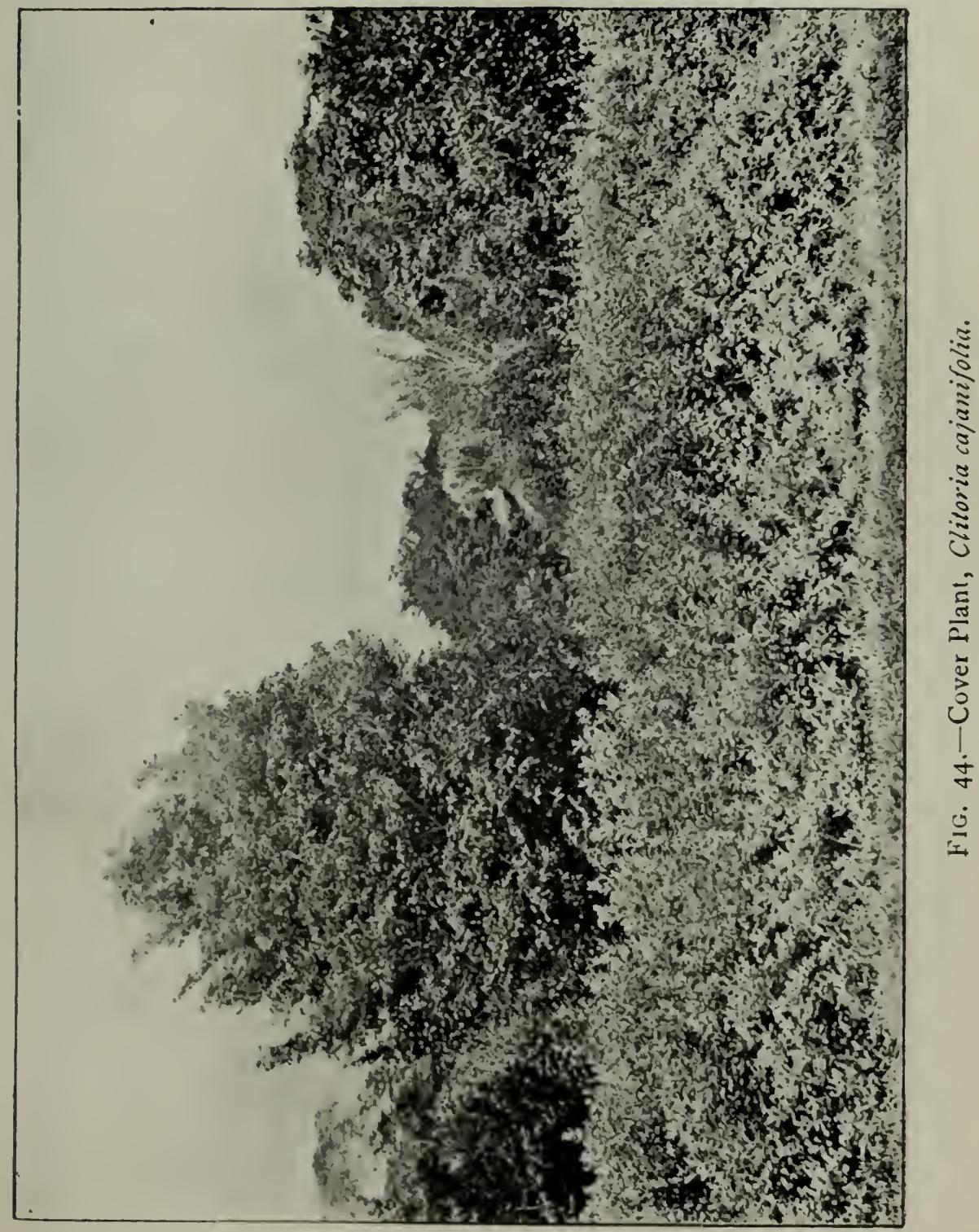

Fo:low +?. 

must be given to a nitrogenous plant if it can be procured and established at a nominal cost. Should the potato creeper be employed little harm is done to the soil so long as it is realized that the creeper must be kept well away from the feeding roots of the tree, also that periodical forking or digging round the tree is a necessity.

This work, which is imperative for the satisfactory development of the palms, involves an amount of expense which is not called for where a nitrogen-producing plant is employed. 
CHAPTER IX.

\section{GATHERING AND STORING THE CROPS.}

When the trees come into bearing it is the usual custom to collect the ripe nuts every two months ; in other words, there are usually six collections in the year. When the trees are not too high for the purpose, the common practice is to remove the nuts by means of a "parang" or knife attached to a pole, and there can be little doubt that this is by far the cheapest method of collecting the product. It must however be remembered that the greatest caution has to be taken (owing to the fact that the nuts on each spathe only ripen gradually) to see that there are no unripe nuts on the bunch that is being cut away. The importance of this is sufficiently evident, as nuts which are less than three-quarters ripe are quite useless for any purpose other than for drinking ; any attempt to use them for making copra would prove very prejudicial to the output. 


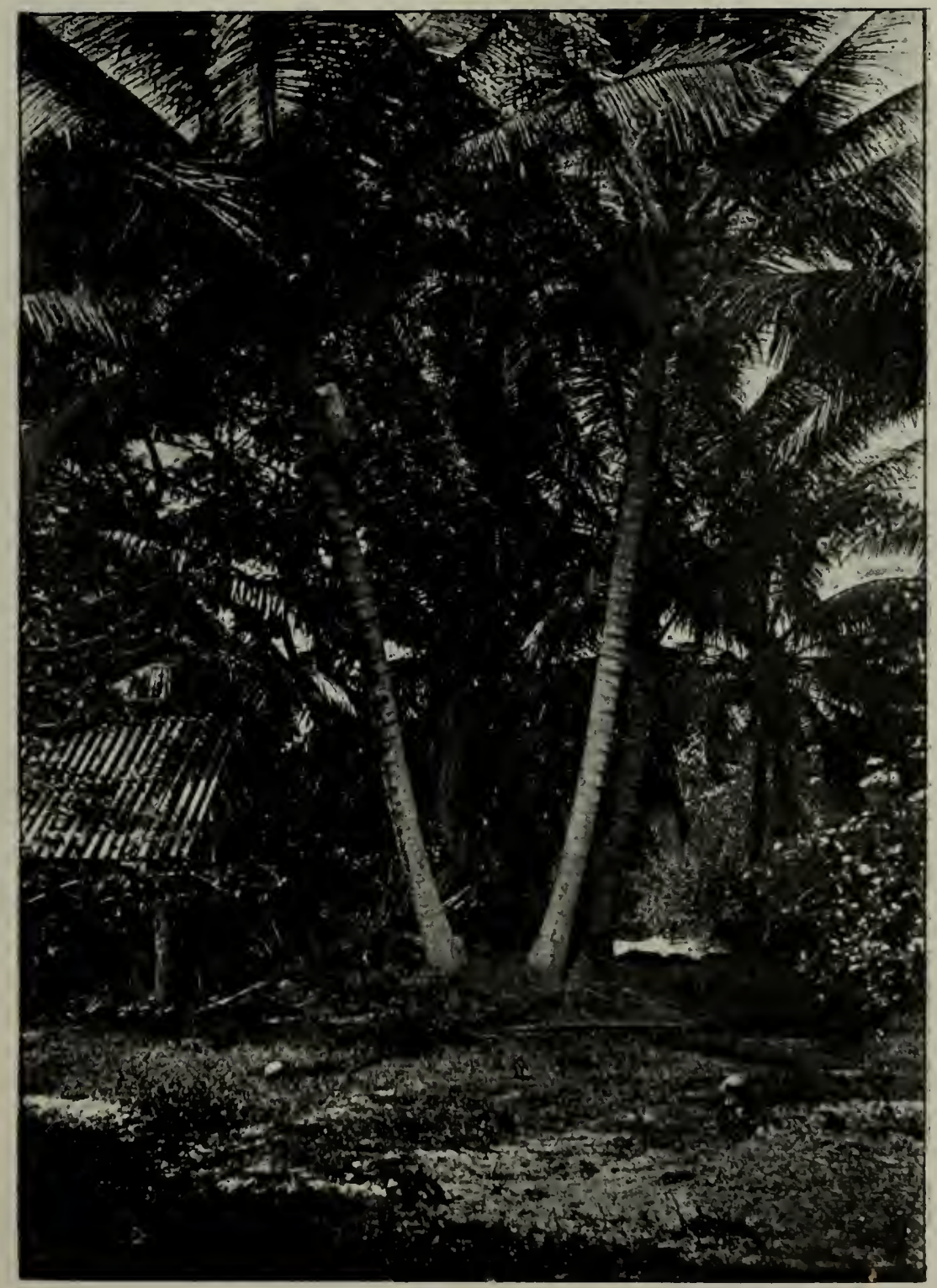

FIG. 45.-Two palms in good bearing, both propagated from the one seed. 



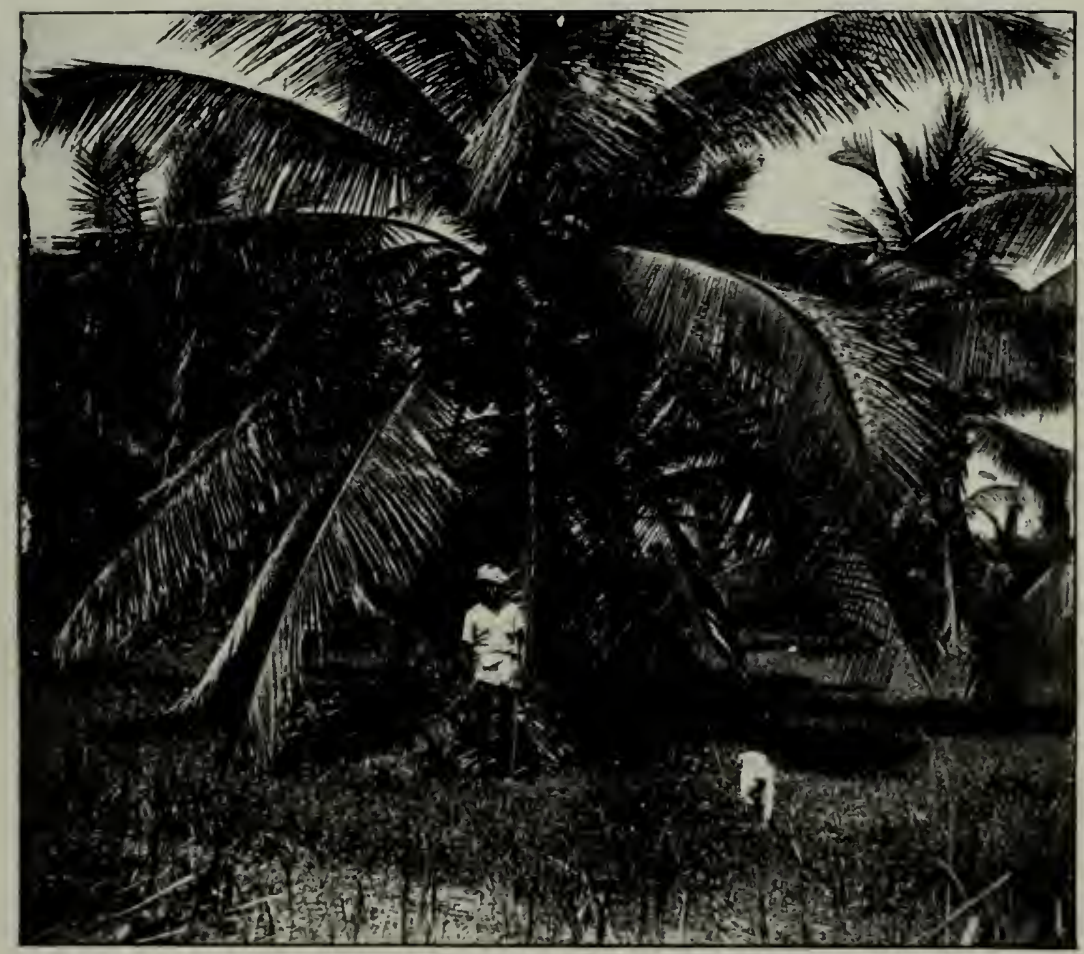

FIG. 46.-Ideal foliage on a young tree.

With a heavy crop supported naturally by its own fronds, without necessity of staking. 

The trees having gained a height of over $50 \mathrm{ft}$. it is better in our opinion always to employ what are known as "coco-nut collectors" for the purpose. These pickers climb the trees until they reach the top, and being in close proximity to the fruit they have no difficulty in detecting the ripe from the unripe nuts, in fact, this is so much in evidence that they will only remove perhaps one or two from one bunch, leaving the other nuts remaining not being matured till the next picking. Another great advantage to be gained by this process of collecting is that the coolie is able at the same time to search the tree for beetles, and should he find any, immediately destroy them. It is not often realized to what extent damage can be done to the tree by rough handling in the process of picking crop, and sometimes one almost wonders whether in the long run it would not be more profitable to allow the ripe nuts to fall and be collected from the ground only. For the benefit of the tree there is no question about this being the right thing to do, but there are other points to be considered.

Loss from theft is quite heavy enough as it 
is, and would certainly increase to an extent that it would be extremely difficult to estimate were the above method a matter of regular practice. This might be done on a small place, but would undoubtedly prove unworkable on a large area.

It should be mentioned also that the climbing of the high trees is only possible on a fairly dry day. In the wet weather the trunk becomes too slippery to allow of the coolie scaling the tree up to a necessary height.

The coir substance which clings to the stem intermingled amongst the leaves and spathes should be on no account interfered with, as it assists in retaining the moisture around the cabbage from which the leaves and fruit emanate and so proves beneficial to its productive powers.

As the nuts are being collected they should be thrown or gathered together in heaps and the husks removed before being taken to the store or place of manufacture into copra. The benefits derived from the procedure are the saving of transport and also that the husks may be used for mulching purposes. There are some estates where the coco-nuts are 


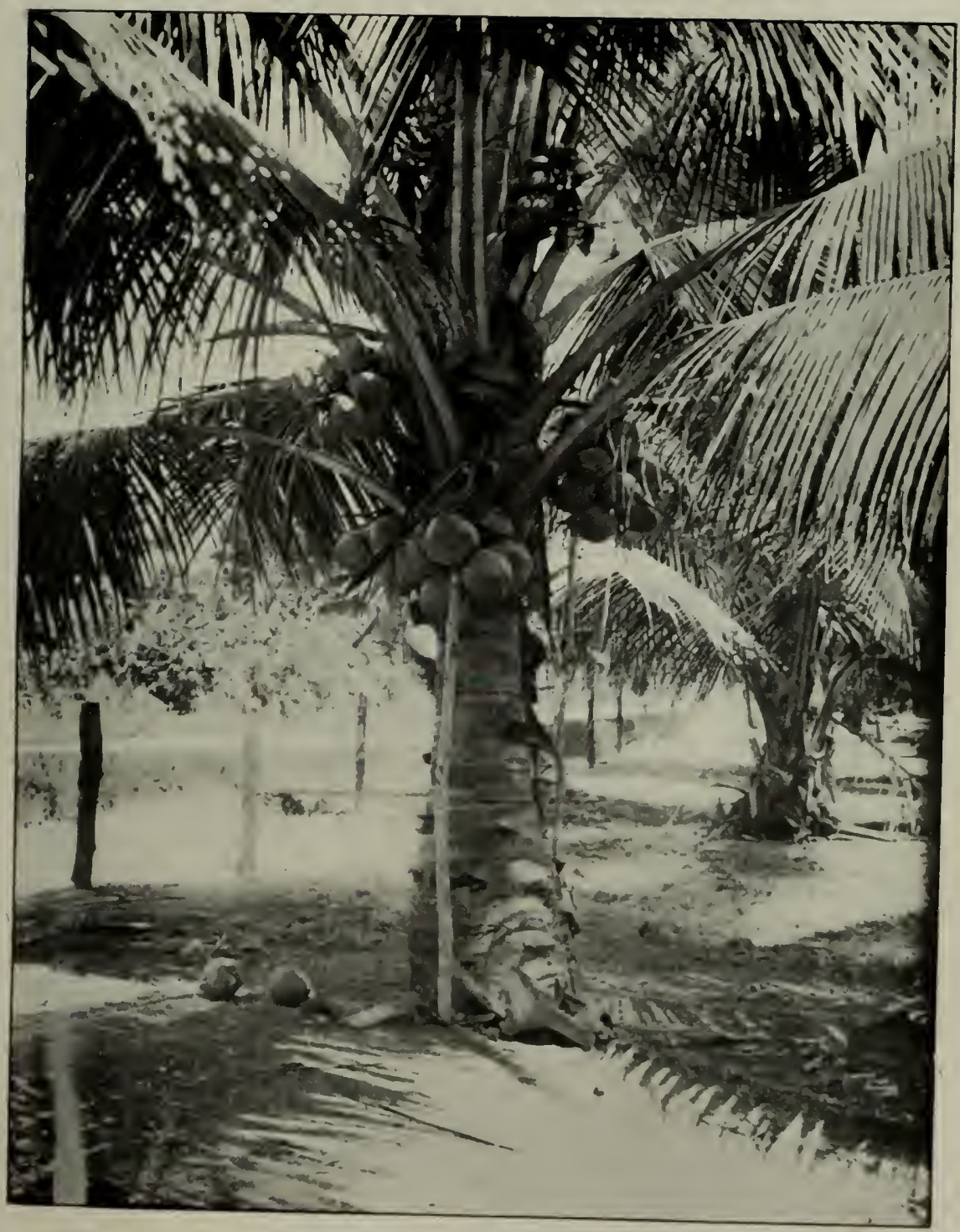

FIc. 47--Staking. One method of preventing crop from young tree falling to the ground prematurely. 



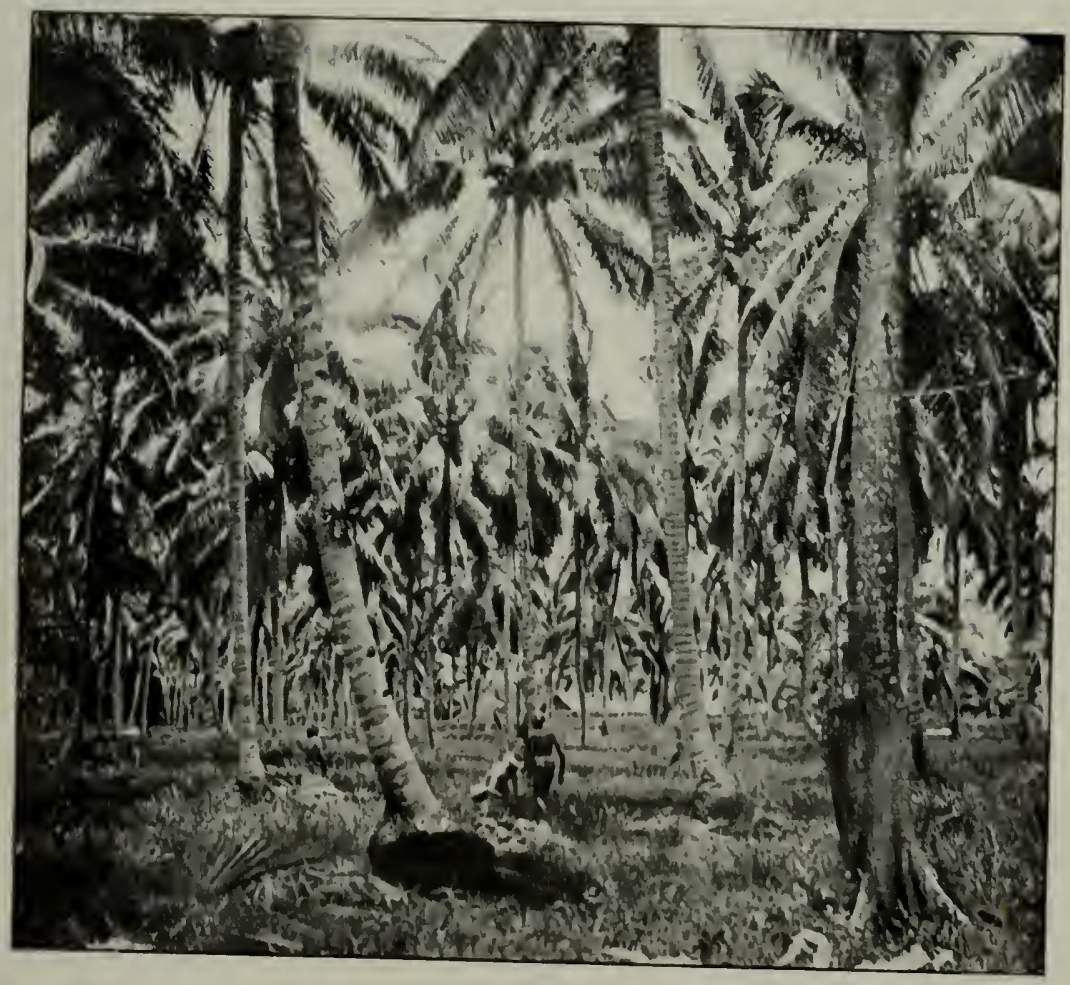

FIG. 48.-Picking Coco-nuts. 

GATHERING AND STORING THE CROPS 85

floated down to the store by canals, in which case the husks are retained, as the numerous drains and volume of water allow of this, and it means a very cheap method of transport, but we think that under the above conditions it might be possible to make use of light boats or rafts, as the husks, either in solid form or as ashes if utilized as fuel for the drying-kiln, have to be returned to the soil whence they came, and of course under no circumstances whatever should the husks be allowed to leave the estate, excepting in the case of seed nuts for planting, in which event a price must be charged proportionate to the amount of value lost.

The idea of allowing any husks to be floated away and lost is inconceivable when it is realized what the amount of loss to the estate is by so doing.

A glance at Mr. Cochran's analysis on page 88 will show the amount of material that can be utilized, and should prove conclusively that there can be no justification for employing any method other than that of leaving the husks in the field, where, no matter how rich the soil may appear to be, the trees will require every bit of it later on. 
The best way of utilizing these husks will be described in the chapter on manuring. Assuming that the average weight of a coconut with the husk is $3 \frac{1}{2} \mathrm{lb}$., the weight of the husk alone will be at least $\mathrm{I} \frac{1}{2} \mathrm{lb}$., so that the calculation regarding the amount of bulk taken from each acre is quite a simple one when we have estimated our output at 2,000 nuts to the acre per annum.

Experiments go to prove conclusively the advantages in the out-turn into copra of allowing nuts to remain unhusked for two or three weeks after gathering. What are often considered immature nuts will in a month's time give an out-turn into copra showing at least 10 per cent. more weight than when they were gathered.

It may be interesting here to note some of the changes that take place during the ripening of the nuts.

The young fruit is solid up to 3 or $4 \mathrm{in.}$ in diameter, subsequently a hollow space is noticeable, and a thin shell is formed which gradually develops into something thicker and harder. Nothing much in the way of a kernel is noticed until the nut has reached practically 


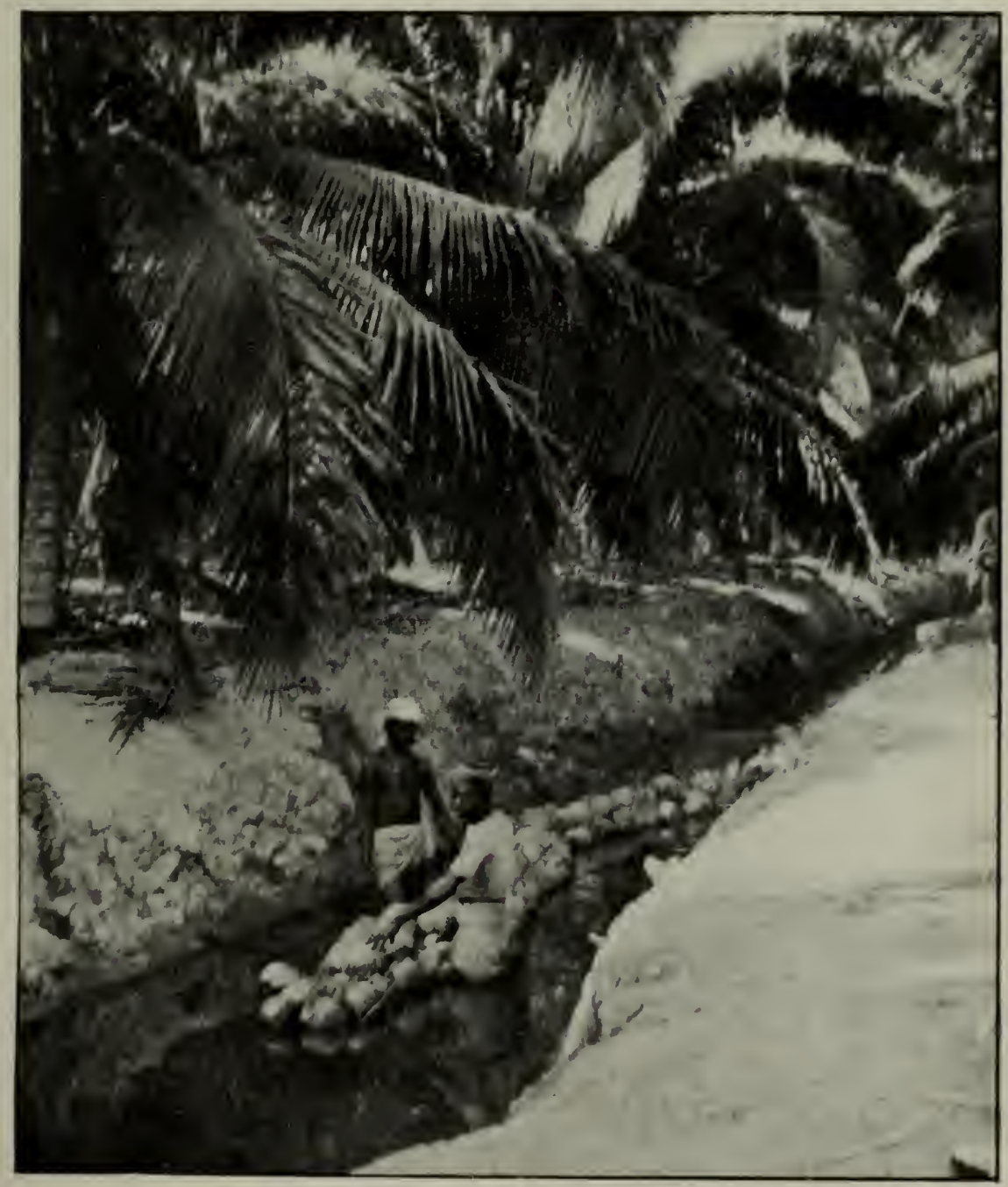

Fig. 49.-Transport of Coco-nuts by Main Estate Drain. 


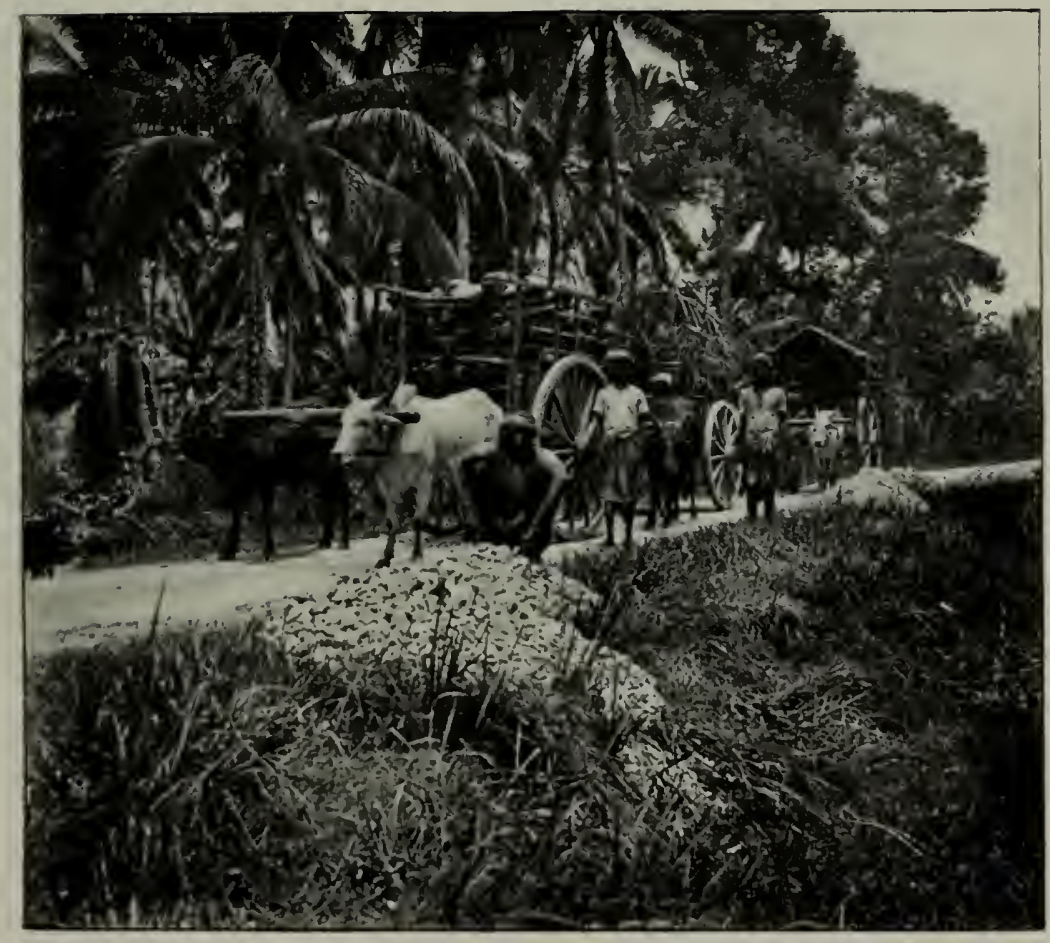

FIG. 50.-Transporting Coco.nuts by Road. 

its maximum size. After the proper formation of the shell the transformation from the slimy, glutinous substance to the well-known coconut meat is fairly quick.

It is universally observed how that the hardening process in the meat continues for some time after the ripe nuts are gathered, practically up to the time the sprout makes its appearance; after that, quite another metamorphosis occurs. The embryo first noticeable at the foot of the sprout gradually enlarges until the whole cavity inside the nut is full. The embryo continues to feed for the benefit of the young plant on what is left. Now the tree is able to fight its way unaided.

Conclusions arrived at from individual tests made show that under normal conditions the time from the blossom to the mature nut may be reckoned at about eleven months.

Photographs of nuts at various stages of development will, we think, be of interest inasmuch as they should serve as a guide when one of the most difficult questions arises, viz., the estimating of the crop.

We shall suppose that planters get forty nuts per tree per annum. Each tree will, at this 
rate of production, remove from the soil in copra in two years :-

$\begin{array}{lcccc}\text { Nitrogen } & \ldots & \ldots & \ldots & 0.4488 \mathrm{lb} . \\ \text { Potash } & \ldots & \ldots & \ldots & 0.0272\end{array}$

It is necessary, however, to take into account the fertilizing ingredients removed from the soil in the husk, the shell and the milk of the ripe nut.

The following analyses show that :-

$$
\begin{aligned}
& 1,000 \text { husks each weighing } 1 \cdot 789 \mathrm{lb} \text {. } \\
& \text { r,000 shells " " } 0.666 \text {, } \\
& \text { Milk } \quad \ldots \quad \ldots \quad \ldots \quad 500,
\end{aligned}
$$

remove from the soil :-

$\begin{array}{lcccr}\text { Nitrogen } & \ldots & \ldots & \ldots & 2.66 \text { I } 8 \text { lb. } \\ \text { Potash } & \ldots & \ldots & \ldots & \text { 13.4706 } \\ \text { Phosphoric acid } & \ldots & \ldots & 0.6420 & \end{array}$

Adding the above to the quantities found in the poonac, we get the amount of nitrogen, potash, and phosphoric acid removed from the soil in two years by a crop of forty nuts per tree per annum :-

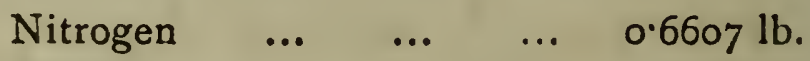

$\begin{array}{lllll}\text { Potash } & \ldots & \ldots & \ldots & \text { I'3497 " }\end{array}$

Phosphoric acid $\quad \ldots \quad \ldots \quad 0.2350$ ", 


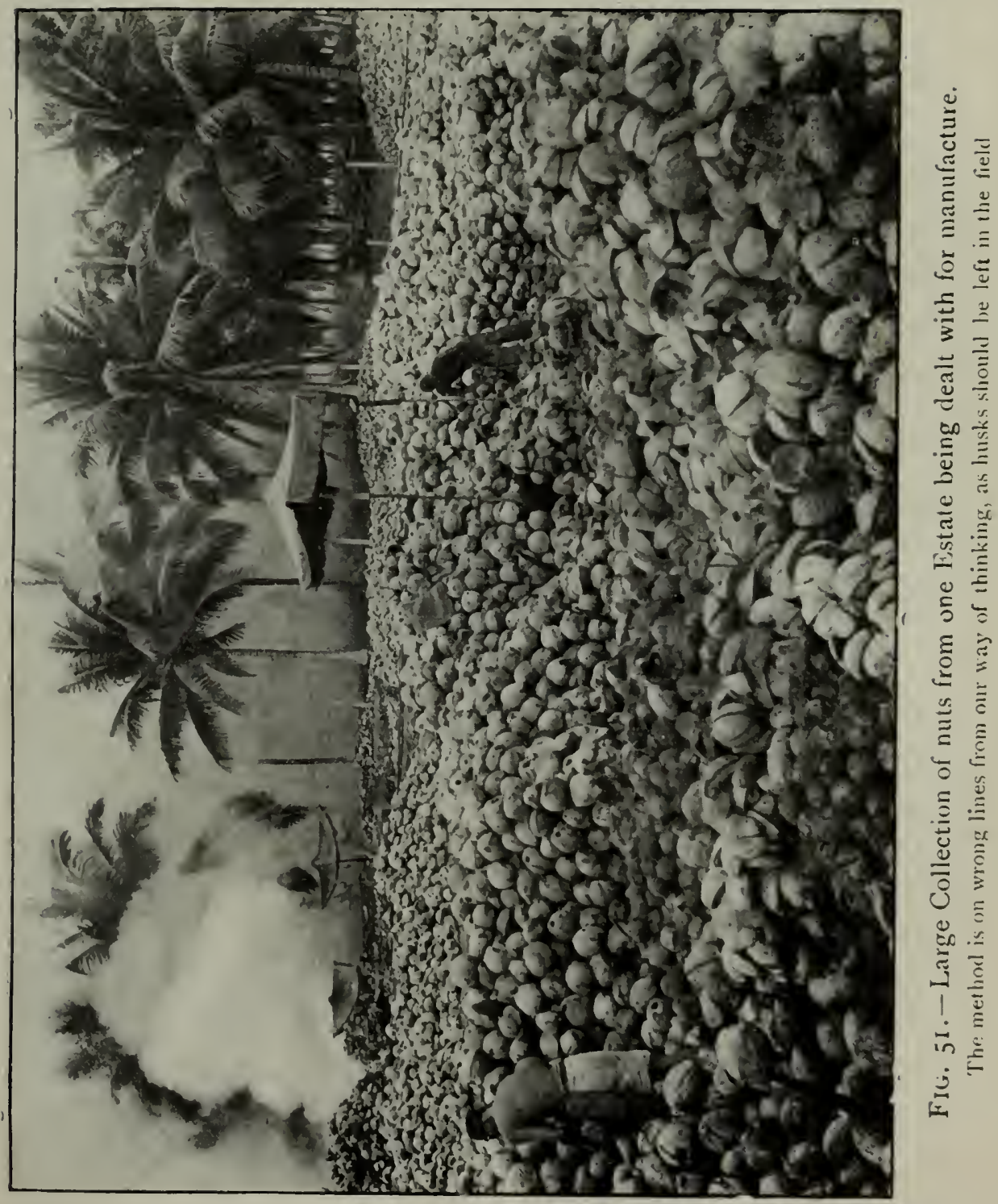





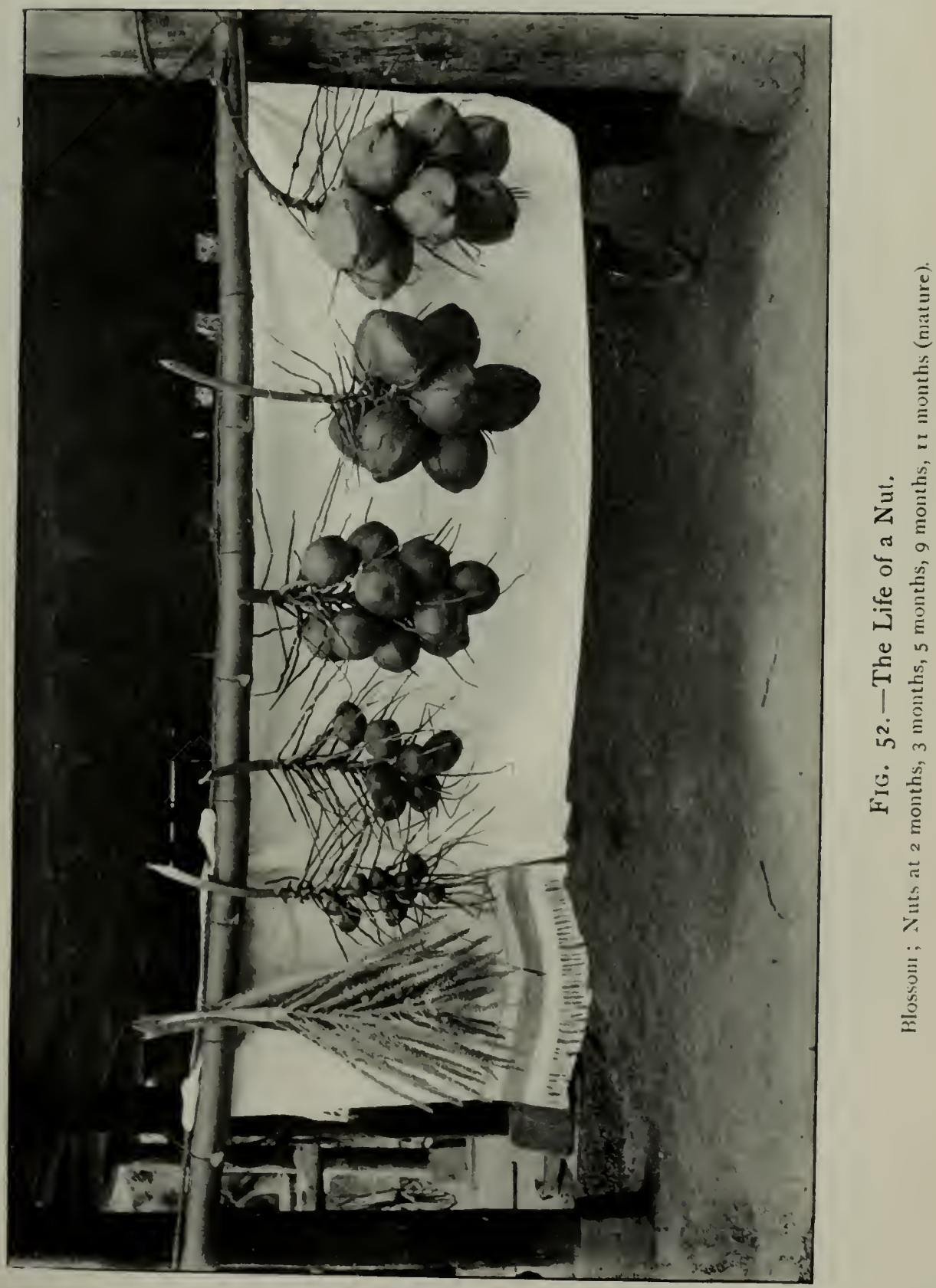





\section{CHAPTER X.}

\section{MANURING.}

When it is necessary to apply artificial manure, this matter has to be very carefully considered on account of the cost, as without a compensating return there is really no advantage to be gained. For this reason as long as vegetable manures will serve the purpose of obtaining regular and good average crops from the trees (as may often be found the case on rich soil for a good number of years) the necessity of going to the expense of buying artificial manures can probably be put off for a very considerable period, more especially if cow dung and fish manures are to be obtained near by and on reasonable terms. In saying this, however, it must also be borne in mind that in stiff and poor soils the application of artificial manures is often absolutely necessary, and when the trees in this class of land fall off in yield this is practically the only means of 
bringing the trees into a good healthy condition again, and of enabling the plantation to make a profitable return. We know also that for anything like a large area cattle manure in sufficient quantities is rarely obtainable. In the use of artificial manures the nature of the soil should first be ascertained in order that the mixture may contain the special ingredients in the right proportions that are most suitable for the land in question, and are therefore likely to give the best results. Another thing that has to be remembered is that a poor and weak tree or a young one does not require so much of the artificial manure as a well grown and more healthy tree. A better plan is to give the weakly tree less at a time, and then a little more perhaps nine months later when its improved condition and vitality can partake of a further amount and benefit thereby. Continuing on this subject the chief points to be taken into account are as follows :-

(I) The nature of the soil under cultivation; (2) the natural requirements of the tree itself Assuming therefore that the soil is not altogether deficient in the recognized fertilizing ingredients required for its successful growth 


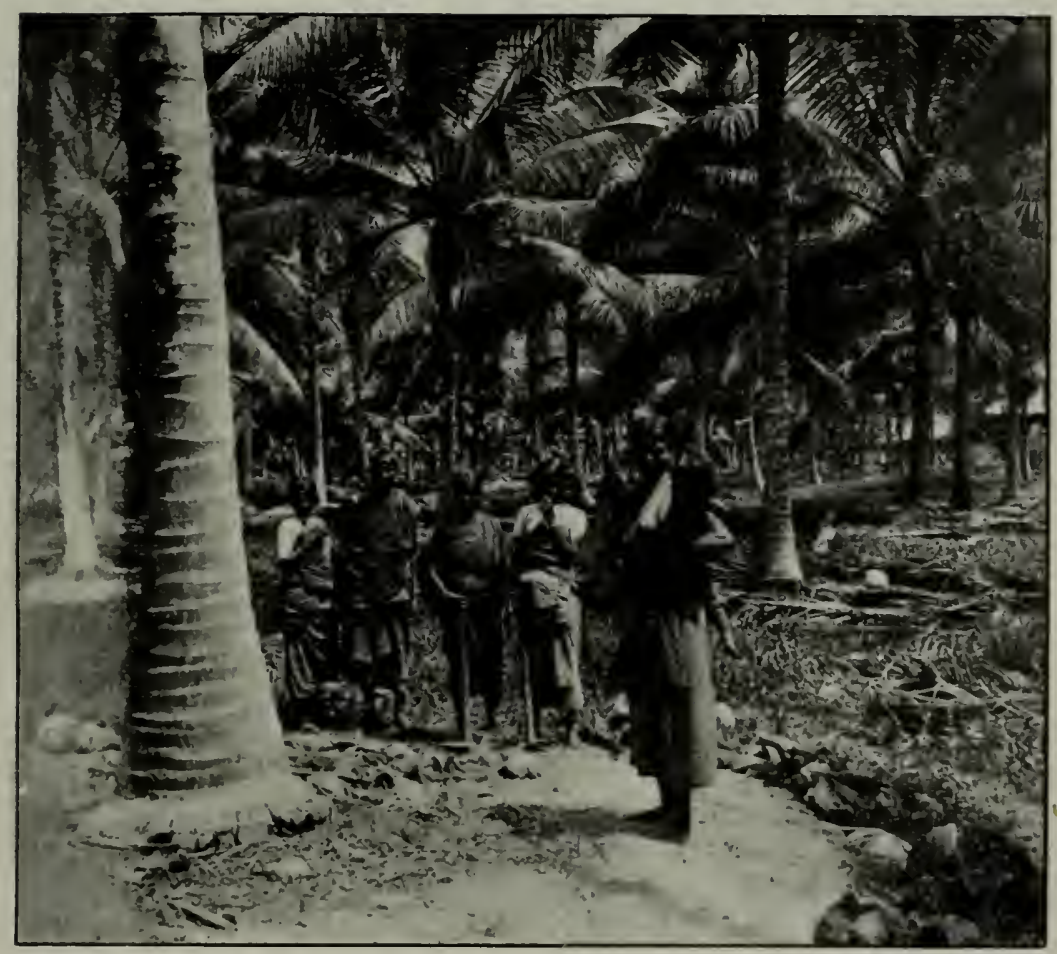

Fic. 53.-. Illustration showing the dis'ance from the tree at which the circle is made for mulching and manuring. 
and yield, there will generally be found enough material available that may be taken advantage of without incurring unnecessary expenditure in artificial manures, at least for a good number of years after the trees actually come into bearing.

It is certainly our opinion that there should be on every large plantation a herd of cattle for grazing and other purposes, and in the ordinary way the cow dung obtained therefrom will go a long way towards manuring the trees. Mixed with salt it can be applied in the following proportions to a full-grown matured tree : a quarter of a cart load of manure to one gantang of salt, while advantage may be taken to do some mulching at the same time.

The system of manuring recommended is as follows: a trench to be dug half round the tree, about ${ }_{5} \mathrm{in}$. in width and say I $\mathrm{ft}$. in depth, close to the extremity of the feeding roots some $6 \mathrm{ft}$. to $8 \mathrm{ft}$. from the base of the stem. The trench may be left open for a time, then the manure filled in and the soil that has been excavated replaced. The following year the other half of the tree may, if found advisable, be treated in a similar. 
manner. The alternative method of spreading the manure at the place required and then forking it in is every bit as good. The area thus treated should be covered up in every case with a mulch.

Fish manure, when it can be obtained in good quantities and at a reasonable cost, is strongly to be recommended.

There are two precautions which must be taken when applying rich fertilizers : the first is that it should always be used as sparingly as possible, the reason being that on subsequent occasions after the effects are wearing off it will be found that to obtain the same results a larger amount of the manure is required until the treatment becomes almost prohibitive on account of the increased cost.

Before proceeding further, it is necessary to touch upon the all important question of applying lime to all classes of soil. We have spoken about our green manures, our mulch and so on, and we have stated in a previous chapter that the soils we have mostly to deal with are of a stiff type. We are assuming also that no land is chosen for coco-nut growing where liming would have to be discussed until 


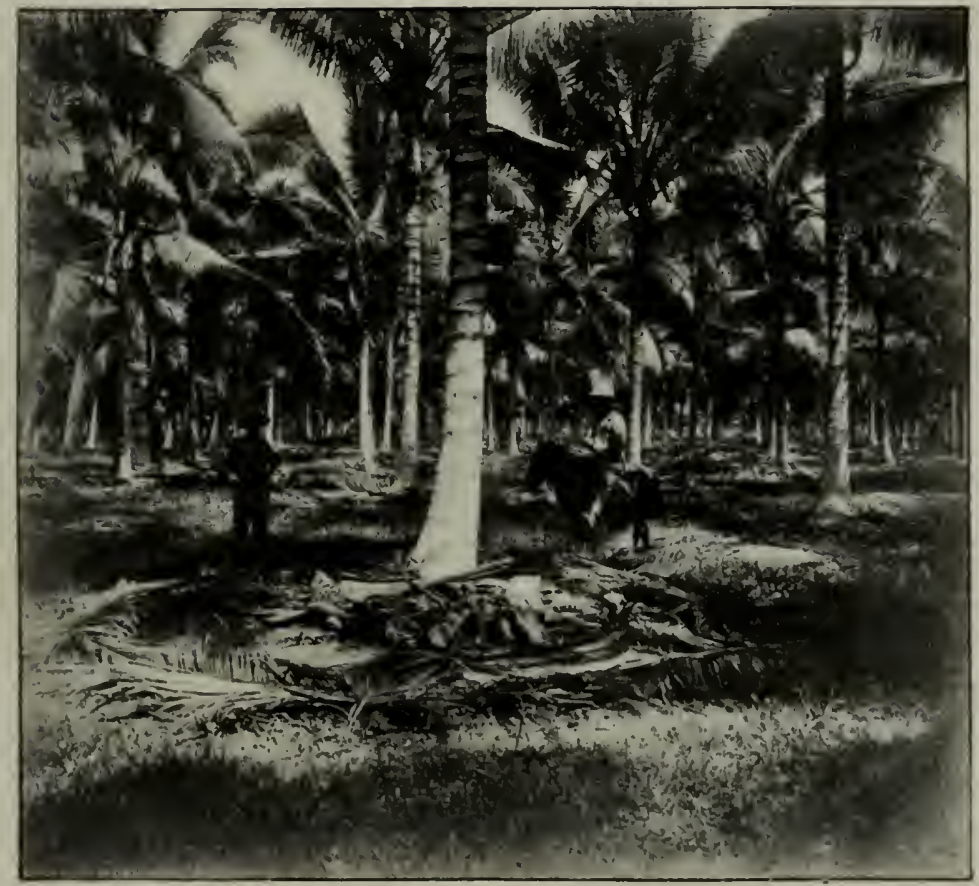

FIg. 54.- Covering the Green Mulch with Coco-nut leaves. 

the fruiting stage, or in other words no land that was devoid of humus or failed to respond to treatment by green manuring.

It is naturally at the yielding stage or soon after that the question of liming would be likely to require serious discussion, excepting, of course, on a certain class of peaty soils where a large proportion of humic acid is found, but we do not advise anyone to plant coco-nuts on land requiring drastic remedial measures.

The action which lime has on hard soils is well known, and it is remarkable in how short a space of time after application favourable results are shown. Food for the plant which may be there all the time is often incapable of being taken up until the ingredients necessary are set free, and every agriculturist knows that being able to create these conditions is one of the most important advantages that lime possesses.

On ordinary soils the action of lime is mostly physical, but the application of it requires more or less careful working out.

As to the quantity required per acre this will depend upon whether the treatment is 
considered necessary over the whole area, or only in wide circles around each tree. If applied with the object of rendering a hard soil friable the ground must be turned over previously, and the lime well forked in.

Encouraging results have been shown by adopting this method round the trees, keeping well outside what are generally known as the feeding roots. In this way about Io or $\mathrm{I} 2 \mathrm{lb}$. of lime to each tree will be sufficient, and the forked area should be covered up with dead leaves, or any other mulch that happens to be available. If required to be spread over the whole area so that the texture of the soil may be uniform, ploughing or harrowing is recommended and the quantity of lime to the acre may be anything from $I$ to 2 tons.

When it is found necessary to apply artificial manure, liming should go hand in hand with it in order that the soil may be in a better condition for the rapid absorption of the fertilizing ingredients. This applies to every class of soil.

There can be little doubt that the full complement of leaf and branch is the primary object to be aimed at, and this being so the 


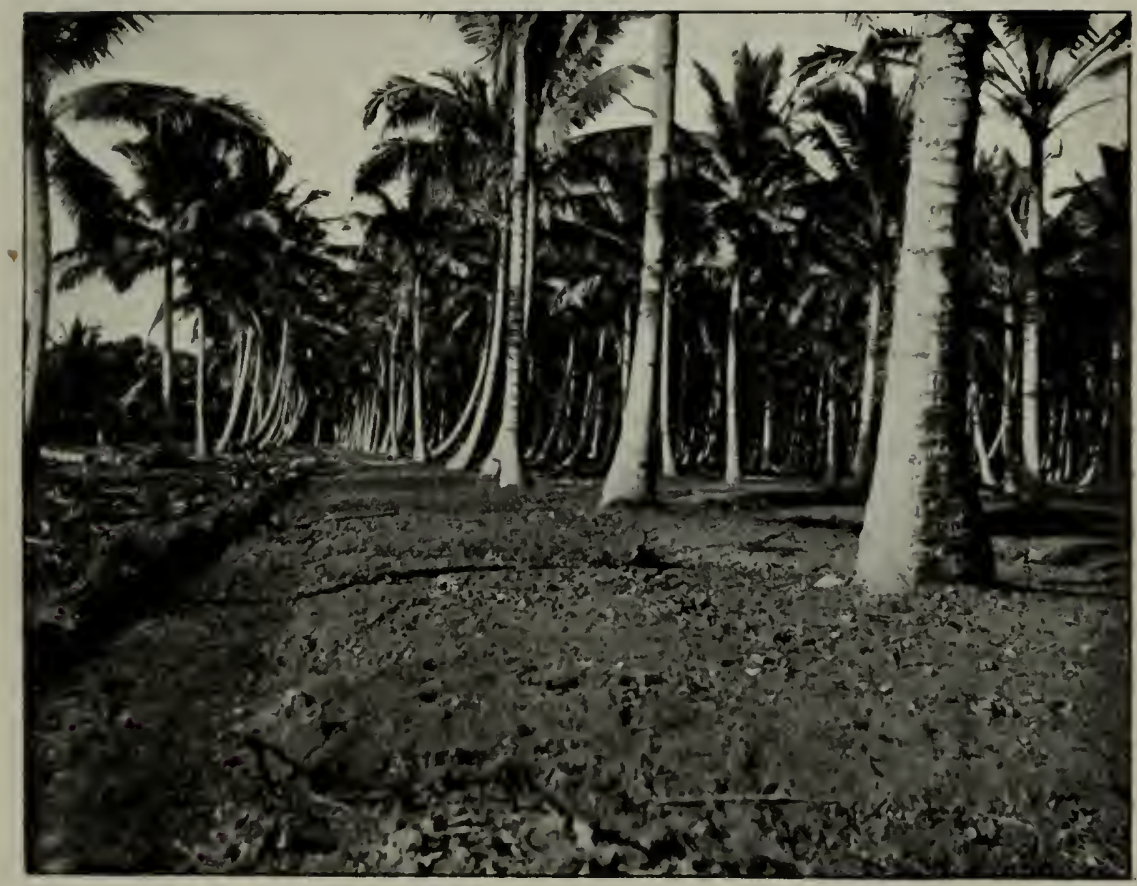

FIG. 55.-Ideal Method of Mounding Trees with Soil from "Scupper" Drains. 

strongest stimulant to the tree for this purpose is nitrogen. Amongst Mr. W. S. Lyons' remarks in Farmer's Bulletin No. 8 of Manila, the following is deserving of great appreciation: "That the coco-nut is able to take up large quantities of salt may not be disputed. That the character of its root is such as to enable it to do so without the injury that would occur to most cultivated plants I have previously shown, whilst the history of the coco-nut's inland career and the records of agricultural chemistry both conclusively point to the fact that its presence is an incident that in no way contributes to the health, vigour, or fruitfulness of the tree.

"When it comes to the specific application of manures, and how to make the most of our resources, we shall have to turn back to the analysis of the nut, and note that relatively to other crops it makes but small demand for nitrogen; at the same time it must not be forgotten that these chemical determinations only refer to the fruit, and with the present incomplete data and lack of investigation of the constituent parts of the roots, stem, leaf, and branch, we have nothing to guide us but 
what we may infer from the behaviour of the plant and its relationship to plants of long deferred cultivation, the application of a generous supply of stimulating nitrogen during its early career and the gradual substitution in later life of manures in which the potash and phosphoric acid (particularly the former predominate) are necessary."

In returning to the soil the fertilizing ingredients removed by the crop, we touched in a previous chapter upon the importance of preserving the husks for the above purpose, and we demonstrated it by analysis. There are several methods of utilizing the husks; they can be burned in the field, buried in pits or trenches, or placed in circles round the trees. There is no doubt that by burying we get the most for our money in the shortest time, and where labour is available there is no doubt about its being the right thing to do. Although the process is far from being a cheap one, as compared with the application of cattle manure, or the trenching of green manures, we distinctly advise it where practicable.

The husks act as very valuable retainers 


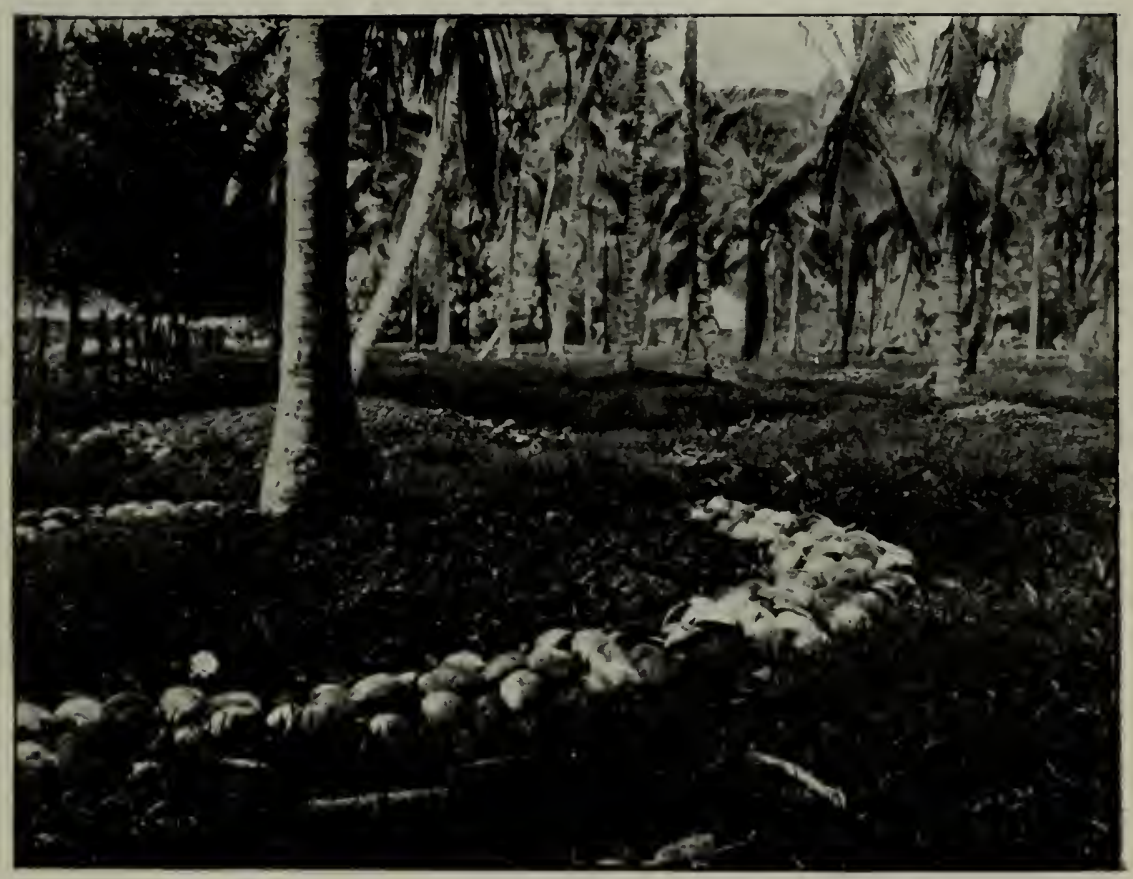

FI(: 56.-Mulching with Coco-nut husks. 

of moisture when placed one by one and overlapping each other, concave side downwards, on the surface of the soil, at a point where the tree is most likely to suffer from lack of moisture during a long spell of dry weather. It is by no means an uncommon thing to come across obstinate cases where trees, having passed by many years the average bearing stage, fail to show any sign of productiveness ; for the treatment of these there are a good many recipes and, perhaps, the most efficacious have been handed down to us by the natives.

In almost every instance drastic treatment would appear to be necessary, and the more severe the shock is to the tree the more quickly it seems to gratefully respond; and however paradoxical it may sound, there is no getting away from the fact, in the face of the many concrete instances that we have seen, that either severe scorching by a fire made right up to the stem, by ring-barking, or laying bare the roots and exposing them to the atmosphere or even the hottest sun and driest weather does bring about in the case of many stubborn trees the most extraordinarily beneficial results. 
We recollect an instance where the first mentioned drastic measure was employed on a tree nineteen years old: a large fire was made to windward of the tree and quite close to the trunk; there was a high wind blowing at the time, so strong, in fact, that pieces of the trunk were not only charred but completely burned away,

In two years' time this tree was bearing well, and was in full bearing within four years after the burn, having received no other kind of special treatment.

- Ring-barking is well known to have had in certain cases a marked stimulating effect upon the trees of the monocotyledon tribe, and we ourselves have observed striking instances of the effect that this rough treatment has had on trees to which every other kind of gentle manipulation had been previously given for the purpose of encouraging them to yield.

Thorough aeration of the roots, almost to the starving point, has been known in obstinate cases to prove as satisfactory a remedy as any of those above mentioned:

It must, however, be clearly understood that when 7 or 8 per cent. of your trees fail 


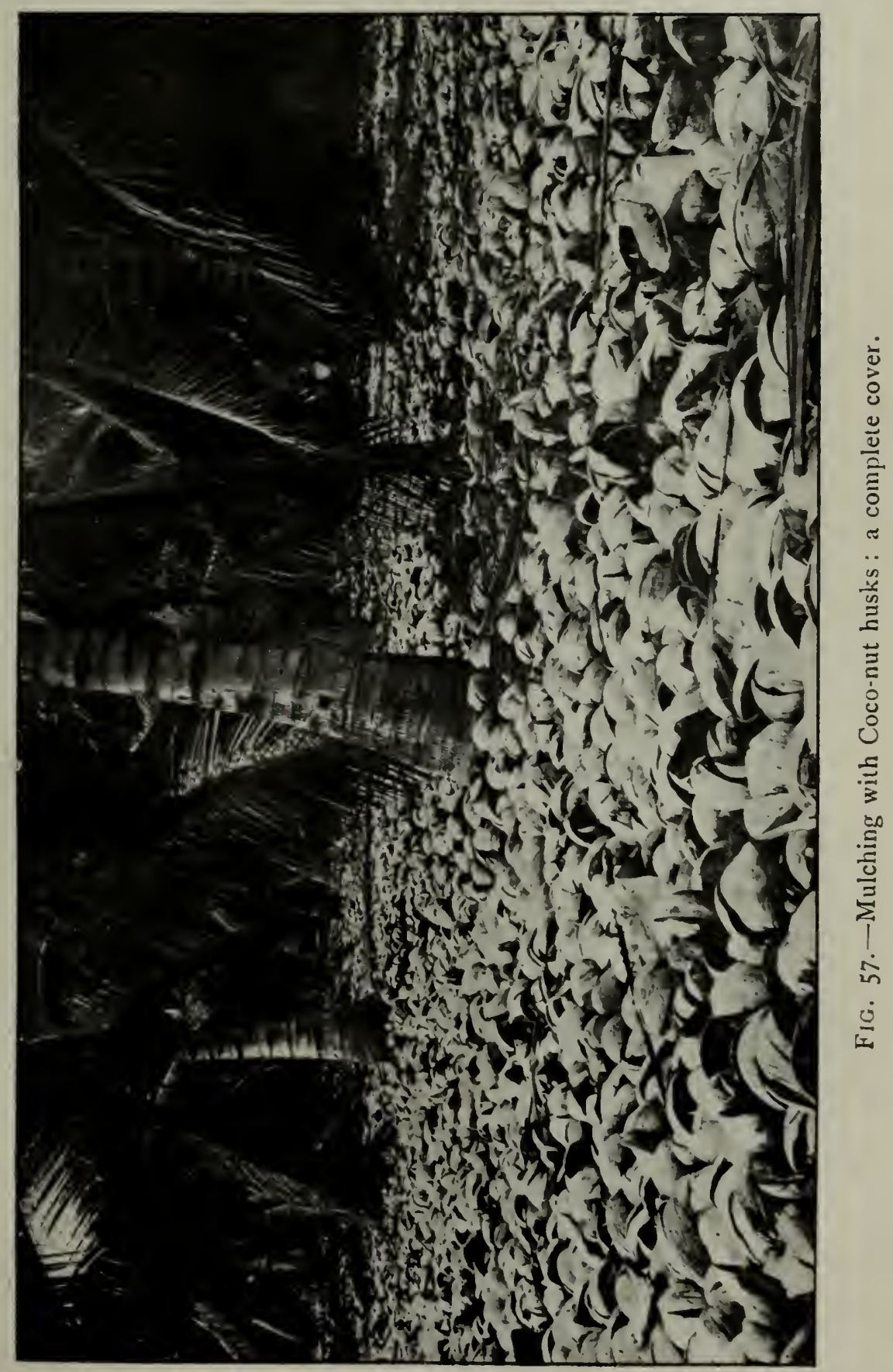

Face p. $9 \delta$. 

to give any crop when the rest of them are normally producing, it will not of necessity be expedient to fly at once to the above remedies. The seat of the trouble is likely sometimes to be in unhealthy or immature seed, but not being gifted with the power of vision into the unknown, it is doubtful if those posing as experts (which certainly we are not) would care to express a definite opinion on this. Still, as a matter of fact, it is more the rule than the exception to see a plantation in full bearing in which at least one or two trees to the acre are barren, but it becomes, after some years of watching the caprices and eccentricities of the palm, fairly easy to determine whether or not the tree is existing under congenial conditions, and whether all ordinary steps have been taken to ensure its well-being.

It is not until every other remedy has been tried that it can possibly be necessary to have recourse to violent handling such as described above.

It has been found by analysis that cattle dung is the best manure, because it contains in the right proportion the various necessary plant foods, viz., nitrogen, potash, and phosphoric acid. 


\section{GUIDE TO COCO-NUT PLANTING}

It is these constituents, therefore, that have to be applied in an available form by artificial means when other methods are impracticable.

The only practical means of determining what chemicals are required, and in what proportions, is by an analysis of the soil and when this task is to be undertaken it is of all importance that samples should be got from different parts of the estate. The depth from which these samples must be taken will naturally vary according to the amount of humus on the surface of the land-assuming that we are wishing to treat soils that are devoid of humus, samples should be drawn from holes cut to a depth of not less than $2 \mathrm{ft}$, and $3 \mathrm{lb}$. to $4 \mathrm{lb}$. will be sufficient for each sample.

It must be remembered that clay soils are very often quite rich in fertilizing ingredients, and only require "working up" to be made normally active.

Basic slag must be recognized as one of the most useful artificial manures, inasmuch as it contains 15 to 18 per cent. of phosphoric acid and 50 per cent. of lime; and for the other 


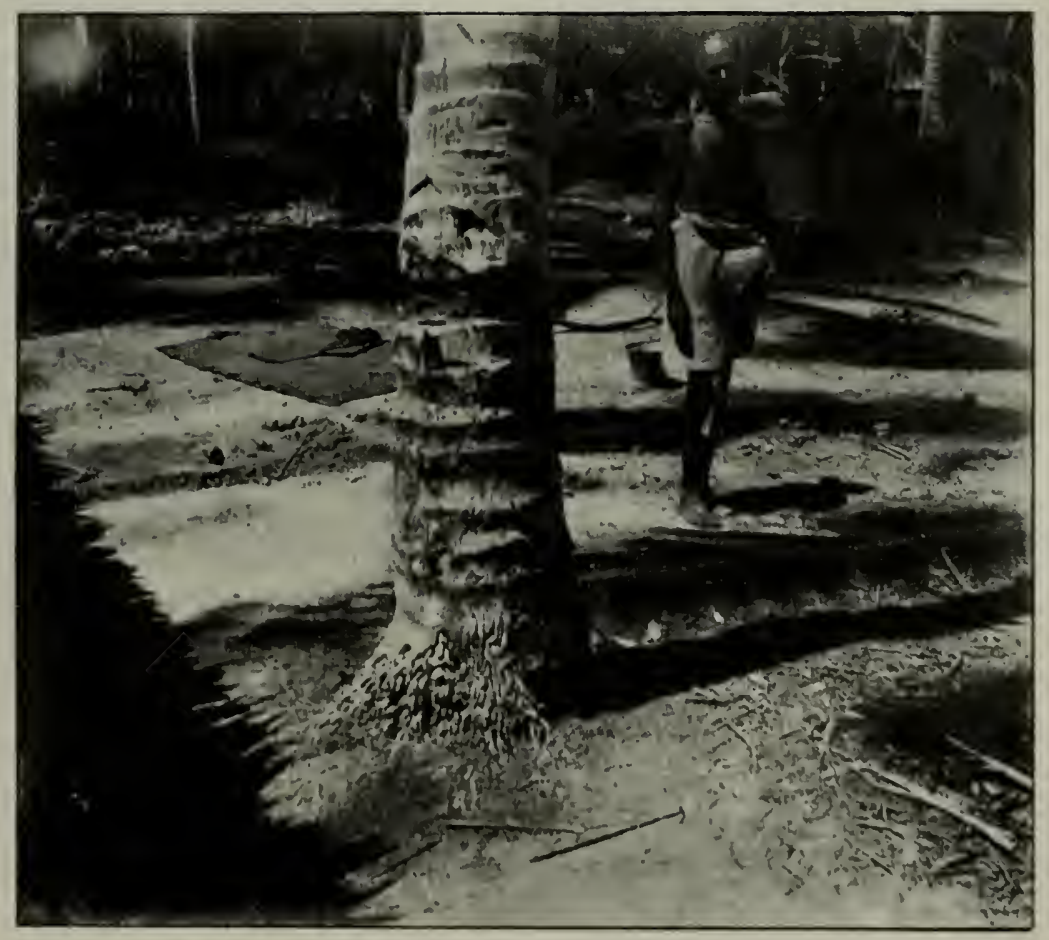

FIG. 58.-Ring-barking. 

ingredients, kamnit and bone meal, or castor cake (when the proportions are discovered) are likely to meet all requirements for coco-nut trees, either young or in bearing.

After all grass and weeds have been removed within a circle about the same as the leaf radius of the tree, a circular trench should be dug not less than $6 \mathrm{ft}$. or $7 \mathrm{ft}$. from the stem of the palm when mature trees are being treated.

Having well mixed the manure apportioned to each tree with any good soil handy, or with that removed from the trenches, the trench is filled in with the mixture, and covered over with oid leaves, husks, or whatever mulch is available. The manure can also be sprinkled broadcast and forked in. We consider the former method preferable. As regards the quantity of mixture required for each tree, about io $\mathrm{lb}$. to $12 \mathrm{lb}$. is usually recommended.

It wili be found that, including purchase of manure and the cost of application, the sum required will work out at somewhere in the neighbourhood of $\$ 20$ per acre.

The following, coming from Mr. Kelway Bamber, of Ceylon, cannot fail, we think, to be of interest to our readers: "It had been 


\section{GUIDE TO COCO-NUT PLANTING}

estimated by Lepine and others that a thirtyyear old coco-nut palm formed 2,240 lb. (or I ton) of organic matter during that period of growth, and absorbed from the soil from 228 to $320 \mathrm{lb}$. of ash or mineral matter, consisting chiefly of potash salts, phosphate of lime, and other lime salts, with a small proportion of sodium chloride and silica. The greater portion of the potash and phosphate of lime was to be found in the leaves, or about 56 per cent.; most of that was returned to the soil when the leaves dropped off, and it showed the importance of utilizing the mineral matter in the fallen leaves to the best advantage. Much of the potash, but little of the phosphate of lime, was to be found in the immature fallen nuts, and there again the advisability of utilizing them as a manure was indicated. The amount of mineral matter estimated to be removed from the soil by one acre of coco-nut palms annually, at sixty-two palms to the acre, was said to be: salt 52 lb., potash salts $32 \mathrm{I} \mathrm{lb}$., phosphate of lime I $94 \mathrm{lb}$., carbonate and sulphate of lime r $40 \mathrm{lb}$., magnesia $2 \mathrm{lb}$., and silica $28 \mathrm{lb}$. - a total of $737 \mathrm{lb}$. The leaves and fruit removed most $(370 \mathrm{lb}$. and $250 \mathrm{lb}$. 


\section{MANURING}

respectively), whilst the trunks utilized $70 \mathrm{lb}$. and the remainder $47 \mathrm{lb}$.

"Those figures show the importance of including a good proportion of lime, potash, and phosphoric acid in a manure mixture even for the growth of the palm, especially if the soils were deficient in those constituents.' 


\section{CHAPTER XI.}

\section{CURING COPRA FOR MARKET.}

Husinga, Splitting, and Drying.

THE well-known method of treatment preparatory to drying requires little description.

Our illustrations show the method usually employed. viz., that of removing the outside husk with a sharp-pointed, spear-like instrument fixed firmly in the ground.

Machinery has been devised to deal with large quantities, but has not so far proved an unqualified success owing to the variation in the form and size of the nuts.

A coolie can treat by hand anything between 600 and 1,000 in an ordinary working day. We have seen Javanese in Sumatra do 1,000 quite easily, and a Chinese coolie on contract will finish 1,500 .

The usual practice on an estate where routine work is being carried on is to allow so many coolies to $2,000,4,000$, or whatever 


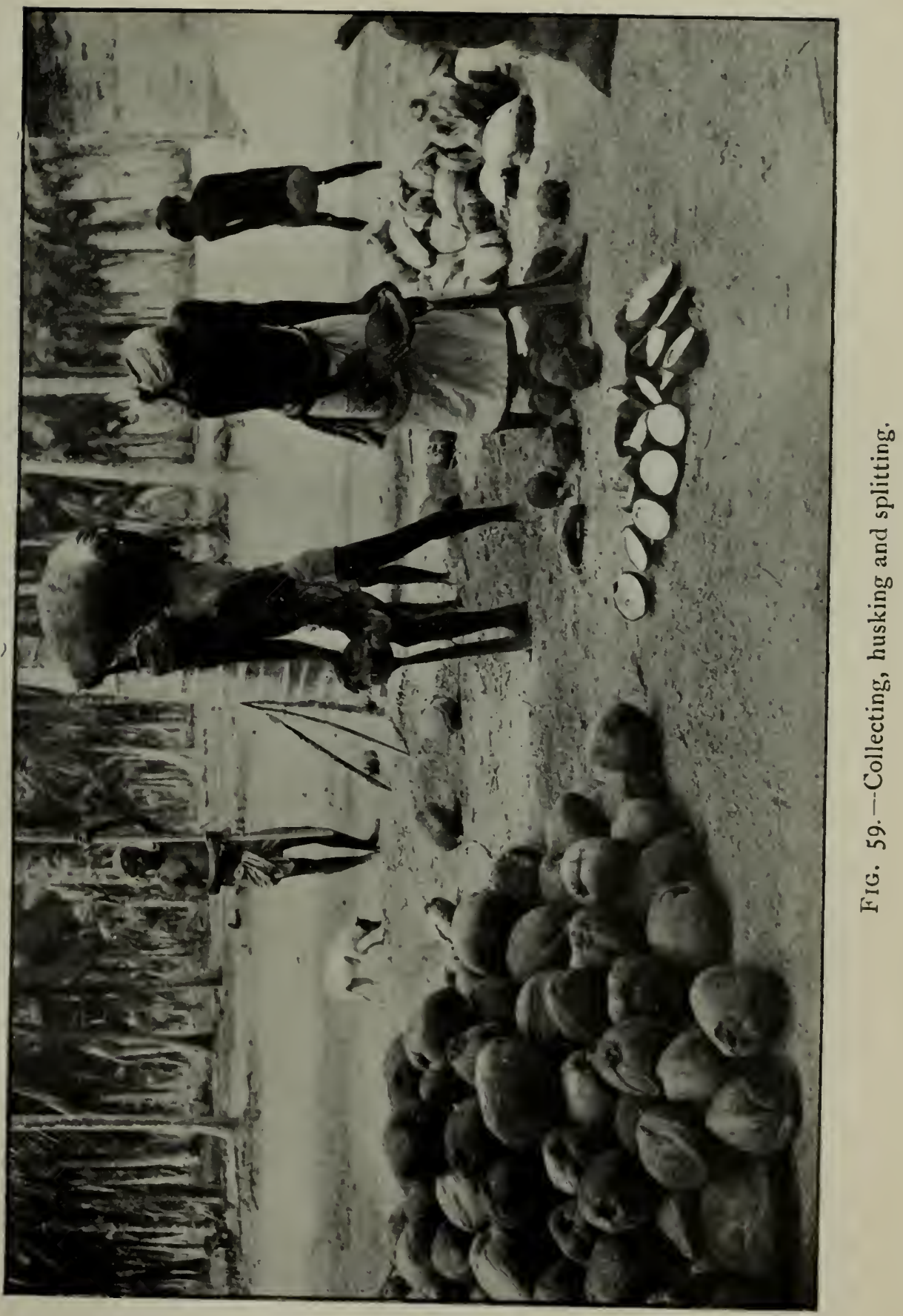

Face p. roq. 



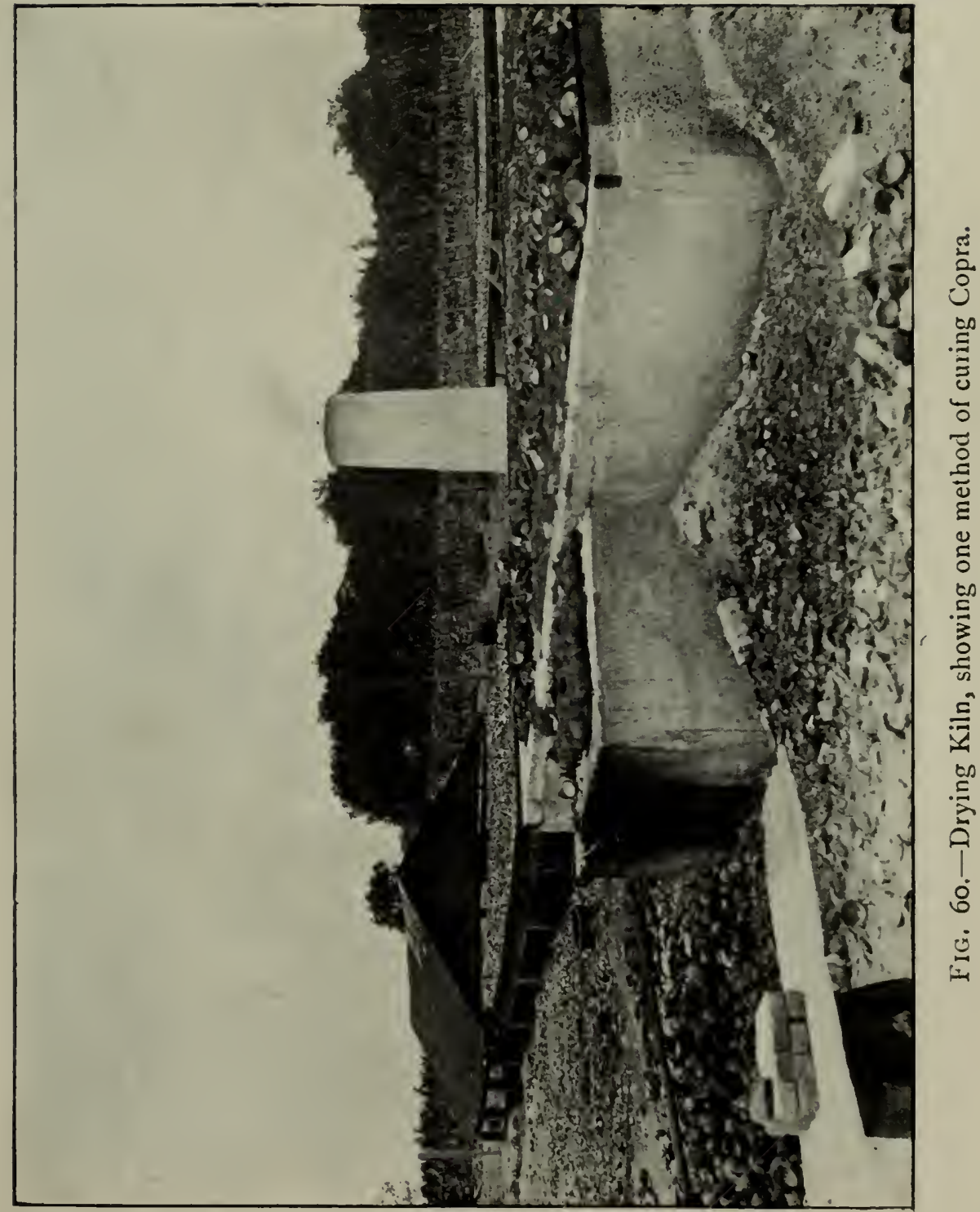

Follow 59. 



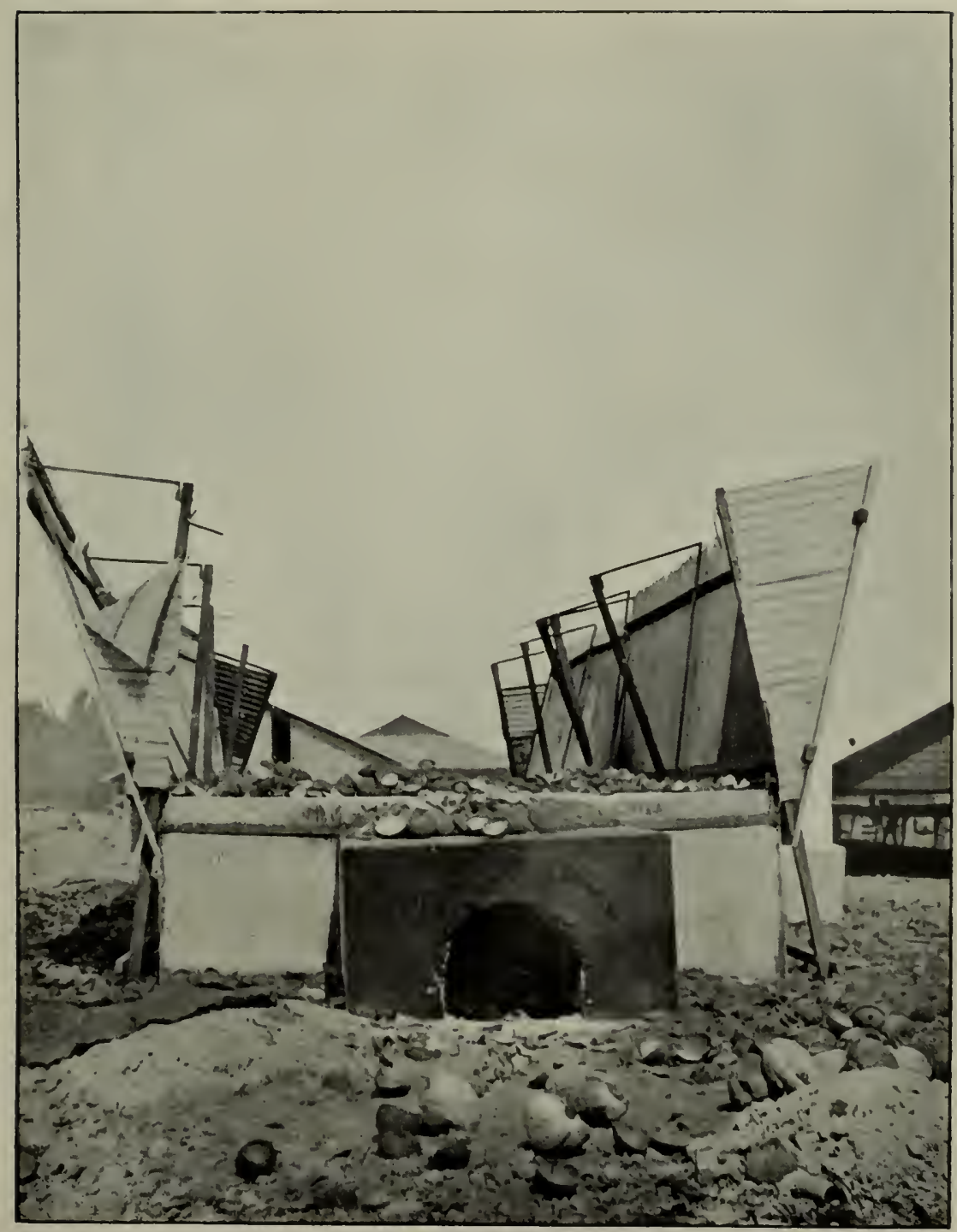

FIG. 6I.-Drying Kiln, showing furnace and adjustable roof.

Follow 60. 



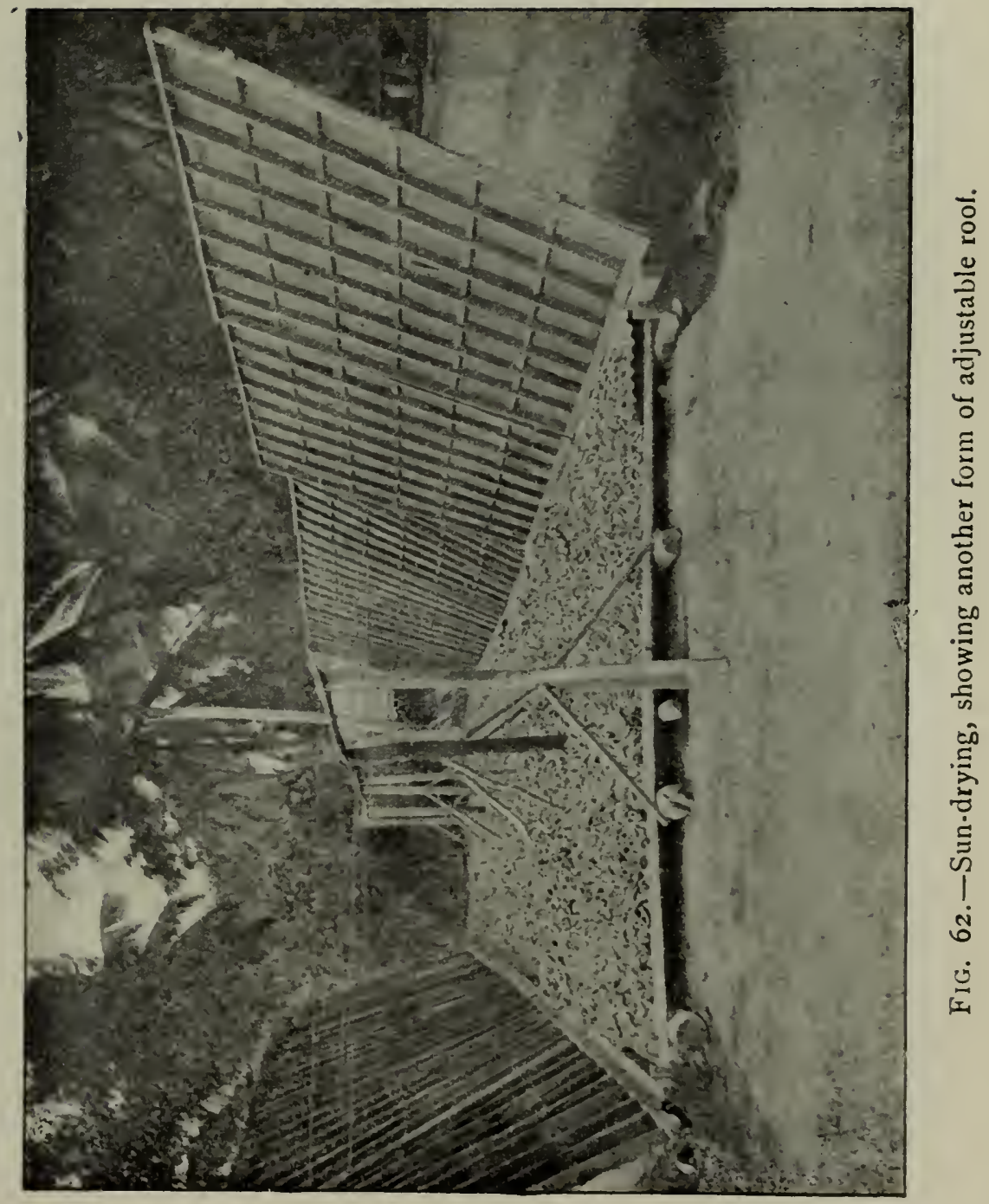

Follow $6 \mathrm{r}$. 



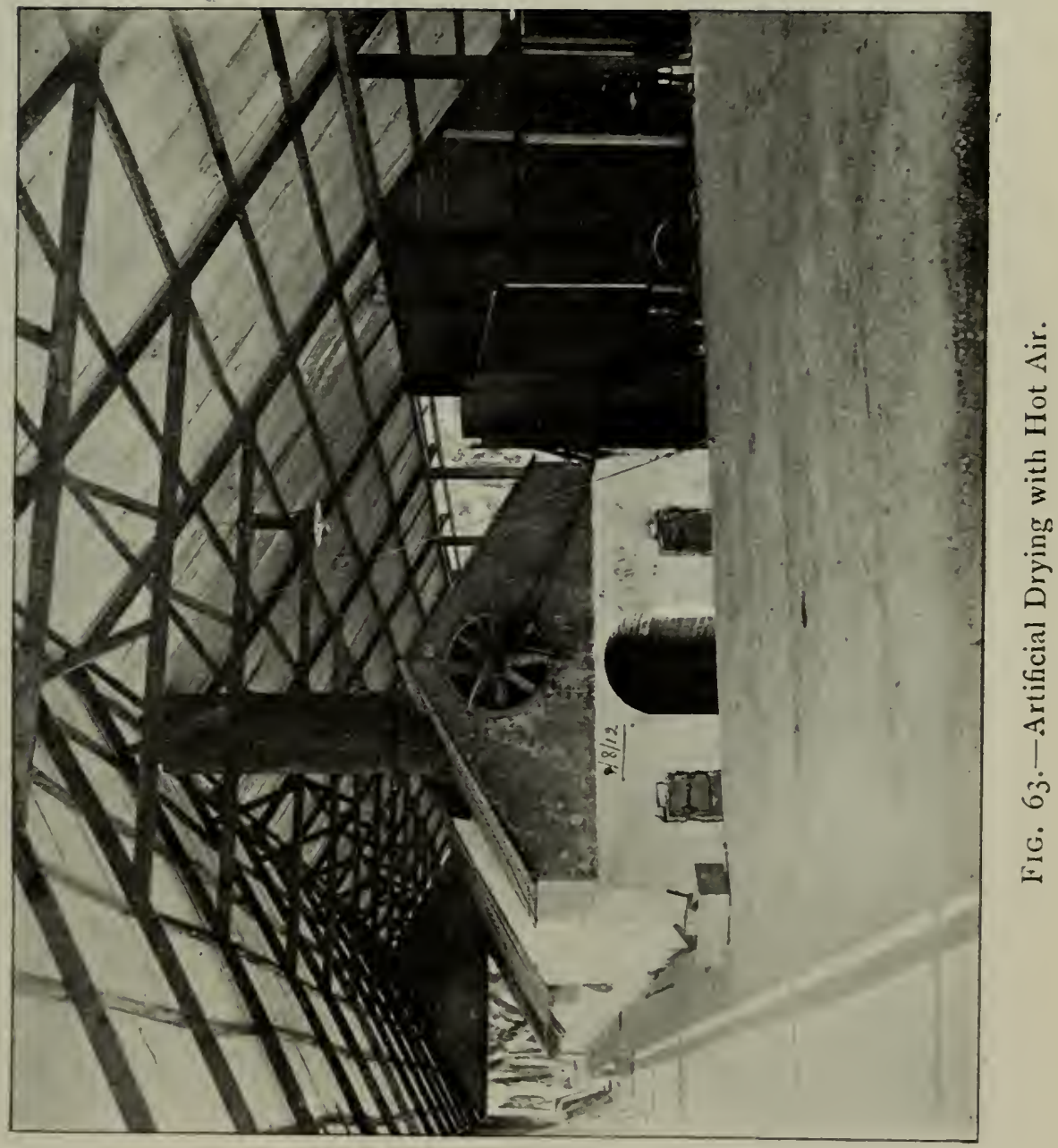

Follow 62. 

amount of nuts the drier is built to deal with at one time. These coolies do the husking, splitting, and transport to the factory, the number varying in accordance with the distance from field to curing place.

As copra can only be satisfactorily sundried during a few months in the year it is hardly necessary to set out here the advantages or otherwise of the process.

Artificial driers are now almost universally employed on European estates, and are capable of turning out the finished article to the complete satisfaction of local buyers all over the Straits.

The native method of curing on raised platforms made with slats of wood or bamboo, with a fireplace underneath, and a roofing overhead to keep the rain off, is good in its way because, if uniformly smoked by the creosote from the shells, husks, or whatever fuel is used, the copra is not so liable to take on mould even in the wet weather. But this principle cannot be put forward as the correct one, as it has been proved the result is a copra containing up to Io per cent. of moisture, and this would not be so acceptable to the buyers 


\section{GUIDE TO COCO-NUT PLANTING}

if shipped to Europe, not only on account of its colour, but also the amount of decomposition by bacteria that is nearly always apparent in most copra, i.e., with anything more than 5 per cent. water in it if kept for any length of time before the oil is expressed from it. It is therefore important to reduce the percentage of moisture to as low a point as possible, and this can be done either by kiln, rotary, hot-air or vacuum drying. The demand for a pure white copra becoming, as it is, stronger every day in European markets, it is necessary that when an estate is coming to the producing stage every inquiry should be made regarding an apparatus that is likely to give the greatest satisfaction.

Our illustrations show some of the kilns which are freely used, and the barbecues employed for the final drying in the sun. When the process of splitting is finished, the nuts which are now in two halves should be immediately placed in the kiln; unless this is strictly adhered to, and should any rain be allowed to fall on the kernel, the result is certain to be a copra of a bad colour, and in which a considerable amount of mould will be visible. 
By the same token the nuts, after being husked, must on no account be left in the sun for any length of time before being split open. The two operations must invariably take place on the same day, as if the husked nuts are allowed to split open by themselves as they will do if exposed to the sun, a mouldy and dirty sample of copra is bound to be the result.

From the time that the split nuts are placed in the kiln to the time that the kernel is able to be easily separated from the shell nine or ten hours are required if subjected to a temperature of $140^{\circ} \mathrm{F}$.

A kiln constructed with flues and baffle plates is a necessity to ensure proper distribution of heat.

The kernel, after being separated from the shell, is removed from the kiln, and.spread out on barbecues, provided with roofing which can be opened or shut according to the weather conditions prevailing. Illustrations show two of these barbecues, both of which serve the purpose.

Four days average must be allowed for the final drying, so that barbecue space has to be 
provided for accordingly. Barbecues should on no account be made of cement, or placed on ground level whatever their construction is. There should invariably be a space underneath to allow for a free current of air.

This very important point is often apt to be lost sight of.

Assuming that we have an estate of 1,000 acres in bearing it is producing, we hope:-

$$
\begin{aligned}
& \begin{array}{l}
\text { Nuts to Total nuts } \\
\text { the acre }
\end{array} \\
& \text { In its first year of yielding } \quad \ldots \quad 500 \quad(500,000) \\
& \text { ", second year } \quad \ldots \quad \ldots . \quad 1,000(1,000,000) \\
& \begin{array}{lllll}
" & \text { third year ... } & \ldots & \ldots & \mathrm{I}, 250(\mathrm{r}, 250,000)
\end{array} \\
& \text { ", fourth year } \quad \ldots \quad \ldots \quad \text { I, } 500(\mathrm{I}, 500,000) \\
& \text { ", fifth year ... } \quad \ldots \quad \ldots \quad 2,000(2,000,000)
\end{aligned}
$$

so that, taking two hundred and fifty working days in the year, one kiln capable of holding 2,000 nuts would be sufficient. In the second year two kilns of the same dimensions and so on. •

Drying on the barbecues takes place more quickly if the meat is cut up into small pieces, and as this process has to be gone through in any case prior to bagging and shipment, it is better to do it as soon as the kernels leave the kiln.

For the brick-kiln in our illustration no 


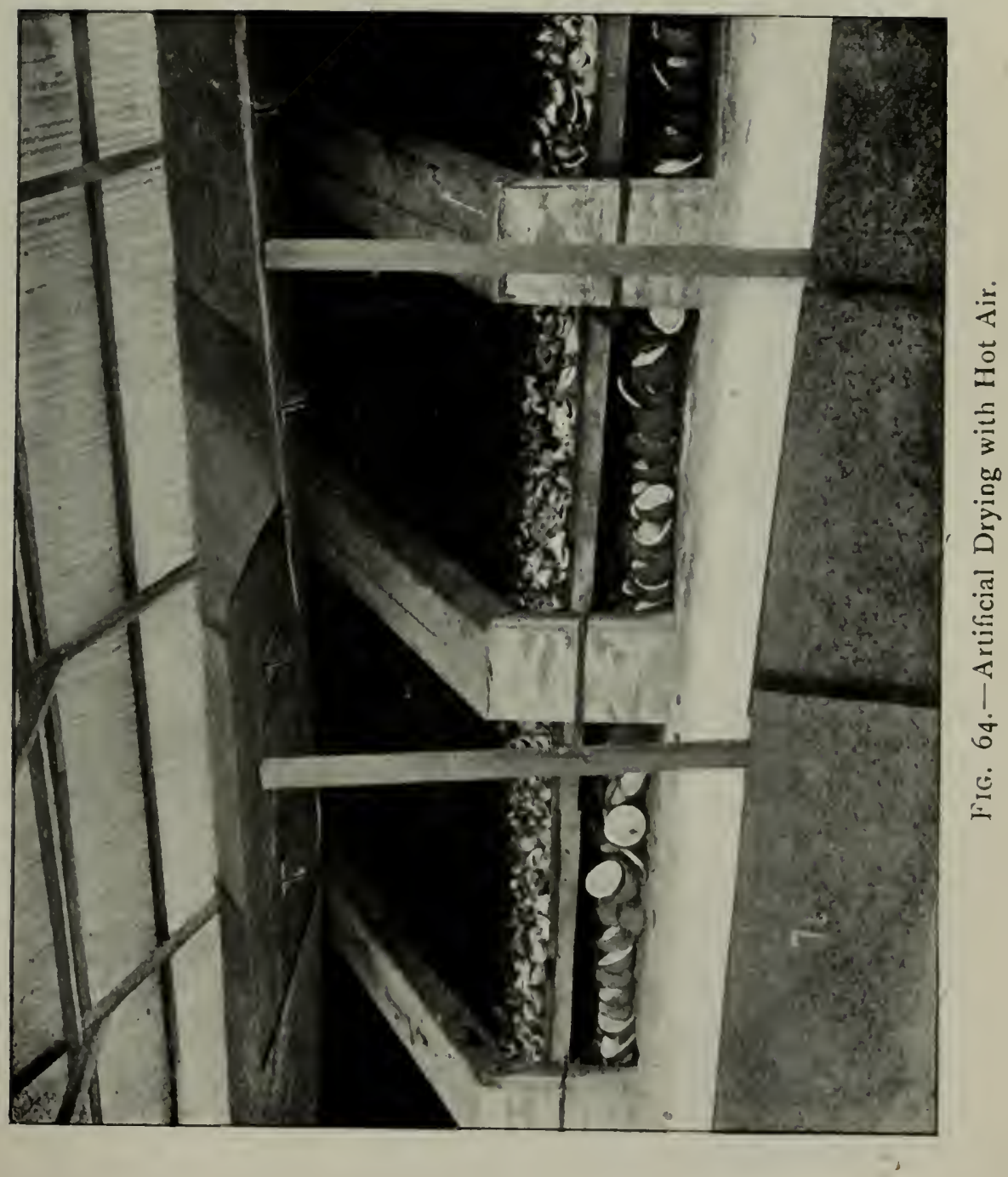



other fuel excepting the coco-nut shells is necessary, and on this account where a saving in firewood, \&c., is such a very great point the kiln in question has very strong recommendations. Of course the coolie who is in charge of the furnace will demonstrate almost to the point of conviction that firewood is a necessity, but with this type of kiln it is absolutely not so; constant application to the fire of small quantities of shell (not husk) is a thing a coolie does not, as a rule, believe in, as it robs him of a certain amount of tranquil repose which he considers himself entitled to.

We know of one place where several of these kilns are in constant use, and not a stick of firewood is ever required. It is well to realize that copra after being sold in a local market is very often mixed and quoted as such in the market reports. There being no real standard quality, no economy can be effected by sending to the market consignments up to Exhibition samples, which cost a higher rate to produce, but the tables are completely turned when it comes to a question. of curing for the European or American market. 


\section{GUIDE TO COCO-NUT PLANTING}

The price at which coco-nut butter has recently been produced by French and German manufacturers appears to have had a marked effect upon the sales of certain compounds in which cotton seed and other oils were used. The importation of raw copra into Germany alone had more than doubled in the three years before the war, and the extension of the industry then seemed to have hinged more upon the ability of the crushers to obtain supplies of the material than upon the consuming abilities of the market.

The raw material contains about 60 per cent. of fat, the melting point being about $76^{\circ} \mathrm{F}$. For the manufacture of an edible fat, the difficulty, up to quite a recent date, has apparently been to eliminate the odour.

This now seems to be successfully done by treating the expressed oil with steam, and neutralizing it with magnesia. The substance is then washed out with warm water and remelted. There appear, however, to be several methods of neutralization, in which the resulting substance is pure white, and something like lard to look at. The melting point of this is about $80^{\circ} \mathrm{F}$. and its congealing point $66^{\circ} \mathrm{F}$., so 


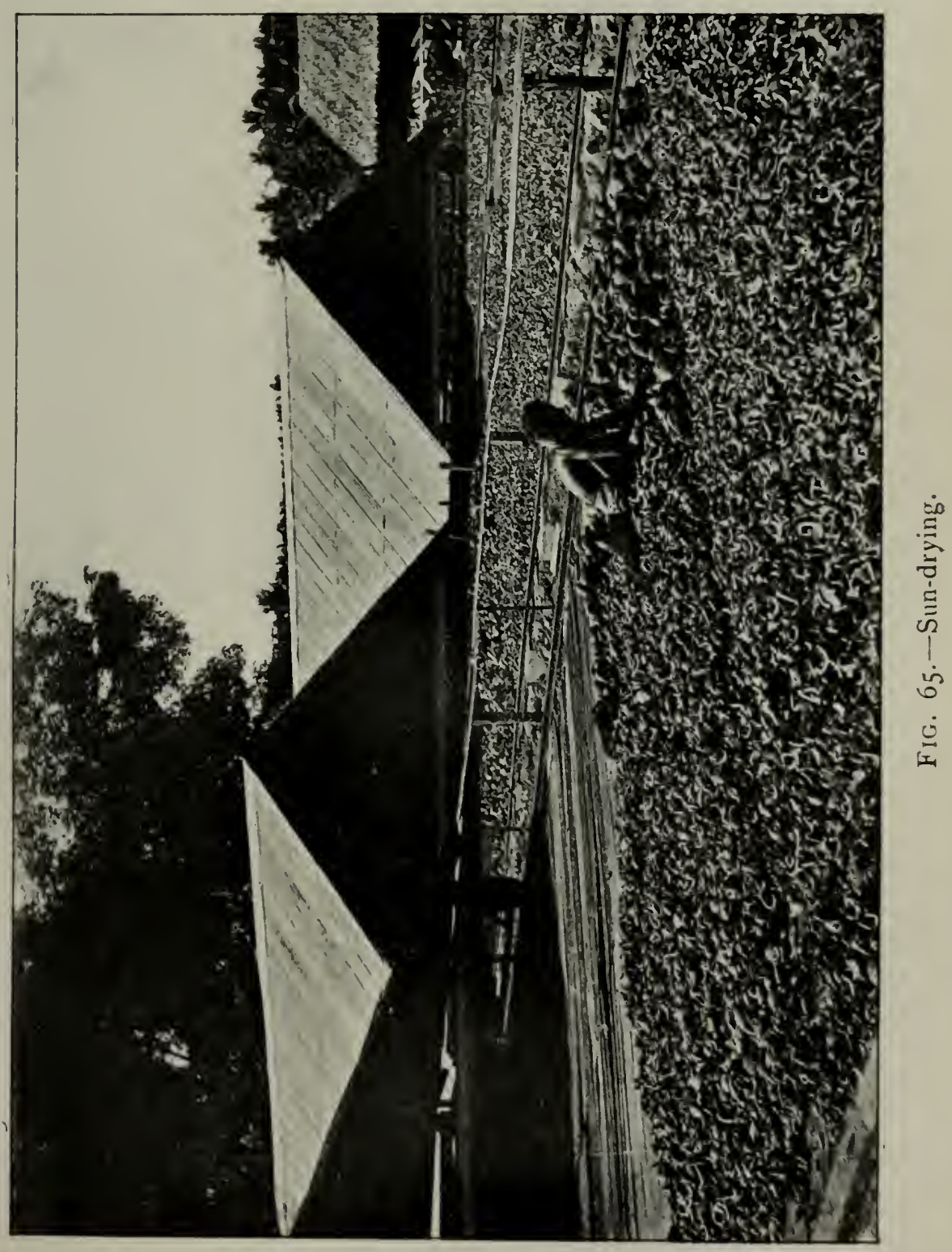



that it keeps well, and does not easily become rancid.

In dealing with the out-turn of nuts to copra there should be very little variation noticeable on a well organized estate in this part of the world. Amongst the native manufacturers it is quite the exception to hear of a better result than 4 piculs to $\mathrm{r}, 000$ nuts. This is brought about entirely by the practice of treating immature nuts, because the actual weight of copra produced by their methods of drying compares favourably enough when ripe nuts are utilized, but with care and good management it should not require more than 230 nuts to make I picul, or say 4,000 nuts to the ton. In the early yielding stages, especially where trees commence to produce at five years, the above result is uncommon owing to the fact that the nuts, though they may be, and generally are, abnormally large, the percentage of moisture is considerably greater than is found in nuts from trees of more mature standing. Where nuts are picked, and not allowed to fall by themselves, they should invariably be kept at least two weeks before being husked and split. Unless this rule be adhered to it 


\section{GUIDE TO COCO-NUT PLANTING}

will be unlikely that a better out-turn than 4,500 nuts to the ton will be obtained. Should one find places where the out-turn mentioned above is not reached, it may safely be asserted that the necessary supervision is not being given to this very important branch of estate management. Soil conditions have a very marked effect upon the constituent parts of the nut itself, and we have known instances where from the inception of the estate the average out-turn has not been less than a picul of copra to 225 nuts.

It does not take long to satisfy ourselves that the chief consideration in all these essential matters is close supervision. 


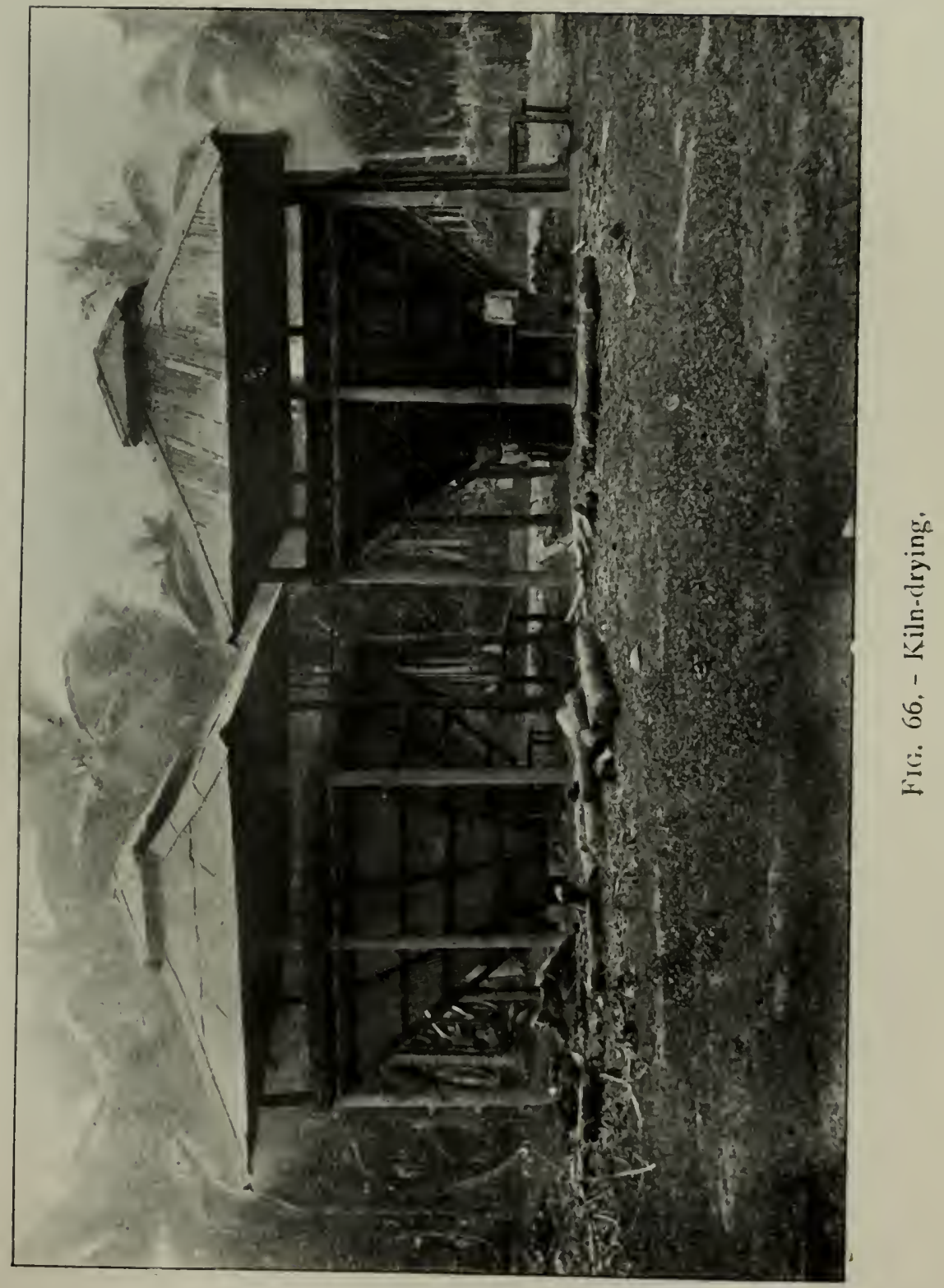

Face p. I12. 



\section{CHAPTER XII. PESTS AND DISEASES.}

In all kinds of agriculture, tropical or otherwise, we are brought face to face with pests at every stage of development.

Perhaps the most common, and at the same time the most harmful to the coco-nut, are the beetles. Much has been written on the subject of the beetle pest, and there is no disguising the fact that this can become the worst possible menace to a coco-nut property.

In the ordinary course of things, however, it is not so in the majority of places in the Malay Peninsula, in fact it is rather rare to come across any place either European or Native that is now suffering to any extent.

A well - organized department of the Federated Malay States Government has done more perhaps than most countries towards the stamping out of the "Oryctes" by a very systematic raid on the breedirig places, and one significant fact is worthy of 


\section{GUIDE TO COCO-NUT PLANTING}

mention here, viz., that the writers of this work had considerable difficulty in obtaining a photograph sufficiently representative to demonstrate to those who have not seen it the damage capable of being wrought by the black beetle, and as regards the red beetle we have still been unable to procure a photographic demonstration of the havoc that we know is done by this pest.

\section{The Red Beetle.}

This insect after it is fully developed does little harm to the tree. It generally lays its eggs at the base of the branches covering the cabbage, and so well are they secreted that the harm being done is often not detected until it is too late to save the tree. The grub does the havoc, and soon after it is hatched commences its operations by gnawing and boring its way inwards until it reaches the very heart of the cabbage. The work is so rapid and the effects so deadly that these grubs are very much more dangerous to the life of the tree than the black beetles, but fortunately the red beetle is scarcer, in fact there is very little of it in the Federated Malay States. It 


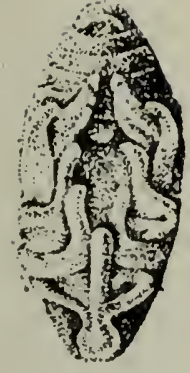

Red Beetle (pupa).

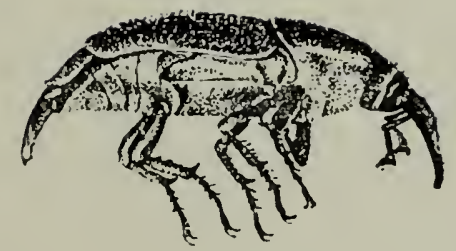

Red Beetle (female).

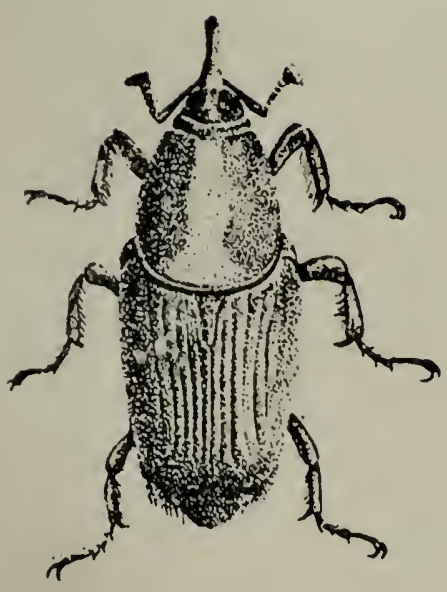

Red Beetle (male).

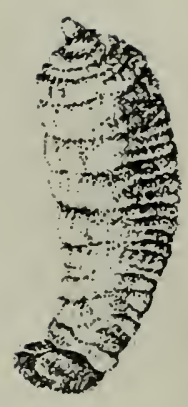

Red Beetle (larra).

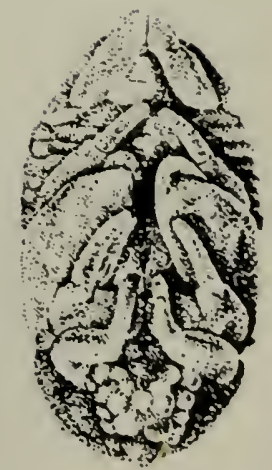

Black Beetle (pupa).

lifi, 67. 

occasionally takes advantage of the borings made by the black beetles to lay its eggs in these cavities, only here it is more easily discovered in searches for the black beetle, so that with proper supervision it may or should be caught before any serious harm has been done. Apart from these haunts there are many other breeding places : a few will be found in manure and rubbish heaps, more again in the rotten dead stumps and roots of nibong sago and serdang palms, and most numerous in a coco-nut tree from which the top has fallen away through their ravages or decayed stump of the same tree. Here the grub will be found covered in a cocoon made of the fibre, and so well does it conceal itself in this way that it is practically not noticeable to the ordinary view and is only discovered when the inside of the tree or stump is scooped out, which must be done effectually, otherwise one or two of the cocoons may escape observation. If allowed to get in the slightest degree out of hand this pest could and would probably be the ruin of a large portion of the property. 


\section{GUIDE TO COCO-NUT PLANTING}

\section{Black Beetles.}

It is on account of their great numbers that these beetles are so much to be feared, and of the fact of their borings, as we have stated previously, affording a means for inroad by the dangerous red beetle. There absolutely seems no limit to the beetles and their grubs, provided the breeding places are sufficiently abundant; and these comprised not only those mentioned in connection with the red beetle, but a great many more, such as underneath and in dead palms of several kinds, sawdust, paddy straw, coffee and paddy husks, and refuse heaps of all descriptions. The grub especially may be found in thousands in quite a small dung heap. When the beetles reach maturity they leave their breeding grounds, and it is then that they make for the coco-nut trees and commence their ravages, slightly above and near the top of the cabbage, boring their way downwards and laying their eggs at the end of the cavities so formed. Owing to their constant and continued onslaughts they do great damage to the trees, nipping with their mandibles the embryo leaves and the stem that bears the fruit just at the time they are 


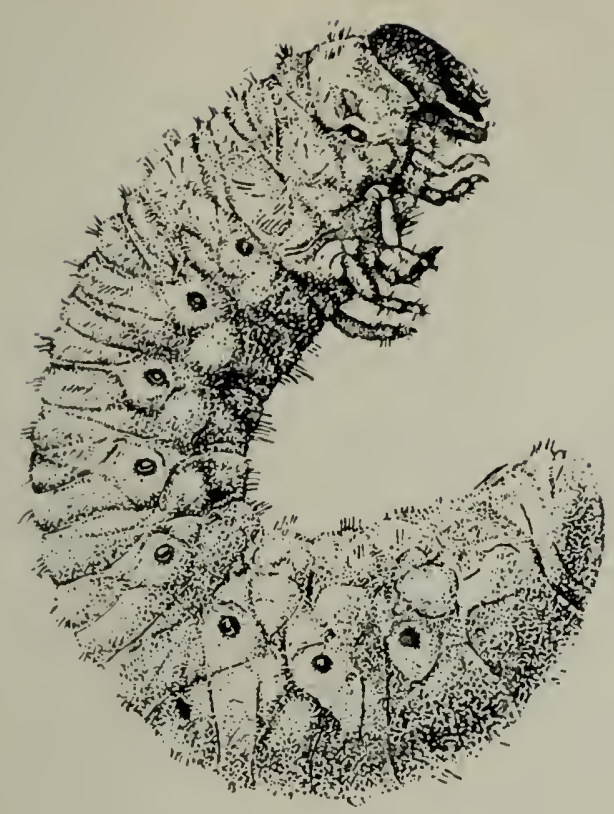

Black Beetle (larva).

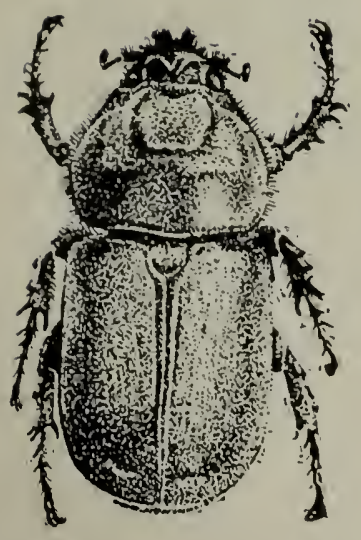

Black Beetle (female).

Face p. 116.

FIG. 68.
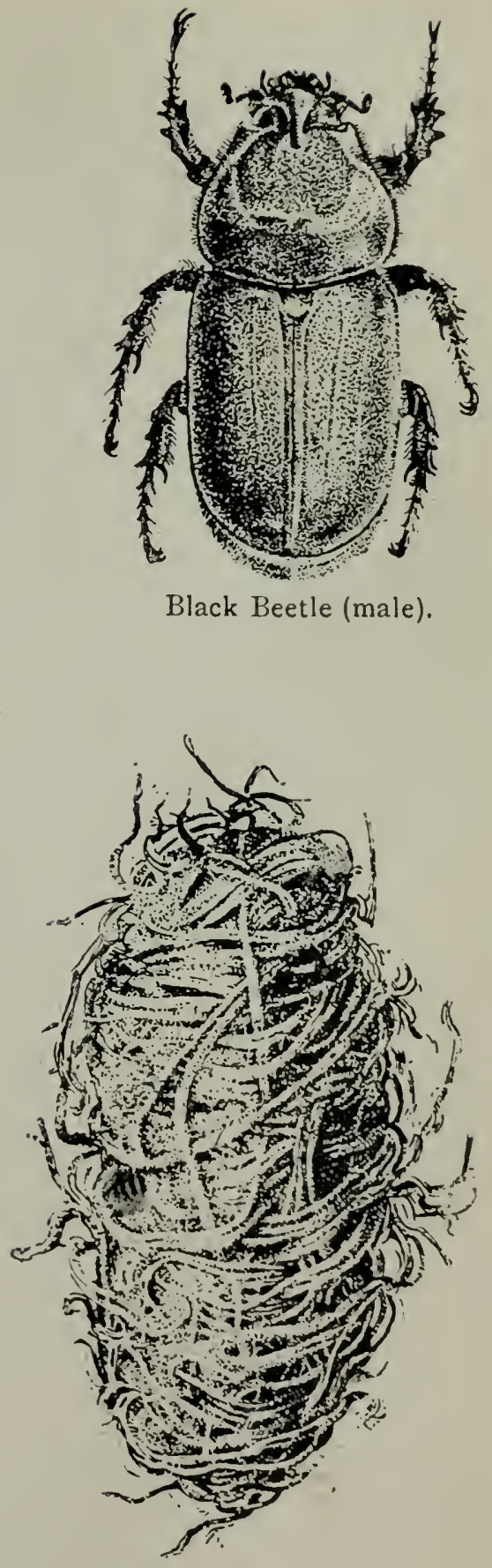

Cocoon. 

forming; the leaves in consequence present a frayed or jagged appearance, and what is more serious, the stem often is killed, and if it does manage to shoot out, probably bears little or no fruit.

There are many varieties of oryctes, nearly all to be found in the Malay Archipelago, and we have heard them often described as leaf beetles, but all the varieties are found on the fronds when leaving the pupa stage, so that this is rather a misnomer. On a wellsupervised plantation it is rather uncommon for the black beetle to attack old trees excepting in individual cases.

In addition to the breeding places already mentioned, it is seldom realized to what extent the larvæ are found in loose top soil, especially on virgin land. We have seen proofs of this on low-lying land during the heavy rainy season, when clearings were completely flooded, and after the water had subsided the land, then dry, was simply covered with dead larvæ. of the oryctes.

It has been often remarked that on young clearings where a cover plant is grown, it is rare to find trees attacked to any serious extent 


\section{GUIDE TO COCO-NUT PLANTING}

by beetles, thus clearly demonstrating that the top soil under these conditions does not form an attractive breeding ground. When the pest first makes its appearance, the trees should be carefully scrutinized at the place where the adult female mostly chooses to burrow. Burrowing is not only to lay eggs, but for food also, so that great damage can be done if careful watch be not kept to prevent the formation of the fibre cocoon.

Their habits are entirely nocturnal, and it is very often impossible to trace their breeding grounds, but it must be remembered that the males make burrows as well as the females, and it is supposed that they accompany the latter at the time of egg-laying.

Do not remove dead leaves, \&c., from the trees to the extent that they may encourage the attacks of adult beetles.

Instances have been recorded where red beetles were never seen until the trees were trimmed by cutting off the branches, so that all leaves, \&c., should be left on the tree until nature disposes of them at her own time and in her own way. They should be allowed to fall by themselves, and on no account whatever be cut. 


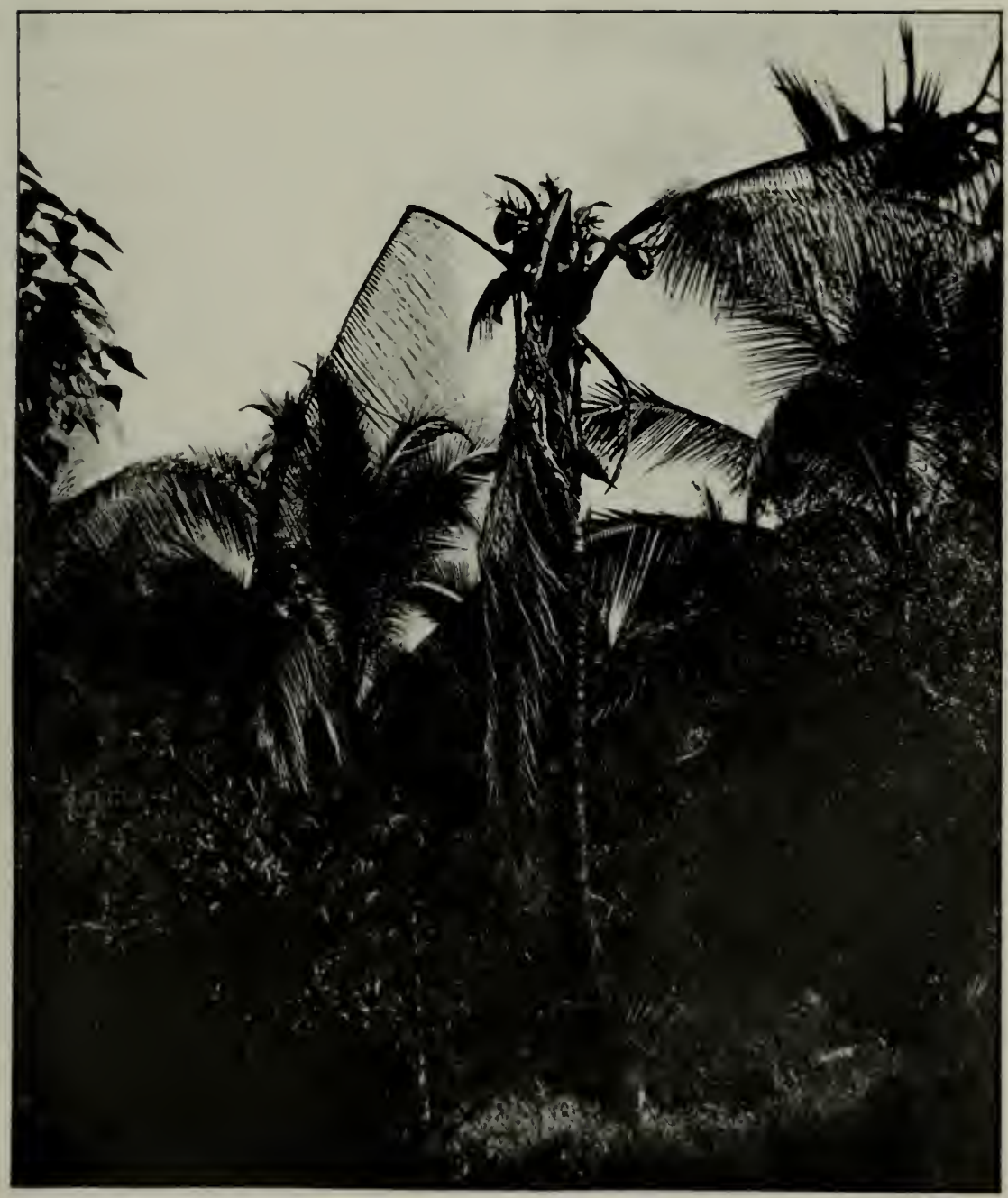

FIG. 69.-A Palm killed by Rhinoceros beetles. 

Managers of estates are sometimes surprised when in the third or fourth year (a period from planting when attacks by beetle are not only to be looked for, but have often to be reckoned with as a matter of course) the oryctes turns out in considerable numbers, and many coolies have to be requisitioned for weeks for a regular inspection of the trees, and for collecting the beetles from their leaves.

Remedial and Preventive Measures.

When the beetles appear in any number it is evident there must be some breeding grounds about. The first thing to do is to search out and destroy all the haunts such as have been described, and everything that is likely to harbour the pests should be burnt. Attention must also be given to the trees themselves, and with regard to this, while the trees are young, the beetles in the first place will be found on the leaves themselves and easily collected. If, however, the beetle has already found its way into, or near, the cabbage of the palm, it should be immediately dealt with. For this purpose a stiff bit of wire about 18 in. long with a barb at the end is 
progged into the hole, and answers very well for collecting the beetle or beetles that may be in the trees. These must of course be destroyed. As soon as the beetles have been extracted from the holes these should be filled up with a mixture of zotal (creosote) and dry sand, in the proportion of a quarter of a pint of zotal to one gatang of sand. Even if no beetle is found in the holes the same treatment should be followed, as it effectually prevents any other beetles from making use of the same haunts. Again (and this is most important), fine sand should be applied copiously to the cavities at the junction with the trunk, as this makes it very difficult for the beetle to make any fresh inlet to the trees.

\section{General.}

While the plantation is young, or if there are a great number of trees not in bearing, it will of course be necessary to keep some coolies to look after and give special attention to the beetles; but when all the trees are in full bearing, or nominally so, and the plantation has been previously well maintained, it may be possible to keep away any real harm from 
attack by beetle merely by employing coco-nut collectors while collecting the nuts, generally every two months, to extract the beetles from the trees. This is the common practice in the Straits Settlements, but, as remarked above, there is generally little cause for alarm as to. damage to trees in full bearing on a well cared for plantation.

RAts.

The usual complaint about rats in Ceylon. is that they climb the trees that are in bearing, attack the half-grown nuts, and in this way do: enormous damage, but there is, as far as our. experience goes, rarely any very great trouble on this account in any of the districts we have. come across, though of course we have seen. certain instances where the rats had built their nest and had their young all round them in the crown of the tree. Unfortunately, the. danger from rats in certain districts of the. Federated Malay States is of an even more serious nature. In the district of Bagan Datoh, Lower Perak, and on the Selangor side of the Bernam River, hundreds of acres of young: coco-nut plants varying from three to fifteen months of age, have been destroyed by them, 


\section{GUIDE TO COCO-NUT PLANTING}

in one single night - nothing more or less than an actual plague of rats, which come in thousands, and this wholesale destruction has been known to continue night after night. The curious thing is that the next morning hardly a rat will be found over the premises where the plants have been destroyed; the pest entirely disappear from one place as suddenly as they came, moving perhaps the next night to the neighbouring estate, where the same detriment is done. If it was a matter of even a fair number of trees scattered here and there being destroyed, the case would not be so bad; some of the suggestions, however, that have been made for the protection of the young plants might prove adequate, especially the method mentioned by the Government Entomologist, F.M.S., Mr. H. C. Pratt, in his Agricultural Bulletin for February, I 9 I 4, as follows:-

"Out of a piece of zinc $\mathrm{s} 8 \mathrm{in.} \mathrm{long}$ and $\mathrm{I} 2 \mathrm{in.}$ wide, an arch is cut at the middle of the longer edge, measuring approximately 7 in. wide at the base, and 5 in. high.

"The nut itself fits into this arch, and by drawing the tin round the tree a cylinder about 


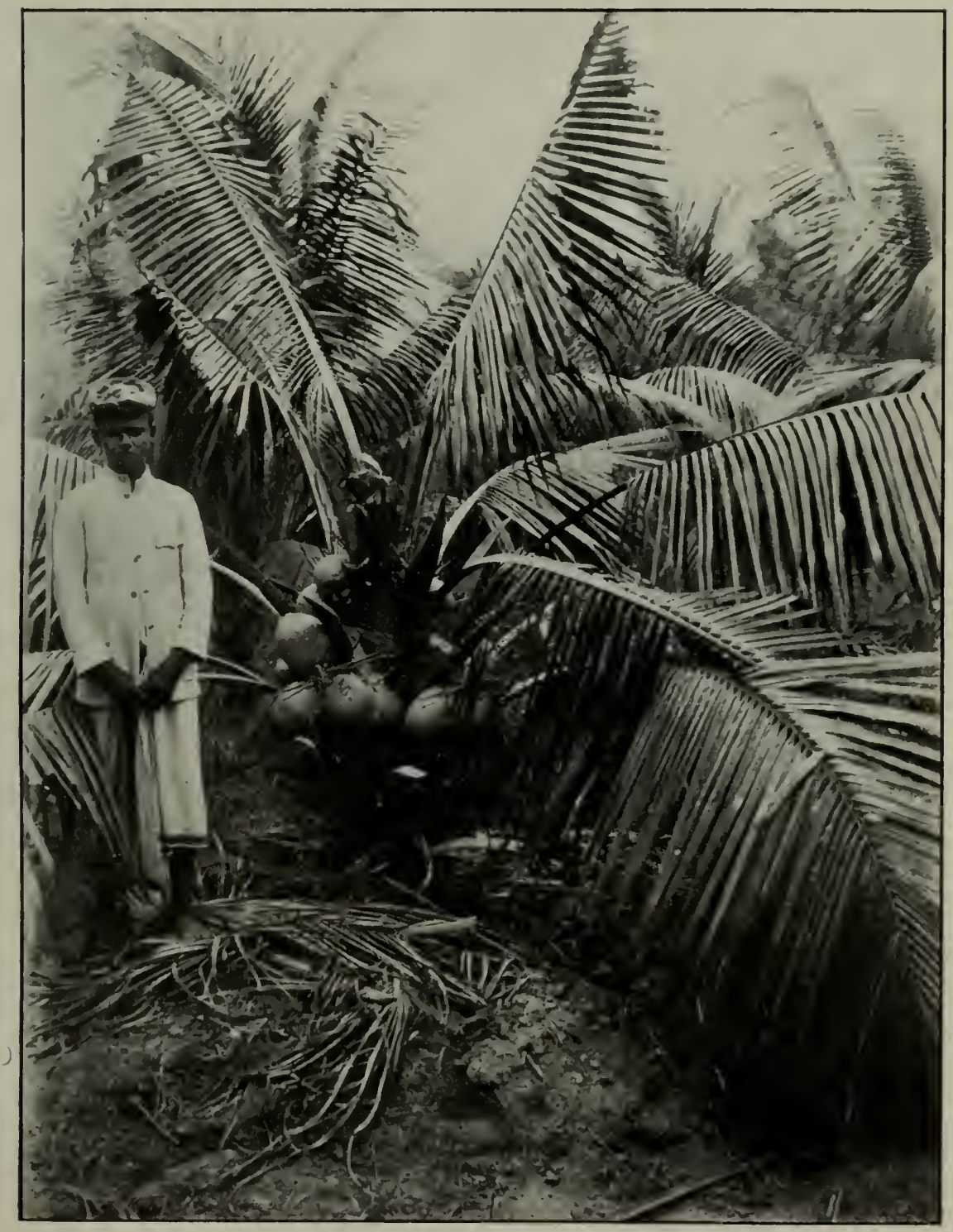

FIG. 70.-A King Coco-nut attacked by beciles. 

5 in. in diameter is formed, enclosing the young tree which practically fills the cylinder. The base of the cylinder on either side of the arch is buried about 3 in. in the ground, thus enabling the top of the arch to fit tightly over the upper part of the nut, and no rat can harm a young plant protected in this way, for if access is obtained by burrowing, there is no room for the rat to work within the enclosure."*

This pest, however, is only known to have been really serious in places where the estate was in the immediate neighbourhood of native holdings and padi fields, and even in the districts mentioned above, one of the most significant facts recorded is that where one estate clean-weeded lost practically all their young plants two years in succession, portions of the estate next door which had a covering of sweet potato came off nearly scot-free. Whereever tried this crop has proved a very real benefit in distracting the rats' attention from the coco-nut plants and affording them what would appear to be more succulent food.

* Reports received from estates where this scheme has been put into practice demonstrate that the results are in every way encouraging. 
Wild Pigs.

These have to be reckoned with on almost every coco-nut estate, and are very often a source of endless trouble. To prevent their inroads it seems to be a popular idea that fencing with wire is the most useful method. Of course, there may be, and no doubt are, certain districts in which it is difficult to obtain at a reasonable price a sufficient quantity of timber, or where the utilizing of it would involve a specially heavy outlay, but there are not likely to be many such districts, so that no greater mistake is made as a rule than by ordering miles of barbed wire for an estate where any quantity of suitable timber is available.

No barbed wire fence that we have seen has ever been satisfactory in keeping out wild pig, and in a large number of instances the purchase and erection of this has been pure waste of money.

Quite the most effectual plan, and the cheapest, is to utilize the timber that remains from the newly burned clearing in the following manner: select the straightest pieces of about 6 to 8 in. in diameter and have these 


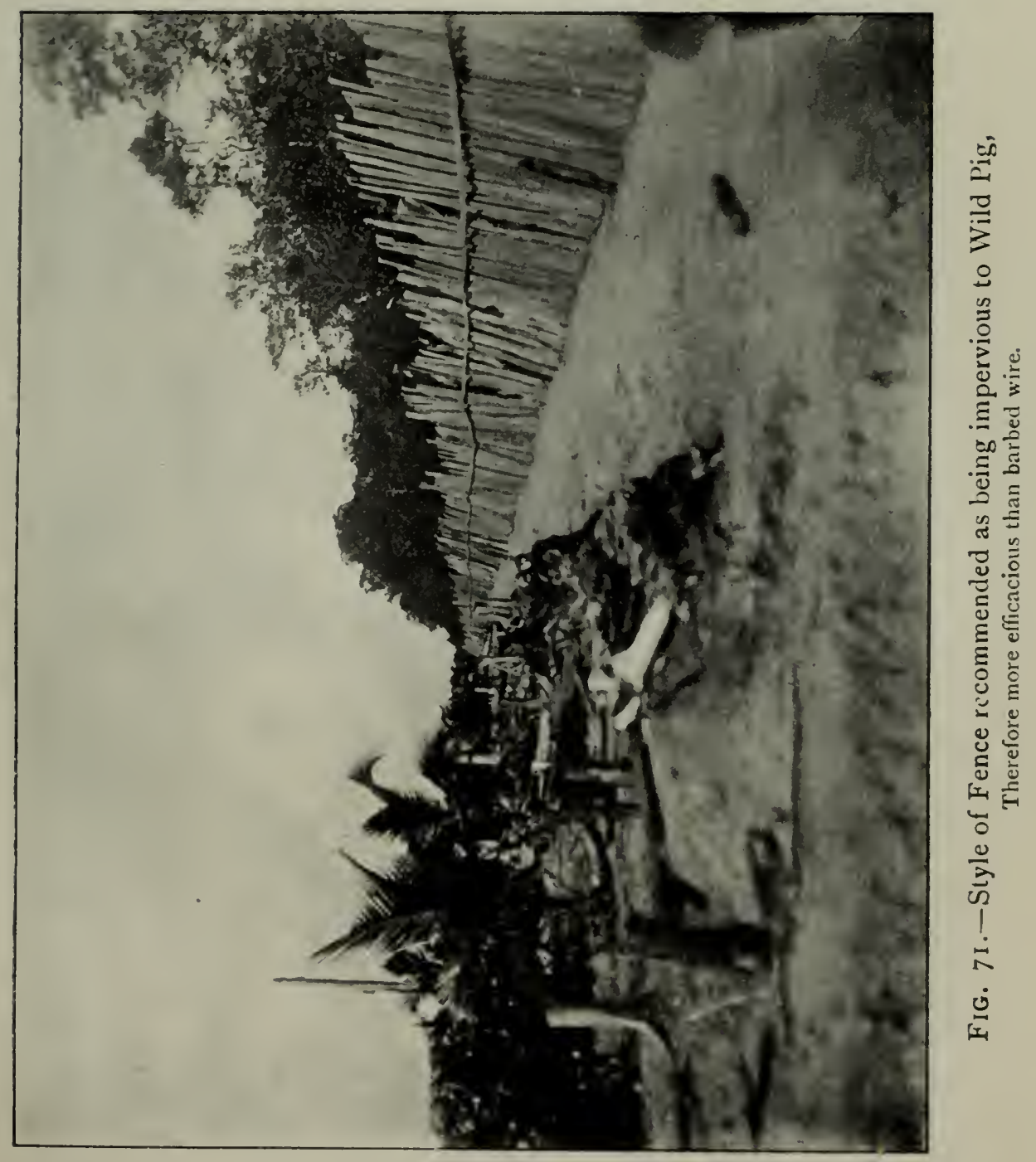



cut into lengths of about $8 \mathrm{ft}$. Sharpen one end and place vertically, burying $2 \mathrm{ft}$. in the ground; put these in a line with one another alongside the boundary of the clearing so that, excepting for the space of an inch or two, they are practically touching. . To keep rigid and in position it is now necessary to nail, or by means of galvanized wire to fix cross pieces about $2 \mathrm{ft}$. from the top of the posts: you now have a fence absolutely impervious by pig, and at a very moderate cost. This is just the sort of work that an Indian coolie does admirably, and at less than half the price of local contract labour.

It is not actually necessary to use hard wood posts, as in any case the fence is not likely to be required for more than twelve or eighteen months. It has been argued that a wire fence is cheap because it can be moved and utilized in other parts of the estate, but this is only theory, and in practice it is not cheap in any way. It may not be effective for one thing, and for another it will be found a labour of exceeding great difficulty when it comes to rolling up and moving the staples, wire, and posts. 


\section{GUIDE TO COCO-NUT PLANTING}

Do not be persuaded into employing watchmen and supplying them with guns and countless rounds of ammunition, as the sort of people obtainable in this country for this kind of work are quite useless, and often do more harm than good. They will be found an expensive luxury.

Hunting the neighbouring covers periodically with a pack of dogs is much to be recommended, because constant worrying of the pigs if not actually killed in any number is sure to have a beneficial effect.

As with rats so also with pigs, and we have seen almost incredible instances where these animals have been attracted by intercrops which they have devoured wholesale, and left the coco-nuts alone; we can vouch for one instance where a clearing was planted, and no fence of any kind placed as a barrier. Wild pig abounded in the immediate neighbourhood, and soon made their appearance in the clearing; great damage must inevitably have resulted but for the cover of sweet potato, the roots of which the pigs demolished in large quantities, but not a single coco-nut plant was touched. 


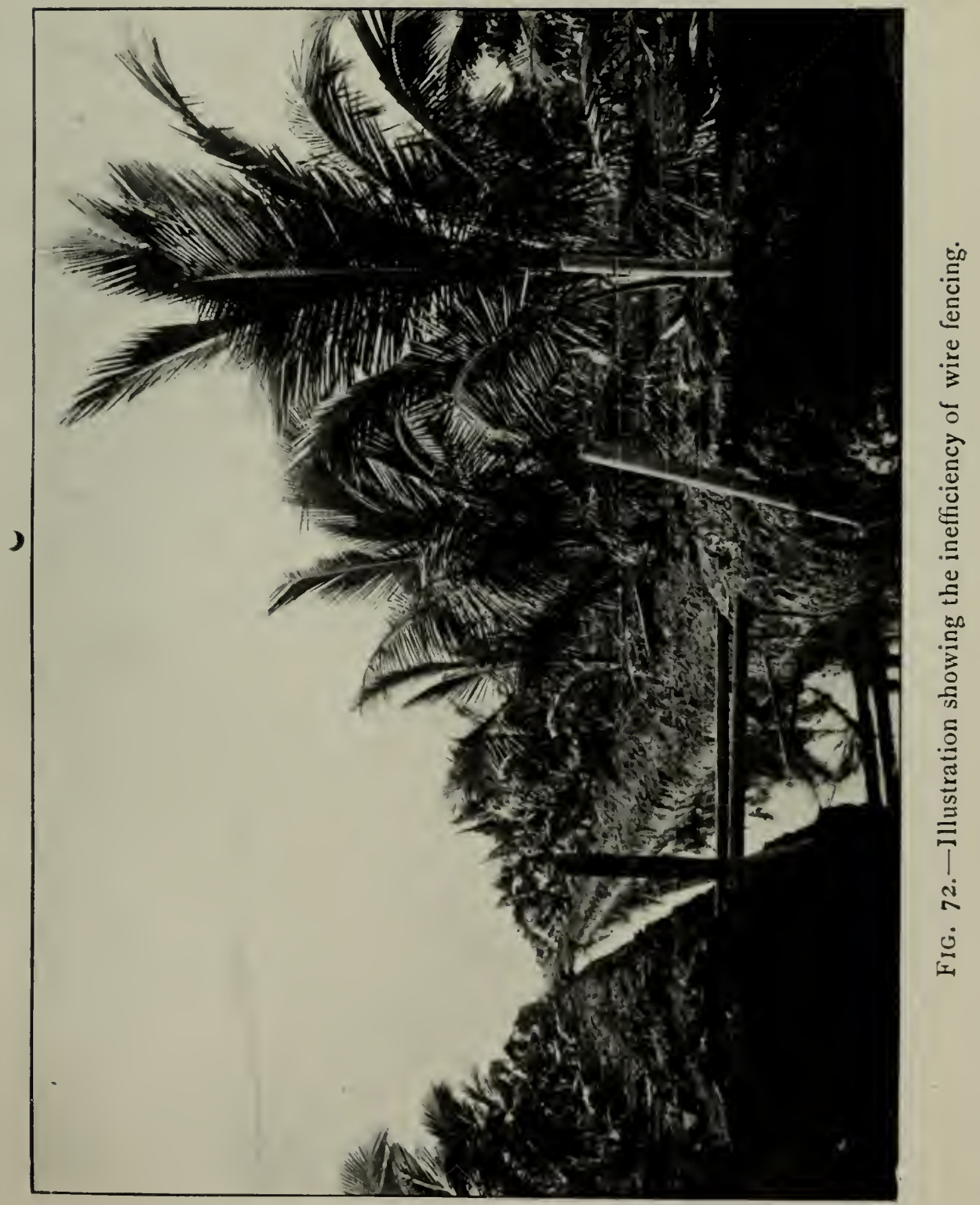



SquirRels are responsible for a considerable loss on nearly every coco-nut estate in bearing, and the only practical method of combating this pest is by trapping or destroying the nests. A native in charge of a gun with the object of shooting them on the trees does more harm than good as a rule, owing to the destruction of blossom and young crop which is bound to occur in the process, also the number of rounds of ammunition required to secure a decent "bag" renders this method of extermination too costly to recommend.

Porcupines.

Fortunately damage by these animals is comparatively rare, but when once they do appear they must be considered a source of great danger to young palms from the planting stage up to the end of the second or third year.

Their habits like most other pests being nocturnal the presence of them even in small numbers is a matter by no means easy to deal with.

\section{Locusts.}

These insects which have lately made their appearance and simply infested some of the 
districts in the Federated Malay States, are capable of doing very serious damage to newly planted areas. The; have, in fact, been known to completely destroy acres of young, healthy plants, but so far as we have been able to ascertain the damage done has been confined to one district, and it has not up to the present been noticed that when searching for food the coco-nut stands out as any particular attraction for the swarms as they fly; it would almost seem to be the reverse in view of the extent to which swarms of locusts abound in districts where there is a considerable area under coco-nuts.

We must confess, however, to a certain feeling of insecurity so long as this destructive pest is with us.

Very strenuous efforts and a good deal of money are being expended by the Government Department of Agriculture in worrying the pest, and there may be said to be at the present time every reason to be sanguine about the ultimate extermination of it.

\section{White Ants.}

The troublesome part of this pest is the secret manner it works towards the demolition 


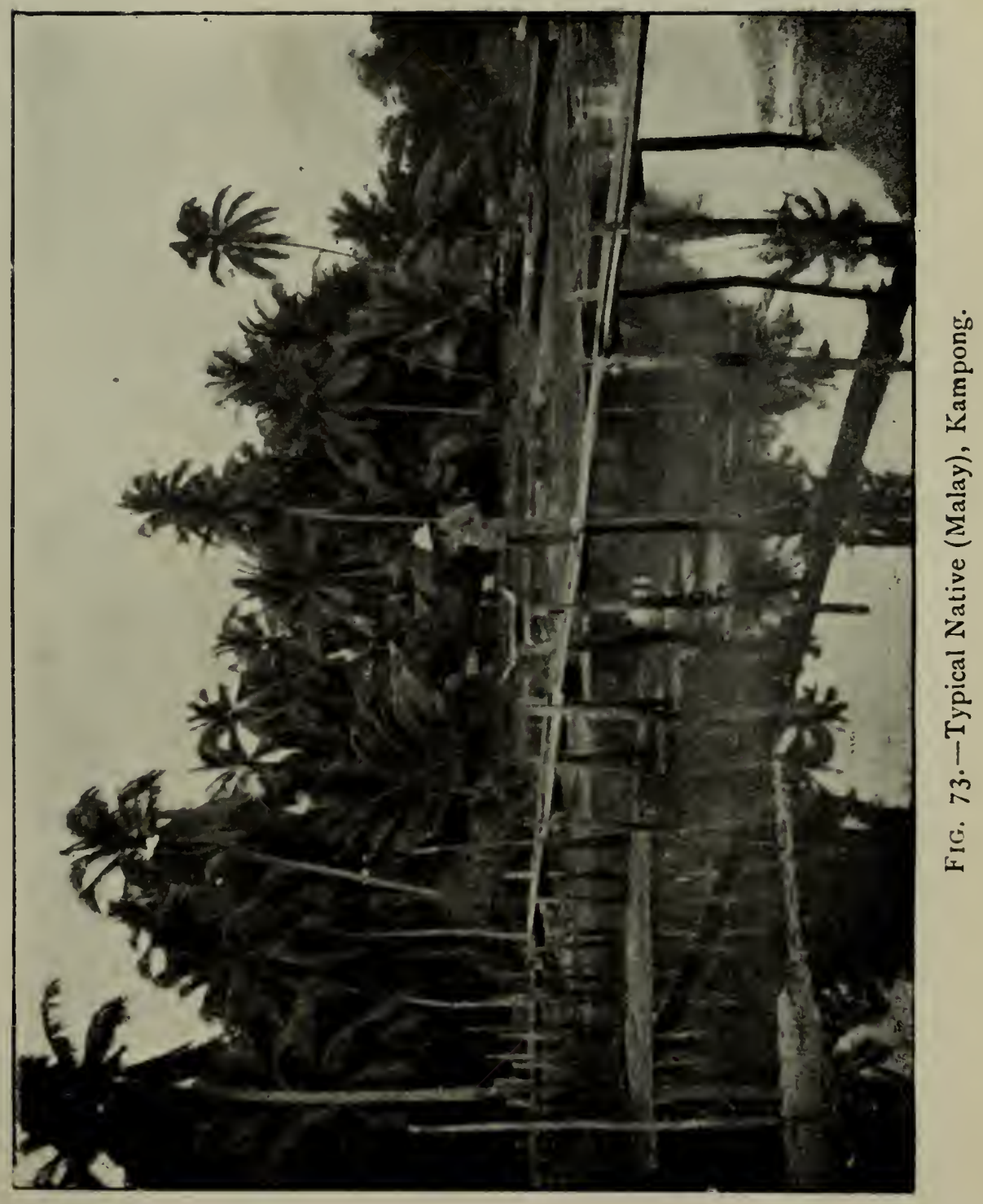

Face p. 128. 

of its prey. The coco-nut tree having no taproot the termites invariably commence their ravages about a foot to 18 in. below the "collar," or spot where in a young tree the lowest fronds protrude, and they work their way up to the heart of the tree which is successfully demolished if allowed sufficient time: the work of complete destruction does not take very long.

The palms do not, as a rule, become an attraction to the white ants until they are about two years old, at least it is very rare to see young plants touched by them excepting in one or two isolated cases over a large area, neither have we seen many cases where a coco-nut tree in bearing has been actually killed by these termites.

It is during the second and up to the fourth year from planting that a special watch has to be kept, and as previously mentioned it is often no easy matter to discover their presence until a good deal of harm has been done. As it is also at this stage of development that the black beetle commences to get busy, it is possible for the coolies when engaged in searching for these to observe and report any cases where the ants 
have begun their attack. To exterminate them from individual trees the best and surest method so far discovered is by the use of the now well known "Universal Fumigator," and in most soils it is possible to use this machine on trees up to two or three years old; after that period the matted roots; stretching as they do a considerable distance from the stem, make the operation a matter of some difficulty.

Should the white ant "machine" prove in certain cases ineffectual, it will be found necessary to have recourse to far more drastic measures, and the following treatment usually brings about the desired result: First of all the lower fronds must be cut off flush with the stem by the use of a sharp pruning knife; by cutting away also the roots round the butt and digging a deep circular trench or bowl, the seat of the trouble can, as a rule, be got at.

Boiling water should first be poured over the lower part of the stem so as to kill the ants actually visible at the time, subsequently the whole of the lower part of the tree should be plastered over with a mixture of slaked lime and common salt. Trees that have thus been handled require constant watching, and 


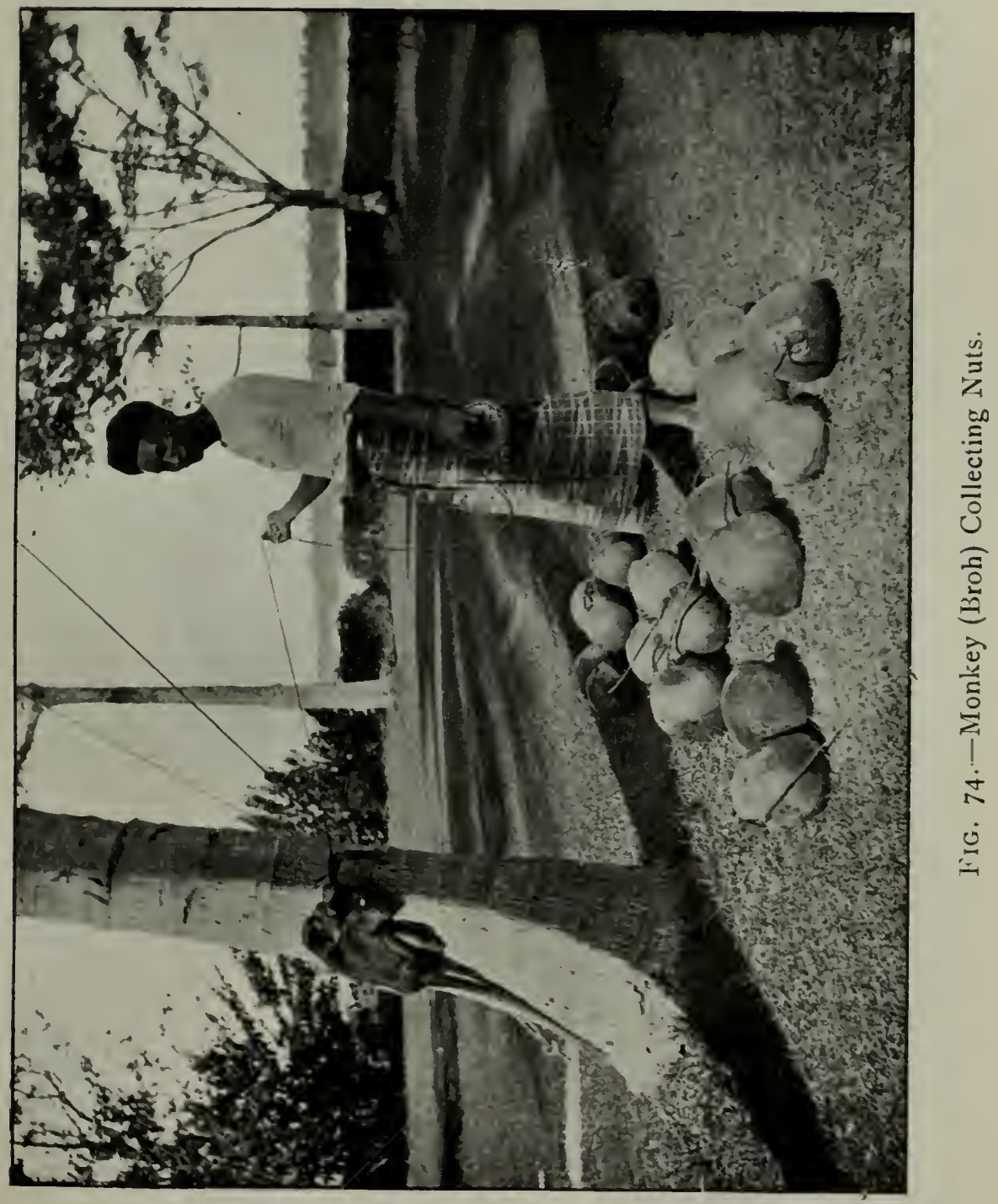





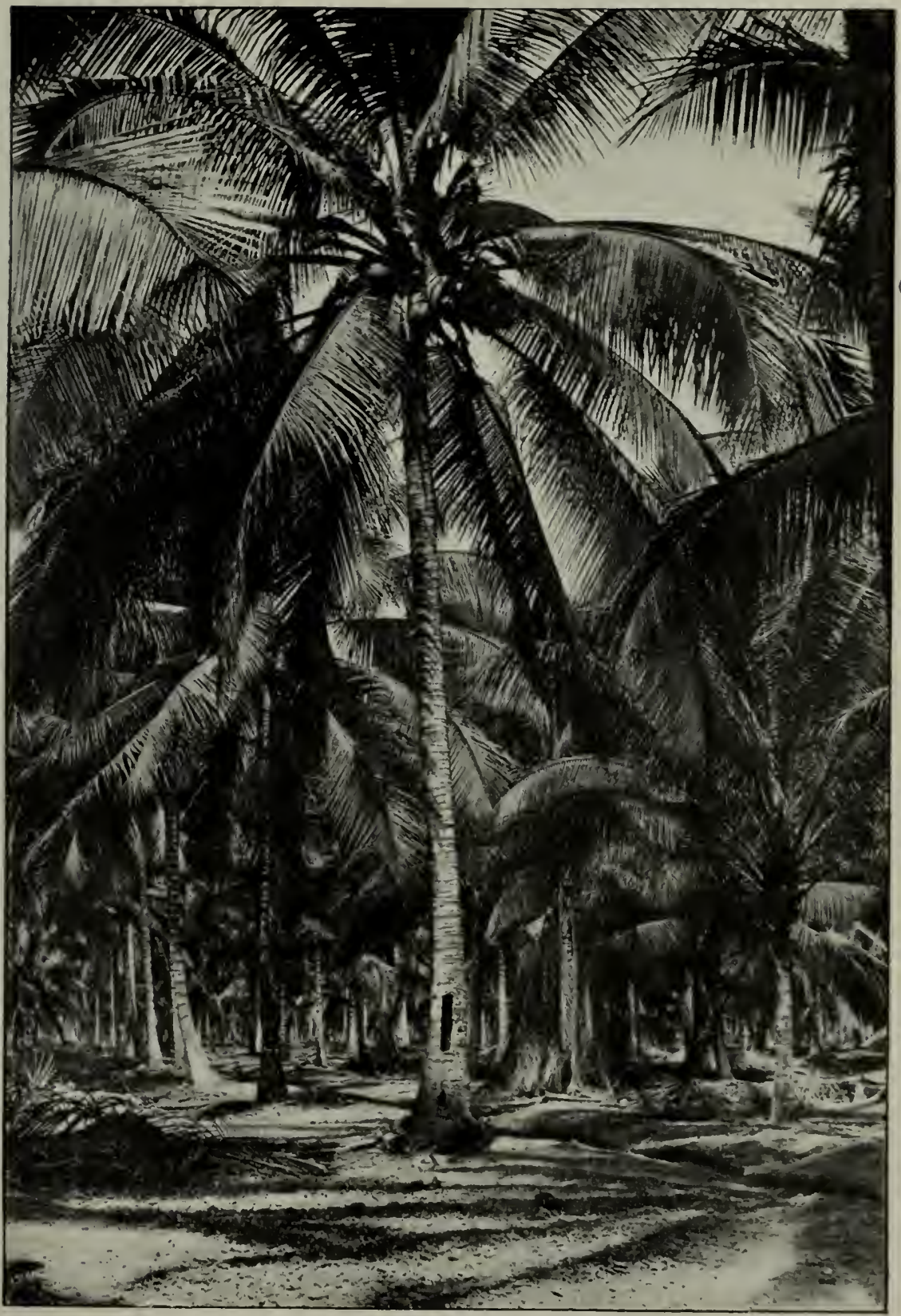

FIG 75.- Coco-nut Tree in bearing, notwithstanding a large hole right Follow 74. through the trunk near its base. 

the above treatment must be continually administered until there is evidence of the ants having disappeared. The trench must, of course, be left open all the time, and no earth should be allowed to come in contact with the tree.

Another mixture for plastering which has been found beneficial, especially in the dry weather, is flour, sugar, and arsenic, mixed to the consistency of whitewash.

Let it not be imagined that the most careful carrying out of the above measures will suffice to rid your whole clearing of the pest; they are only suggested as the means of keeping it in check.

In a very interesting article by Mr. Towgood (late of Riverside Estate, Kuala, Selangor), published in the Agricultural Bulletin of the Straits and Federated Malay States, as far back as 1909, various species of termites are dealt with, and from researches and thorough investigations made by him, it requires little convincing regarding the necessity for following up the runs of the Termes gestroi and capturing the "queens," to insure the total eradication of the pest from the clearings. 
Peaty soils no doubt encourage $T$. gestroi, because, as Mr. Towgood remarks, they contain, as a rule, a large proportion of "kumpas," and "meranti" trees, for which the termitaria are known to have a particular fancy.

In the systematic endeavour to rid the estate of the pest, it must be realized at the commencement that various species of termites exist, but it is only the gestroi that is the objective in the crusade against white ants, as the other species are mostly "mound" termites, whose presence does not endanger a living tree.

In the above-mentioned concise and com. prehensive article the importance of discovering the source of infection is urged. It will invariably be found to be a buried root or stump from which the termites make their way in search of food by means of tunnels. They may be found at a depth of 6 in. to $3 \mathrm{ft}$. below the surface of the ground, and these should be followed up, although it is a tedious matter at the best.

Mr. Towgood truly remarks that some planters are lulled into a sense of security by the fact that none of their young trees have 
been attacked, but it is well worth while to make a search for $T$. gestroi in timber lying in clearings, for although the trees may not be attacked now, they will be sooner or later if $T$.gestroi is present.

The Ordinary Red Ant, though as a rule a friend of the coco-nut planter, may in some cases prove to be the reverse. As a friend it preys upon scale insects, and does good in various other ways, but trees sometimes become infested with them to such an extent. that the proper searching for beetles by coolies is often dangerously neglected on account of the painful attacks on the human body which these ants make with their mandibles.

On one occasion owing to the anxiety of the manager we were asked to visit an estate on which a two-year-old clearing had become sickly looking for some reason or other. The Agricultural Department was to be advised, and a Government expert in mycology sent for. The visiting agent having reported that the estate was free from beetle, and the manager having given his assurance that beetle collectors were untiring in their systematic searches, it was at first sight doubtful 
as to what this new pest could be that caused the trees to present such a forlorn aspect.

Upon entering the clearing it was noticed how that nearly every tree seemed to be weighed down with masses of these nipping ants, showing conclusively that the estate beetle-collectors (who are no more willing than any other human being to suffer unnecessary pain) had found this field practically impenetrable, and had failed to report the fact to the manager of the estate.

In the process of satisfying ourselves as to the source of all the trouble we also had to suffer a little, and were not sorry to get out of the field; we had found the trees simply riddled with the "oryctes" in various stages of development, but all went on swimmingly afterwards as far as we ever heard.

The extermination of the red ant pest from a field is not really a difficult matter as it is only necessary to find the nests. Having done this, get a piece of $I$ in. hollow bamboo about 12 in. long. This blow-pipe, we call it, requires sharpening at one end; on the sharpened point place a small quantity of London Purple, and after inserting the end 
in the ants' nest blow lightly down the tube, seeing that the poison goes well into the nest. To make a success of this operation it is essential that it be performed either in the evening or in the early morning before the dew is off the leaves.

As this poison is very deadly, the operators should be properly instructed as to its use. It requires only a small amount of this if accidentally drawn into the mouth and swallowed to cause very severe sickness, and possibly death.

\section{Diseases.}

Fortunately the coco-nut palm in the Malay Archipelago is comparatively free from diseases of what may be called a serious nature.

Pestalozzia palmarum, commonly known as the leaf disease, although very frequently seen, with the exception of a rather severe outbreak on some of the young nurseries in Sumatra, some time ago, very little serious harm has really been done so far as our experience goes. At the same time, if it shows itself to any degree, immediate attention should be given to the fungus. The spots are 
yellowish, then increase in size and frequently run together, finally becoming of a grey colour with a brown margin. From our observation the disease is much more prevalent now than it used to be. The leaves drop off and wither at the top and die, the leaf area being in consequence much diminished.

The spores of the fungus are produced on the spotted parts of the leaves, and are blown about from one leaf to another, and in this way the disease is spread.

It will generally be found that young plants which are unhealthy and backward in growth are affected most, and that the more vigorous and healthy plants suffer comparatively little, indicating that the fungus is more prone to attack places where the soil is poor, or shows a want of proper cultivation.

It may be seen occasionally on the older trees and a description of this is given on pages 148-150. The disease very often appears either in the nursery or a month or two (sometimes a year) after the young plants have been put out. The most virulent attacks have been observed in places where soil conditions are uncongenial. When this is so it is necessary 
to cut off the leaves that have been attacked and burn them as soon as the spores are first detected, and after this is done the plants may be sprayed with Bordeaux mixture in the following solution :-

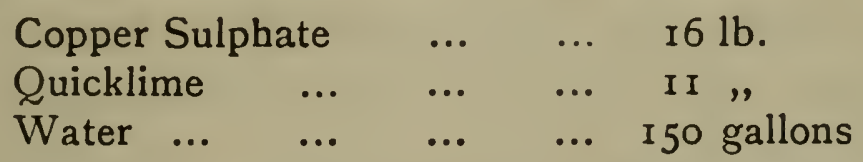

and special attention should be given to the young plants. To induce more vigorous growth by improved soil conditions has usually been found the best and surest remedy.

A lepidopterous pest, Brachartena caloxantha, has occasionally broken out in some districts in the Federated Malay States and the Straits, and although the trees ultimately recover it affects them very seriously for six or eight months. The lower leaves are first attacked and the pest then works upwards. The leaves turn a brownish colour, wither, and gradually die off, during which time the flower and fruit shrivel up; the nuts that fall off are useless and the trees altogether present a most sickly appearance. Fortunately the pest does not for some reason or other molest the leaves near to the crown, and it is no doubt this which saves the life of the tree. 
Remedial Measures.-On the very first appearance of the pest, for which close examination should be made, all the leaves that have been attacked must be cut off and burnt, and if taken in time and the treatment be carried out thoroughly the disease may possibly be arrested before the leaves are affected to any serious extent. On one occasion when some coco-nut trees were found to be very seriously affected by the grub, in order to prevent further spreading the trees were for a time completely defoliated and the leaves burnt, leaving only those standing near the crown which had not been affected. This drastic treatment was entirely successful for the purpose, and before three months had elapsed new foliage had already commenced to a large extent, while about 20 per cent. of the trees were in blossom again very soon afterwards. It has, however, since been ascertained by the Acting Government Entomologist that the spread of the pest can be entirely arrested by a parasitic ichneumon, sometimes found present in large numbers at the same time that the grub of Brachartena caloxantha makes its appearance. 
Helmithospodium is another pest which has been known to attack young plants, but this again may be easily arrested by spraying with Bordeaux mixture in the following proportion :-

$$
\begin{aligned}
& \text { Copper sulphate } \quad \ldots \quad \ldots \quad 8 \mathrm{lb} \text {. } \\
& \text { Quicklime } \quad \ldots \quad \ldots \quad \text {... } 16 \text {, } \\
& \begin{array}{lllll}
\text { Water } & \ldots & \ldots & \ldots & \ldots
\end{array} \text { roo gallons }
\end{aligned}
$$

when the young plants will very soon recover without any ill-effects beyond being retarded in growth for a time.

\section{Caterpillar Pests.}

Chrysalids collected by Mr. Norris, and larvæ which were fed in the laboratory of the Agricultural Department of the Federated Malay States, produced three species of butterflies belonging to the family Hesperidæ which were identified by Mr. Holman-Hunt as :-

Hidara ivava.

Evinota thrax.

Corona palmarum-Telicota palmarum.

The first two are widespread throughout the Malay Peninsula.

The life history of none of the species has yet been worked out in detail. 'The main features are as follow :- 
Eggs are laid on both upper and lower sides of the coco-nut palm fronds. The eggs are roughly hemispherical. The young larvæ are elongate, green, naked, the head pale brown, the prothorax just behind the head compressed, giving the appearance of a neck. Older larvæ have the head dark brown and the body greyish green with a slight mealiness over the whole surface. The pupa is long, cylindrical, tapering to hind end. Pupation takes place in the folded leaf. The life history is short, probably from six to eight weeks.

The nature of the damage to trees is characteristic. The larvæ connect together with stout silk adhesives the two edges of the underside of one pinna, or the underside of one to the top of the next, forming a tunnel in which it lives and feeds. The caterpillar feeds towards the rachis and the result of a bad attack is that the pinnæ of each frond are stripped to midrib, half way or more towards the rachis. No preference appears to be shown for young or old leaves, all being attacked. Young coco-nut palms of a few months are attacked equally with palms in bearing. 


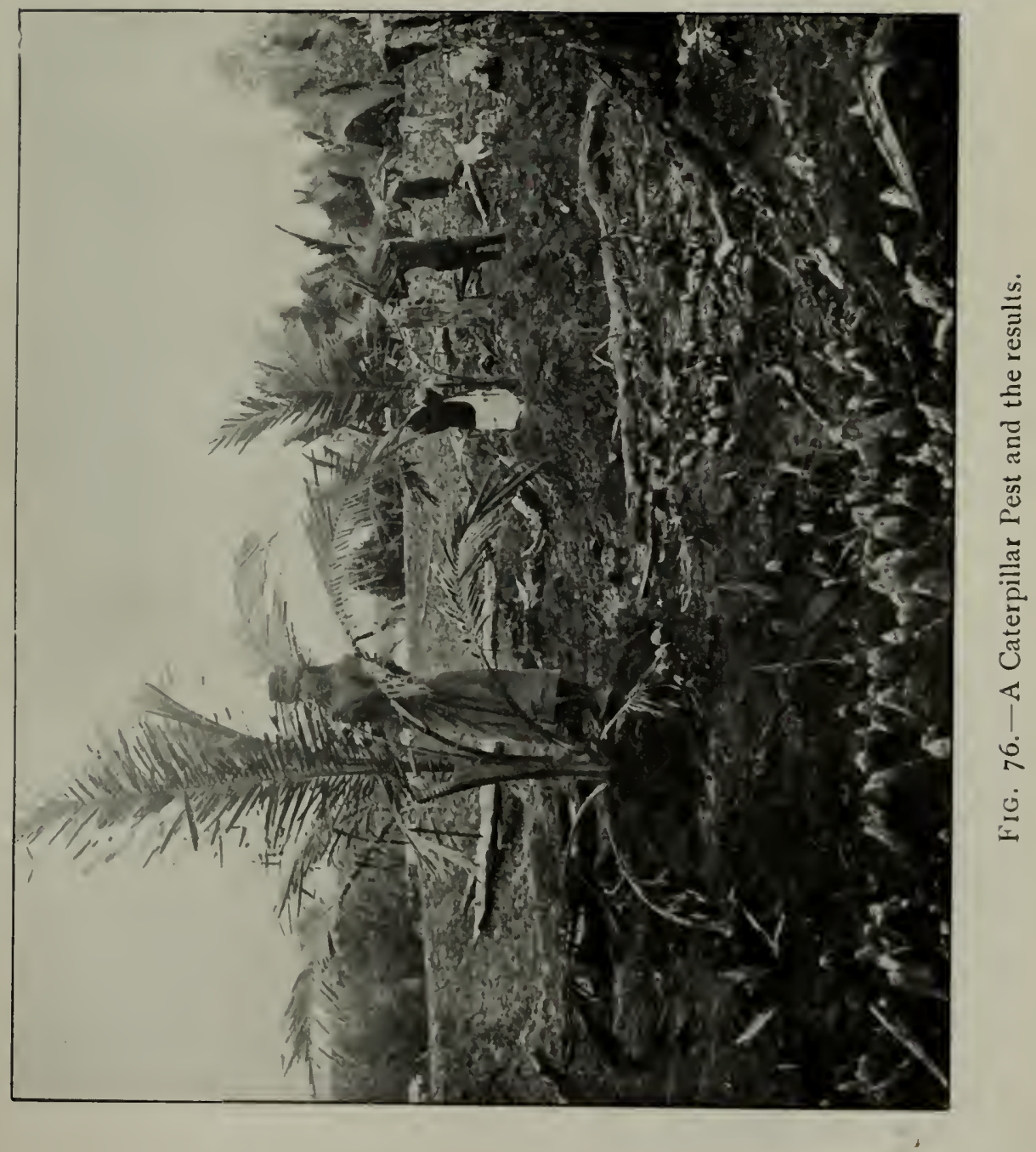



Other caterpillar pests have been observed and watched in various districts, but have not proved in our opinion to be of a nature serious enough to warrant special description.

Remedial Measures.-The caterpillar when feeding devours the whole of the tissue of the leaf-segment which forms its tunnel with the exception of the central supporting rib.

It is evident, therefore, that if a poison be applied all over the leaf, so that the caterpillar is compelled to eat the poison or starve, the attack will be checked. The poison used must be insoluble and adhesive, to withstand tropical rain, and it must be innocuous to the foliage. These conditions are best met by lead arsenate.

This substance can be obtained in a very fine state of division in the form of a paste. When mixed with water a uniform spray fluid is obtained, capable of being sprayed as a fine mist; a very small quantity suffices to kill the caterpillar, and the cost of the material is small.

To make the spray fluid $I_{\frac{1}{2}} \mathrm{lb}$. of lead arsenate paste, equivalent roughly to $\mathrm{I} \mathrm{lb}$. of lead arsenate, is mixed with 60 gallons of 


\section{GUIDE TO COCO-NUT PLANTING}

water. Ten pounds of slaked lime may with advantage be added, as this increases the covering power of the mixture, and prevents any soluble arsenic which may be present from burning the foliage. Any sprayer with a nozzle giving a fine misty spray may be used for applying the poison. All the leaves should be sprayed as evenly and fully as possible and spraying should cease as soon as any tendency to drip is observed.

The drier the day the better for spraying. Once the spray has dried on the leaf it is very adhesive, retaining its toxic properties for weeks, notwithstanding subsequent rain. Immediately an attack is observed spraying should be commenced, and if the young caterpillars are dealt with immediately after hatching all the foliage will be saved.

\section{Bud-rot Disease.}

Professor F. G. Earle, one of the Commissioners appointed by President Gomez to investigate the disease which was killing coconut trees in Cuba, especially at Baracoa, Oriente Province, has, it is understood, made a preliminary report to the Government, who pub- 


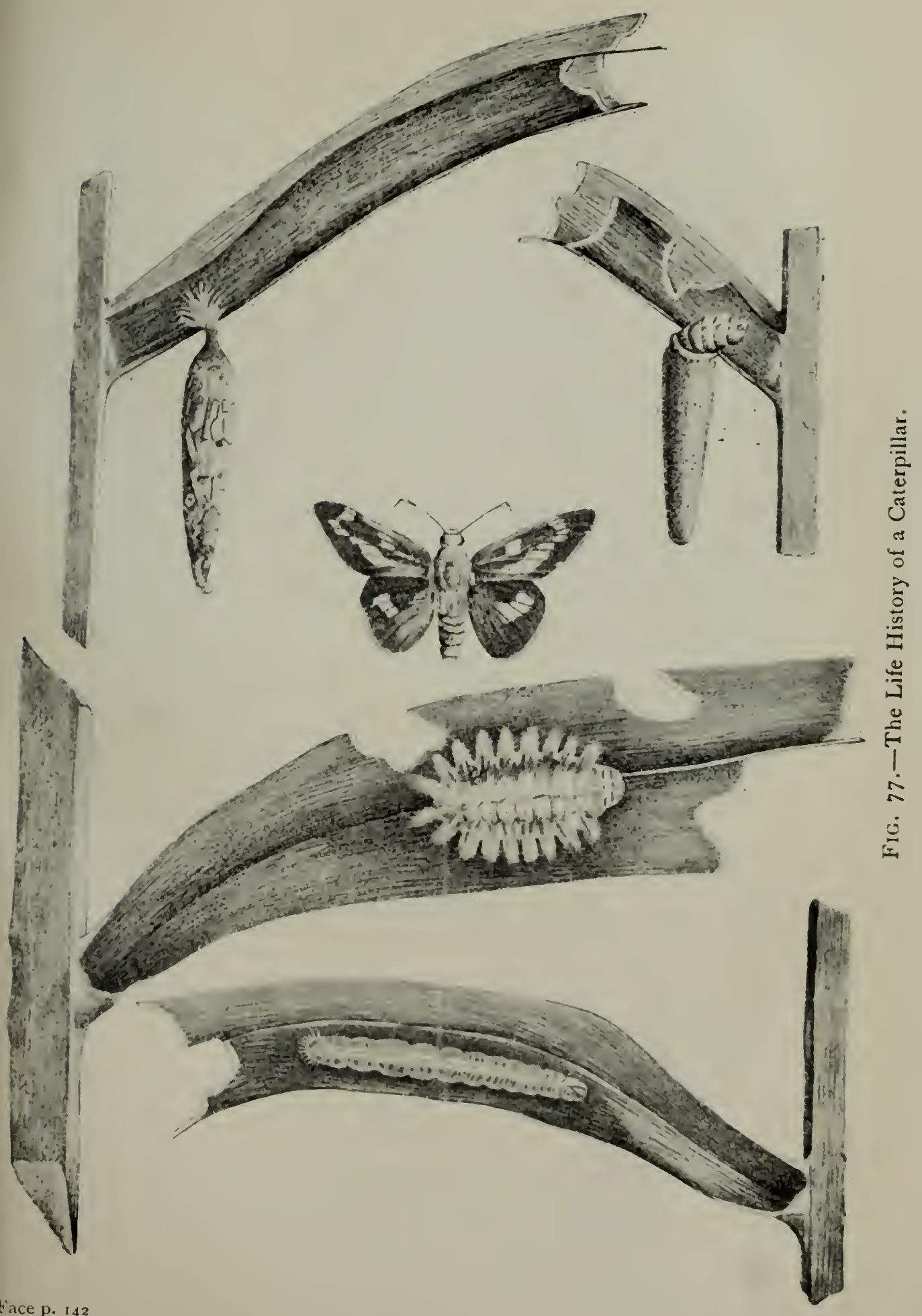



lished it in the West India Committee Gazetle. He states that the exports of coco-nuts from Baracoa have dropped from i 8,000,000 to $6,000,000$, that more than half the trees are dead, and that many are affected. The factory for making oil from unshipped nuts that operated day and night now operates only two days a week. The disease has been virulent five years.

Affected trees are found on all kinds of soils and at all altitudes. Whole plantations have been completely destroyed. It is a serious calamity to the district, as coco-nut groves are the prime source of revenue. Some trees die within a few weeks, while others last longer, but all succumb when the terminal bud is attacked.

Royal palm trees are sometimes attacked, but no other native growth is affected by the disease.

The Commission has reached no decision as to cure, but all the members favour destroying by cutting down and burning the diseased trees whenever found.

(The above is of interest in view of the recent report of a coco-nut bud disease in Penang.) 


\section{GUIDE TO COCO-NUT PLANTING}

A disease, the cause of which is not stated, did damage to the coco-nut trees in Jamaica some years ago. The following description of the disease is taken from the Jamaica Gleaner, for January I 2, I903 :-

"The heart leaves drop out and the leaves, which are usually upright, fall down. When a tree in this condition is cut down the heart is found to be one mass of bad smelling, decaying vegetation, while the root and trunk are in perfect condition. The disease often attacks the flower spikes, with the result that many of the coco-nuts drop off while still young. This is frequently preliminary to the disease getting to the heart leaves, after which nothing can save the tree."

Again, in the Journal of the New York Botanical Garden, vol. iv, pp. 4 to $7, \mathrm{Mr}$. F. S. Earle gives an account of his recent visit to Jamaica.

He examined coco-nut trees suffering from what is apparently the same disease as that described above. Mr. Earle attributes the disease to bacterium. He points out the necessity for prompt cutting and burning of all infected trees, and says that it is claimed by 


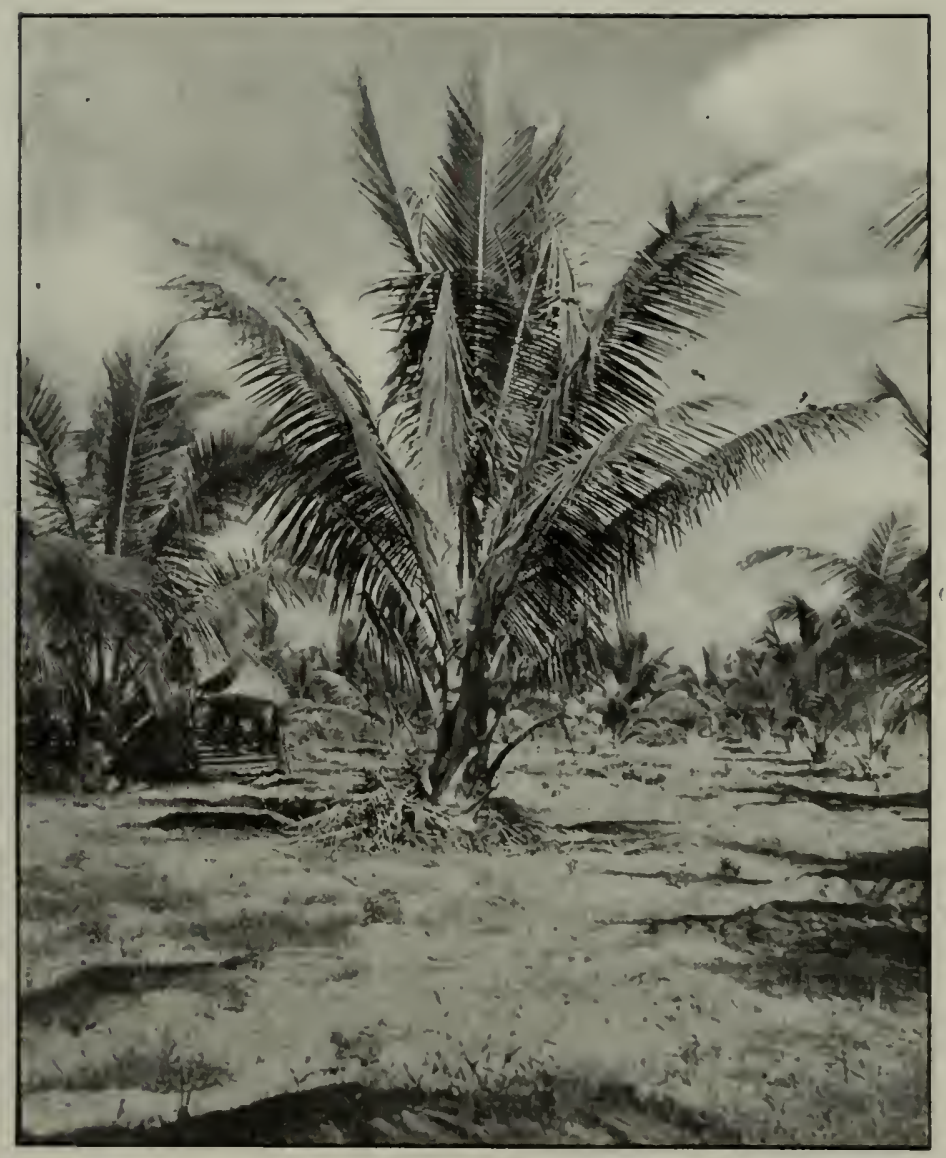

Fir. 78.-Bud-rot disease : restalozzia palmarum.

(See Mr. Richard's report.) 

some planters that a certain green-skinned variety of coco-nut is less liable to this disease than the reddish and yellowish kinds. If this be confirmed there is a possibility of raising a resistant race of coco-nuts. A disease similar in many symptoms is the subject of a paper in Bulletin No. 38, New Series, Division of Vegetable Pathology and Physiology of the United States Department of Agriculture. The disease appeared among coco-nut palms in the Province of Santiago, Cuba. The first indication of trouble was the falling of the young fruit. Shortly after, the larger nuts dropped and the leaves assumed a yellowish colour. Within a month all the large lower leaves drooped and fell, leaving only the pale, sickly tops which blew over at the first heavy wind. Here also, from the root to within a few inches of the top, the trunk was found to be perfectly sound. Perforating the entire upper part of the trunk for 2 to $12 \mathrm{in.}$ downwards was found the mycelium of a fungus, the fruiting bodies of which appeared as small white spots on the underside of the leaves. These might easily be mistaken for the scale insects (Aspidiotus) often found there. 


\section{GUIDE TO COCO-NUT PLANTING}

The fungus was identified as Pestalozzia palmarum. On breaking open the lower leaves and cutting the centre of the green growing part open the heart is found to be one putrid, offensive smelling mass. It was found that the best way of preventing the spread of the disease was cutting down and burning the diseased palms. It is not necessary to burn the entire trunk, but only the top, with a couple of feet of the upper end of the trunk. In order that this preventive measure may have its greatest effect, it is absolutely necessary that united action should be taken. It would obviously be futile for the proprietors of one estate to eradicate the disease within its limits, if the owners of a neighbouring estate omit the precautions and allow the disease to multiply and send its spores abroad to the others.

These two diseases are so similar in their symptoms that it would seem not improbable that they are really one and the same. This, however, cannot be definitely settled until something more is known of the cause of the disease in Jamaica. We trust further information will be obtained as the result of the work 


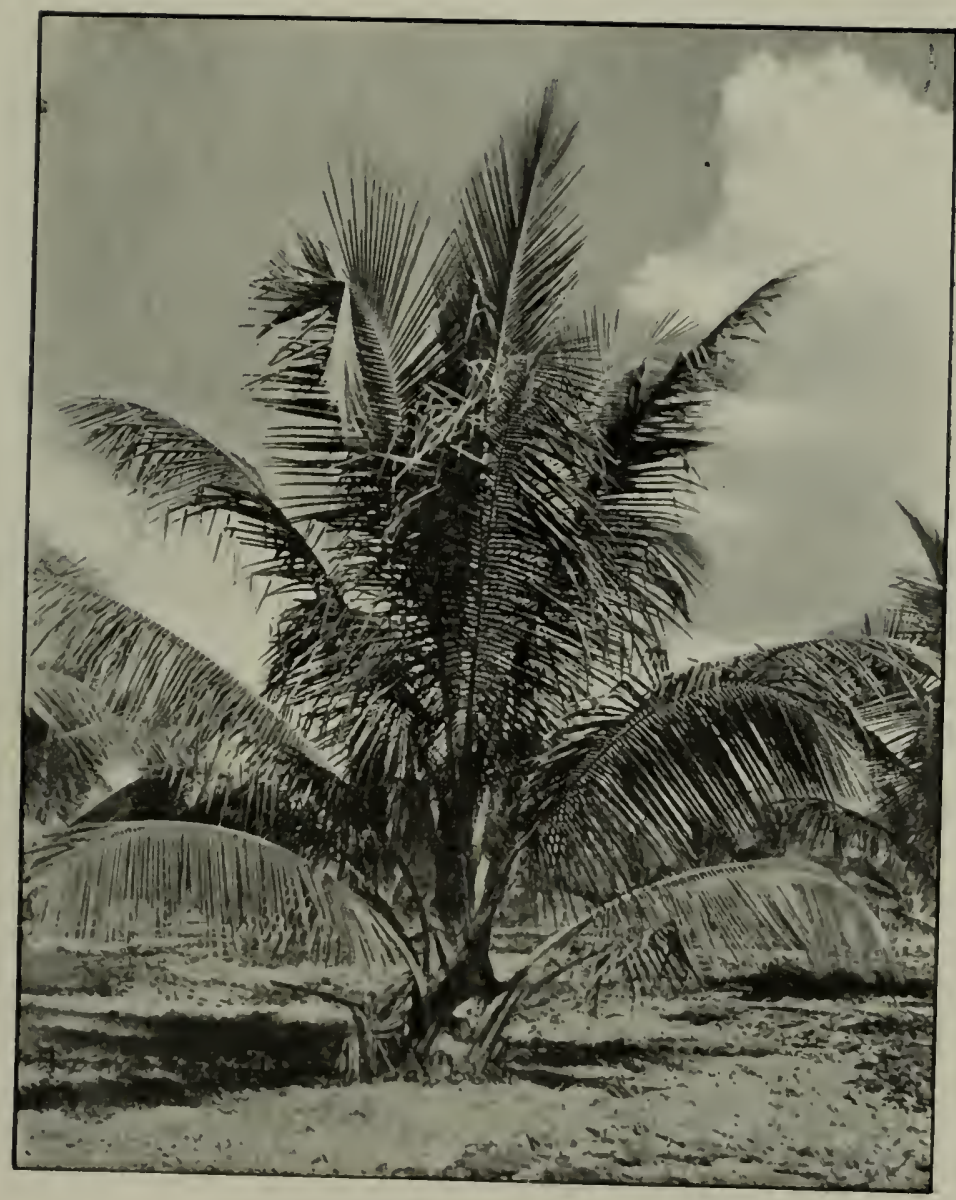

FIG. 79.-Bud-rot disease at an early stage. 

which, we understand, Mr. F. S. Earle has in hand at the New York Botanical Garden, and of the field experiments of Mr. W. Cradwick, of the Department of Agriculture, Jamaica.

It will be gathered from the foregoing, and also from Mr. Richards's observations which follow, that scientific research has not yet been able to clearly diagnose the disease which we fear is, for want of a better name, too often termed "bud-rot."

On nearly every young coco-nut estate individual trees will be found suffering from a disease which has attacked the heart through channels other than the outer leaves, demonstrating that neither "Pestalozzia" nor "Diplodia" are to be held directly responsible for the decay.

In these cases we think that one must often look to root trouble, which does not, as a rule, appear to be infectious; but in cases where the disease starts in the manner described by Mr. Richards, and which we ourselves have seen, the origin may, we think, be found in one or other of the two fungi mentioned; possibly, more in the latter than the former, especially when the attack occurs amongst trees where 


\section{8}

\section{GUIDE TO COCO-NUT PLANTING}

the question of unfavourable conditions could not be raised.

"Circular Letter.

"The Laboratory,

"Caledonia Estate,

"Province Wellesley,

"February 5, I9I 5.

"A Disease of Coco-nut Palms.

"Dear Sir,-During the past few weeks coco-nut palms on a number of estates have been attacked by a fungus known as Pestalozzia palmarum, mentioned as causing a leaf disease in the Mycologist's report for I9I2 and I9I3. On p. 25 in this report the first signs of the disease are described.

"Until recently no serious injury has been caused by the disease, as previously only outer leaves of small palms were killed.

"Now, however, the disease has become much more serious, and it is advisable that you should become acquainted with the first stages of this new phase of the disease. The first stages are well shown in photographs I and 2. The tips of one or more leaves towards the middle or youngest leaf wither and drop. The 


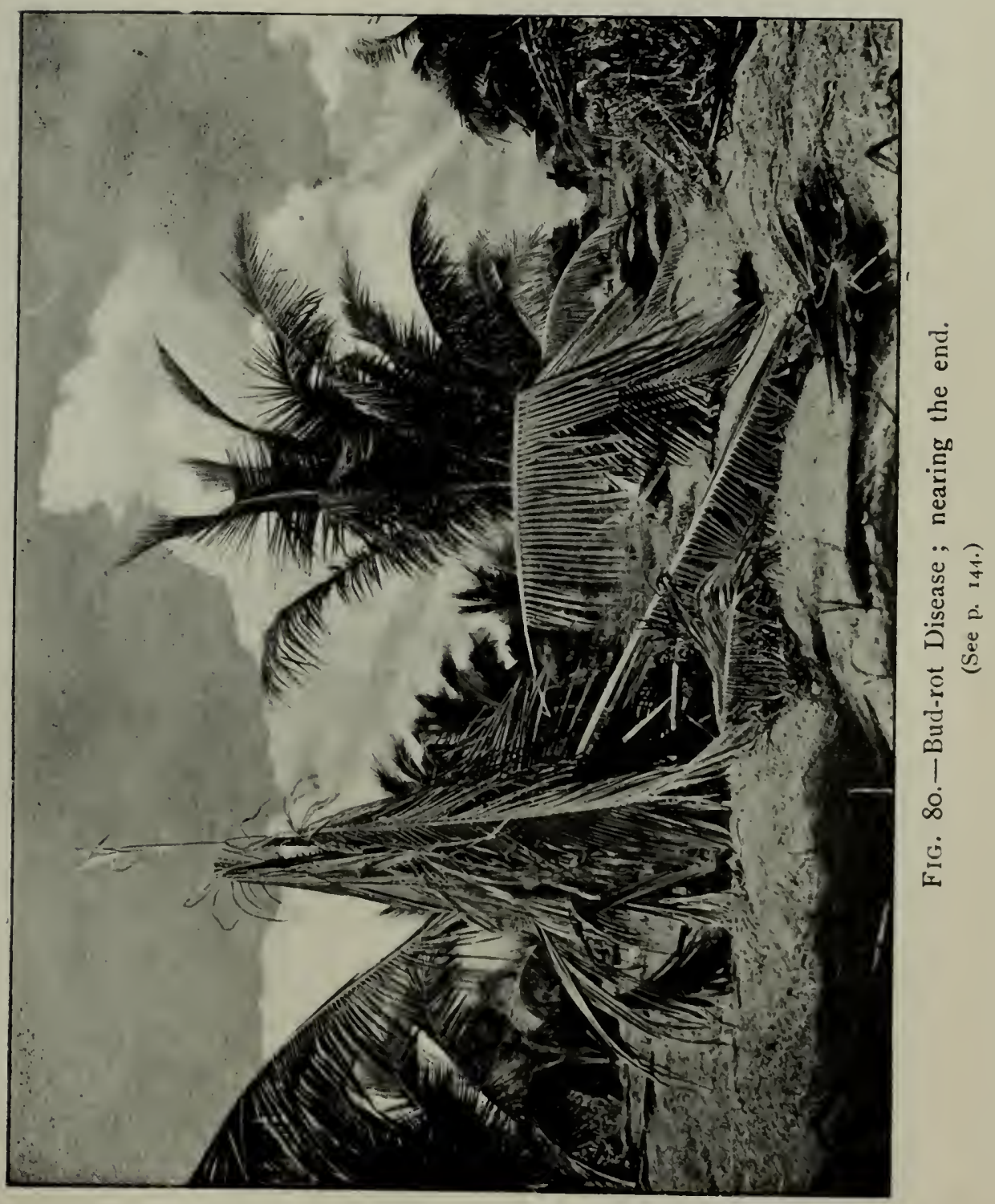

Face p. 148 . 

withered portion, about I $\mathrm{ft}$. or $2 \mathrm{ft}$. from the tip, partially breaks and hangs down from the remaining part of the leaf stalk. This is shown quite plainly in photographs I and 2 . The drooping tip is at first yellow, but finally has the usual brown appearance of a dead coco-nut leaf. This may be known as the first effect of the disease. By cutting away the affected leaves at this stage the trees may be saved.

"The fungus spreads into the healthy lower part of the leaf, travelling down the leaf-stalk, turning the outer side of the leaf-stalk brown. In slightly affected leaves it is necessary to look for this brown mark extending down the leaf-stalk, so that the leaf may be cut away at a point below the end of the brown mark or beyond the limit of the diseased tissue.

"If the affected palms are not treated at this stage the fungus attacks other leaves, and, moreover, the spores spread very quickly to other palms. The fungus growing rapidly after the first stages kills all the leaves, as shown in photograph No. 3, and eventually the palm dies.

"A group of palms killed by the disease is shown in photograph No. 4. 
"Remedial Measures.-In case of attack the measures mentioned above, i.e., the cutting away of slightly affected or seriously affected leaves, should be adopted. This method should check the growth and spread of the fungus.

"All diseased leaves and dead palms must be burned on the spot, and not carried away through the fields to be destroyed in any other place. The spores, which are produced in great numbers, spread very quickly.

"Note.-Although Pestalozzia palmarum has been described as causing identically the same symptoms of disease as shown by these photographs, it is necessary to point out that in all examinations of diseased leaves not only has the fungus Pestalozzia palmarum been found but also Gloesporium (sp.) and 'Diplodia,' the two fungi which are responsible for the die-back of Hevea trees. At the present time we cannot say whether Pestalozzia causes the full effects described or whether the injuries are due to these other fungi as well. We shall be glad to give more detailed information on this subject when we have completed our experimental work.

"(Signed) R. M. Richards, "Mycologist." 


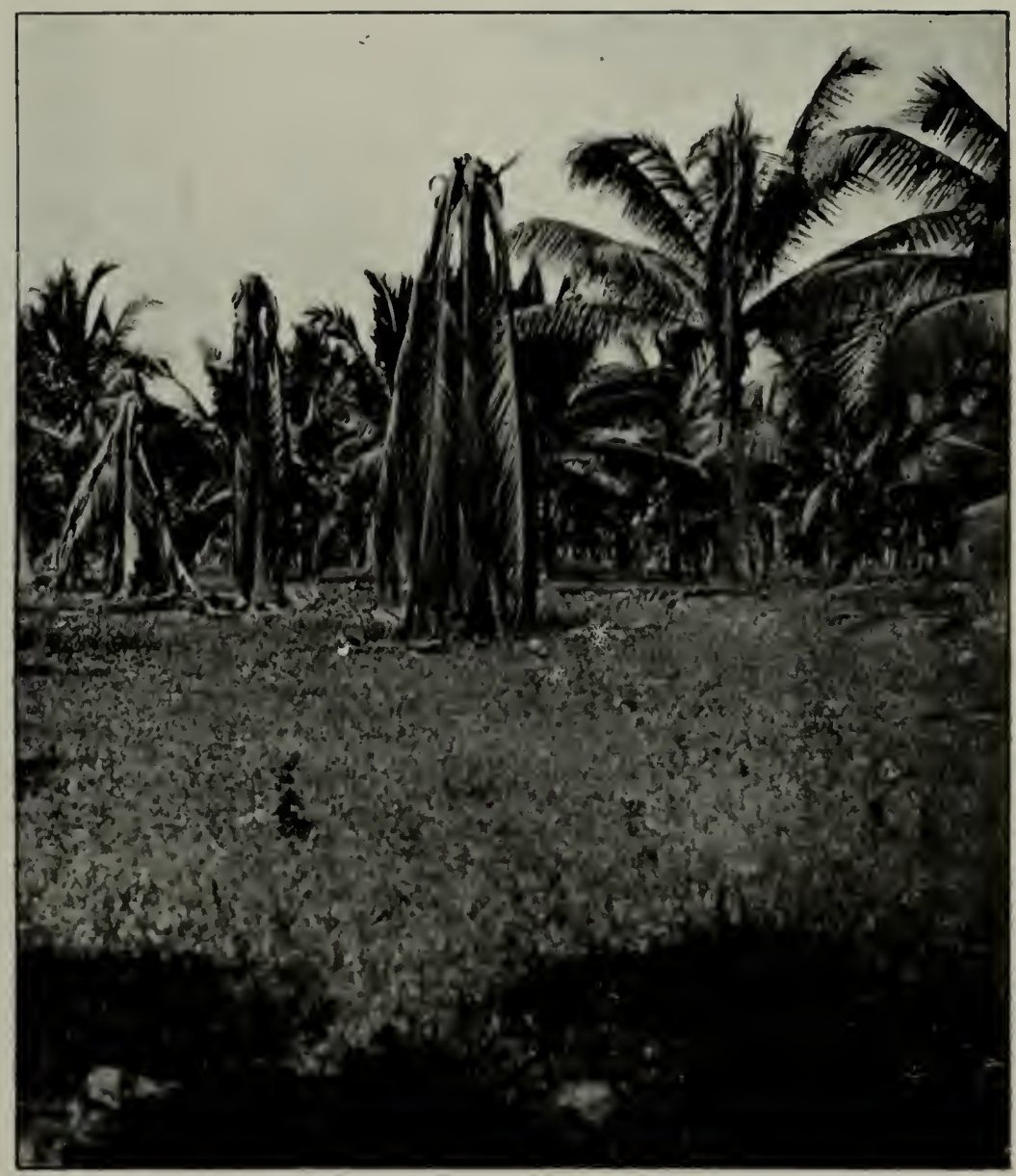

FiG. 8I.-Bud-rot disease: the final stage.

(See p. 144.) 

An outbreak occurred a short time ago on an estate in a coast district of Selangor, and from specimens sent the same diagnosis precisely was made by the experts at the Kuala Lumpur Agricultural Department.

As far as we recollect, the number of trees that suffered seriously or perished was under fifteen over an area of 500 acres. The remedial measures described above were carefully carried out.

Bordeaux Mixture.

Millardot and Gayer first gave us Bordeaux mixture in definite form. Since that time ( 1882 ) Bordeaux mixture has been continually used, but only during the last few years have the best formulæ and methods of preparation been discovered. Bordeaux mixture consists of varying preparations of copper sulphate $\left(\mathrm{CuSO}_{4}\right)$, lime, and water.

The proportions of $\mathrm{CuSO}_{4}$, lime, and water in general use is one in which $14 \mathrm{lb}$. of $\mathrm{CuSO}_{4}, 9 \mathrm{lb}$. of lime, and 100 gallons of water are taken to make up the mixture. To simplify matters, we may write such formulæ as follows :- 


$\begin{array}{ccccc}\mathrm{CuSO}_{4} & & \text { Lime } & & \text { Water } \\ \mathrm{I}_{4} & \ldots & 9 & \ldots & \text { 100 }\end{array}$

Bordeaux mixture, made up from these quantities of materials, would probably be quite serviceable in the control of "Pink" disease. Planters must remember that the use of Bordeaux mixture against the spread of Pink disease is entirely in the experimental stage, and also that the use of copper fungicides amongst Hevea brasiliensis which is in bearing must be very carefully attended to, on account of the toxic action of copper compounds upon the rubber produced from the latex. Other formulæ for preparing Bordeaux mixture are :

$\begin{array}{ccccc}\mathrm{CuSO}_{4} & & \mathrm{CaO} & & \text { Water } \\ 8 & \ldots & 8 & \ldots & 100 \\ \mathrm{I} 9 & \ldots & 8 & \ldots & 100\end{array}$

Method of Preparation.-Great care must be exercised in the mixing of the materials, and also in their selection, as regards purity of composition. With regard to the copper sulphate, an article of 98 per cent. purity should be obtained; substances described as "agricultural bluestone" or "agricultural sulphate of copper," must be avoided, as these are usually adulterated with iron sulphate. 
The lime must be freshly burnt, i.e., in the form of "quicklime." Powdered air slaked lime is useless in the preparation of Bordeaux mixture.

Supposing we wish to make up Ioo gallons of Bordeaux mixture of the $8: 8:$ ioo formula:

(I) Take the $8 \mathrm{lb}$. of copper sulphate and tie up in a piece of coarse sacking. Suspend this in 50 gallons of water, from a stick placed across the top of the barrel, by means of a string. The water must be contained in a wooden receptacle. If left overnight till the following day all the copper sulphate will be dissolved.

Place the $8 \mathrm{lb}$. quicklime in a bucket, take the other 50 gallons of water and from this add a few pints of water to slake the lime. Care must be taken not to add too great a quantity of water at first, just sufficient to produce a thick creamy paste. Now add the rest of the 50 gallons of water. In this way we obtain 50 gallons of milk of lime.

Now pour the milk of lime into the copper sulphate solution, through a coarse sieve, if possible, in order to prevent any undissolved lumps of lime getting into the mixture. The 
mixture of the two substances results in the production of a flocculent precipitate of minute particles of insoluble basic copper carbonate.

Upon the nature of this precipitate of basic copper carbonate depends the fungicidal quality of Bordeaux mixture. This precipitate varies greatly according to the method of mixing.

The aim, in preparing Bordeaux mixture, is to produce as fine a precipitate as possible of basic copper carbonate. The smaller the particles precipitated, the better the mixture will be, for the particles will not settle so quickly in the spraying machine, and the nozzle, upon which much of the success of spraying with Bordeaux mixture depends, is not so easily choked up.

It is highly important that the copper sulphate and quicklime should be dissolved and diluted before mixing. On no account must Bordeaux mixture be made by adding strong copper sulphate solution to a strong mixture of lime, and then supplying the required quantity of water.

This is the method usually adopted in making Bordeaux mixture. Recent investi- 


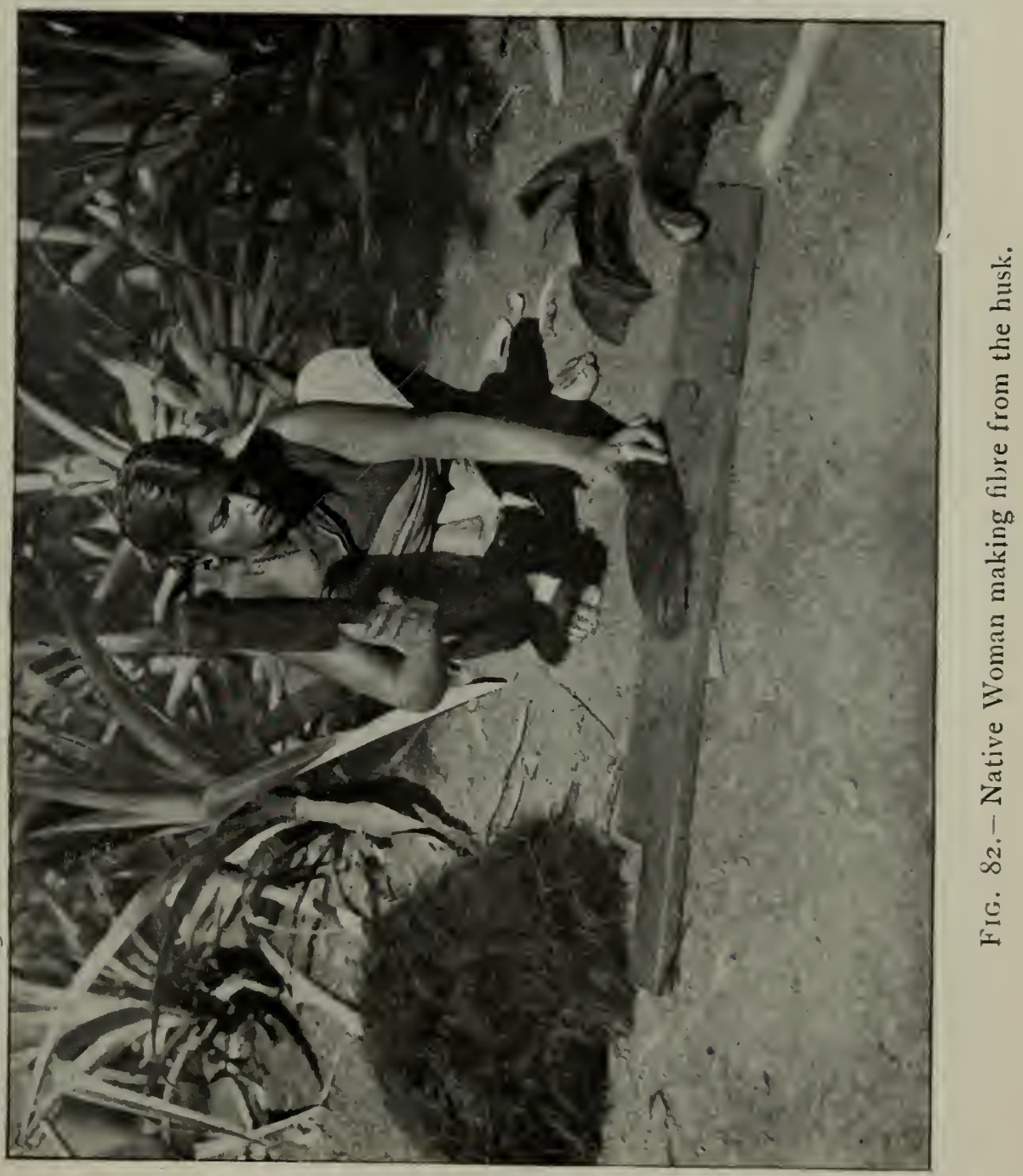



gation at Woburn Experiment Station, by Mr. Spencer Pickering, has resulted in the discovery of what is claimed as a superior method to that described. The method in volved is to make copper sulphate solution as strong as possible, taking first sufficient water to dissolve the whole of it. Then the rest of the water, according to formula, is added to the quicklime so that the quicklime is mingled in as weak a solution as possible. The milk of lime so formed is stirred up several times within half an hour, to dissolve as much of the lime as possible. Then the milk of lime is allowed to stand for a little time in order that the grosser particles might settle. After standing, the copper sulphate is added to the milk of lime. 


\section{CHAPTER XIII. ESTIMATES.}

WE are aware that in the past much criticism has been raised over the estimates in the Bulletin No. I I, and even on the revised figures which appeared in the Agricultural Bulletin for the month of October, 1912, of the Federated Malay States.

So far as those estimates went we find that any exception taken was generally to cover some extravagant, and in our opinion unnecessary, expenditure for which naturally no allowance was made.

We realize that with the additional interest taken in the industry there must necessarily be an increasing demand for accurate figures, and the extent to which many who have interested themselves in coco-nut planting propositions in various parts of the country have been dissatisfied with the cost of opening work has been obvious of late.

As mentioned in the preface to this book, 


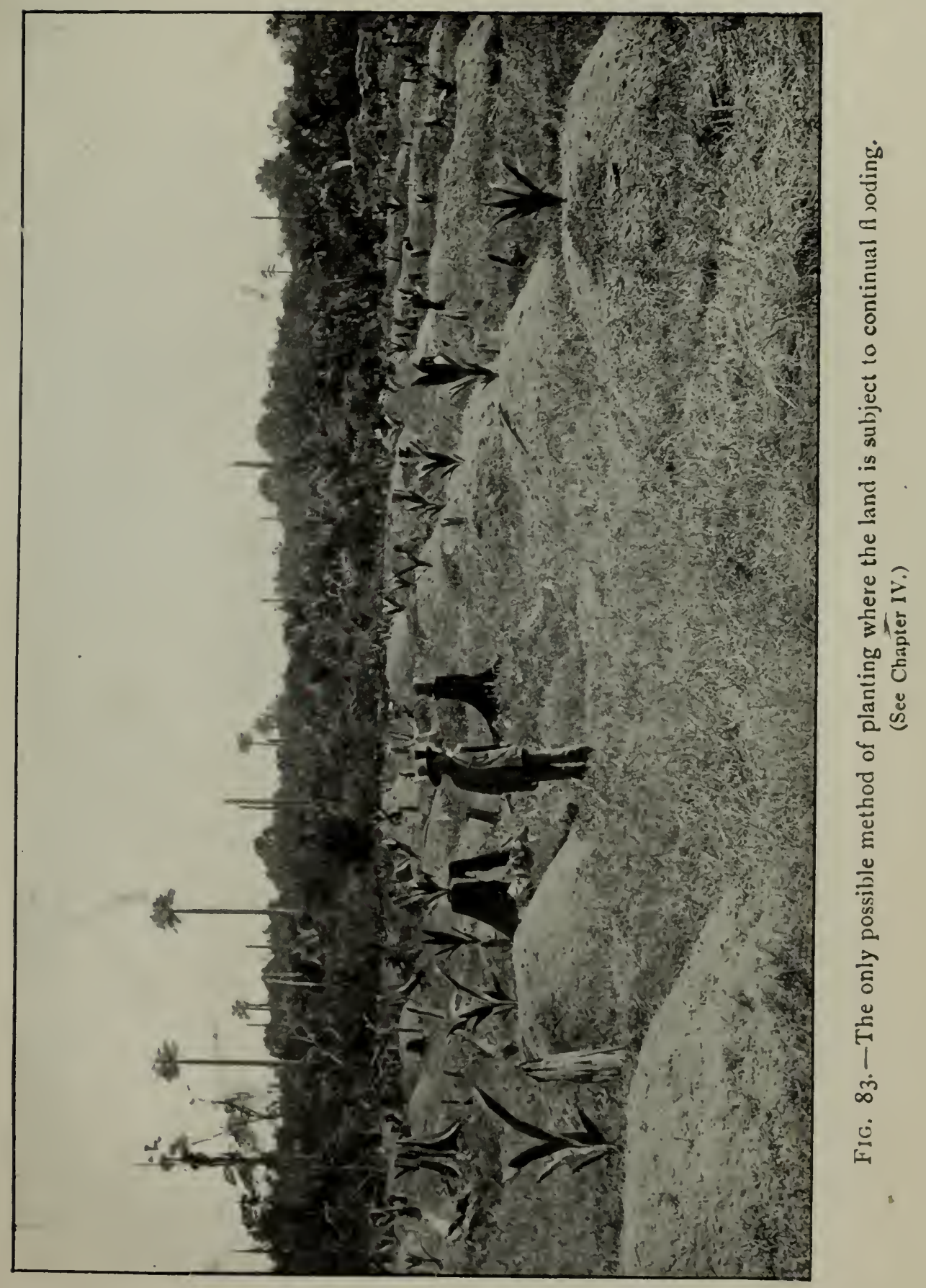

Face p. 15. 

adverse criticisms on results achieved are more often than not the outcome of unwise selection as regards position of land, management, advisers, agents, \&c.

It is obviously impossible to draw up any estimates so as to bring them into line with the extravagant and unnecessary figures, lower than which, managers in some districts have affirmed, it is impossible to get work done.

It is within our knowledge that in a number of cases the opening of estates has been entrusted to men not only with little knowledge of local conditions, but practically no planting experience at all, so it cannot be considered surprising that wonder is being expressed as to whether plantations can be made self-supporting within a reasonable time from planting. It should be distinctly understood that the cultivation is coco-nuts and not tea, coffee, cocoa, or cardamoms, \&c., and that there is a very wide comparative margin between the periods of revenue producing; indicating that special efforts should be made towards strict economy in working. In drafting estimates, such items as those for "heavy" 


\section{GUIDE TO COCO-NUT PLANTING}

expenditure on buildings, water supply, and coolie lines should be omitted, also for expensive superintendence and agents' fees.

Generally speaking, we are not in favour of the last item being included, excepting when the necessity arises, as it does in some cases, for employing middlemen to negotiate sales of produce.

Under fairly normal conditions the cost of opening and maintenance up to the sixth year (taking an estate of say 500 acres) where cheap labour and transport facilities are obtainable, exclusive of drying kilns, should be approximately as under :-

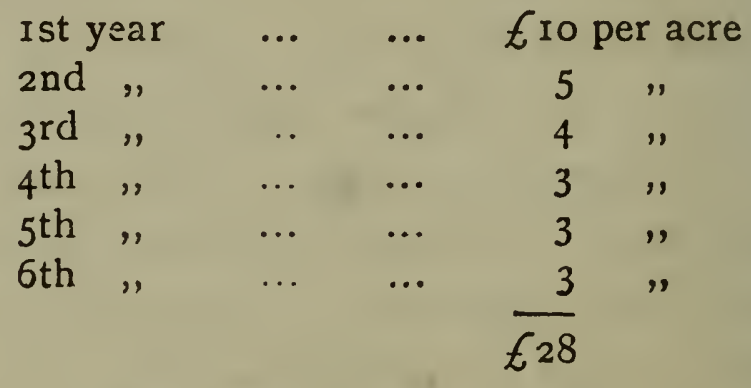

Before closing the capital account another $£_{2}$ or $£_{3}$ must be allowed for permanent buildings, drying kilns, \&c. Estimates of revenue may be roughly calculated as follows :- 


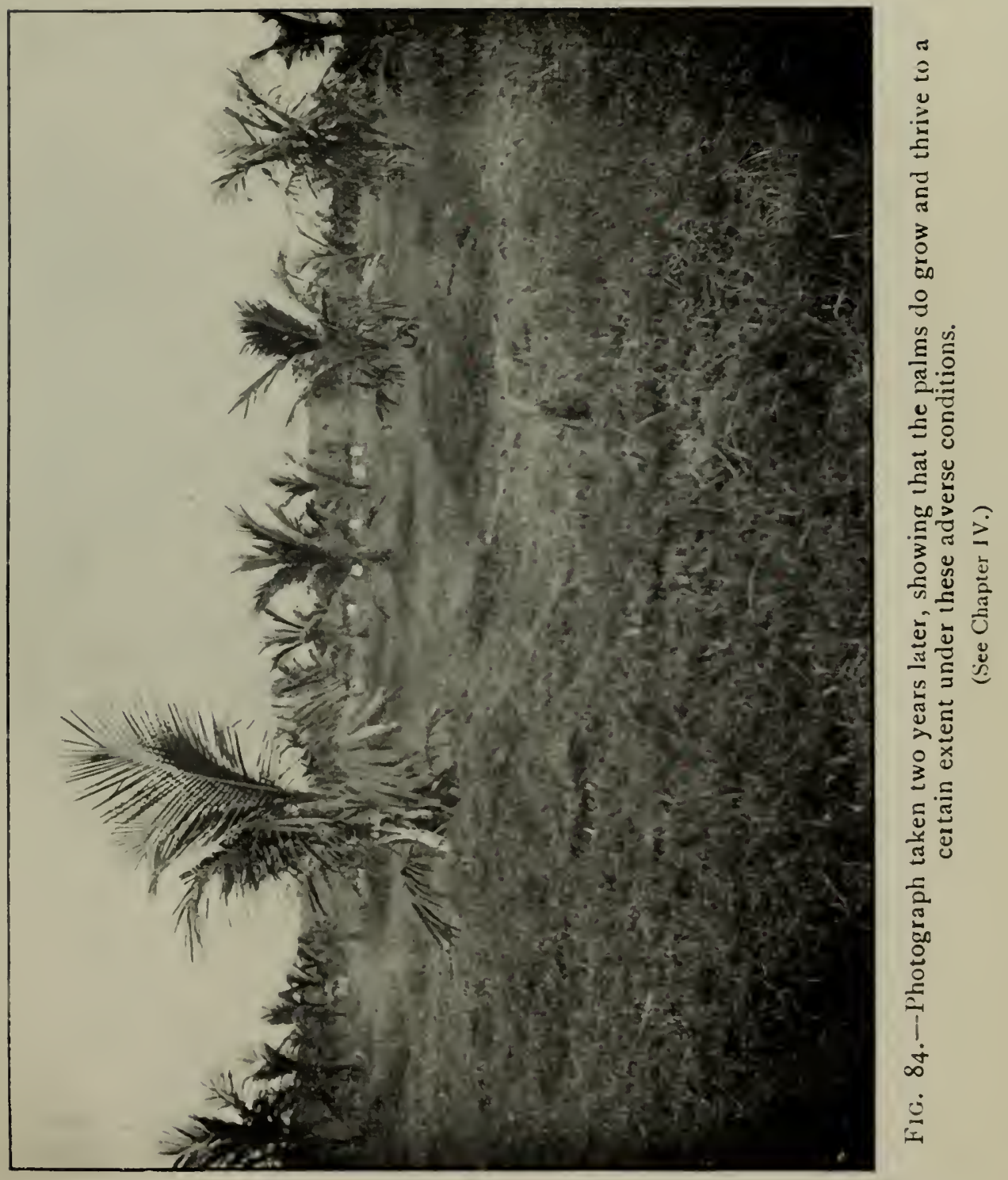

Face p. 158 . 



\section{ESTIMATES}

\begin{tabular}{|c|c|c|c|c|}
\hline 6 th year & $\cdots$ & 500 & uts & per a \\
\hline $7^{\text {th }}$, & $\ldots$ & $I, 000$ & $"$ & $"$ \\
\hline ," & $\cdots$ & $I, 500$ & $"$ & " \\
\hline$"$, & $\ldots$ & 2,000 & $" \prime$ & " \\
\hline ", & $\ldots$ & 2,000 & ", & ") \\
\hline$:$ & $\cdots$ & $2,35^{\circ}$ & ", & $"$ \\
\hline ", & ... & 2,500 & ", & " \\
\hline
\end{tabular}

The above figures indicate that seven and a half years may be allowed before the estate reaches the self-supporting stage (assuming that the net profit is $£ 3$ per 1 , 000 nuts).

There exist, we are aware, certain favoured spots where in the sixth year after planting crops of 1,000 nuts per acre have been recorded. Yields in the fifth year are not unknown, but with a fluctuating crop like coco-nuts nothing of the kind should be estimated for or even thought of. 
CHAPTER XIV.

\section{THE PRINCIPAL COMMERCIAL PRODUCTS OF THE COCO-NUT TREE.}

THE coco-nut tree, when fully matured and in good crop (the stem varying from 30 to $80 \mathrm{ft}$. in height, with its fine foliage, thirty leaves or more of a deep green colour and clusters of fruit in the heart of the crown), is without doubt one of the most elegant palms to be seen all over the world; however, apart from its beauty the real intrinsic value of the trees lies in the fact that practically its whole substance, that is to say, every part of it, may be utilized by the natives in all tropical countries where it is grown, but our intention here is only to mention those products derived from it of special commercial value.

Toddy and Sugar.-The process of extracting the juice for either the one or the other is the same. As soon as the spathe has sufficiently advanced so that the buds have all 


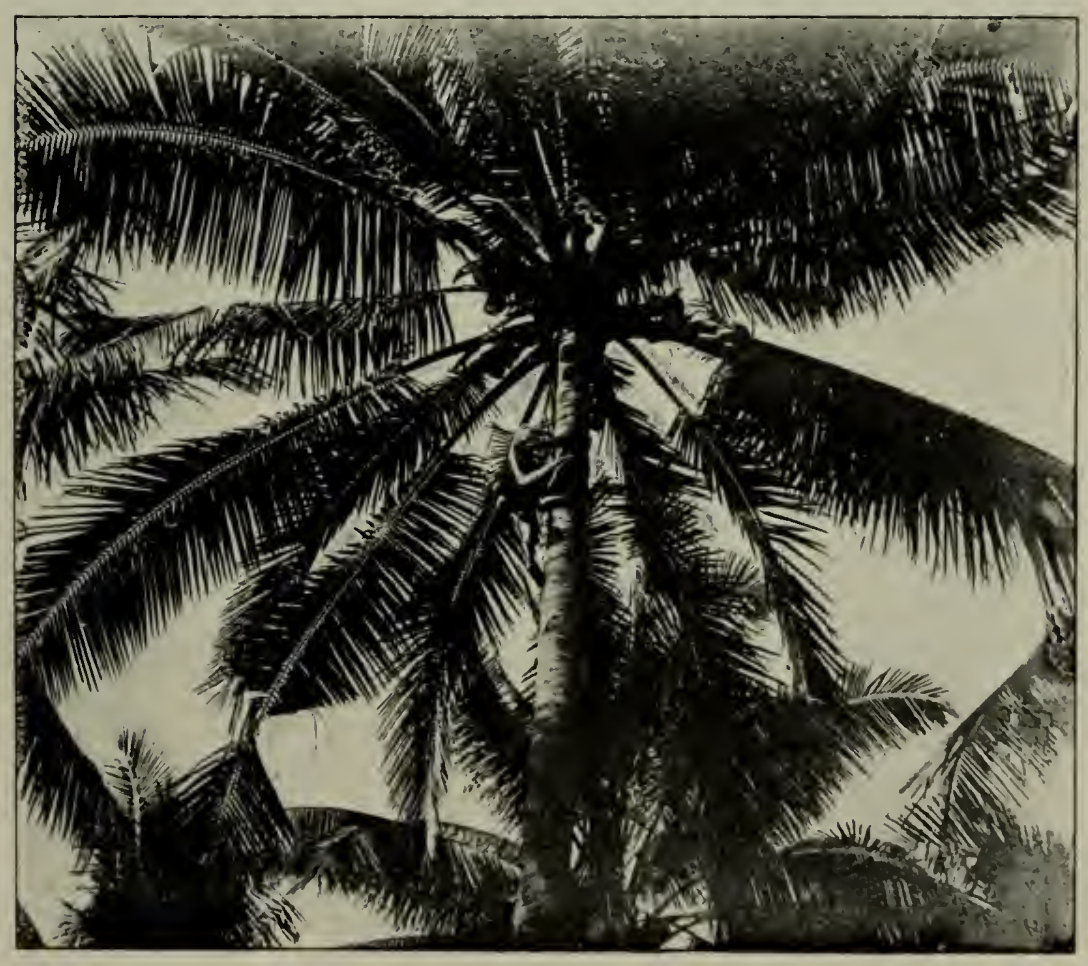

FIG. 85.- Native collecting toddy. 



\section{PRINCIPAL COMMERCIAL PRODUCTS 161}

formed just before they come into blossom, it is compressed and tightly bound round by pieces torn off from the under side of the leaf and tied in knots covering the buds and preventing them from coming into blossom; after which it is bruised all round with a bit of hard wood so that each part of it is slightly tapped to enable the juice to exude freely. It is then allowed to remain for, say five days, and at the end of this period the spathe is bruised in the same manner again and about 2 in. cut off from the end of the spathe. An earthenware or other vessel is then attached to the stem in such a manner as to collect the juice as it exudes. On the following day the same process is gone through and this is generally continued for twenty or .twenty-five days afterwards, or until such time as the juice ceases to flow.

This juice when fermented is commonly known as "toddy" and if not in any way tampered with or drugged as an alcoholic drink it is not considered unhealthy. Owing to its being a very favourite beverage among the Tamils and Indians generally, it has, a good marketable value; while if taken immedi- 


\section{GUIDE TO COCO-NUT PLANTING}

ately it comes from the spathe, quite fresh, it is by no means an unpleasant drink and in this way is often taken by natives (Malays themselves).

When it is intended to make "sugar" the juice is stored in earthenware jars and mixed with a certain bark which causes it to condense. Afterwards the liquid is placed in a large shallow iron pan and put over a slow fire; during the process of cooking the scum is removed from time to time and the contents kept continually stirred until it becomes of the consistency of sugar. It is then removed and usually put up in small packets made from a part of the coco-nut leaf and sold in this way.

The heavy cropping noticeable in some native holdings is very often attributable to the fact of the trees having been farmed out to the toddy-drawers. During the process of tapping no harvesting of nuts is of course to be expected, but, so far from damaging the tree, the treatment only tends to make it more prolific, and it will be noticed almost invariably that heavy yields ensue for two or more years after suspension of the tapping process.

Fibre Coir and Rope. - The husks are 


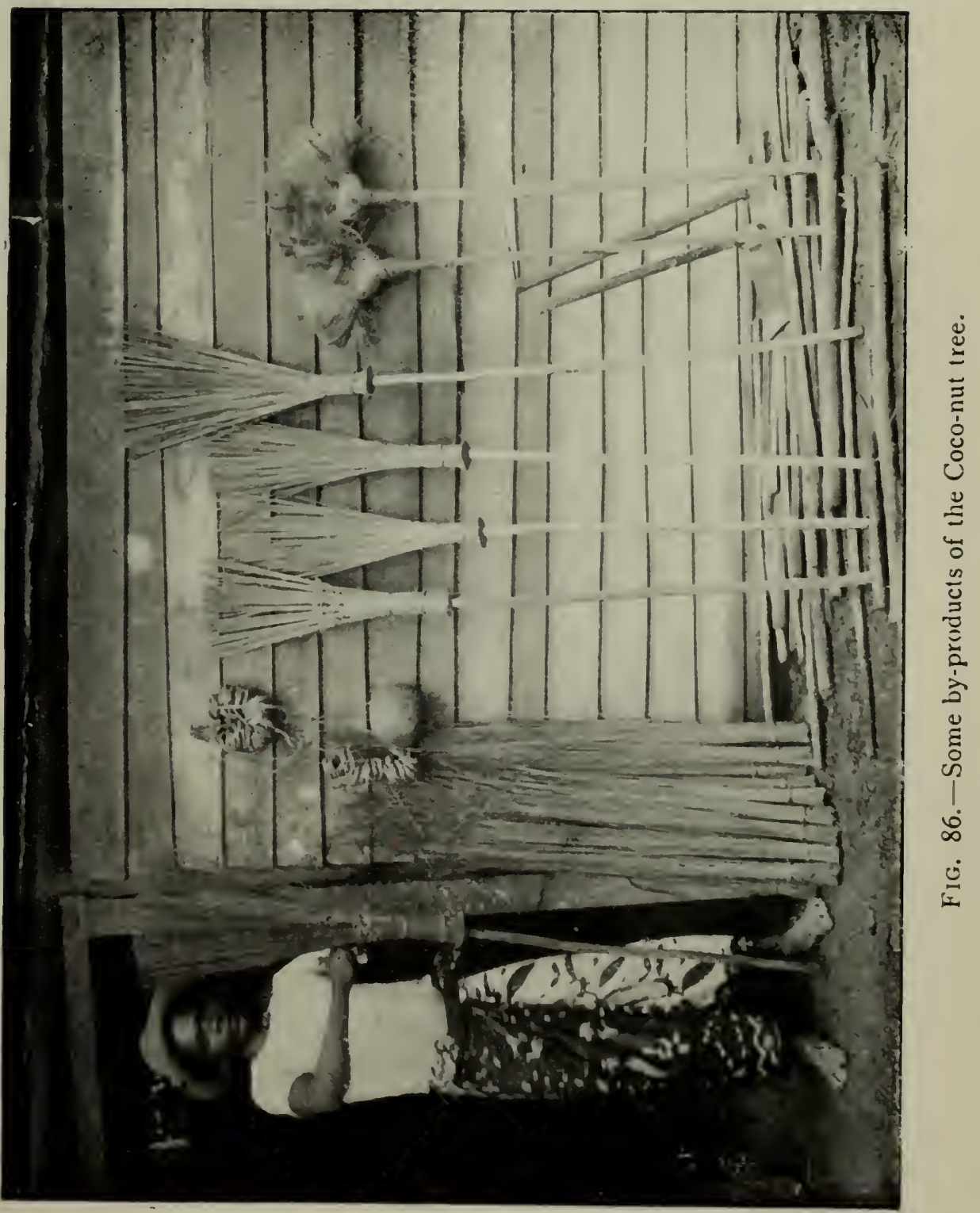



usually thoroughly soaked before being made into fibre and coir, and if these are to be produced on a commercial scale they must be dealt with by machinery for the purpose; at the same time it is quite possible to do the work by hand.

Copra is the kernel of the nut after it has been removed from the shell and dried, under a process which has been explained previously. It is from the copra that what is known as coco-nut oil is extracted, and from the refuse afterwards oil cake is made, mostly used for feeding cattle and other animals, and is also a valuable manure.

Oil.-Being a matter of such common knowledge it is hardly necessary to state that the coco-nut would not be cultivated from an economic point of view, with all its productiveness as mentioned above, were it not for the extreme value of oil contained in the kernel of the nut. Forming as it does the basis of all soaps it would appear that to the manufacturer of this article coco-nut oil is practically indispensable.

For the soap-maker many fatty ingredients are available, such as tallow, lard, palm oil. 


\section{GUIDE TO COCO-NUT PLANTING}

fish oil, and other lower grades for soft soaps, $\& c$. ; and if the outlets for coco-nut oil were confined to this market alone it is conceivable that at some time or other the supply might be in excess of the demand : but the increased value of coco-nut oil during recent years finds most of its explanation in the very extensive consumption of this particular oil as an article of food.

If it could be obtained in sufficient quantities, there appears little doubt that, owing to the up-to-date methods of refining, it need fear no competitor in the markets where a vegetable oil is a necessity. 


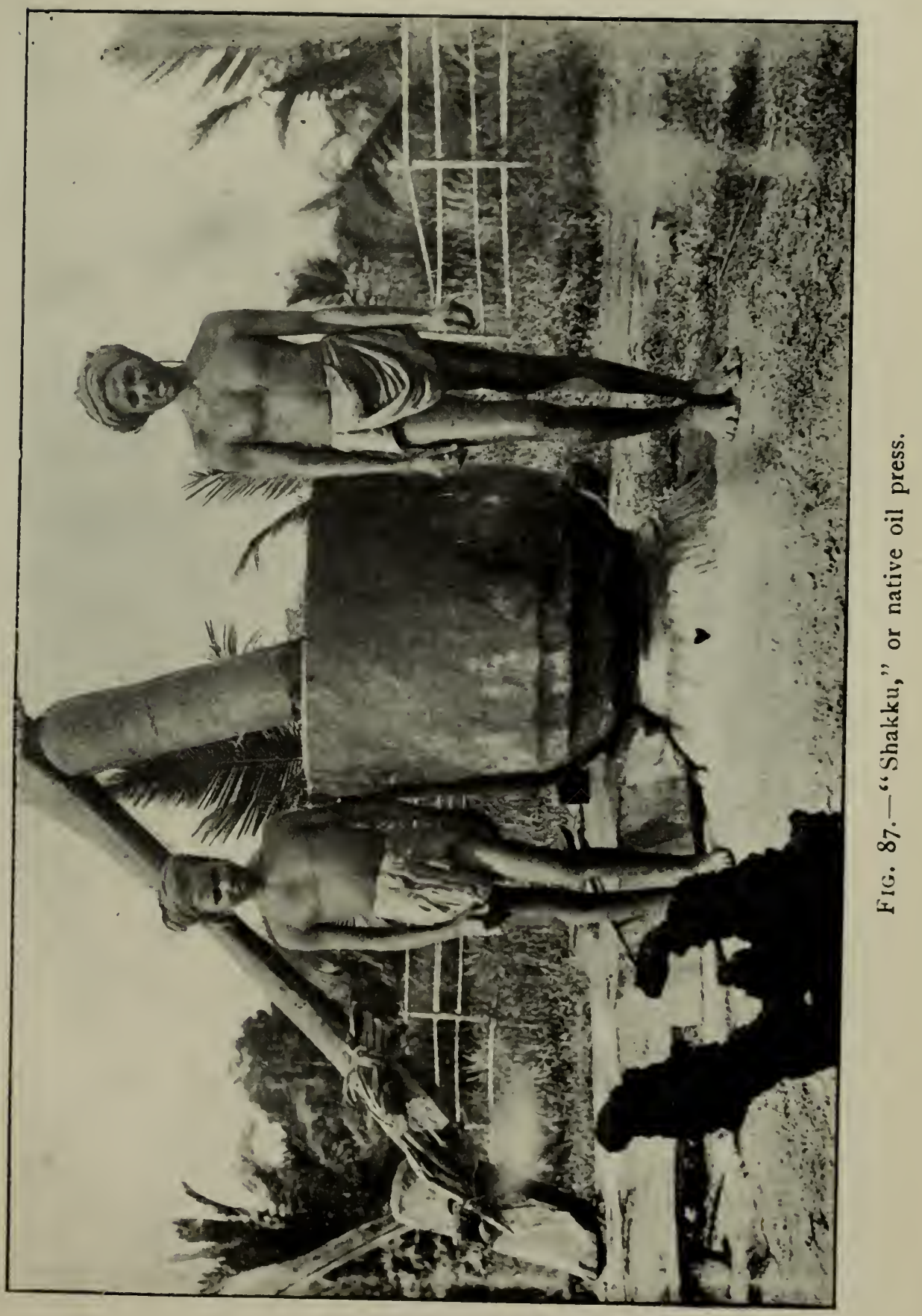





\section{THE COCO-NUT INDUSTRY IN THE FEDERATED MALAY STATES.}

THE area planted with coco-nuts at the end of I9I3 was approximately about I74,234 acres, apportioned to the four States as follows :-

$$
\begin{array}{lllllll}
\text { Perak } & \ldots & \ldots & \ldots & \ldots & 90,664 & \text { acres } \\
\text { Selangor } & \ldots & \ldots & \ldots & \ldots & 43,56 \text { I } & , \\
\text { Negri Sembilan } & \ldots & \ldots & \ldots & 20,875 & \\
\text { Pahang } & \ldots & \ldots & \ldots & \ldots & \text { I9, I34 } & \text { ", }
\end{array}
$$

showing an increase for the year of 16,634 acres, or equivalent to about IO $\frac{1}{2}$ per cent., a very satisfactory extension.

The following tables, which show the progress of the industry in the States during the last ten years, may not prove uninteresting :- 
166 GUIDE TO COCO-NUT PLANTING

Extension of Area under Cultivation. At the end of $1903 \quad \ldots \quad \ldots \quad 77,500$ acres

\begin{tabular}{|c|c|c|c|c|c|c|}
\hline " & $"$ & 1904 & $\cdots$ & $\cdots$ & 89,600 & $"$ \\
\hline " & , & 1905 & ... & $\ldots$ & 100,000 & $"$ \\
\hline$"$ & $"$ & I9o6 & $\cdots$ & $\cdots$ & 105,000 & ", \\
\hline$"$ & $"$ & 1907 & $\ldots$ & $\ldots$ & I I 2,000 & $"$, \\
\hline$"$ & $"$ & I908 & $\cdots$ & $\ldots$ & I I 8,697 & " \\
\hline$"$ & $"$ & I909 & $\cdots$ & $\cdots$ & I 23,8 I 5 & $"$ \\
\hline$"$ & $"$ & I9IO & $\cdots$ & $\cdots$ & I 30,344 & " \\
\hline$"$ & $"$ & I 9 I I & $\cdots$ & $\ldots$ & I 42,774 & $"$ \\
\hline$"$ & $"$ & I9I 2 & $\cdots$ & $\cdots$ & I 57,600 & $"$ \\
\hline$"$ & ", & I9I3 & $\cdots$ & $\cdots$ & I 74,234 & $"$, \\
\hline$"$ & $"$ & 1914 & $\ldots$ & $\cdots$ & I 98,000 & " (about) \\
\hline
\end{tabular}

Copra Prices.

\begin{tabular}{|c|c|c|c|c|c|c|c|c|c|c|c|c|}
\hline & 1903 & 1904 & I905 & 1906 & I907 & I908 & 1909 & Igro & rgri & I912 & 1913 & 1914 \\
\hline Highest \$ & 9.85 & $9^{\circ} 10$ & $8 \cdot 70$ & I I $1^{\circ} \infty$ & $I I \cdot 30$ & $8 \cdot 50$ & 10.70 & I I 80 & 12.00 & $11 \cdot 75$ & $14^{\circ} 00$ & 12.40 \\
\hline Lowest \$ & $6 \cdot 30$ & 7.00 & $6 \cdot 80$ & $7^{\circ} 00$ & $7 \cdot 40$ & $6 \cdot 15$ & $7 \cdot 25$ & $9 \cdot 25$ & $8 \cdot 35$ & 10.20 & I I 20 & 6.00 \\
\hline
\end{tabular}

Production of Copra Exported.

During I904 Piculs I6,404 Valued \$I23,2I6

\begin{tabular}{|c|c|c|c|c|c|}
\hline , & 1905 & ," & 30, I 72 & ", & 230,665 \\
\hline " & 1906 & $"$ & 38,772 & $"$ & 302,383 \\
\hline " & 1907 & ", & 49,326 & $"$ & $45^{2,270}$ \\
\hline " & I 908 & $"$ & $7 \mathrm{I}, 98 \mathrm{I}$ & $"$ & 462,870 \\
\hline " & I909 & " & 104,469 & $"$ & 726,884 \\
\hline " & rgro & $"$ & I 25,770 & $"$ & $1,194,226$ \\
\hline " & IgI I & $"$ & I 35,064 & " & $I, 294,301$ \\
\hline " & I9I 2 & ", & $\mathrm{I} 29,53 \mathrm{I}$ & " & $I, 303,169$ \\
\hline " & I9I 3 & " & I 56,033 & ", & $1,808,933$ \\
\hline & & $\mathrm{Pl}$ & 357,522 & & $\$ 7,898,917$ \\
\hline
\end{tabular}




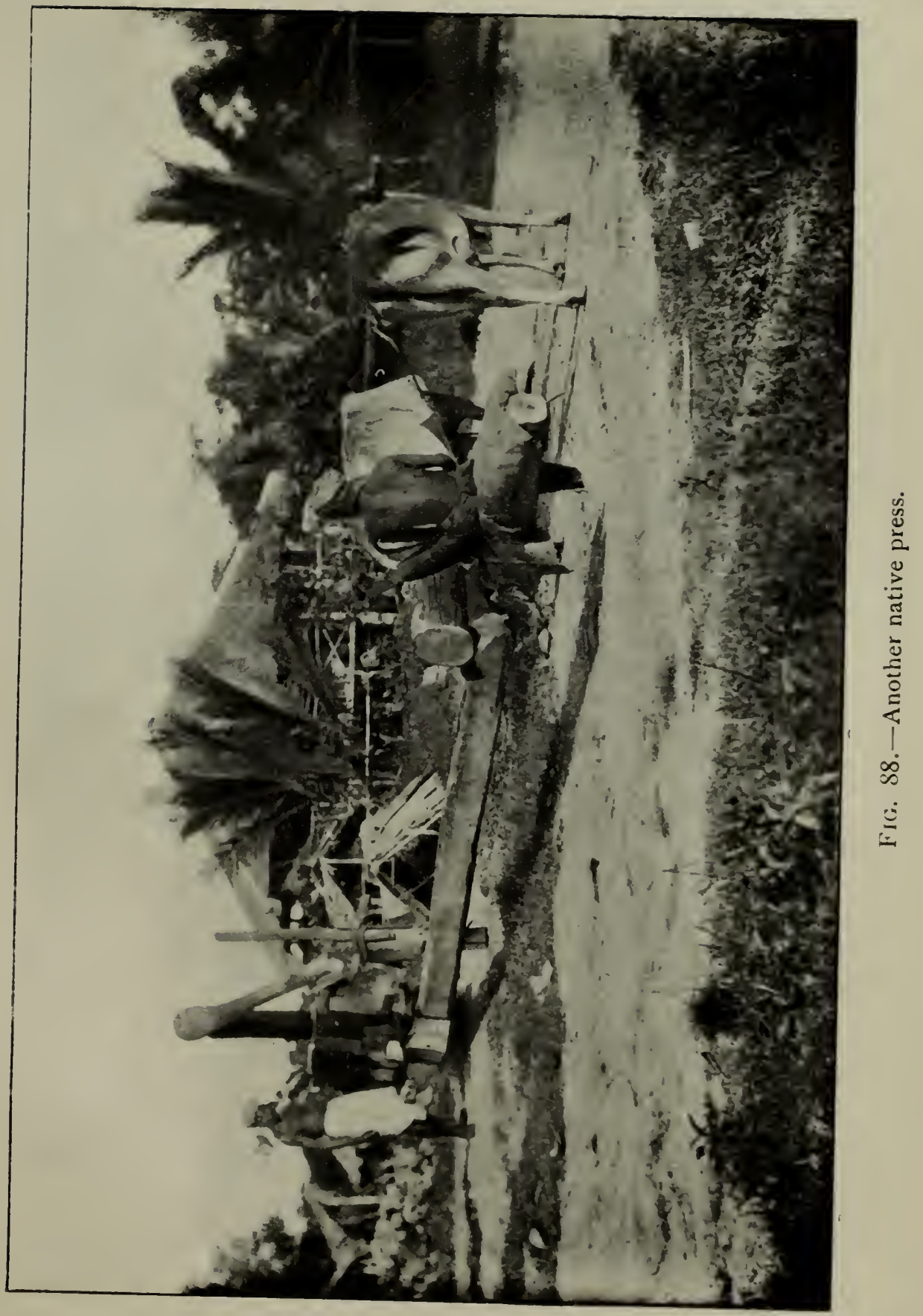

Fare p. 166. 

The average price obtained for nuts in "Native Holdings" during the same period was as follows:-

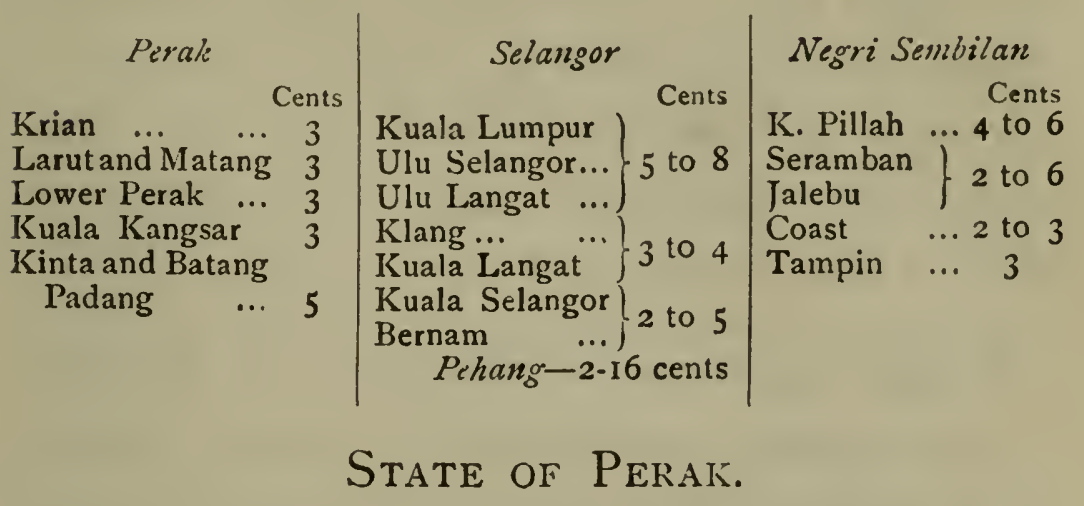

The largest contiguous area planted is in the district of Lower Perak, between the Perak and Bernam Rivers. The land in these parts is flat and low-lying, and the soil, which is alluvial, is very rich, and where thorough drainage is obtainable can be made well suited for coco-nut cultivation. It is not uncommon here to see the young trees showing flower in their third and fourth years, and also when they come into bearing the yields are generally satisfactory, while a good average crop may be depended upon each year when the palm has reached maturity. There are also several other parts on or near the coast where the trees may be seen doing well. 


\section{State of Selangor.}

As in Perak, most of the plantations, where the trees come into early bearing; are on the coast and some little way inland between the Bernam and Sepang Rivers, and are grown practically under the same favourable conditions and advantages as in Lower Perak.

\section{States of Negri Sembilan and Pahang.}

As regards Negri Sembilan we may mention that a particularly interesting feature in the industry was the introduction of the dwarf coco-nut during 1912, on what we may fairly call "a commercial basis." The two estates, which are about seven miles distant from Port Dickson, in the coast district, adjoin one another, but until the trees are more matured it is impossible to say how the experiment is likely to turn out. The promoters certainly deserve success for testing what, anyhow on a large scale, may be called an untried cultivation,. and we trust that the result may be such as to induce others to go in for it. With the exception of these two estates and one large estate at Kuala Pahang, the areas at present in these States mostly belong to Malays, and 
are termed native holdings or kampongs, to which reference will be made further on.

European Cultivation.-It is difficult to estimate, except approximately, the actual cultivation under European ownership, but roughly speaking it may be probably about 40,000 acres. The trees in nearly all these estates are still comparatively young, but on the few plantations where the trees have reached maturity there is reason to suppose that the yields will not be unsatisfactory and will show quite a good return on the outlay.

This may account for the fact that the extension by the Europeans of the cultivation is rapidly increasing, and recently large tracts of land have been acquired by them in the coast districts of Perak and Selangor.

On some of the estates above referred to it has been thought advisable to inter-plant coffee and other crops with a view to assisting towards the expense of maintenance until the area becomes self-supporting.

The scheme, although more than feasible theoretically, has not all the advantages claimed, as it is obviously impossible to give intensive cultivation to two products, and 
therefore in the majority of cases the one has had to suffer for the other. Unfortunately, it is mostly the main product that has been allowed to suffer, otherwise better results would have been shown as regards the yields from coco-nuts.

\section{Native Holdings and Kampongs.}

Of the area under cultivation already mentioned, perhaps as much as four-fifths comes under this heading. The majority of these are held in small lots varying from two to ten acres. These kampongs are for the greater part situated near or on the banks of the several rivers running through the States, again on the various Permatangs, or higher land among the paddy lands, while a good many will be found in close proximity to the villages bordering on the sea.

Some very fine palms may be seen in these small plantations, yielding in certain cases an average of quite roo nuts per tree per annum; at the same time there can be little doubt that this is mainly due to the number of houses erected and persons living on the premises-in fact, the former are often almost 
surrounded by trees. Since the establishment of the Government Department towards the end of 1902, expressly formulated to deal with and rigorously enforce the provisions of the Coco-nut Trees Preservation Enactment, the maintenance of the kampongs generally is much improved and, in consequence, the natives are getting better results from the trees in many cases than they formerly did; but there is still room for further improvement, and it is reasonable to anticipate that with the greater powers given by the Pest Enactment, lately introduced, a good deal may, in the future, be done in this direction.

The Coco-nut Ordinance was drafted merely for the purpose of dealing with the coco-nut beetles, which at the time were causing enormous havoc among the trees; and there can, we think, be little doubt, had not prompt and proper measures been taken to arrest the spread of the pests, that a great deal of the land under coco-nuts would have been abandoned. As it is, the interest in coco-nut cultivation has had a distinct set-back and suffered accordingly. Fortunately, through the efforts of the staff, the danger has now been entirely 
overcome, and in addition much has been accomplished, mostly by persuasive measures, to encourage the natives to give more attention to their holdings by demonstrating to them the advantage to be gained by better husbandry. The results, we are pleased to say, have in many districts proved fairly successful, and some of the Malays are beginning to realize the benefits that accrue from following the advice tendered to them.

As regards these holdings it would be difficult to imagine anything more ideal for the habitation of Malays than some of the kampongs in the district of Temelok, Pahang. They are exceptionally favourably situated on the banks of the Pahang river, the water of which for the greater part of the year is some 20 to $25 \mathrm{ft}$. below the level of their land. Now that the owners have been induced in their own interest to give more attention to the cultivation of their coco-nuts many of the kampongs are quite clean and maintained in good order. The grass, kept down by the grazing of sheep and buffaloes, is generally of a bright soft colour which lends a very pleasant appearance to the plantation. On 


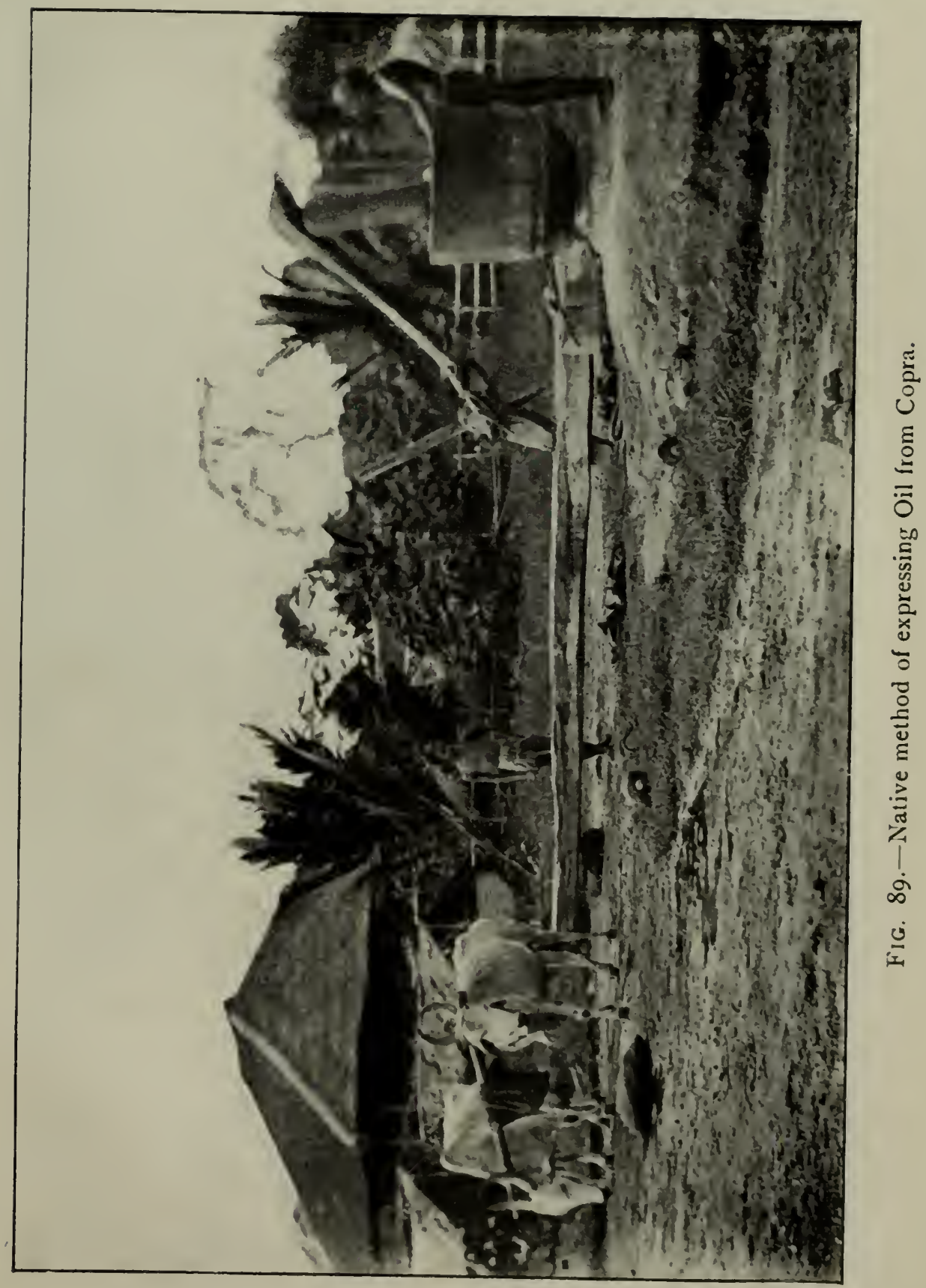



each kampong there is always at least one commodious attap building, and sometimes more, for the owner and his family and relations, and with the adjoining paddy land also cultivated, and the coco-nuts, fruit trees, \&c., on the premises, the products of which alone should prove ample for their support, the Malays appear to have everything that is needful for their welfare. That the Government attach great importance to these native holdings may be gathered from the fact that at the end of 1913 a law was passed entitled the "Malay Reservations Enactment" for reserving and delineating in the States certain areas for the sole occupation of Malays, and the conditions of the land held under the Enactment are as follows :-

(a) No State land within the reservation shall be sold or leased to any person not being a Malay;

(b) No right or interest of a Malay in such land may be transferred;

(c) Neither execution, sale, nor charge shall be of effect. The provision marked (b) may be permitted for a period not exceeding thrée years. 


\section{GUIDE TO COCO-NUT PLANTING}

While on the subject of native holdings, we may here point out the advantages the natives gain under the "Coco-nut Cultivation Enactment" in Kedah, an adjacent State, the object of which is to encourage the planting of coco-nuts by small proprietors in certain districts outside the paddy-planting area.

Any person who is cultivating, in any of the districts enumerated in the Schedule of the Enactment, land of which the area does not exceed 20 relongs ( 26 acres) and in respect of which he has paid land tax or land rent for the past year, may, on planting not less than thirty coco-nuts, obtain remission of land tax or land rent in respect of one relong of his land for three years. Further, he can obtain remission of land tax for the same period for an additional half relong of land for every fifteen trees planted.

In order to obtain the remission authorized, the owner of the land with coco-nuts must report to the penghulu within six months from the date of planting. The penghulu himself, or his deputy, is then required to visit the land, inspect it and count the number of trees upon it which, in his opinion, are not more 
than six months old. After this, he is to issue a certificate to the owner, who has to take it to the land officer of the district. The latter is empowered to act on the penghulu's certificate without further inquiry and to issue to the owner a second certificate exempting him from land tax or land rent in respect of that area of his land which contains coco-nut trees at the rate of 30 to the relong, no areas being included in addition to the first relong that is less than half a relong in extent.

When the land officer's certificate covers all the land owned by the proprietor, the latter is exempt from attendance at the land office until the fourth year; when only part is so covered the proprietor is required to pay land tax or land rent upon the residue not planted in coco-nuts, or not retaining them at the specified rate.

If a man plants coco-nuts on part of his land only in the first year and obtains remission of the land tax or land rent for that year, and then plants a further portion of his land in the second year he can obtain a second certificate from the penghulu in respect of the second portion, which entitles him to the remission 


\section{GUIDE TO COCO-NUT PLANTING}

of land tax or land rent in respect of that portion for a further period of three years.

The Director of Lands is required to send land rangers to inspect lands for which the special privileges of this enactment have been granted, and the same officer must, on a report from the land officer, send land rangers to make inquiries if a penghulu is suspected of neglecting his duties, or of not acting in accordance with the provisions of the Enactment. Thus a certain amount of supervision is provided.

We cannot conclude our remarks on the native holdings without alluding to what was once a very common practice by Malays of collecting coco-nuts with the monkey called the "Broh." We do not all take life in the patient and easy way of the Malay, and this is a particular instance, we think, of their peculiar character in this respect, for while it might certainly, perhaps, be both an amusing and interesting spectacle to watch for a short time, we do not think there are many nationalities who would have the patience that the proceeding requires. In the first place, it very often takes much urgent pressure to get the monkey 
A series of fourteen photographs illustrating the life and work in progress on various estates. 



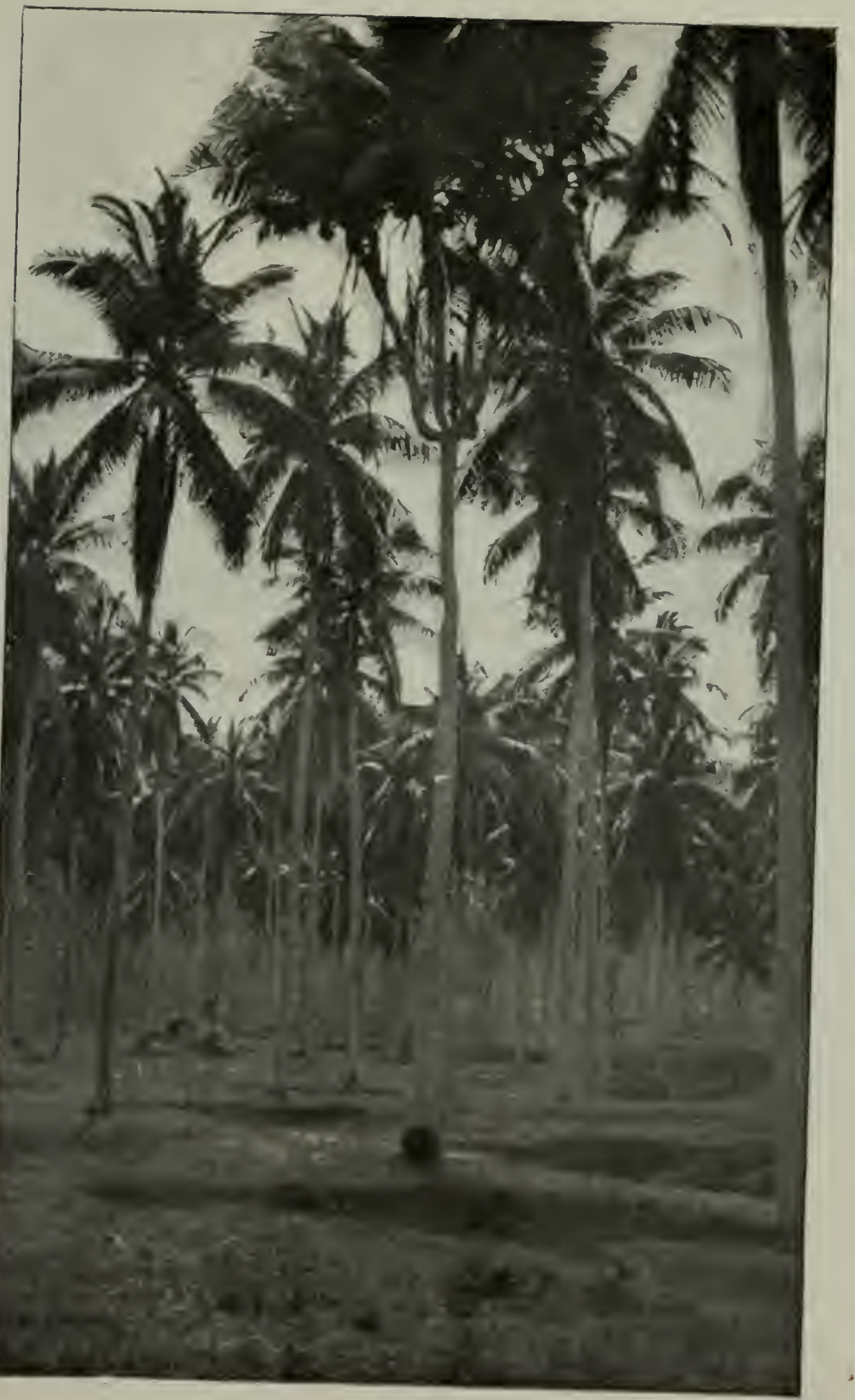




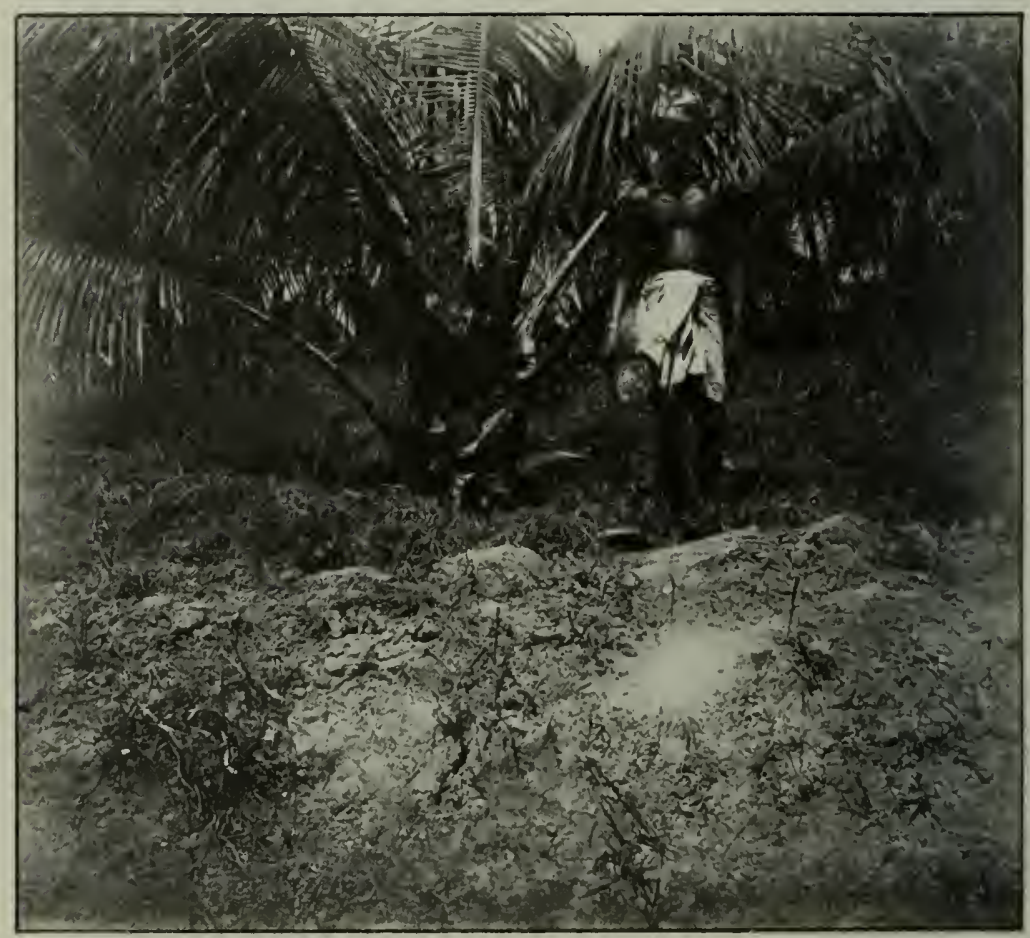




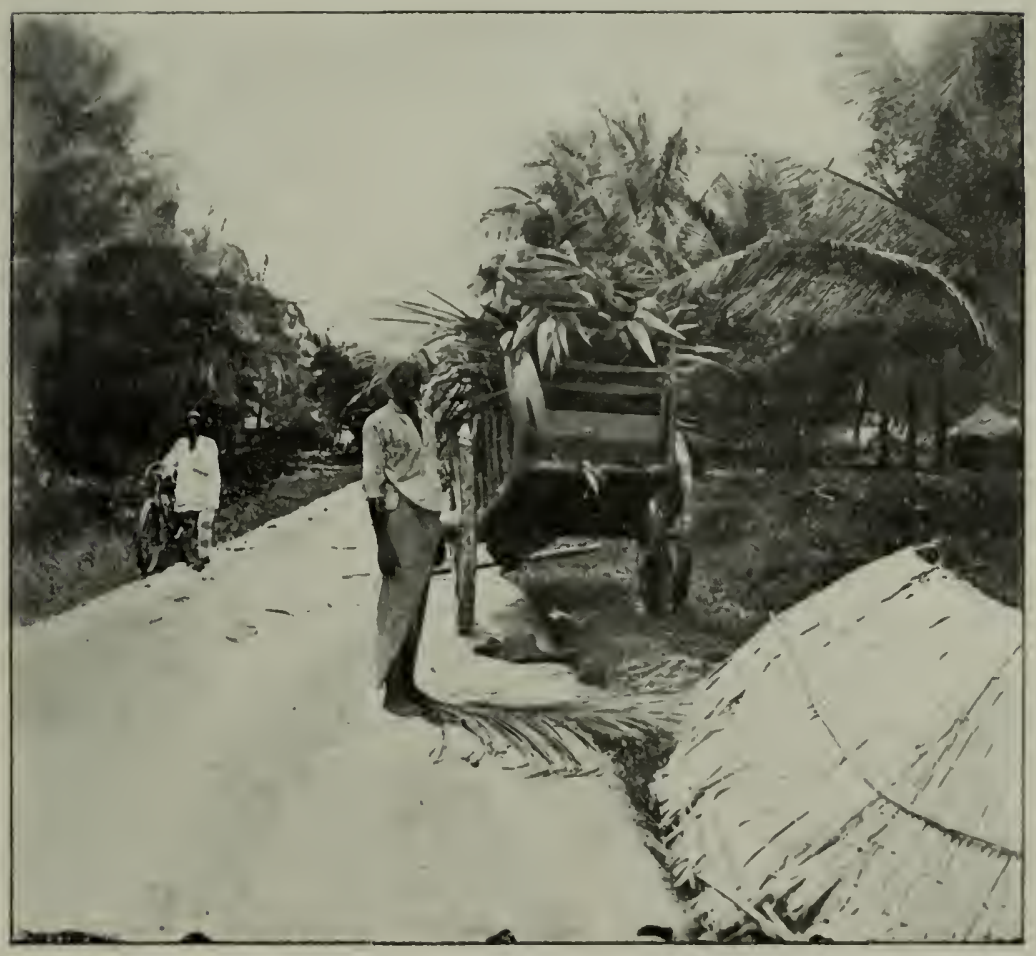




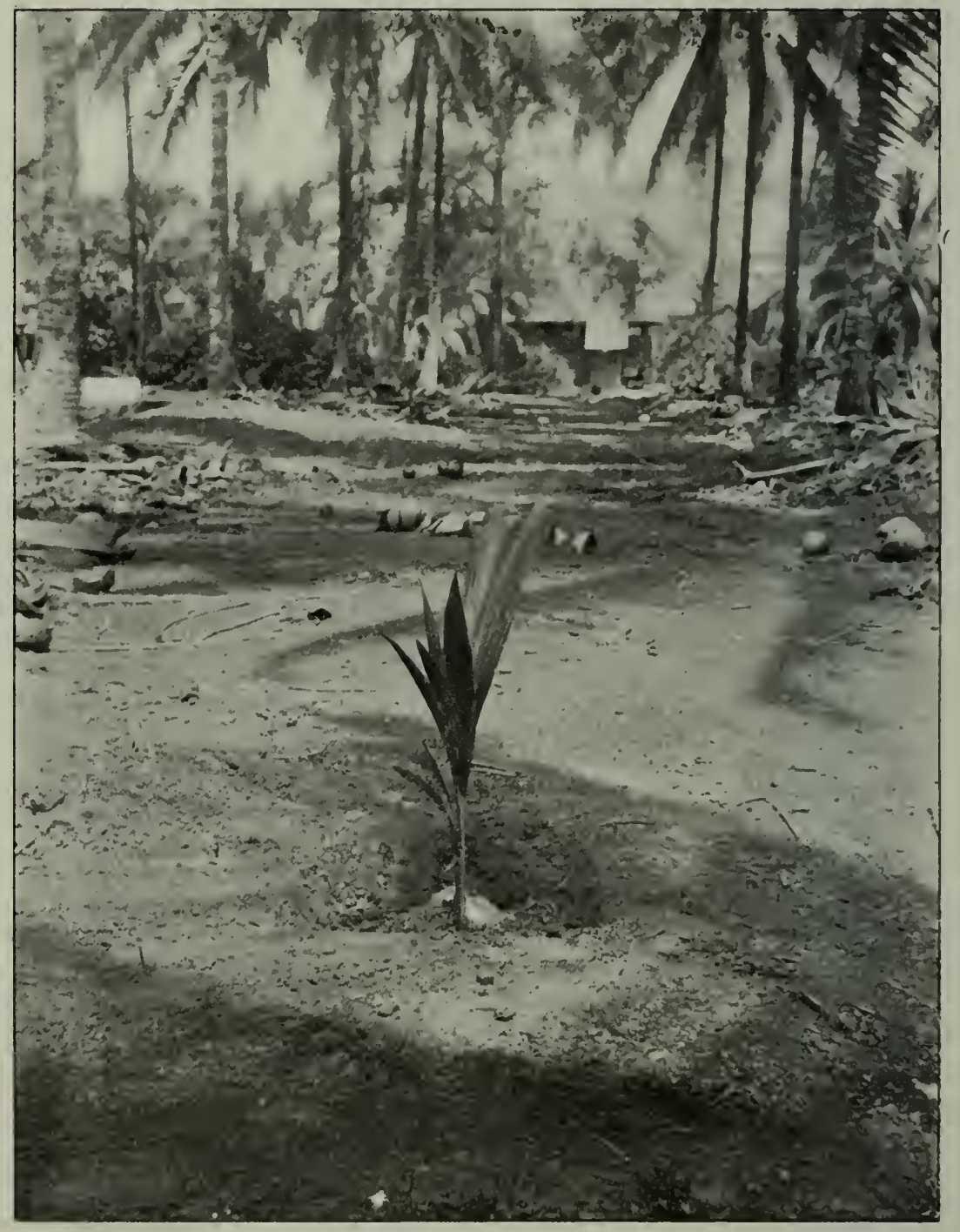




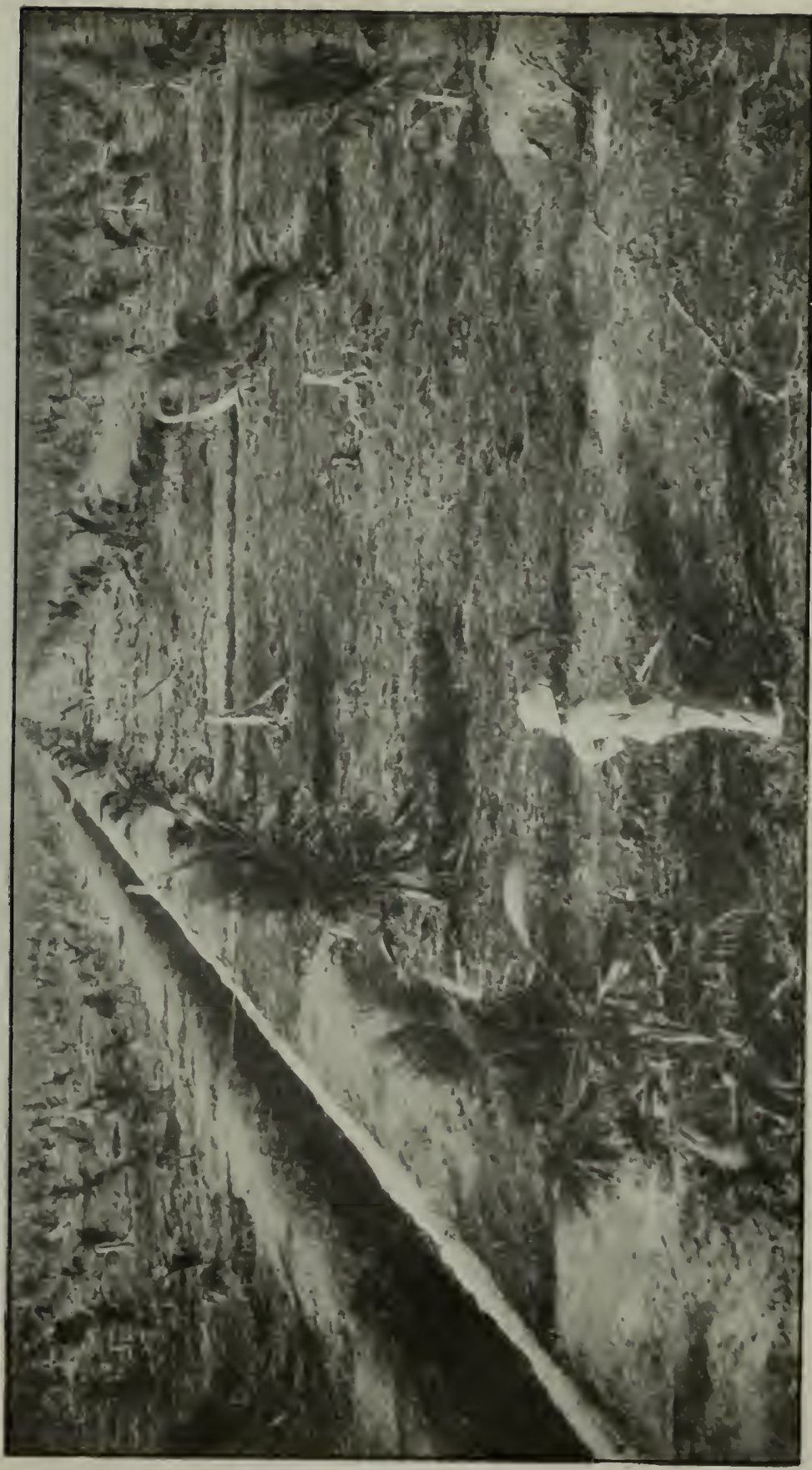




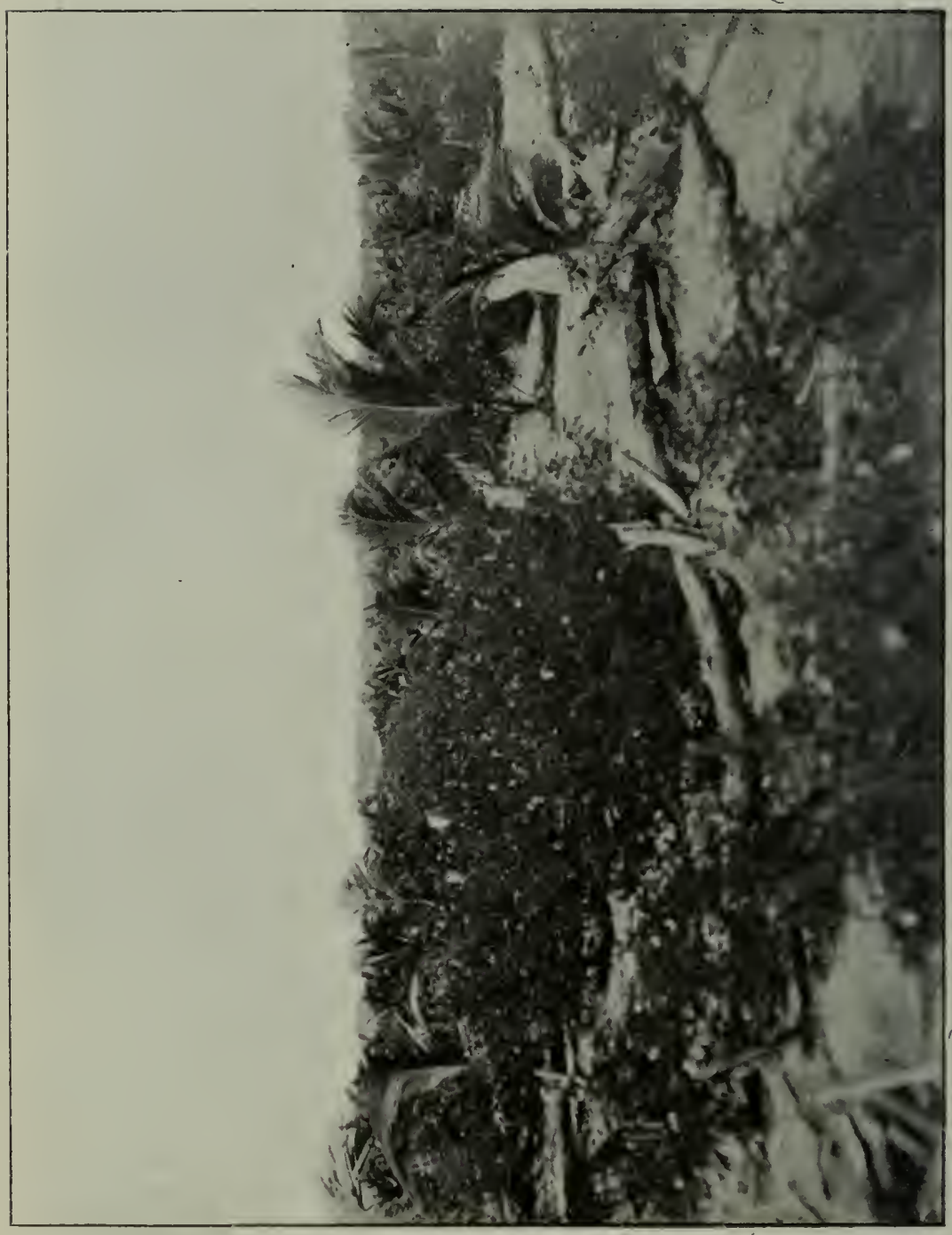




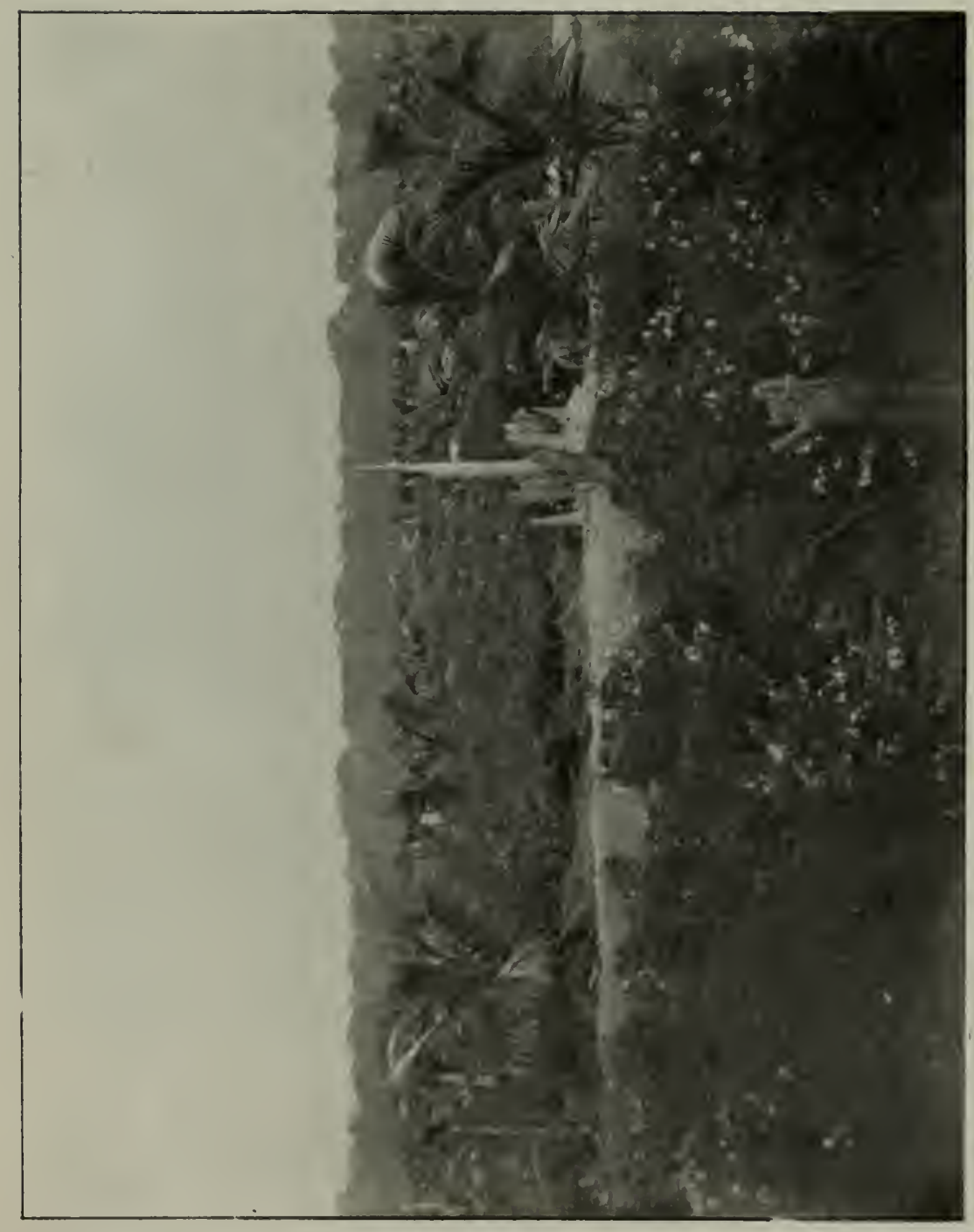




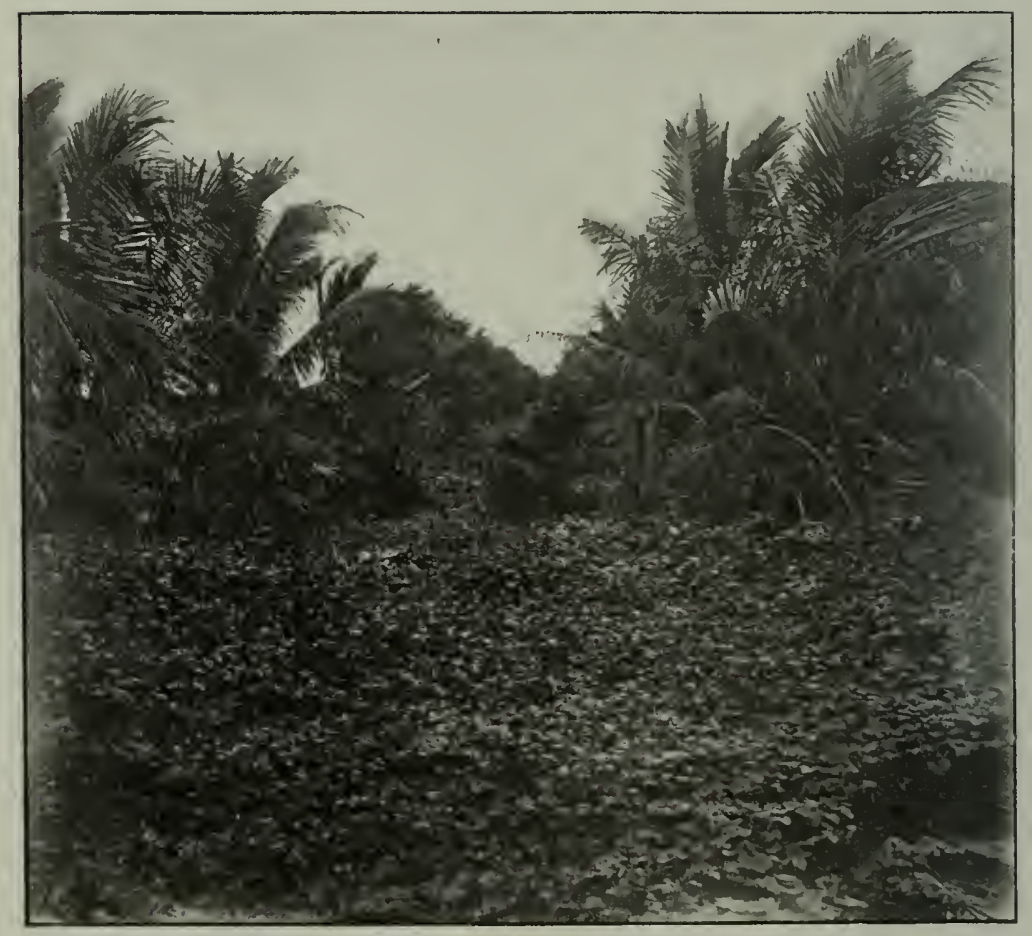




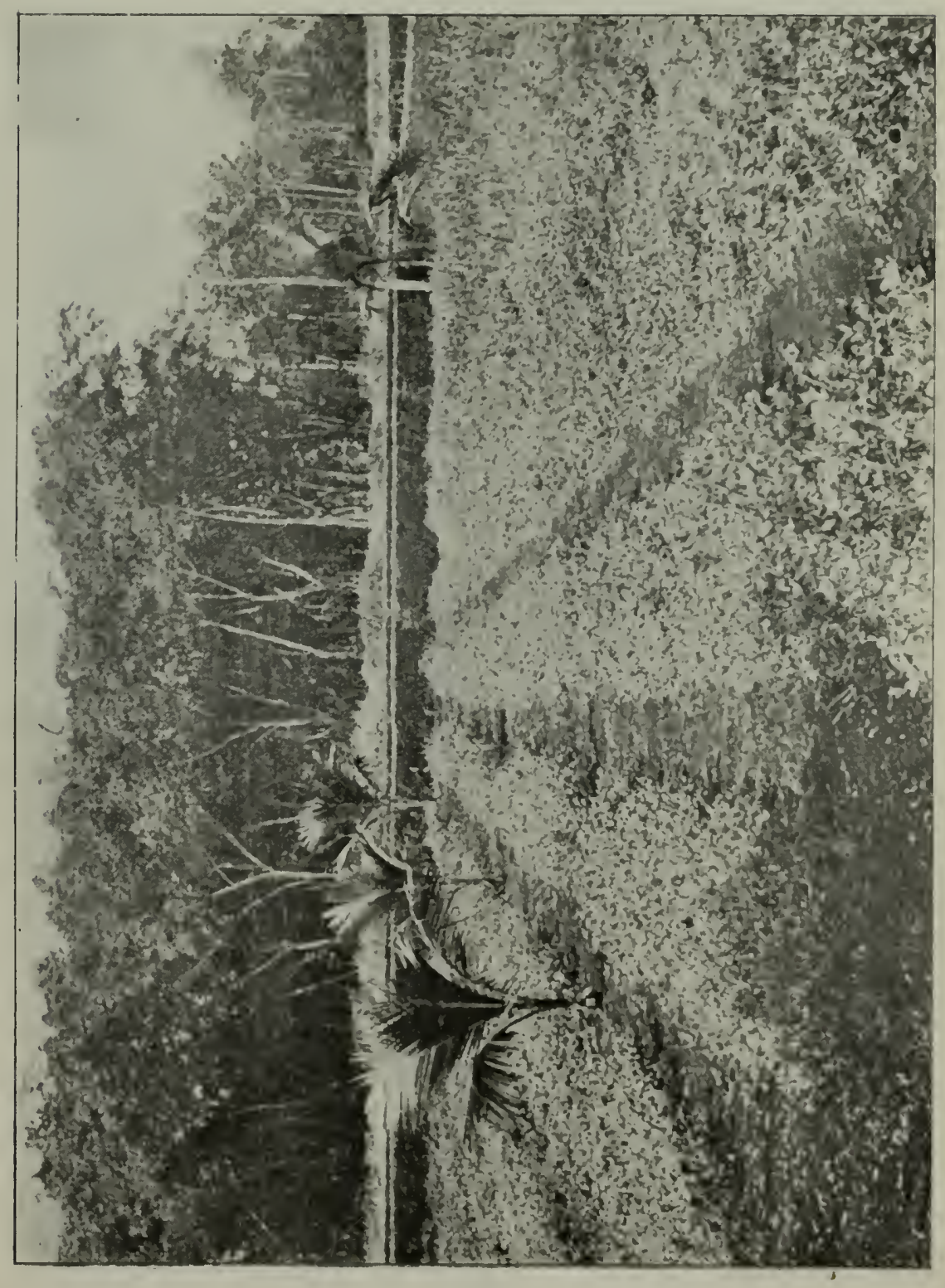




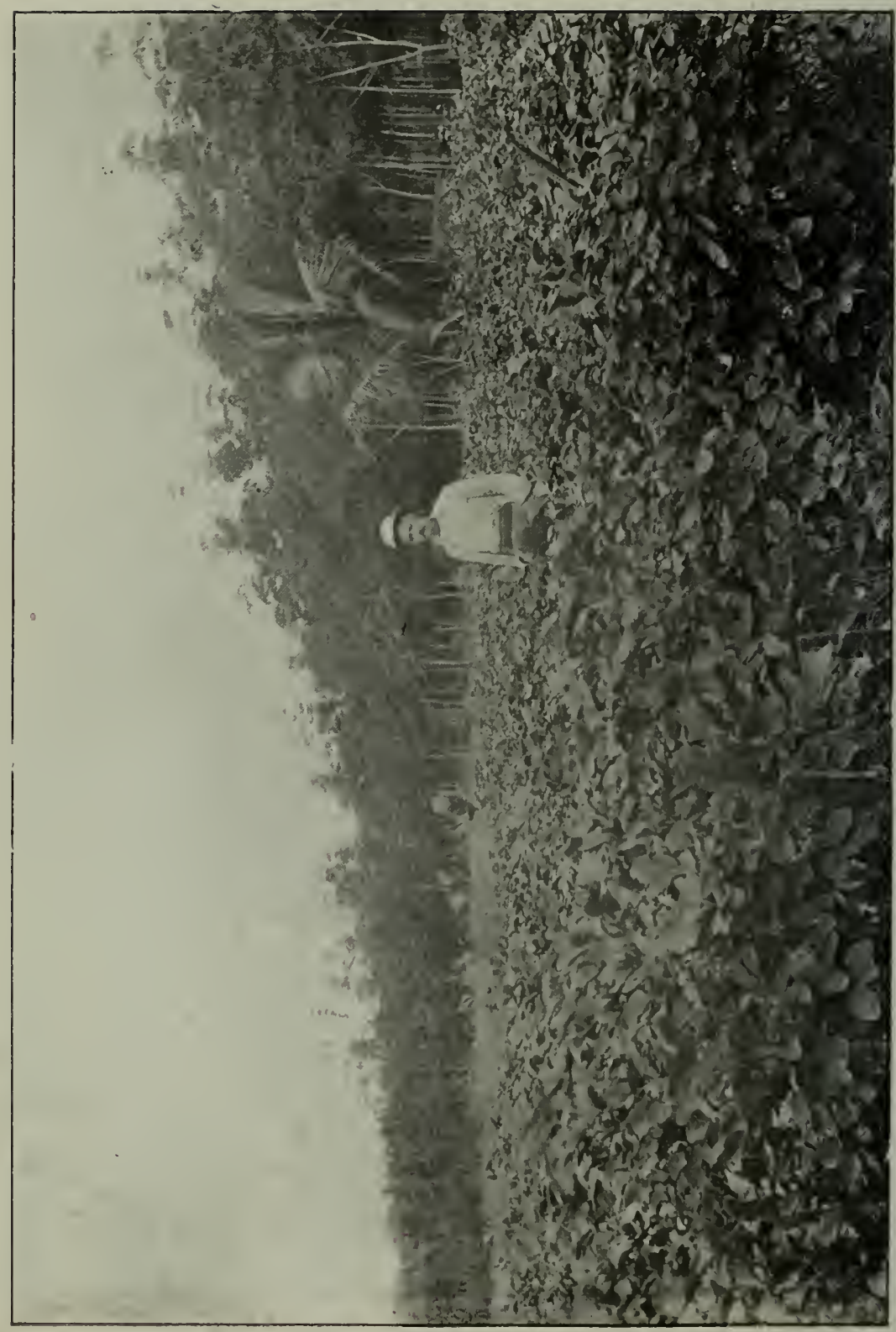




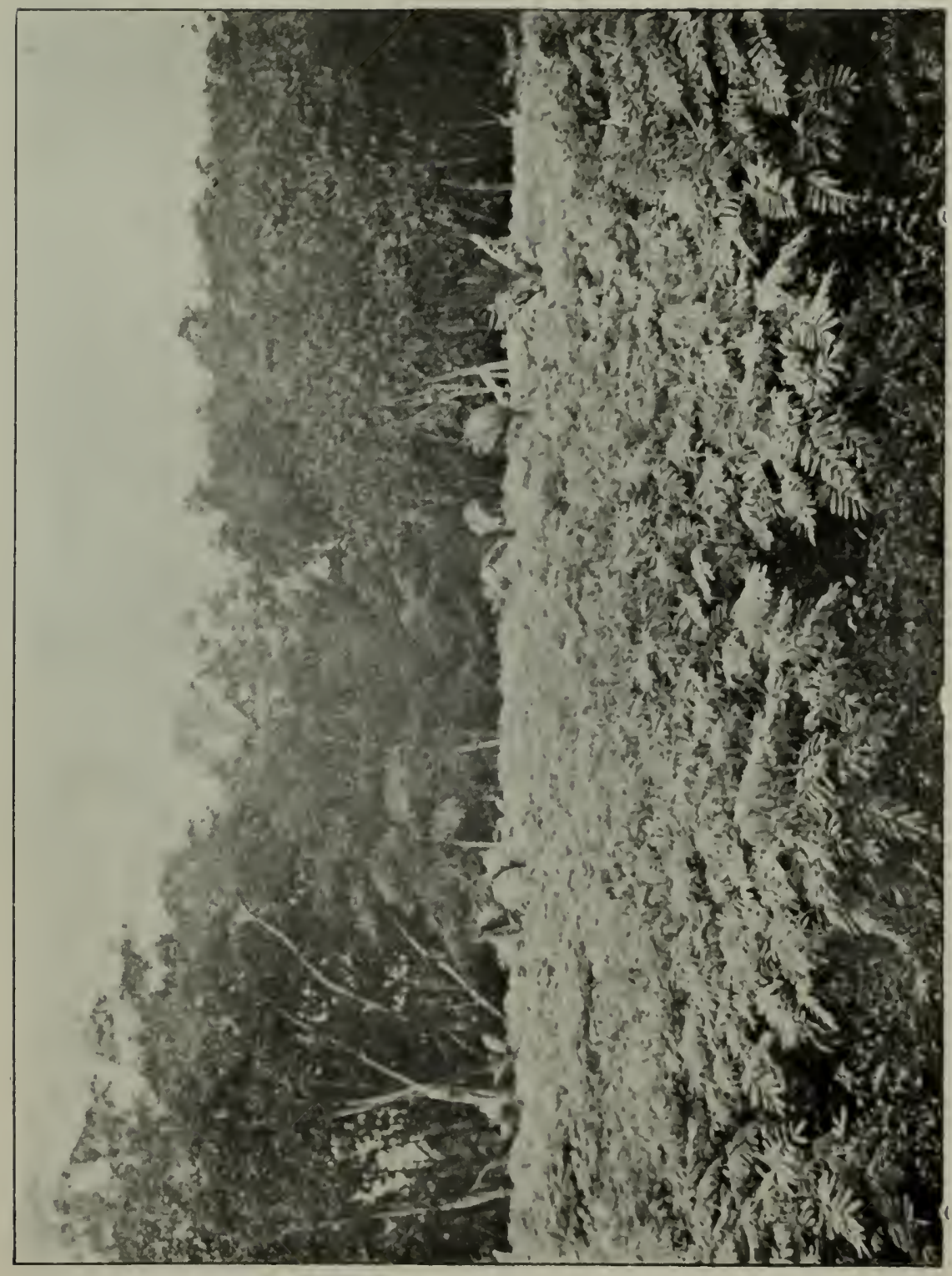




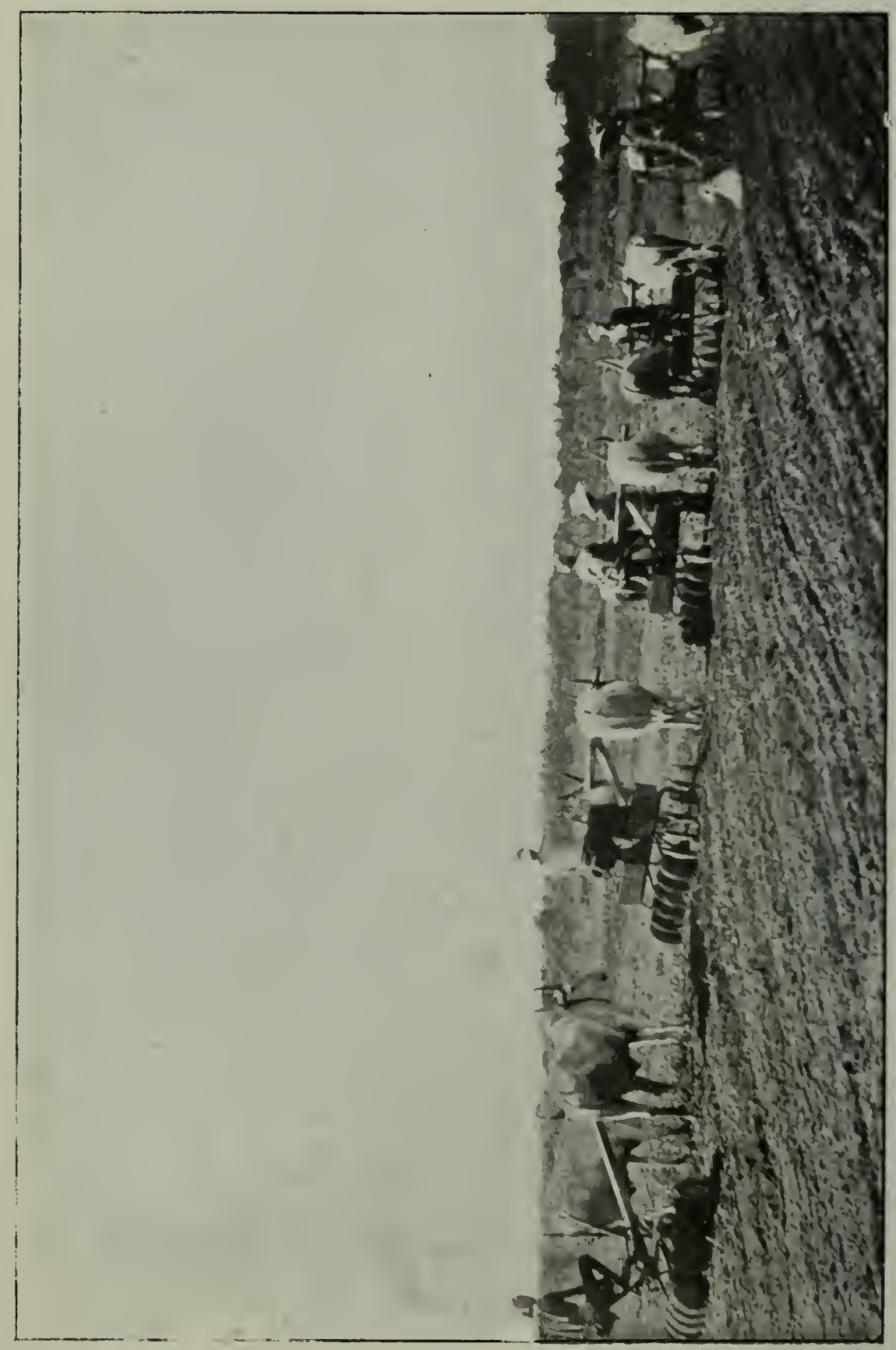




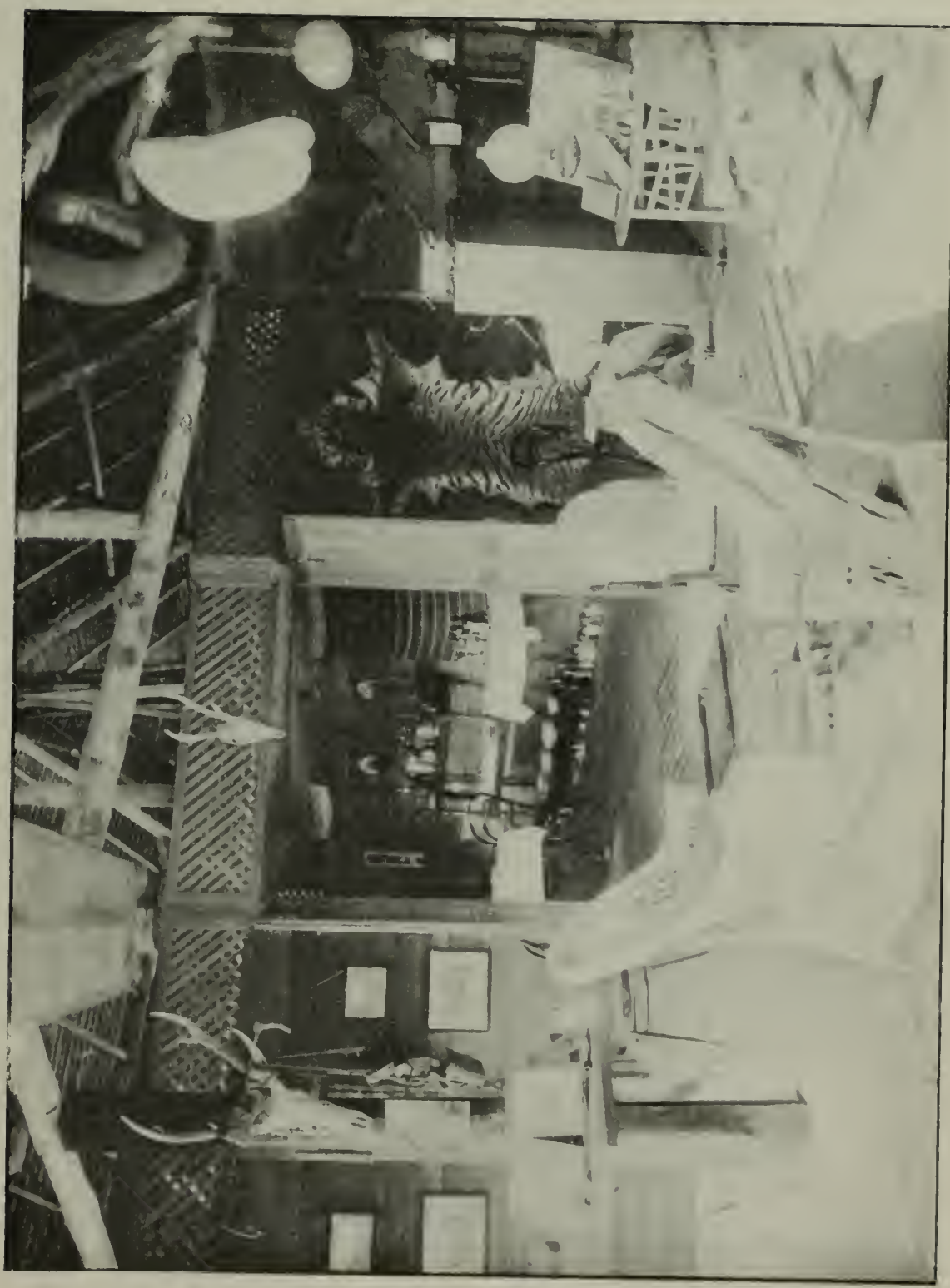




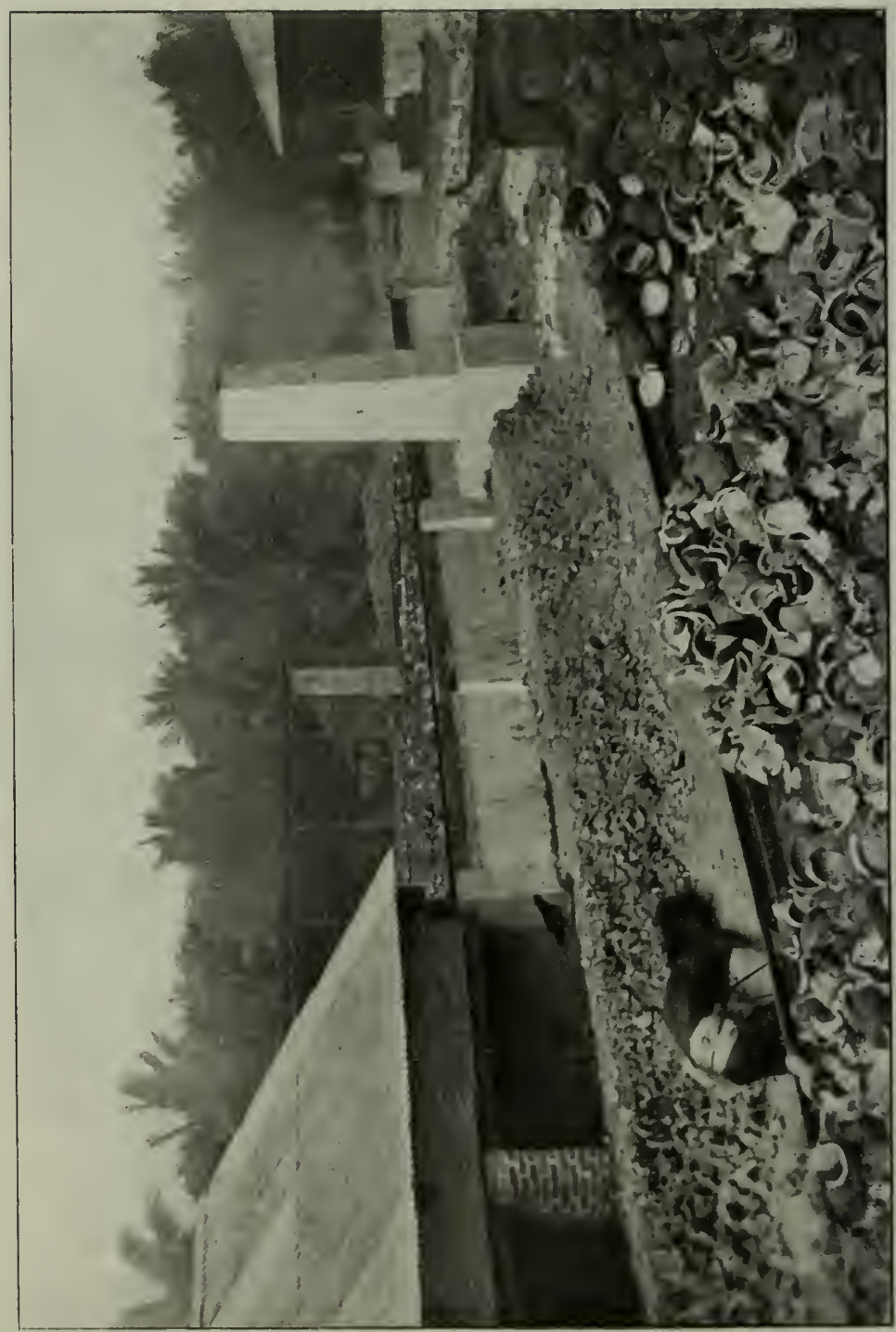


to climb the tree at all. When it does at last reach the crown of the tree many tugs by the Malay at the rope to which the monkey is tied (as will be seen in the illustration given) are required to direct the animal to the ripe fruit that has been selected; meantime, often more than one unripe nut comes away before the proper one is collected. Again the monkey absolutely refuses-notwithstanding that there are many shouts and commands from the man at the foot of the tree-to be hurried and apparently takes his own time in doing the work required.

Apart from this very tedious process it would, we think, be quite impossible to devise a worse method of collection. Fortunately, therefore, the custom, with the exception of the "State of Pahang and a few other places, has almost ceased to exist in the Malay States. 


\section{APPENDIX.}

The Diwarf or King Coco-nut (Nyor Gading) in Federated Malay States.

(Contributed by the Editor of Tropical Life.)

WhILsT passing this second impression for publication several communications came to hand almost simultaneously, with further particulars of the dwarf coco-nut mentioned by the authors on pp. 35-37. As one of my letters was from Mr. L. C. Brown, giving me a discretion in the matter, I have decided to "lift" from the September-October, I9 I 9, issue of The Agricultural Bulletin of the Federated Malay States, an important article contributed by Mr. Will. P. Handover, manager of the Sungei Nipah Estate in Negri Sembilan, on the progress made with this variety since pp. 35-37 were written, and to publish these notes as an illustrated appendix.

I take it that wherever the palms on the 


\section{APPENDIX}

Sungei Nipah Estate came from, the variety itself hailed probably in the first place from the dwarf variety that flourishes in the Nicobar Islands, and which is said to yield about eighteen to twenty-four months from the date of planting. ${ }^{1}$ Dean Copeland, when in charge of the Los Baños Agricultural College in the Philippines, discusses the various kinds on pp. I I I-I I 3 of his book, "The Coco-nut," where he tells us a good deal more of these smaller palms than any other writer whose books or articles have so far come before me. One wonders, therefore, whether there are more dwarf varieties or trees of one variety, to be met with in the Philippines than elsewhere. Perhaps some reader of these notes can throw some light on the subject.

Coming to Mr. Handover's article in the Federated Malay States Bulletin, he tells us that "the increasing rise in the price of copra having given renewed activity to coco-nut

${ }^{1}$ See C. G. Chakrapani Ayangar, B.A., in the December, I9I9, issue of the Wealth of India, p. 535. What is meant by the term "from the date of planting" ? Ic must be from the time that the seedling, not the seednut, is put out in the field.-(ED., T.L.) 


\section{GUIDE TO COCO-NUT PLANTING}

planting in this country it is important that some facts of that interesting variety, the Dwarf Coco-nut, should be put on record," and he then goes on to say:-

Description. - The dwarf coco-nut known in this country as nyiur gading (or nyor gading) is remarkable for its early fruiting, palms only Io $\mathrm{ft}$. high bearing abundant fruits touching the ground. The young palm grown under good conditions starts to flower in its third year and produces ripe fruit in about nine months from the appearance of the flower spike. The initial flower spikes contain only male flowers, but other spikes occurring in rapid succession are larger and bear an increasing number of female flowers also, a spike from a six-year-old tree being counted with 200 young female flowers, whilst trusses of fruit from similar trees have been found with as many as fifty-five ripe nuts. The dwarf coconut is generally of a bright yellow colour, and Windstedt in his quotations from Malayan Folk Lore speaks of 'nyiur gading, the golden coco-nut, only to be found in princes' gardens.'

There is, besides, a distinct brick-red variety, also a green variety, and a number of inter- 


\section{APPENDIX}

mediate colours which might be ranged as ivory yellow (hence "gading"), golden yellow, orange, brick red, green bronze, and deep green. The flower spikes, leaf bases, and leaf ribs, correspond in colour with the fruit, giving the compact trees a very handsome appearance. Again there are semi-tall trees of these different colours, which are later coming into bearing, have slightly larger nuts, and are less prolific than the true dwarf.

The dwarf yellow strain appears as the most prolific, whilst the other varieties vary proportionately in their productiveness and also in the shape and size of the nut; they are evidently the outcome of cross fertilization from original types, or "mutants."

The different varieties are distinguished amongst the Malays and Javanese under particular names, such as nyiur (klapa) gading, $k$. merah (or rajah), k. kapak, k. prsang; k. puyok, k. babi,k. sepang and k. mipah (klappa, of course, is the Dutch term for coco-nuts).

A full grown leaf of the "nyiur gading" measures only $\mathrm{I} 2 \mathrm{ft}$. from base to tip, whilst an average ripe nut is $22 \frac{1}{2} \mathrm{in}$. by $24 \mathrm{in}$. in circumference, and the palm stem 24 in. in girth; the 


\section{GUIDE TO COCO-NUT PLANTING}

nut has an average amount of fibre, a thin shell, and proportionately with the big nut a good thickness of white kernel. This "meat" is said by the Malays to be richer in oil and sweeter in taste than that of the big coco-nut, and it is therefore very popular with them for domestic purposes.

In spite of diligent inquiry it has not been possible for the writer to find out the definite origin of this dwarf nut, but it seems first to have occurred as a "sport" or "mutant" probably in Java. Trees, thirty years old or so, occur in different parts of the peninsula and many of these still bear abundantly.

In I9 I 2, 500 acres were planted with these dwarf nuts at Sungei Nipah Estate, on the coast between Port Dickson and Sepang Point, and this is probably the only estate of dwarf coco-nuts in the world. The seed nuts for this were obtained from trees, then about twelve years old, grown by the Malays on the "bendangs" of the Krian rice district, who are reported to have got their original seed, individually at a dollar each, from ships arriving at Pendng probably from Java. From reliable reports from India it appears that this dwarf 
form is practically unknown, either in Malabar, the Madras Presidency, or Ceylon, though isolated groups, as that of the "king coco-nuts" at Mount Lavinia, doubtless occur. Scattered trees also occur throughout Java and Sumatra, but not in any quantity, seed for planting having been sent to all the places named, also to Manila, and to the northern and eastern States of the Malay Peninsula.

With regard to its growth, like all coconuts, this dwarf form appears to be exceedingly hardy, growing well either in white clay, red loam, or deep peat; in fact it seems to thrive in any situation where wa'er is abundant, yet not stagnant, though it is evident that well drained alluvium suits it best. In such a soil six-year-old palms have been counted with 234 nuts on (excluding ovules) and the trees average eighty nuts a year. The only figures available, however, are those from Sungei Nipah, where, unfortunately, the young palms were allowed in the early days of the war to get choked by lalang during the third year, and although they have responded wonderfully to better treatment since, this set-back at so critical a period will doubtless have its effect 


\section{GUIDE TO COCO-NUT PLANTING}

throughout the life of the trees. The Malays say " nyiur gadang suka perkawan," and palms near dwellings readily demonstrate how well it responds to good treatment.

The crop in the first year of production at Sungei Nipah, over 225 acres, was 102,000 nuts, whilst the second year it was 574,000 nuts, and the third year it will probably be nearly a million; from which the writer considers an average yield for dwarf nuts may be predicted as follows :-

At the end of $4^{\text {th }}$ year $=$ Ist yielding year $=$ Io nuts per tree.

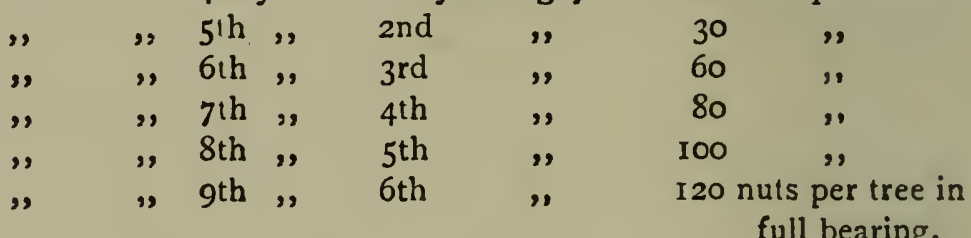

full bearing.

1 I have heard that this estimate was not reached. If it was not, there must have been something seriously the matter, but I cannot, unfortunately, say what the cause was unless the smaller crop was due to the enforced neglect and consequent choking by lalang mentioned on page 183. Critics have claimed that these dwarf varieties do not maintain the excellent yields they start with; one correspondent in the Malay Mail for instance, spoke, from hearsay, of the crop going down after the eleventh year, but this was denied. If, however, the estate ur.der discussion did not reach the estimated million nuts in the third year, during which $\mathrm{Mr}$. Handover 


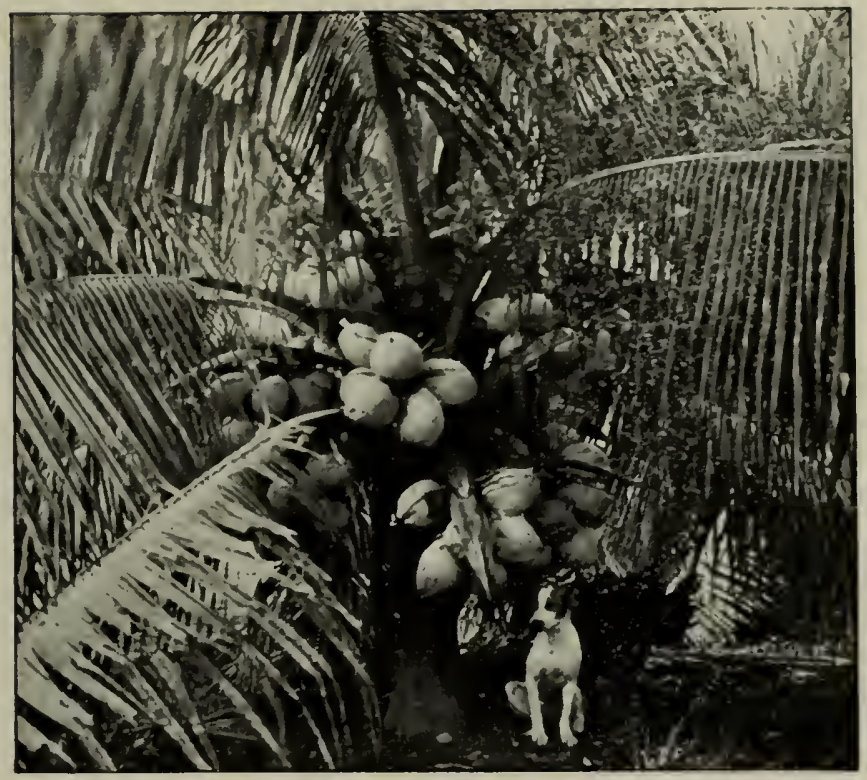

FIG. 90.-Dwarf coco-nuts growing on clay, Negri Sembilan, Federated Malay States.

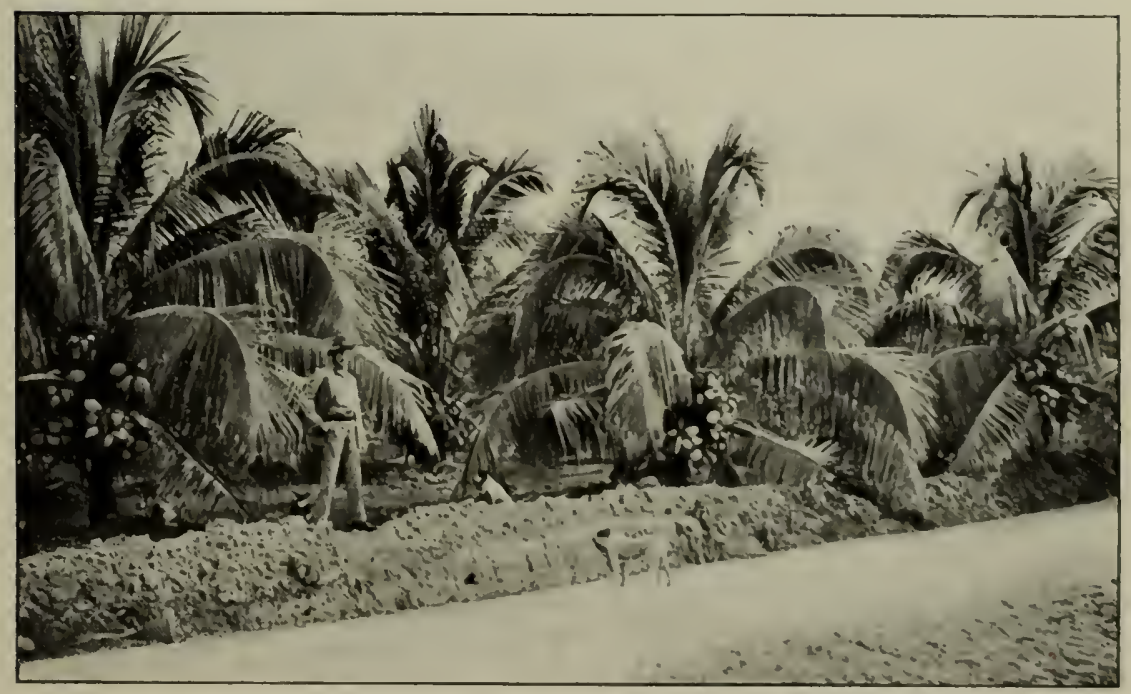

FIG. 91.-Dwarf coco-nuts on four-year-old trees on Sungei Napah Estate (taken Christmas, 19I7), Negri Sembilan, Federated Malay States. 




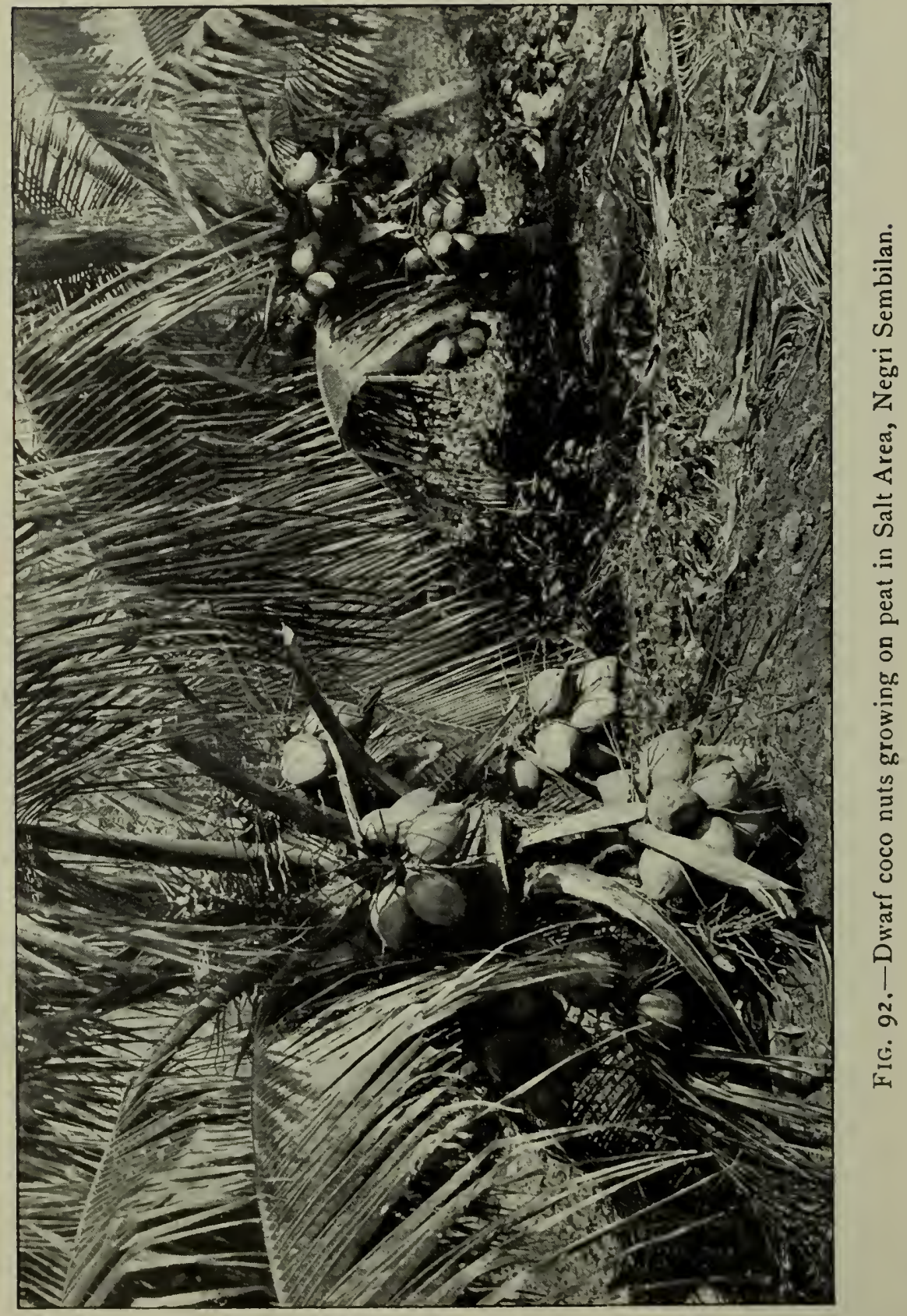




\section{APPENDIX}

These estimates in face of yields from individual trees will appear conservative, but there are many points which have tc be considered when dealing with average yields, and no doubt under ideal conditions a much higher average could be obtained.

In making copra it has been found that the nut from a young tree is smaller than that coming later, and its kernel likewise thinner, whilst of course on heavy yielding trees the nuts are a little below the average in size, but 500 nuts to a picul of copra is a general average, which would be decreased somewhat later as more even nuts with thicker "meat" were obtained. With the leaf length only

was writing his article, if the reputation of these dwarf palms is not to suffer, the exact cause of this "throwback" must be ascertained. We want to know what the total crop amounted to in I.9I9, and also-in due course-what it will work out at during the present year, for, if the output starts to shrink and remains on a lower level, the claims made by this article fall to the ground. Suppose, for the sake of argument, only three-quarters of a million nuts were gathered in 1919, or, if wished, only half a million, which means a crop smaller than the one shown for I9I8; what could have caused such a falling off, and is the cause a temporary or a permanent one? [Ed. T.L. June, I920.] 


\section{GUIDE TO COCO-NUT PLANTING}

I $2 \mathrm{ft}$. it was found convenient to plant the palms $24 \mathrm{ft}$. by $20 \mathrm{ft}$., which gave 90 to the acre, a number nearly double of that required when planting big palms.

It will be evident, therefore, that with this planting we should get, say, in the fifth year of planting $90 \times 30$ nuts $=2,700$ nuts per acre $=\frac{27}{5}=5 \frac{2}{5}$ piculs copra per acre. Likewise, in the ninth year $90 \times 120=10,800$ nuts per acre $=\frac{108}{5}=2 \mathrm{I} \frac{3}{5}$ piculs copra per acre. Comparing this with the big coconut which does not produce till after its fifth year but might be estimated as giving in its ninth year 45 trees at 40 nuts $=\mathrm{I}, 800$ nuts per acre $=\frac{1800}{220}=8$ piculs of copra per acre. With the dwarf trees there is the great advantage of easy and rapid picking, and inspection for beetles and other pests, though of course in manufacture one has to handle almost $2 \frac{1}{2}$ times the number of nuts per picul of copra, but this is not of so great consequence when working with newly devised methods and machinery and dealing with large quantities.

The profit per acre from five-year-old dwarf coco-nuts to-day can even stand comparison with that of rubber, and the man who 


\section{APPENDIX}

is planting to-day and has to consider markets five years ahead, might do worse than place confidence in the dwarf coco-nut.

Leaving Mr. Handover to show what actual crops his dwarf palms gave last year and what they will yield during 1920, it will be interesting to know, in any case, the parent centre of the dwarf coco-nut, and how many varieties there are. Are they "sports" or "freaks" and the bigger palms and nuts but more vigorous strains and bétter developed varieties of the normal parents of these smaller trees? Mr. O. W. Barrett, in his Bulletin No. 25, on "The Philippine Coco-nut Industry," published from Manila in 1913, speaks on p. $5^{1}$ of the Dwarf, Dahili or Mangipod nuts, "which palm appears to be more or less common throughout the Archipelago, and from its habits of early maturity and apparent prolificness, it is recommended as a variety for planting. Besides this there is still another rare form of dwarf coco-nut which yields a large number of small nuts, some of them not more than 6 to 8 centimetres ( 2 to 3 inches) in diameter when husked." .

In contrast to these, the same paragraph 


\section{GUIDE TO COCO-NUT PLANTING}

goes on to say that extremely large nuts probably do not pay. It is questionable whether the giant nuts, claims Mr. Barrett, are anything more than vigorous strains of the more common kinds. The chances are that nuts of the giant type when planted in a nursery with others, would not only develop a stronger seedling, but that the plant itself would tend to show the character of the parent even under adverse conditions. If this is so, why cannot the opposite happen and so cause these dwarf varieties, either in the Nicobars, in the Philippines, or elsewhere, to do the same as the giants but in the opposite direction, and so become smaller instead of larger. Furthermore, whilst the planting of the giants is not considered to be advisable, as the yield in copra per acre does not seem as being likely to equal that from ordinary palms, the yield in copra per acre from the dwarf varieties, or at least from some of them, seems to surpass that obtained from the usual run of coco-nuts on the estates and in the smaller gardens.

Dean Copeland in his book on "The Coconut," also in the Philippines, tells us of several dwarf varieties (see p. II I), as, for instance, 
the coco niño, or baby nut, which produces at four years of age, when the trunk is so short that the nuts can be collected for several years by persons standing on the ground. Mr. Handover's photographs make it appear as if the nuts themselves touch the ground in some cases. The coco niño is also exceedingly productive and has been known to give I 2 and I05 nuts in two successive cuttings two months apart. It yields a rather thick and hard copra. The Pugai, we are told, is a very dwarf nut, 7 centimetres in diameter, with a husk 2 centimetres thick. Apparently rather a curiosity than a useful nut. It probably fruits at three years. There is also a variety, very likely identical with this, in India, also a dwarf variety introduced from Ceylon to Madagascar. We are not told, however, whether it was indigenous to Ceylon. Is it a "sport," and did it come from elsewhere?

Then again, Dean Copeland goes on to say that there is the dwarf nut known in the Visayan Islands as Daliili and another known in Laguna as Mañgipod. The latter reminds one from the description, of the Nyor Gading palms in Malaya, for they, as shown by $\mathrm{Mr}$. 


\section{GUIDE TO COCO-NUT PLANTING}

Handover's illustration, bear nuts right on the ground, for, Mr. Copeland says, the Mañgipod produces fruit when the tree is so small that the cluster rests directly on the ground. The dwarf Jaffna variety of Ceylon and the Kalapa Babi of Java are, claims the Philippine authority, like the Mañgipod or identical with it.

Mons. Em. Prudhomme, of Paris, in his otherwise exhaustive work on the Coco-nut, barely mentions these dwarf varieties. All he tells us is that they produce at an early age and yield prolific crops (see p. 27) of his book.

All this is of interest to anyone thinking of planting dwarf varieties of coco-nuts as it will enable him to choose his variety or the nearest centre to which he can look for supplies. It does not, however, help us to say whether these "dwarfs" are as natural as the ordinary kinds, nor does it seem possible to prove definitely whether these have come from one common centre in fairly recent years, or whether, if ever, all the varieties were as one in the beginning, that the dwarfs, like the giants, have been evolved from a "sport" or smaller or larger growth at the several centres 
where they are now to be found under one name or the other.

Possibly Eastern coco-nut and vegetable-oil men generally, would be surprised if they realized how few of those who supply the machinery and appliances needed to extract the oil from the nuts or who otherwise have to do with the industries connected with oil extraction and distribution, are aware of the existence of these dwarf species of palms and their fruits.

I discovered that this is so, however, when showing the MS. of these additional notes to those who are interested in vegetable-oil machinery, in order to get one or two points explained. The tendency seems to be to confuse dwarf coco-nuts with other tropical oil-yielding nuts used in commerce, such as the corozo, the cohune, and those nuts which bear the ambiguous name of coquito. The latter name must be a diminutive of the Spanish word coco $=$ a coco-nut, and should therefore, I take it, refer to the nuts of the dwarf palms. Under the name of coquito however, I notice that recent correspondents have included the babassu or coco-babassu nut as well as the others. 
Since this is so, would it not be as well to start "right now" and straighten out this confusion, or else, when ordering the necessary machinery, mistakes of an aggravating and costly nature are likely to occur, especially as such machinery as a rule will have to be sent to the countries of origin (since the freight on the nuts themselves would surely prohibit their being shipped for the extraction to be done at the distributing and consuming centres), and mistakes like those I am warning you to avoid would only be found out when the machinery has been made, shipped across and erected and a start made to deal with the nuts, if not in the actual extraction of the oil itself.

I say this because I take it that when it comes to extracting the oil, the kernels to be treated are all one and the same to the crushing machine or presses, since the larger pieces of meat or kernel would be broken up or otherwise reduced in size. On this account it does not seem likely that an estate having dwarf nuts as well as nuts more normal in size, would have to put up special machinery to treat the meat or copra for oil-extraction. One standard equipment should do for all. 


\section{APPENDIX}

The smaller nuts would probably contain a little more oil. The difference in their size would have no effect except, that possibly a slightly larger quantity could be and would be passed through a given size of breaking rolls. The difference in this case would, I imagine, be too slight to be anything but negligible. This is a point however that only the man on the spot, the planter on the one hand and the engineer on the other, can say for certain after seeing the nuts to be treated. All I am now advising is that no machine be ordered without samples of the nuts to be treated being first sent to the engineers making the equipment; the name or a description of the nuts is not sufficient to be entirely reliable.

The only difference in the equipment that I can think of on the spur of the moment would arise when a firm, that is, a planter, wished to include a nut-splitting machine. This of course would have to be adjusted in order to take the smaller sized nuts. I am also told that the reducing rolis might have to be "set-up," but if so, the remainder of the plant would be the same as for the ordinary 


\section{GUIDE TO COCO-NUT PLANTING}

sized nuts. The whole matter, however, is too new for a decisive opinion to be expressed. Before this can be done, news must be received from Sungei Nipah of the dwarf palms having established their claim as large, permanent yielders, and when the reputation of these small nuts enjoys the confidence of future planters, then it will be time to agitate with the engineers to evolve the exact type of machinery needed throughout. Meanwhile I am sure we are much obliged to $\mathrm{Mr}$. Handover for the publicity he has given to. the experimental planting on a commercial scale of these dwarf palms, and I personally am also indebted to the Company (strange to say, one of our leading West Indian firms) for the further information they have given me to. augment what $\mathrm{Mr}$. Handover has had to say in his notes. Without this help from the Company in London, this Appendix might never have been written; it certainly would have been less useful to future planters than I hope it may now prove to be as time goes on. 


\section{INDEX.}

\section{All the items refer to Coco-nuts unless otherwise stated.}

The term trees is used in preference to palms.

AERATION of soil quickens returns, 48

American market for copra, 109

Analysis of crops before manuring 95,96

Ants, see white ants, red ants, termites, \&c.

Arsenic, sugar and flour for white ants, I 3 I

Artificial manures and their application, 94

Aspidiotus or scale insects, 145

Backward trees and their treatment, 97

- may be due to seed-nuts, 99

Bacteria in copra, 106

Bamber (Mr. Kelway) and green manures, 70

- - on plant food absorbed by the trees, IO2

Bananas as an inter-crop, 65, 66

Baracoa (Cuba), what bud-rot did in, 143

Barbecues and how they must be erected, 108

- for drying, 106

Barrett, O. W., on mulching, $5 \mathrm{I}$

Basic slag as a manure, 100

Beetles, 83, II 3 et seq.

- discouraged by green manures, II 7,118

- , remedial and preventive measures, II 9 , I20

Black beetles and the damage they do, I 16

Boga medelloa, see Tephrosia candida

Boiling water for white ants, 130
Bonâme, M. (of Mauritius) or ine sword bean, 76

Bone meal as a manure, ror

- v. green manure, 73

Bordeaux mixtures discussed, $15 \mathrm{I}$ I 55

- - for $P$. palmarum or leaf disease, I 37

- - , how to make, 137, I39

- - its proportions and formulie, I51, I52

Borneo river bank soil, I7

Brachartena coloxantha, a lepidopterous pest, described, 137

- - possible remedies for, 138

"Brohs," see Monkeys, I76, I77

Bud-rot disease discussed, 142, 143

- see also Festalozzia palmarum

Buffaloes keep down grass, 172

Burning after felling, 20

- a "good burn," 20-2I

- and the next process, 23

- Packing the growth for, 22

- Stacking for the second, 22

Butter from coco-nuts, I 10

Canazalia ensiformis as a green manure, 70

- - see also Sword Bean

Careful treatment of the trees pays, 4

Castor cake as a manure, IOI

- $v$. Green manure, 73

Castor-oil as an inter-crop, 65

Catch and cover crops, 60

Catch crops may harm the main one, $6 \mathrm{I}$

- - may not pay Europeans, 63

_ - must last four years to pay, 63 


\section{GUIDE TO COCO-NUT PLANTING}

Catch crop: their merits and demerits, $62-63$

Caterpillar pests, I 39

Caterpillars and larvæ; the damage they do, 140

- remedies for, 14 I-142

Cattle-breeding can start after fifth or sixth year, 54

- dung is among the finest manures for coco-nuts, 53

- - the best manure and why, 99

- for manuring estates, 91

- keeping not to be adopted without thought, 53

- manure $v$. husks or green manures, 96

-, I 50 can manure 100 acres, 56

- sheds and where to place them, 54

- to be kept on the move, 54

Cement not suitable for barbecues, I08

Centrosema plumieri as a green manure, 69,70

Chinese sweet potatoes as an interor cover-crop, 63

Citronella grass as an inter-crop, 63

Clay soil devoid of humus not first class, 18

- - needs drainage, I 5

- - predominates in the F.M.S,, 46

- soils may need "working up," 100

- - respond less quickly to mulching, 48

_. under coco.nuts and how to treat them, 46,47

- soil, under deep humus hastened growth, 16

- subsoils give longer and quicker crop periods than sandy ones, 46

$-v$. sandy soil, 18

Clean-weeding sometimes a mistake, 43

Climate in F.M.S. is most favourable to coco-nuts and rubber, 14

Clitoria ca,anifolia as a green manure, 70

Coast districts preferable, 4
Coast land extends to four or five miles inland, 5

Cocoa as an inter-crop, 65

Coco-nut culture, the need of extension, I

- and sword beans, 78

- and their ripening process, 86

- and water, 68

- in the F.M.S. discussed, 165-177

- maturing, blossoms to ripe nuts about eleven months, 87

- must not be sacrificed to catch crops, 6I

- ordinances and enactmerts, I7 I

- respond to special treatment, 38

- tree killed by termites (white ants), I 29

- - harmed by cattle treading the soil, 53

- - , their critical stage, 40

- yields less certain than rubber, 39

Coffee as an inter-crop, $61,62,63,64$

Coir covering (the) on stems retains moisture, 84

- fibre and rope, 162,163

Commercial products of the coconut tree, I60 et seq.

Copeland (Dr. E. B.) on water and the coco-nut palm, 68

Copra and its formation, 86,87

- - moisture limit, IOó

- - oil content, I IO

- content increased by good drainage, 27,28

- curing for market, 104

- discussed, 163

-, exhibition and market standards, I09

- exports from F.M.S., 166

- from king coco-nuts, more, 37

- oil, removal of odour in, IIO

- -, see also Oil.

- prices in the F.M.S., 166

-, the demand for pure white, ro6

-, the 'ack of a standard of quality, Iog

- yield per I,000 nuts, III, I12

Corona palmarum, a caterpillar pest, I 39

Cover and catch crops, see also Green-manuring. 
Cover crop. Is the best kind known? 67

- - see also Green-manuring.

- plants (green manure) not too easy to establish, I 8

Cradwick (Mr. W.), of Jamaica, on coco-nut diseases, 147

Creosote for beetle holes, I 20

Crop, gathering and storing the, 82

Crotolaria striata as a green manure, 70

Cuba, bud-rot disease in, $\mathbf{J} 42, \mathrm{I} 43$

Cultivation and maintenance, 38

- and tillage can be harmful, 50

-, its uses and importance, 68

- means good crops, 6

Cultivate round the roots against drought, 40

Dadaps have 4.78 of nitrogen, 73

Decayed vegetable soils and their drawbacks, 47

Deep planting always unwise, if not fatal, 33

_- - not recommended, 47

- rooting recommended, 43

Desmodium tortusum as a green manure, 70

Diagonal $v$. square planting, 3 I

Dindings, terms of land sales, If

Diplodia (die-back) or Pestalozzia as cause of leaf trouble, 150

Diseases II 3, I 35

Distances, see Planting distances

Dogs good for hunting pigs, I 26

Drainage for peaty solls, I9

- in clay soils, 15

- must be thoroughly done, 5, 57

- needs attention, 2

- on new soils, 42

- well-clrained land gives thicker meat and more oil, 27, 28

Drains must be kept clean, 57

-, subsidiary cross outlets, 58

Draught cattle and stock-raising, 56

Driers and drying, I05

-, artificial $v$. native methods, 105

Drought and its effect on the trees, 68, 69

— and seedlings, 49
Drought, effects lessened by green manures, 45

Droughts a great danger with coconuts, 38

-, their effects on the trees and the remedy, 38,39

Drying at $140^{\circ} \mathrm{F},{ }^{107}$

-, kiln and barbecues, 106

- large $v$. small pieces, 108

- the copra, how to start, 105

-, time required, 107,108

Dung and urine pit, 54

Dwarf coco-nuts, see King coco-nuts

Earle (Prof. E. G.) on bud-rot disease, I 42

- - - visits Jamaica, 144

Erinota thrax a caterpillar pest, I 39

Estates improved by legislation, I7 I, I 72

Estimates of expenditure, wise and unwise, 156 et $\mathrm{seq}$.

European cultivation in the F.M.S., I69, I 70

European market for copra, I09

Experimental work a necessity, 39

F.M.S. (The) and corditions for acquiring land, 7

- and their coco-nut industry, I65, I77

- and their copra exports, 166

- , copra prices in the, 166

-, total area under coco-nuts, I65, 166

Felling, how to finance it, 20

-, the usual months for, 2 I

Fencing for wild pigs, 34

- often liseless against pigs, 124

Fibre, coir and rope, 162, 163

Fire for backward trees, 97,98

Iish manures, 92

Flooding lowers copra and oil contents, 28

Floods kill oryctes larve, II 7 .

Flour, sugar and arsenic for white ants, I 3 I

Fruit trees on ideal estates, 173

Fuels for drying, 109 
Gambier as an inter-crop, 65

Gathering coco-nuts, dropping, the question of theft, 83,84

- - by climbing has advantages, 83

- - hy monkeys or Brohs, I76, I 77

- - , hardening and embryos, 87

- - leave them in heaps, 86

- - the knife or by climbing, 82, 83

- - , picked $v$. fallen nuts, I II

Germany's copra imports, I IO

Germinating seed-nuts before planting, 29

Ginger as an inter-crop, 66

Gloesporium (sp.) or Pestalozzia as cause of leaf trouble, I 50

Goats as bad as beetles or grasshoppers, 55

- to be tabooed, 55

Green manure crops must not be put in too early, 44

Green manures, $4 \mathrm{I}$

- - and their plant-food yields, 73

- - discourage beetles, I1 7, I 18

- - most suitable ones recommended, 69

- - need care to establish, 44

- - on poor soil, 67

- - should be used more, 65

- - to counteract droughts, 45

- $v$. dung or husks, 96

- manuring advocated, 18

Ground-nuts as an inter-crop, 66

Harrowing, 50

- after liming and mulching, 94

Heavy jungle soil, I7

Helmithospodium arrested by Bordeaux mixture, 139

Hevea brasiliensis and Bordeaux mixture, I 52

Hidara irava, a caterpillar pest, 139

High lands, draining and felling, 19,20

Hoeing without tillage harmful to the soil, 45

Hoes and their uses need more thought and study, 48
Holing (for planting) sizes and distances, $3 \mathrm{I}$

-, planting and refilling, 32

Humus always needed, 65

- generally sufficient in Malay soils, 45

- must not be wasted, $50,5 \mathrm{I}$

- removed by hoe-weeding, and its return, 49

Husked nuts must be split at once, I07

Husking-rate per day, 104

- the nuts, hand $v$. machines, 104

FIusks and their fertilizing importance, 96

- as a mulch after gathering, 84

- - to prevent evaporation, 97

- proportion of weight to whole nut, 86

- should never leave the estate, 85

Ichneumon, a parasite of Brachartena grubs, 138

Illumination good for the trees, 4

Immature nuts, 82-86, I I I

Indigo as an inter-crop, 66

Inland plantations, I

- soils should pay, I

Intensive cultivation, does it pay? I7

Inter-crops draw rats and pigs from the coco-nut trees, I26

- see also Catch crops

Ipecacuanha as an inter-crop, 66

Jamaica troubled by unnamed disease, 144

Java volcanic soils very fine, 46

Johore as a producing centre, 6

Kainit as a manure, IOI

Kampongs, see Native holdings

Kedah (State of) is encouraging coco-nut cultivation, I 74

Kelantan and its area, 6

Kilns for drying, 106

- of brick, I08, 109

King coco-nuts and yield, 36

- - may need high cultivation, 37

- - , their advantage on paper, 37

- (Nyor Gading), two estates planted, 35 
Kuantan (in Pahang State) district encouraging sales of land, $\delta$

"Kumpas" trees a favourite of termites, I32

Lalang and its damage if misunderstood, 24

-, its eradication after burning, 23,24

Land conditions in the F.M.S., 7

- - when purchasing, I

- in F.M.S. becoming scarce, 2

- , the selection of, I

Laterite soil in times of drought, 2

Leaf disease, see Pestalozzia palmarum

Leaves and their plant-food require. ments, 102-103

Lemon-grass as an inter-crop, 63

Lime and its action on hard.soils, 93

- application, 94

— for the soil, 92

-, quantity per acre, 93,94

- removed per acre of palms, 102

- salts absorbed, 102

- (slaked) for caterpillars, 142

- - for white ants, 130

Locusts may cause very serious damage, 128, 129

London purple to get rid of red ants, 134, 135

Lyons (Mr. W. S.), of Manila, on the coco-nut and its food, 95

Magnesia removed per acre of palms, IO2

Maintenance and cultivation, 38

- of an estate, The cost of, $5^{8}$

Malay Reservations Enactments (1913), I 73

Manure from live stock, 54, 55

- little and often at times, 90

Manures, artificial and others, 89

- discussed, 64,65

- needed for stiff and poor soils, 89

Manuring, 89

- beware of over-rich applications, 92

- by analysis of crops, 95
Manuring stock, I 50 caltle to 100 acres, 56

- cost per acre, IOI

- quantity per tree, IoI

- the primary object aimed at, 94

- system recommended, 9 I

- (with artificials), a mistake without tillage, 44

"Meranti" trees a favourite of termites, I 32

Millardot and Gayer gave the first Bordeaux mixture, 5 I $^{\text {I }}$

Mimosa pudica as a green manure, 69

Moisture greater in young nuts, I I 1

- in copra Io per cent. tco high, 105

Monkeys (Brohs) for gathering nuts, I 76,177

Moulding up after planting, 32, 33

Muciena speciosa, as a green manure, 69

- or "Mascate," see Velvet bean

Mulching against droughts, IS

- and lime, 94

- and manuring, IOI

- may add 15 per cent. to the world's crops, 52

- - be better than tillage, $5^{\text {I }}$

- shows quicker results on sandy than clay soils, $4 \delta$

- the roots against drought, 4 I

- with husks, S4, $97^{-}$

Native holdings in F.M.S., I70, I 7 I

- methods should be noted and respecied, 33

- treatment of backward trees, 97

Negri Sembilan area under coconuts, I 65

-- - its estates described, I6\$, I69

Nitrates needed to establish green manures, So

Nitrogen as a stimulant, 95

- removed by husks, $S S$

- - in copra, SS

- supplied by green manures, 73

-, when generous supplies are necessary, 96 
Nitrogenous soils hastened growth, I6

Nurseries, carefully prepared beds the best, 29

- , old ways and new, 28

Nursery beds and how to make them and place the seed-nuts, 29

Nuts affected by soil conditions, I 2

- and their plant food requirements, 102, 103

- of young trees have more moisture, I I I

- per acre, I 59

- prices in F.M.S., 167

- to ton or picul of copra, II 2

- yield of copra per I, 000, I I I, I I 2

- - per acre, 108

- see also Coco-nuts

Nyor Gading, see King coco-nuts

Odour in copra oil and its removal, 110

Oil (coco-nut) and its melting point, I IO

- - and its uses, $16_{3}, 16_{4}$

- content increased by good drainage, 27,28

- - of copra, 110

- from King coco-nuts, larger yield of, 37

-, see also Copra and Coco-nut oil Opening up an estate, the cost of, 158

Oryctes and their extermination, I I 3, II 4

- larvæ killed by floods, II 7

-, many varieties, 117

- neglected on ant-infested trees, I 34

Pahang (State of) and its quit rents, Io

- area under coco-nuts, 165

- estates described, I68.169

- is encouraging cultivation, 8

- (State of) still has land available, 2

Passiflora, its advantages and defects, 80

Peat soils and their drawbacks, 47
Peat soils must not be smothered with green crops, 80

Peaty soils and drains, 57

- - encourage Termes gestroi, I 32

- - how to prepare them for planting, I9

Pekan (Penarg State) district encouraging sales of land, 9

Penang, bud-rot disease reported in, 143

- land terms, I2

Perak (State of) and its most suitable land, 4

-, area under coco-nuts, 165

- - its lands and crops dis. cussed, I69

Pestalozzia falmarum described by the mycologist (Mr. R. M. Richards), I 48 - I 50

- - did much harm in Sumatra nurseries, I 35

- - or leaf disease described, I35, 136

-- , remedies suggested, I 50

-, , see also Bud-rot and leaf disease

P tends to increase, 136

Pests, I I 3

Phosphate of lime absorbed ty the tree, IO2

- - removed per acre of palms, 102

Phosphatic soil hastened growth, 16

Phosphoric acid supplied by green manures, 73

Pickering (Mr. Spencer) of Woburn, and a superior Bordeaux mixture, I 55

Pigs (wild) an endless trouble, I24

- and seedlings, 34

- and seed-nuts, 30

-, dogs, but not watchmen, an advantage against, 126

- how to keep them off an estate, I24, I25

Pine-apples as an inter-crnp, 63

Pink disease and Bordeaux mixture, 152

Plant-foods absorbed by $30-y e a r$ old tree, 102

- and their importance, 103 
Plant-foods removed by husks, 88

- in soil removed by copra, 88

Planting and planting distances, $3 \mathrm{I}$

- and then moulding-up, 32, 33

- "at stake" might be the best, 35

- aistances for King coco-nuts, 37

- out, do not be over orthodox, 32

- preparing the land previous to, 3 I

- to evade wild pigs, 34

Ploughing, 50

- alter liming and mulching, 94

Pois sabre, see Sword bean

Porcupines scarce, but can give much trouble, I 27

Porosity of the soil greater near the sea, 2

- - an important factor, 46

Port Dickson has two King coco. nut estates, 36

Potash absorbed by 30-year-old tree, IO2

- and phosphates needed for leaves and stems, 70

- removed per acre of palms, 102

- supplied by green manure, 73

Pratt's (Mr. H. C.) suggestion for a rat shield, 122,123

Preparation of land for planting, 19

Province Wellesley's land terms, I 2

Prunings and their plant-food yield, 73

Quit rents in Pahang, Io

Rain discolours copra when drying, I06

Rats and their ravages, 121,122

- encouraged by native holdings, 123

- in Ceylon and F.M.S., 121

-, like pigs, prefer inter-crops, 126

- - sweet potatoes, 123

-, protection for young plants against, 122, 123

Red ants, both friend and foe, 133

- - discourage beetle collectors, 133

- - killed by London purple, I34, 135
Red beetles and their work, II4

Revenue, estimates of, I 59

Richards (Mr. R. M.), the mycolo. gist, on Lud-rot and otherwise, I 47 - I 50

Ring-barking for backward trees, 97,98

Roots and their character, 95

- growth, 43

- bared for backward trees, 97,98

- growing deep an advantage, 43

- should be covered against droughts, 40, 4I

Root-trenching for white ants, 130

Rope, coir and fibre, 162,163

Rubber and coco-nuts, I 5

- yields more certain than coconuts, 39

Salt for white ants, I 30

- removed per acre of palms, 102

- taken up by the trees, 95

- to be mixed with manures, 9 I

- water has no influence on the trees, I, 2

Sand for beetle prevention, 120

Sandy soils in the F.M.S. need special treatment, 47

- subsoils give a shorter crop period than clay subsoils, 46

$-v$. clay soils, 18

Scale insects fed upon by red ants, I 33

Seashore estates and yields, the, 2, 3

- or coast plantations, 4

--, see also Coast

Seedlings and their care, 48,49

-, best age to remove them, 34

-, late $v$. early removal, 34,35

- need frequent weeding, 48,49

Seed-nuts producing backward trees, 99

Seed-nut selection, the greatest care necessary, 26

- - , the question of age, 28

Seed-nuts best from a distance, $2 \$$

- cutting the husks before planting, 29

- germinating before planting, 29

-, how and what to choose, 26 
Seed-nuts, how to place them when plariting, 29

-, the hardening or curing-off process, 27

- where good ones come from, 27

Selangor and its most suitable land, 5

-, area under coco-nuts, 165

-, its land discussed, I68

Shade for seed-nuts, 29

Sheep breeding can start after fifth year, or sixth year, 54

- do not care for coco-nut leaves, 55

- dung is among the finest manures for coco-nuts, 53

- keep down grass, 172

- pens should be raised, 55

-, why they can be allowed to wander, 55

Shells (coco-nut) as fuel, Io9

Shipping facilities in the F.M.S. 9

Siamese border and Johore, 6

Silica absorbed, 102

- removed per acre of palms, IO2

Sisal as an inter-crop, 63

Small plantations are quite remunerative, 3

Smoke-drying copra, 105

Sodium chloride absorbed, 102

Soil analyses and how to make them, 100

- conditions affect nuts, II 2

-, keep it friable, 65

- in Sumatra, 7

- in F. M. S. mostly clay, 46

- selection and treatment, 42, 43

Soils, 13

- along river banks, 17

-, differentiate between inland and coast, I4

- in low-lying areas and their drains, 19

- in the F. M. S. discussed, 2,3

- must be carefully considered, 15

- near jungle lands, 17

- under crops must be kept friable, $4 \mathrm{I}, 42$

-, what ronstitutes first-class coconut, 13

- under intensive cultivation, 17

— unsuitable for coco-nuts, 92, 93
Sour soil and stagnant water, 58 joya-beans as an inter-crop, 66

Spray fluids for caterpillars, I4 I Squirrels cause much loss. The gun a remedy, 127

Standari's in quality in copra, 109

Sugar as an inter-crop, 63

-, flour and arsenic for white ants, 131

- from the coco-nut spathe, I60, I6r

Sulphate of potash $v$. green manure, 73

Sumatra river-bank soil, I 7

Sumatra's available land, 7

- land tenure, 13

- volcanic soils very fine, 7,46

Swampy soil gives lower copra and oil contents, 28

Sweet potatoes, 8o

- - as an inter-crop, 63

- draw rats from coco-nuts, 123

Sword beans (Pois sabre, Canavaiia ensiformis), 76, 77

- - a fine leguminous plant, 77

-- as a green manure, 77

- - a very valuable cattle food, 77

- -, full analysis, 77

- - rapidly established, how to secure this, 78

Tapioca as an inter-crop, 6I, 63

Tea as an inter-crop, 6r, 64

Telicota palmarum, a caterpillar pest, I 39

Temelok (Pahang) has ideal native holdings, 172

Tephrosia candida, analysis of, $7 \mathrm{I}$

- - as a green manure, 69

- - takes longer to establish than beans, 79

- purpurea, as a green manure, 60

Termes gestroi, capture the "queens," I 3 I

Termites, "mound" kinds not so dangerous as white ants, 132

- see also IVihite ants.

Tillage gives quicker returns on sandy soils, 48

- may do more harn than good, 50 
Tilling and cultivation, the need of, 40,42

Toddy extraction, 160, 161

Towgood (Mr.), of Selangor, on termite destruction, I3I

Transplanting seedlings. Which age is best? 34,35

Transport by water usually the cheapest, 4

- in F. M. S., 9

Transporting coco-nuts, 84,85

Trees and salt water, 1,2

Trenching for manures, $9 \mathrm{r}$

Trengganu and its area, 6

Universal fumigator (the) for white ants, 130

Velvet beans as food for cattle, 75

_- , black variety has 25 per cent more nitrogenous matter than other plants, 75

_ - full analysis, 76

_- stems and leaves make good forage, 75,76

- - , white, mottled, black, 74, 75

Volcanic soils in Java and Sumatra, very fine, 46

Watchmen for pigs, \&c., not recommended, 126

Water and its effect on the trees, 2 - relations of the coco-nuts, 68
Weed first, then manure, 101

- fortnightly among seedlings, 48,49

Weeding and mulching, 48

- necessary up to third or fourth year, 40

- or its substitutes, 44,45

-, see also Clean weeding

Weeds after burning off, 23

White ants and remedial measures, I30

- - , their secret methods, I28, 129

- - do more harm to trees over two years old, 129

- - not a "mound" termite, 132

- - see also Termites.

Wind good for the trees, the, 4

Wire hooks to get beetles out, II9, 120

Yields on native holdings, I 70, 171

- per acre,. 108, I 59

- per annum, 108

Appendix. The Dwarf or King Coconut-

$A$. Under cultivation in the Federated Malay States, 178 $B$. Different varieties in the Philippines, \&c., 187

John Bale, Sons \& Danielsson, Ltu., \$3.91, Great Titchfield Street, Orford Streot, $\mathbf{w} .1$. 



\section{MODERN}

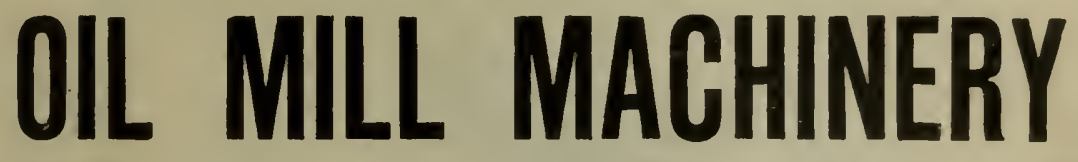

For COPRA, PALM KERNELS, and all Oil-bearing Seeds.

COMPLETE MILLS FOR ANY QUANTITY.

OIL REFINERIES, FILTERS, \&C.

$$
\text { SPECIALITY : }
$$

SOLVENT EXTRACTION PLANT.

\section{ROSE, DOWNS \& THOMPSON \\ OLD FOUNDRY, HULL.}

12, MARK LANE, LONDON, E.C. 20, FOOCHOW RD., SHANGHAI.

Estd. 1777. 


\section{Eating money!

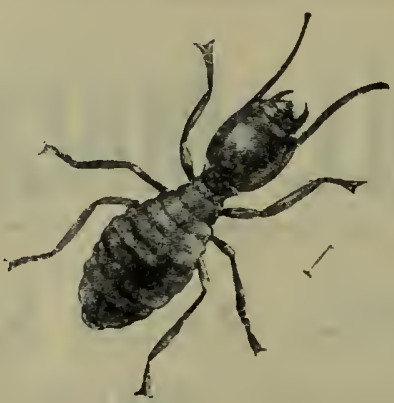

T no instance could this metaphor be more aptly applied than when speaking of White Ants. I Their wholesale destruction of timber, and the consequent heavy renewal costs, are a source of considerable loss and annoyance alike to commercial concerns and private individuals.

This calls for a positive and economic method of timber preservation-

\section{"Atlas A"}

\section{Wood Preservative,}

the outcome of 20 years' scientific effort and practical experience, renders timber positively immune from the ravages of White Ants, Borer Beetle, and all other insects of destruction.

Furthermore, "Atlas A" which can be simply applied on the spot, by brush or immersion, is a sure preventative of organic decay, and fireproofs in the ratio of 4 to 1 as compared with untreated timber.

A Booklet will interest, a trial will convince.

Agents holding stocks at principal commercial centres throughout the World.

ATLAs PRESERYATIVE COMPANY, Ltd. DEPTFORD, LONDON, S.E. 8. 


\section{NUTRIENT, Ltd.,}

24/27, ROOD LANE, LONDON, E.C. 3.

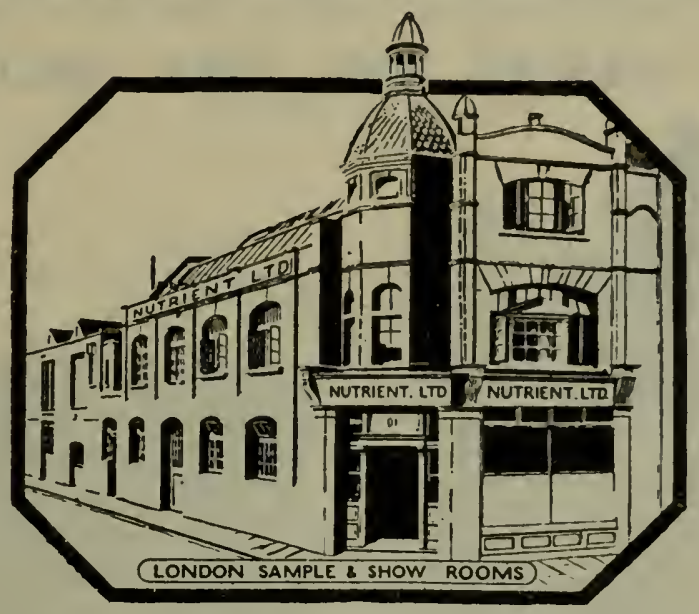

Coconut Oil, Palm Kernel Oil, Ground Nut Oil, Cotton Seed Oil, Copra, Palm Kernels, Ground Nuts, Cotton Seed, and other Eastern and Colonial Produce. Send us your enquiries.

Telephones-AVENUE 6845 and 7766 ; LEE GREEN 674 and 1525. Cables-"NUTRIENT, LONDON"

Telegrams-" NUTRIENT, GRACE, LONDON."

Code used-"MARCONI INTERNATIONAL."

Bankers-BARCLAY'S BANK, Ltd., 170, Fenchurch St., London, E.C. 


\section{OIL SEED CRUSHING MAGHINERY}

LAs sverzing ro ras

\section{LEADING OIL MILLS \\ IN}

ALL PARTS OF THE WORLD.
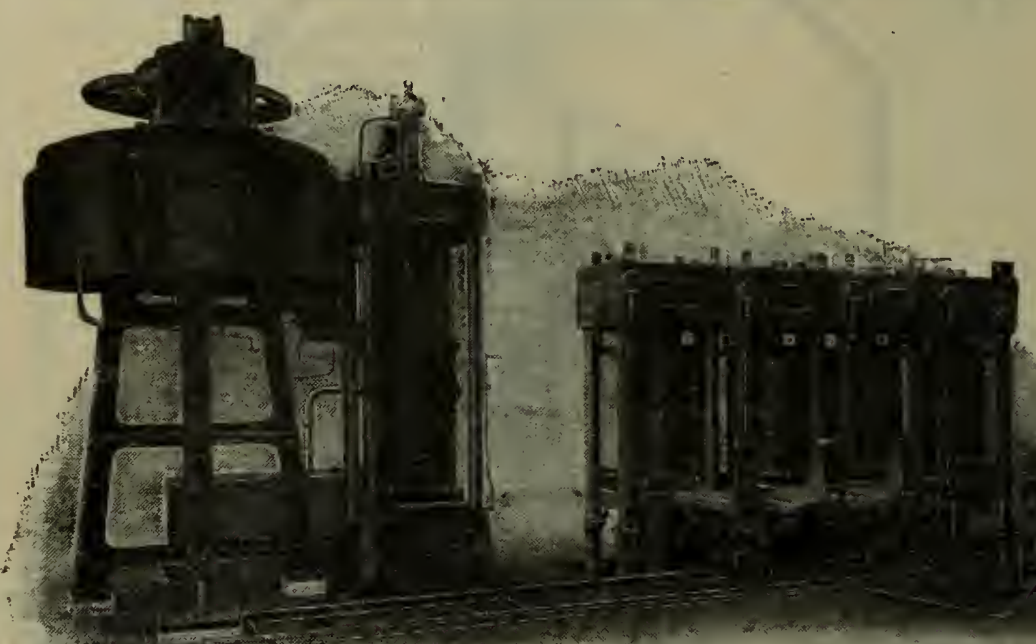

We specialise in the most modern machinery for treating every known oil bearing seed and nut, and shall be pleased to quote either for single machines or for complete plants, and to give full information as to output obtainable.

GREENWOOD \& BATLEY LIMITED, ENGINEERS, LEEDS. 


\section{Coconut, Cohune Nut, Ground Nuts, and other Vegetable Oil extraction Plant.}

\section{MARGARINE MACHINERY}

The Latest,

Best, Most Efficient and Most Economical.

\section{COMPLETE INSTALLATIONS UNDERTAKEN.}

Expert Advice given to those about to start on how to proceed and what is necessary.

Full particulars, prices, Ec., from:-

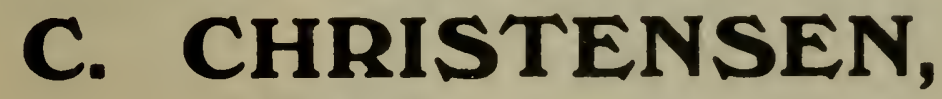

Margarine Expert,

24/27, Rood Lane, LONDON, E.C. 3. WORKS IN DENMARK.

Telephones-AVENUE 6845 and 7766 ; LEE GREEN 674 and 1525.

Cables-"NUT'RIENT, LONDON."

Telegrams-"NUTRIENT, GRACE, LONDON."

Code used-"MARCONI INTERNATIONAL."

Bankers-BARCLAYS BANK, LTD., J70, Fenchurch Street, London, E.C. 


\section{COCO-NUTS AND NITROGENOUS PLANT FOODS}

are freely discussed between the covers of this book, especially around page 95 . The information there given is from one who has had wide spread yet deep-seated experience in the Philippines. It confirms the view that

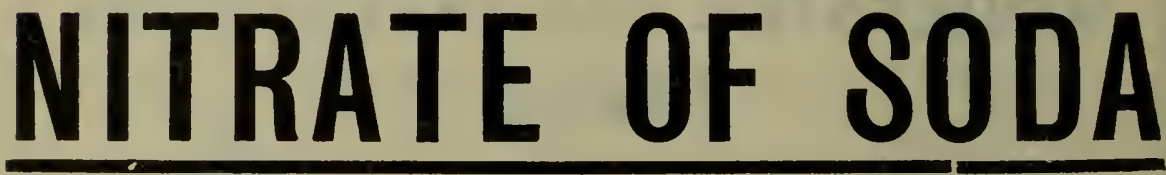

\section{IS THE NITROGENOUS FERTILISER TO USE FOR COCO-NUT CROPS.}

Applied when needed in small quantities and on the lines suggested on pages 95-96, it cannot fail to benefit Owners of Estates by increasing both the number and weight of the nuts.

For fuller particulars and free pamphlets apply to the following Delegations of the Chilean Nitrate Committee:

Australasia :

The Chilean Nitrate Committee, P.O. Box 1197,

SYDNEY, New South Wales. Cuba :

Comité del Nitrato de Chile,

Lonja del Comercio, 542, HAVANA.

India :

The Chilean Nitrate Committee,

1, Royal Exchange Place, CALCUTTA.

Japan, China and Philippines : The Chilean Nitrate Committee,

1, Yayesu-cho, Itchome, Kojimachi Ku, TOKIO.
South Africa:

The Chilean Nitrate Committee, P.O. Box 433, BLOEMFONTEIN, O.R.C.

U.S.A. and Hawaii :

The Chilean Nitrate Committee, 25, Madison Avenue, NEW YORK.

West Indies :

The Chilean Nitrate Committee, P.O. Box 234, PORT-OF-SPAIN, Trinidad, B.W.I.

Or from

\section{THE GHILEAN NITRATE GOMMITTEE} FRIARS HOUSE,

NEW BROAD STREET, LONDON, E.C. 2. 


\section{OIL MILL NIACHINERY FOR}

\section{EVERY YARIETY OF SEED OR NUT.}

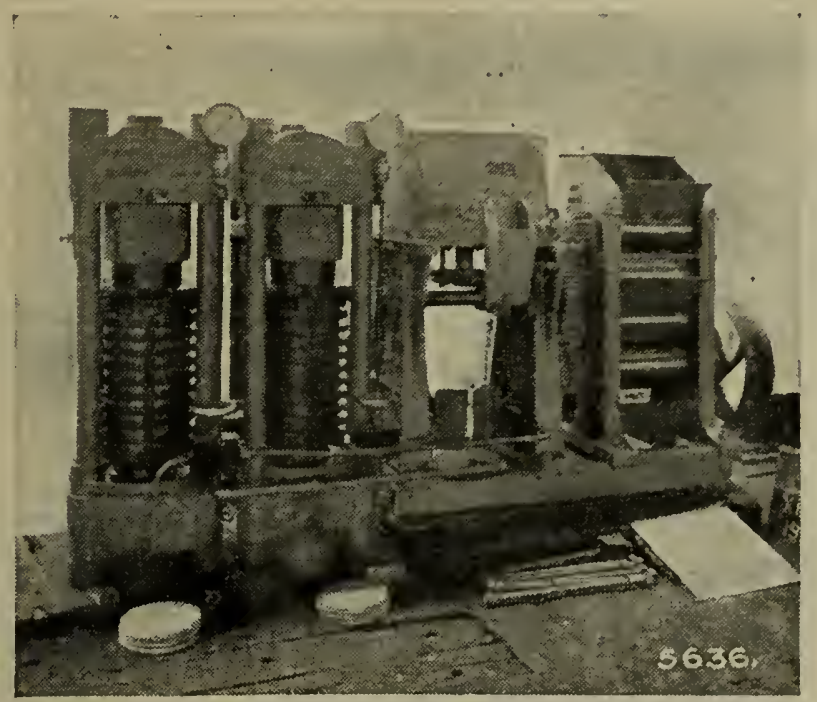

The CAGE PRESS SYSTEM is the ideal method of OIL EXTRAC. TION FROM COPRA.

Illustration shows self-contained Cage Press Mill, cupacity one ton per day.

COM PLETE PLANTS from 1 ton to 100 tons per day capacity

QRITE FOR

LIST S.451.

MANLOVE,

ALLIOTT

\& CO., Ltd.,

Bloomsgrove Works,

Nottingham,

ENGLAND.

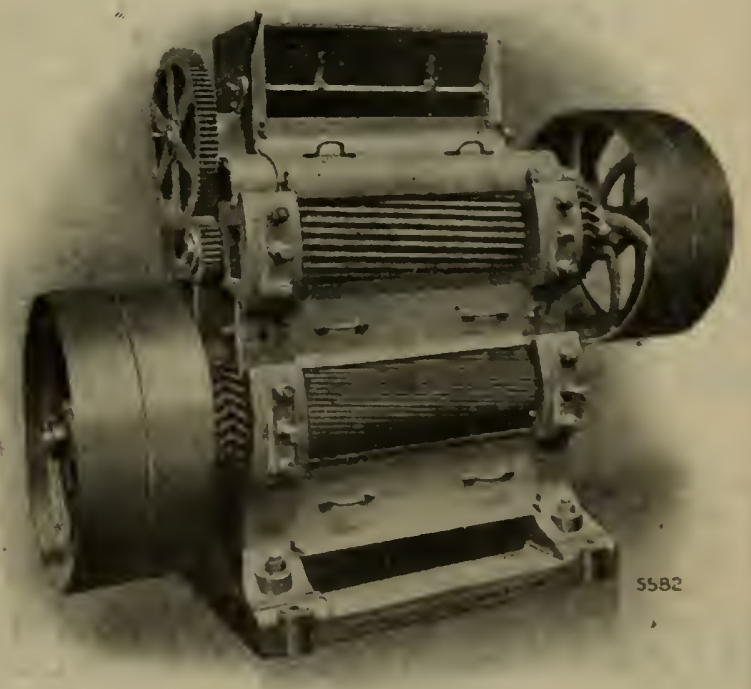

Reduction Rolls for Copra. 


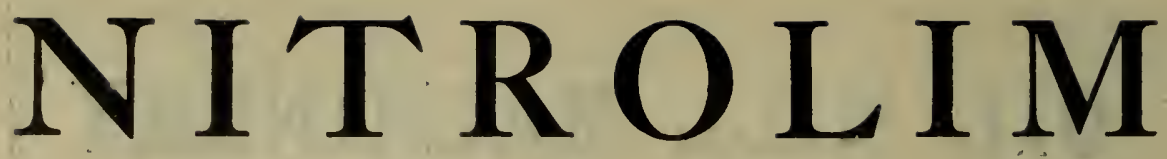

(Calcium Cyanamide).

$\begin{array}{lccc}\text { ANALYSIS. } & \\ \text { NITROGEN } & \ldots & \ldots & 19 \text { per cent. } \\ \text { AMMONIA } & \text { equal to } & & \\ \text { AM } & \ldots & \ldots & 23 \text { per cent. } \\ \text { TOTAL LIME } & \ldots & \ldots & 60 \text { per cent. }\end{array}$

The great advantages of this fertiliser for Coco-nut Plantations may be gathered from the following extract from Chapter $X$. on Manuring:-

"When it is found necessary to apply artificial manure, liming should go hand in hand with it in order that the soil may be in better condition for the rapid absorption of the fertilising ingredients. This applies to every class of soil. There can be little doubt that the full complement of leaf and branch is the primary object to be aimed at, and this being so the strongest stimulant to the tree for this purpose is nitrogen."

\section{TRY THE FERTILISER THAT SUPPLIES} NITROGEN AND LIME TOGETHER.

Full particulars from NITROGEN FERTILISERS, LTD., WINCHESTER HOUSE, OLD BROAD STREET, LONDON, E.C. 2. 
8010

\section{DOUGLAS \& GRANT, LTD.,} MANUFACTURERS

OF

OIL MILL MACHINERY

COMPLETE INSTALLATIONS

FOR THE TREATMENT OF

ALL VARIETIES

OF

OIL-BEARING SEED \& NUTS

London Office:

HASTINGS HOUSE, NORFOLK ST., STRAND, W.C. 2.

Eastern Branches:

CALCUTTA, MADRAS, RANGOON, BANGKOK, SAIGON \& HAIPHONG.

HEAD OFFICE AND WORKS:

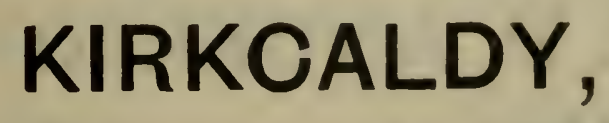

80

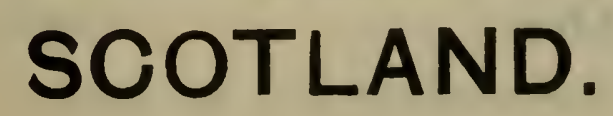




\section{THE ANDERSON OIL EXPELLER A CONTINUOUS PRESS}

For Extracting Oil from Castor Beans, Copra, Cotton Seed, Mustard Seed, Pea Nuts, Soya Beans, and other oleaginous Seeds and Nuts.

Requires No Press Cloths.

Can be operated without skilled help.

Can be used for first pressing where hydraulic presses are operated.

Used in all parts of the World.

MANUFACTURED BY

The V. D. ANDERSON CO. CLEVELAND, OHIO, U.S.A. catalogue on REQUEST. 


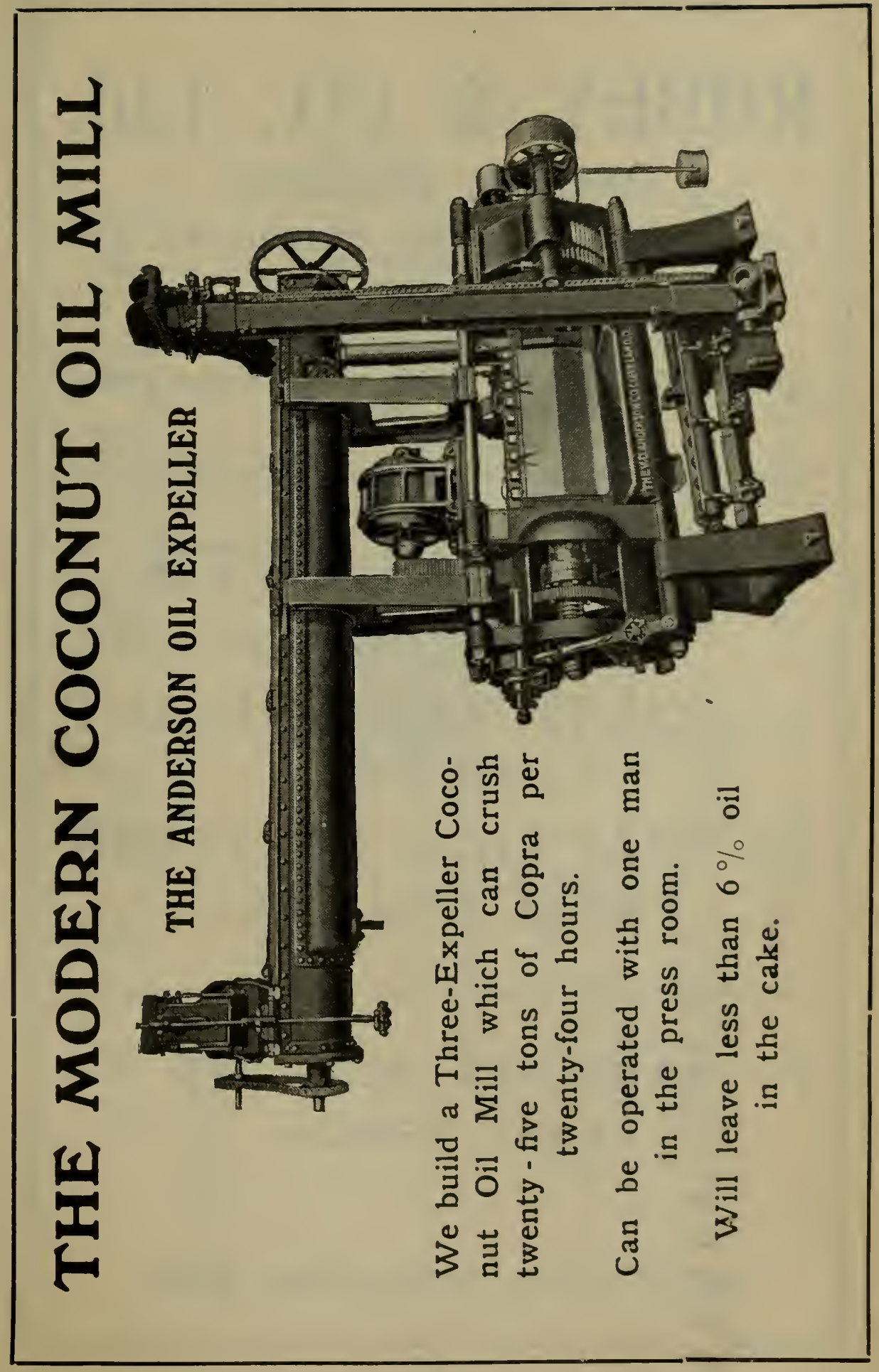




\section{The Lancaster Engineering Corporation.}

MANUFACTURERS AND SUPPLIERS OF

Machinery and Appliances for the Vegetable Oil Industry,

including-

Coconut Huskers or de-podders, Coconut Scourers and Husk Separators, Coconut Shell Scorers and Crackers, Copra Dryers and Curers and Macerators, Coconut Steamifiers, Castormean Hullers. Also for

Tagua Drying, Soya Bean Decorticators, Cohune Nuts, Coco-babassu, and other nuts.

In the same, way that $77,078,300$ Coconuts are returned as having been imported into New York during 1919-the Franklin-Baker Co. alone being down for $32,000,000$ nutsso are many millions of nuts handled and treated at producing centres.

Wherever such work is being done, look out for the Lancaster Machinery and Appliances.

If you are not allowed to examine these, then write direct for full particulars to

JAMES H. LANCASTER, President.

The Lancaster Engineering Corporation, HUDSON TERMINAL BUILDING,

50, CHURCH STREET, NEW YORK CITY, U.S.A. 


\section{The Lancaster Engineering Corporation, NEW YORK CITY, U.S.A.,}

specially appeals to Miners throughout the World to send them a note of their requirements for Dredging and Pumping, as well as for General Mining work.

Latin America, Malaya and similar centres, interested in Mining, in Vegetable Oil production, Tapioca and other crops, will learn much from us as to the most suitable machinery for their work. We save you Time, Money and Labour.

Our machines for treating Coco-babassu and Cohune Nuts are unequalled. Let us know your needs, and we will let you know how to satisfy them, and make money whilst doing so.

Address to-

\section{JAMes H. LANCAster, President.}

\section{The Lancaster Engineering Corporation,}

HUDSON TERMINAL BUILDING,

50, CHURCH STREET, NEW YORK CITY, U.S.A. 


\section{EDOUARD VALENSI \& FILS}

(Courtier depuis 1882),

30, rue de la Darse,

M A R S F L工F.

Adresse Télégraphique: "Evalsi."

Téléphone: 14-80.

Courtiers d'importation directe:

Matières premières pour l'Huilerie,

laSavonnerie \& la Stéarinerie.

Produits Tannants \& Tinctoriaux,

Droguerie, Produits Chimiques,

Denrées Coloniales. 


\section{Green Manures and Manuring in the Tropics.}

By P. DE SORNAY, translated from the French by F. W. Flattely. Royal 8 vo, pp. 460, with all the original illustrations, bound in cloth, lettered, 16s. net, postage 1s., abroad 1s. $6 \mathrm{~d}$.

\section{The Rubber Industry of the Amazon} and How its Supremacy can be Maintained.

By JOSEPH F. WOODROFFE and HAROLD HAMEL SMITH. Demy 8 vo, pp. 435 + xlviii, with 48 illustrations, 21s. net; postage, inland 1s.; abroad 1s.

\section{The African Rubber Industry.}

By CUTHBERT CHRISTY, M.B., C.M.(Edin.), Profusely illustrated. Demy 8vo, pp. $252+\mathrm{xvi}$, cloth, 12s. 6d. net, postage 1s. ; abroad 1s.

\section{Sierra Leone: Its People, Products,}

\section{and Secret Societies.}

By H. OSMAN NEWLAND, F.R.HrsT.S., F.I.D.

Demy 8vo, pp. 270, illustrated by 19 plates, cloth boards, 7s. 6d. net; postage $9 \mathrm{~d}$.

Works by H. HAMEL SMITH.

How to Pay for the War

by developing the latent resources of the Empire. Price 5s. net. Special sections on Labour, Finance, Education, India, \&c.

\section{Soil and Plant Sanitation on Cacao and Rubber Estates.}

Crown 8vo, cloth, lettered, pp. $632+\mathrm{lii}, 10 \mathrm{~s}$. net; postago $1 \mathrm{~s}$.

\section{Coco-Nuts : the Consols of the East.}

Second Edition. Crown 8vo, pp. $644+$ lxviii, cloth, lettered, 12s. 6d. net, postage 1s.

\section{The Fermentation of Cacao.}

Crown 8 vo, pp. 318, cloth, gilt lettered, 10s. net, postage $8 \mathrm{~d}$.

\section{The Future of Cacao Planting.} Crown 8vo, pp. 95, 1s. net, postage 3d.

The High Price of Sugar and How to Reduce It by increasing the Production within the Empire. (Second Impression.) Demy 8vo, 1s. net, postage 3d.

JOHN BALE, SONS \& DANIELSSON, Ltd., 83, 85, 87, 89, 91, GT. TITCHFIELD ST., LONDON, W. 1. 


\section{Technical Handhooks}

Indispensable to all interested in the subjects of which they treat.

\section{By H. R. CARTER.}

Author of "Modern Flax, Hemp and Jute Spinning."

Demy $8 \mathrm{vo}$, strongly bound in paper covers.

1. CORDAGE FIBRES: Their Cultivation, Extraction and Preparation for the Market. (Illustrated.) Price 3/- net. Postage 6d.

2. THE MANUFACTURE OF LINEN, HEMP AND JUTE FABRICS. (Illustrated.) Price $4 /$ - net. Postage 6d.

3. ROPE, TWINE AND THREAD MAKING. (Illustrated with Full Page Piates.) Price 5/6 net. Postage 6d.

4. FLAX, HEMP AND JUTE SPINNERS' CATECHISM. (Illustrated.) Price 8/- net. Postage 9d.

5. PRACTICAL MILL AND FACTORY ARITHMETIC. Price $3 / 6$ net. Postage 6d.

6. BLEACHING AND DYEING OF FLAX, HEMP AND JUTE YARNS AND FABRICS. Price $3 /-$ net. Postage 6d.

7. COMBERS AND COMBING: Their Setting and Principles of their Working. (Illustrated.) Price 5/- net. Postage 6d.

8. Flax and its Products. (Illuustrated.) Price 10/6 net. Postage gd.

JOHN BALE, SONS \& DANIELSSON, Ltd., 83-91, Gt. Titchfield St., Oxford St., London, W.I. 

DATE DUE

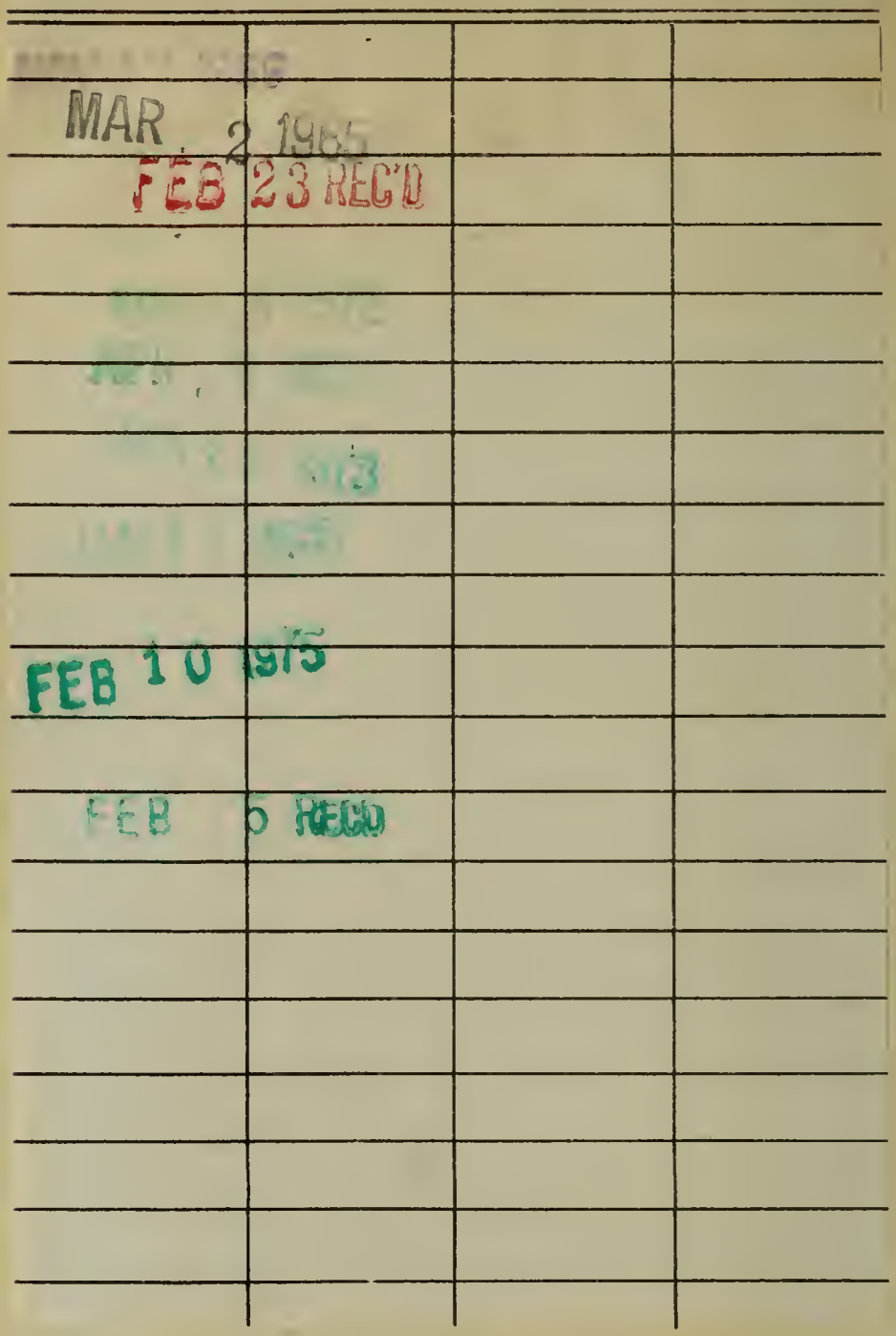


$S B 401$

C $6 M 8$
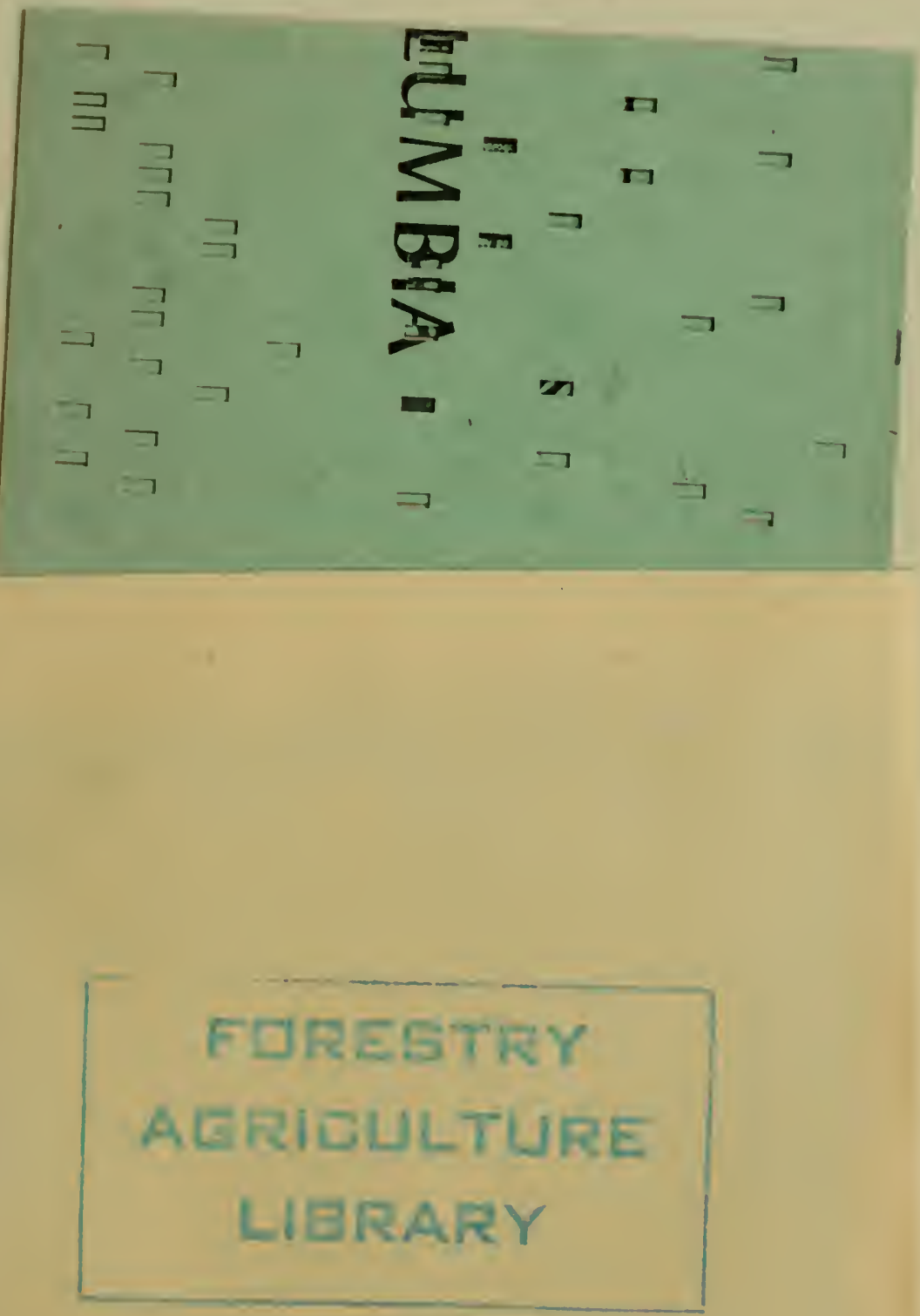
